\title{
Pharmakologische Untersuchungen zu endokrinen Effekten des UV-Filters Ethylhexyl-methoxycinnamat
}

\author{
Dissertation \\ zur Erlangung des Doktorgrades \\ der Mathematisch-Naturwissenschaftlichen Fakultäten \\ der Georg-August Universität zu Göttingen
}

vorgelegt von

Holger Klammer

aus Cuxhaven

Göttingen

2006 
D 7

Referent: Prof. Dr. R. Hardeland

Korreferent: Prof. Dr. D. Doenecke

Tag der mündlichen Prüfung: 03.05.2006 


\section{Abkürzungsverzeichnis}

In dieser Arbeit wurden die internationalen SI-Einheiten, und die davon abgeleiteten Einheiten sowie die SI-Präfixe benutzt.

$3 \mathrm{MC}$

5 'DI/II

A/T/G/C/UTP

Abb.

AhR

ANOVA

APCl

API

BrdU

BSA

bzw.

C

C3

CAMP

CDNA

CED

CES

$\mathrm{cpm}$

$\mathrm{Da}$

DAD

DDT

DES

dest

DMEM

DMSO

DNA

DNase

dNTP

DTT

E2(V)

EAC

ED

EDTA

EGF

ELISA

EPA

ER

ERE

EROD

ERR

ESI

EU

evtl.

FAM
3-Methylcholanthren

5'-Deiodasen Typ I/II

Adenosin-/Thymidin-/Guanosin-/Cytidin-/Uridintriphosphat

Abbildung

Arylhydrocarbon-Rezeptor

Analysis of variances

Pressure Chemical Ionization

Atmospheric Pressure Ionization

5-Bromo-2'deoxyuridine

bovines Serumalbumin

beziehungsweise

Cytidin

Komplement Protein 3

zyklisches Adenosinmonophosphat

komplementäre DNA

kritische Effektdosis

kritische Effektgröße

counts per minute

Dalton

Diode Array Detection

Dichlordiphenyltrichlorethan

Diethylstilbestrol

destilliert

Dulbecco's Modified Eagle's Medium

Dimethylsulfoxid

Desoxyribonukleinsäure

Desoxyribonuklease

desoxy-Nukleotidtriphosphat

Dithiotreitol

17b-Estradiol-(Valerat)

endokrin aktive Chemikalie

endokriner Disruptor

Ethylendiaminotetraacetat

epidermal growth factor

enzyme linked immuno-sorbent assay

US-Umweltschutzbehörde

Estrogen Rezeptor

estrogen response element

Ethoxyresorufin-O-deethylase

estrogen receptor related protein

Elektrospray Ionization

Europäische Union

eventuell

6-Carboxy-fluorescein 


\begin{tabular}{|c|c|}
\hline FKS & fetales Kälberserum \\
\hline $\mathrm{FSH}$ & follicle stimulating hormone \\
\hline fT3/4 & freies T3/T4 \\
\hline G & Guanosin \\
\hline GAR & Ziege-anti-Kaninchen \\
\hline $\mathrm{GH}$ & growth hormone \\
\hline $\mathrm{GnRH}$ & gonadotropin releasing hormone \\
\hline HDL & high density lipoprotein \\
\hline $\mathrm{HE}$ & Haematoxylin - Eosin \\
\hline HEPES & Na 2-(4-(2-Hydroxyethyl)-1-piperazinyl) ethansulfonat \\
\hline HPG & Hypothalamus-Hypophyse-Gonaden \\
\hline HPLC & high pressure liquid chromatography \\
\hline HPT & Hypothalamus-Hypophyse-Schilddrüse \\
\hline HRP & Meerrettichperoxidase \\
\hline i.d.R. & in der Regel \\
\hline $\lg$ & Immunoglobulin \\
\hline IGF & insulin-like growth factor \\
\hline IP3 & Inositoltriphosphat \\
\hline KO & Kontrolle/Kontrollgruppe \\
\hline KosmetikV & Kosmetikverordnung \\
\hline LDL & low density lipoprotein \\
\hline LH & luteinizing hormone \\
\hline LOAEL & lowest observed adverse effect level \\
\hline $\mathrm{MBH}$ & mediobasaler Hypothalamus \\
\hline mRNA & messenger RNA \\
\hline MS & Massenspektroskopie \\
\hline MTT & 3-(4,5-Dimethyl-2-thiazolyl)-2,5-diphenyl-2H-tetrazoliumbromide \\
\hline NIS & Natrium/lodid-Symporters \\
\hline NOAEL & no observed adverse effect level \\
\hline OD & optische Dichte \\
\hline OECD & Organization for Economic Co-operation and Development \\
\hline OMC & Octyl-(Ethyhexyl)methoxycinnamat \\
\hline PBS & Phosphat-gepufferte Saline \\
\hline PCR & Polymerase-Kettenreaktion \\
\hline $\mathrm{pH}$ & negativer dekadischer Logarithmus der Wasserstoffionenkonzentration \\
\hline PTU & 6-n- Propyl-2-tiouracil \\
\hline RBA & Rezeptorbindungsassay \\
\hline RIA & Radioimmunoassay \\
\hline RLB & reporter lysis buffer \\
\hline RNA & Ribonukleinsäure \\
\hline RNasin & Ribonuklease-Inhibitor \\
\hline RT & Raumtemperatur \\
\hline RT & reverse Transkription \\
\hline s.o. & siehe oben \\
\hline SD & Standardabweichung \\
\hline SDS & Sodiumdodecylsulfat \\
\hline SEM & Standardfehler des Mittelwertes \\
\hline SERM & selective estrogen receptor modulator \\
\hline
\end{tabular}


Abkürzungsverzeichnis

sog.

sogenannte

SRC

Steroid-Rezeptor-Koaktivator

T3

Trijodthyronin

T4

Tab.

Tetrajodthyronin, Thyroxin

Tabelle

TAMRA

6-Carboxy-tetramethyl-rhodamin

TERP1

truncated estrogen receptor protein

TPO

Schilddrüsenperoxidase

TRH

thyrotropin releasing hormone

TRIS

Tris-(hydroxymethyl)aminomethan

TSH

thyroid stimulating hormone

TSHR

$U$

Thyrotropin-Rezeptor

Unit

UF

Upm

UV

Unsicherheitsfaktor

Umdrehungen pro Minute

ultraviolett

WHO

Z.B.

Weltgesundheitsorganisation

ZNS

zum Beispiel

zentrales Nervensystem 


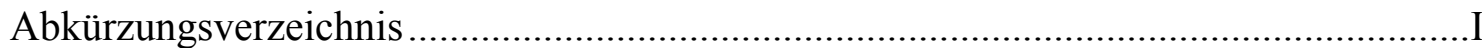

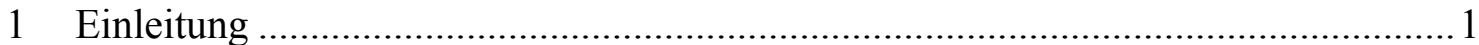
1.1 Können komplexe chemische Moleküle in kosmetischen Produkten einen Einfluss auf endokrine Systeme haben?

1.1.1 Endokrin Aktive Chemikalien und Endokrine Disruptoren

1.1.2 Einschätzung des Gefährdungspotentials möglicher EACs bzw. EDs für den Menschen....2

1.1.3 Strategie zur Identifikation von EACs der OECD ........................................................... 4

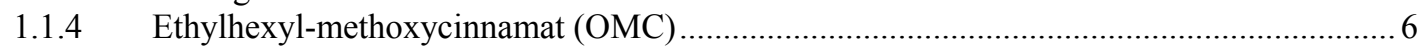

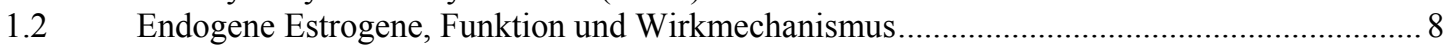

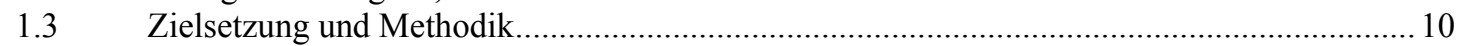

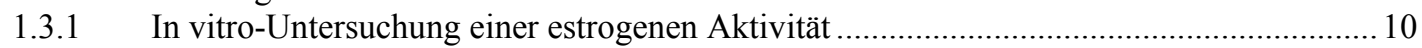

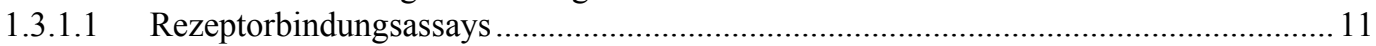

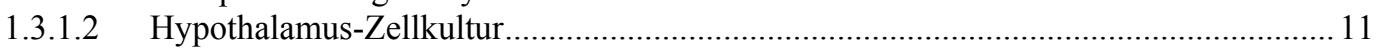

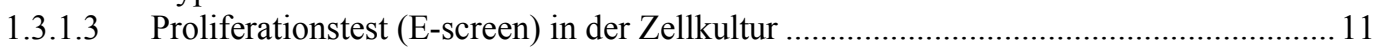

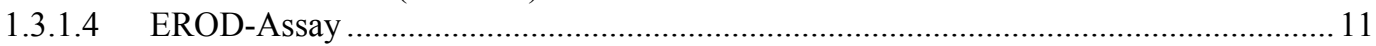

1.3.2 In vivo-Untersuchungen im erweiterten uterotrophen Assay ……………….................... 12

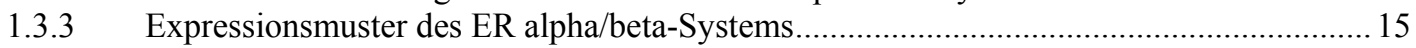

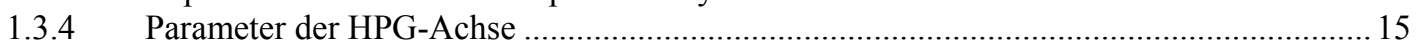

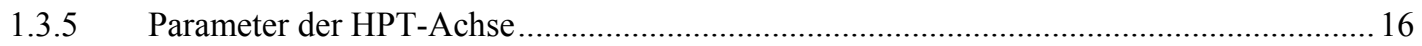

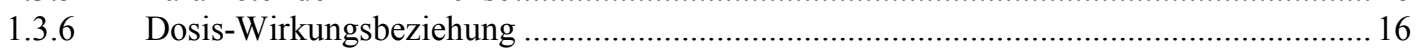

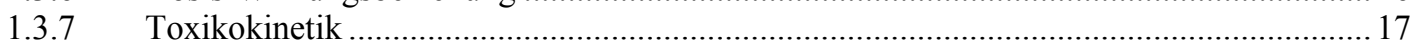

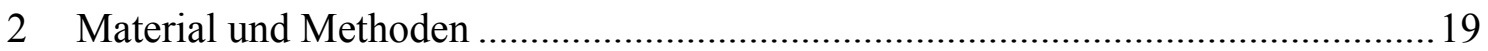

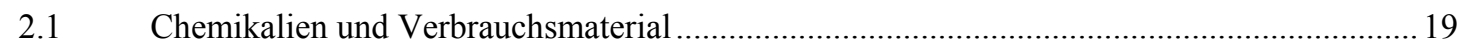

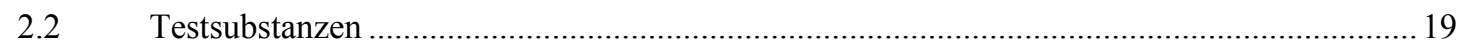

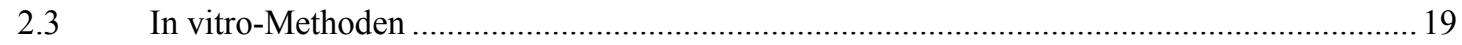

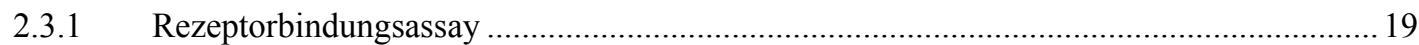

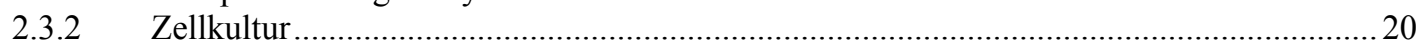

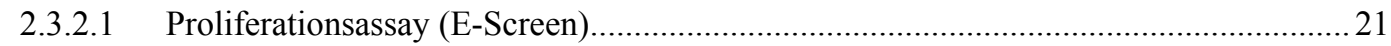

2.3.2.2 Proliferationsassay (BrdU) mit H4IIE-Zellen............................................................. 22

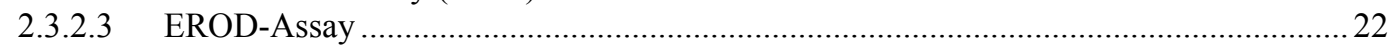

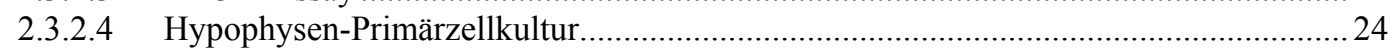

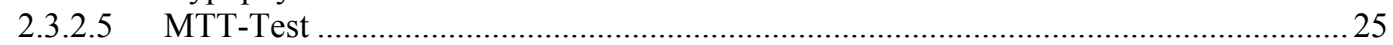

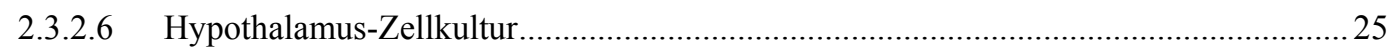

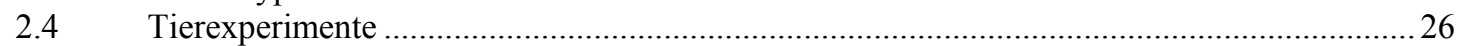

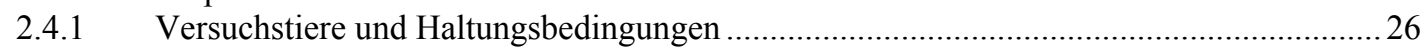

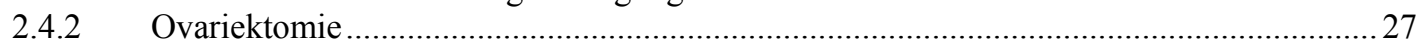

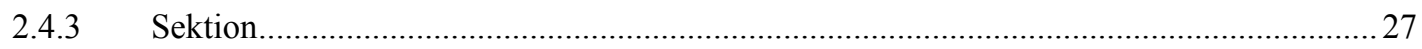

2.4.4 Subakute Applikation der Testsubstanzen an ovariektomierten weiblichen Ratten ............22

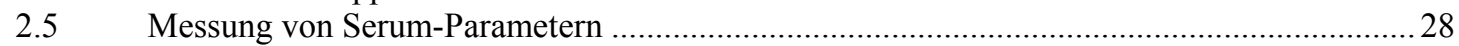

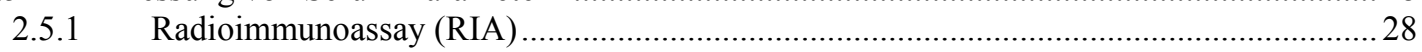

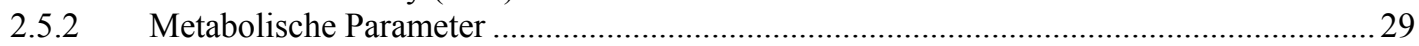

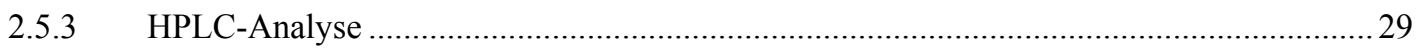

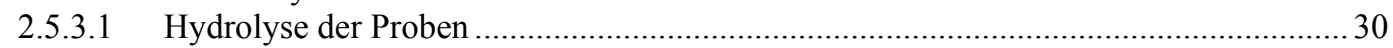

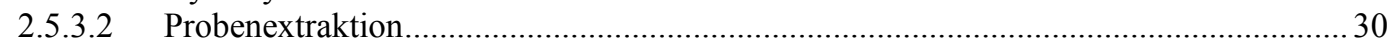

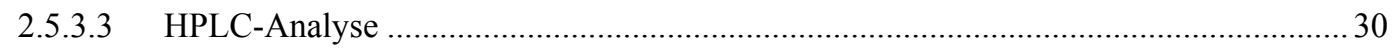

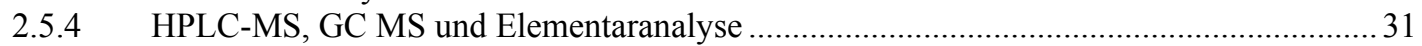

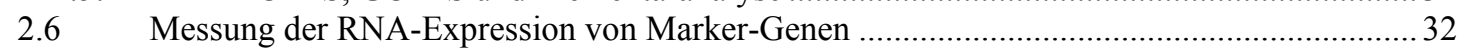

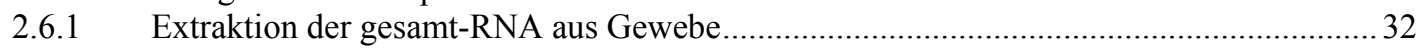

2.6.2 Bestimmung der Konzentration und der Reinheit der RNA ……......................................... 33

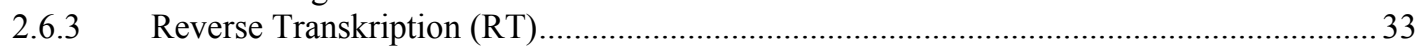

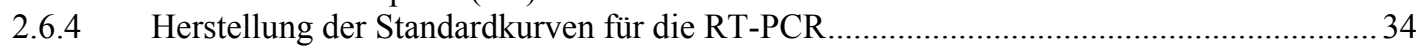

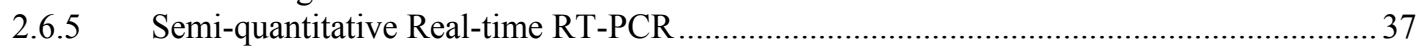

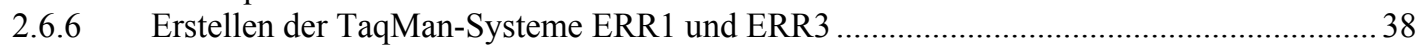

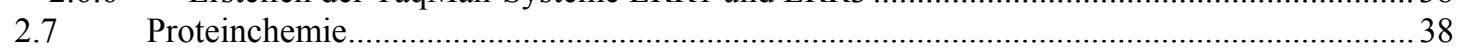

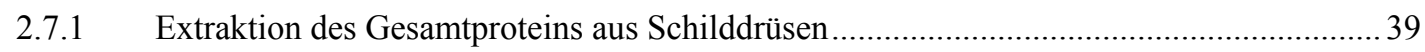

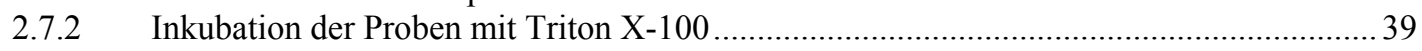




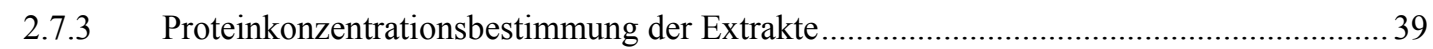

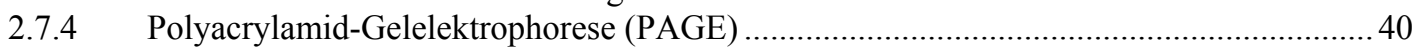

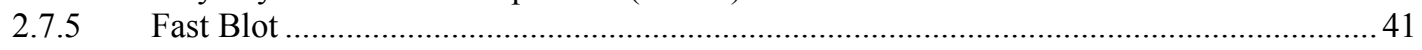

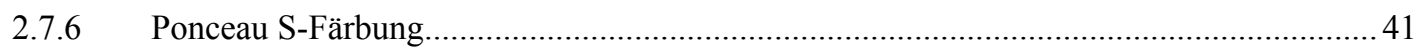

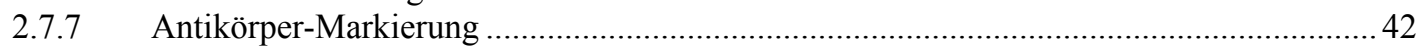

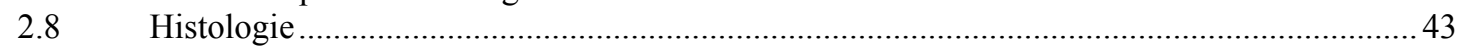

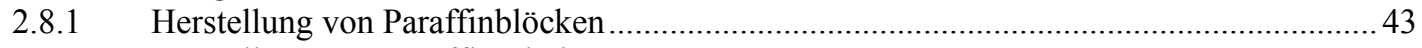

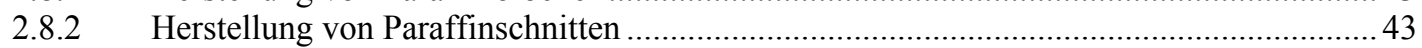

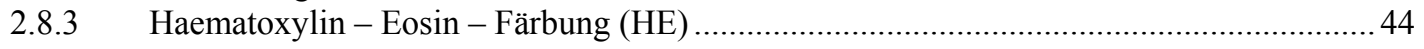

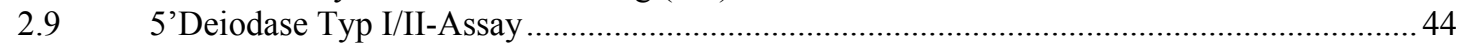

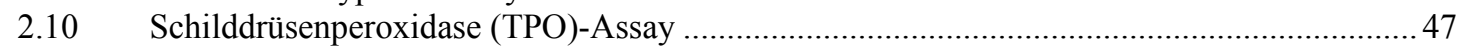

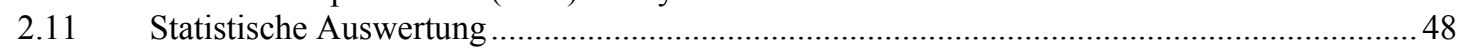

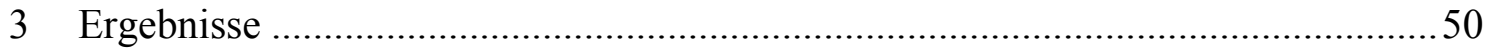

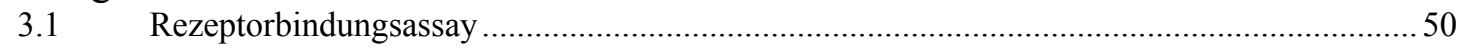

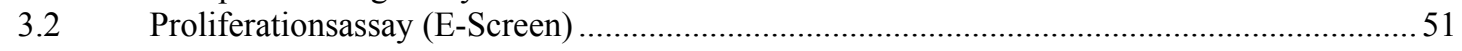

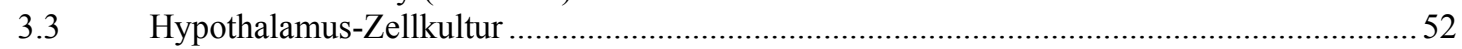

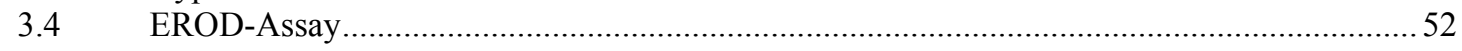

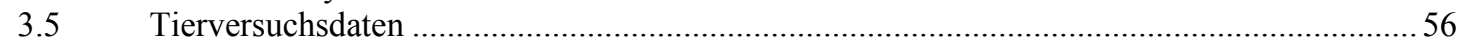

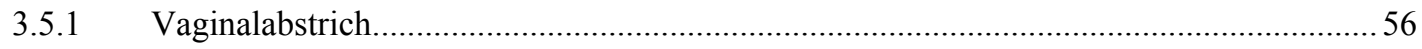

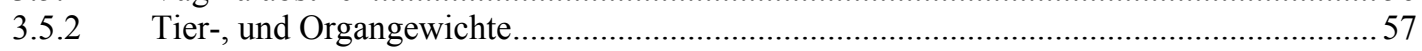

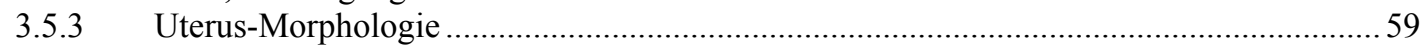

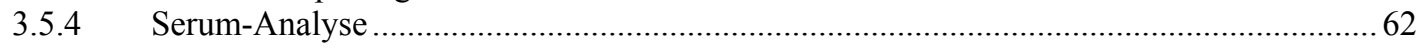

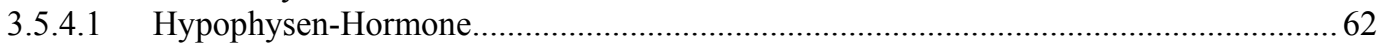

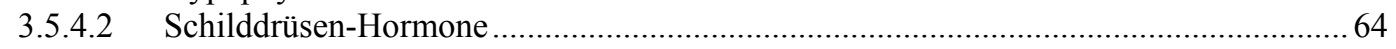

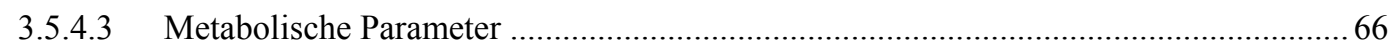

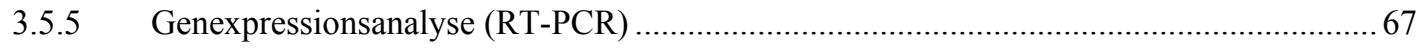

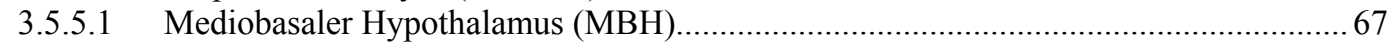

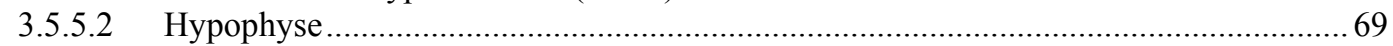

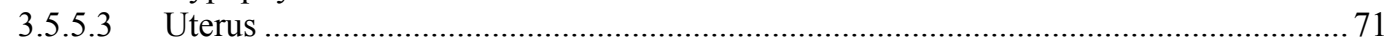

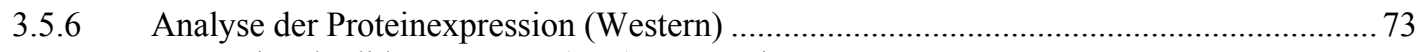

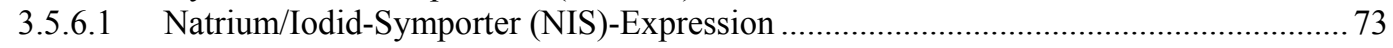

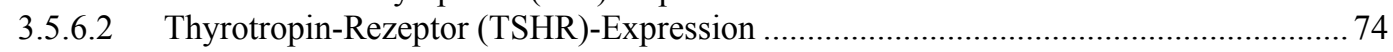

3.5.7 Typ I und II 5'Deiodase- und Schilddrüsenperoxidase-Aktivität.................................. 74

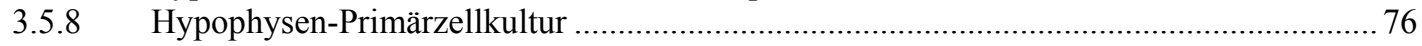

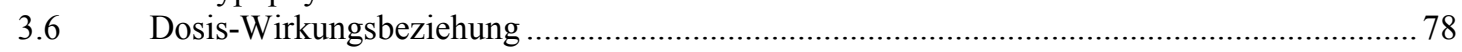

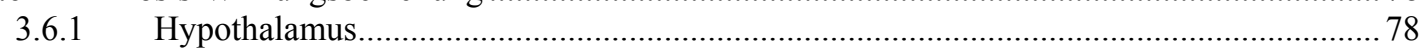

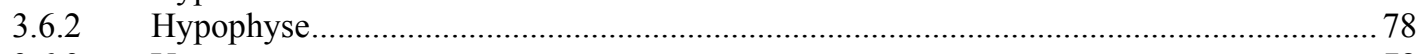

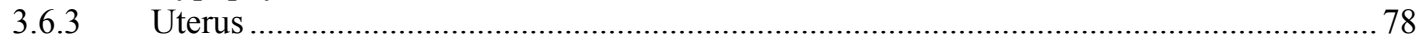

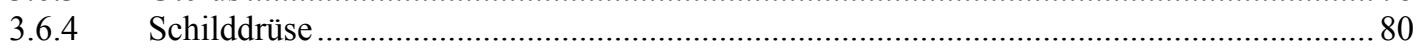

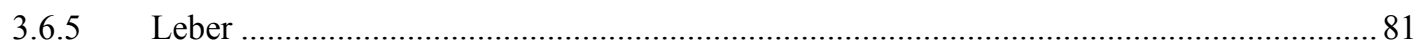

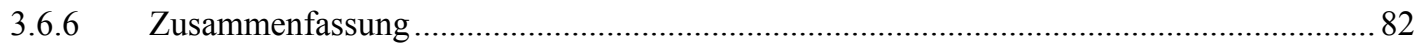

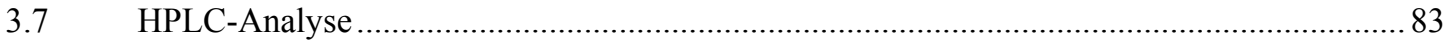

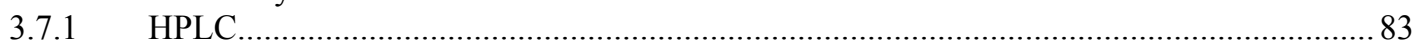

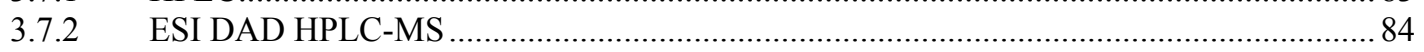

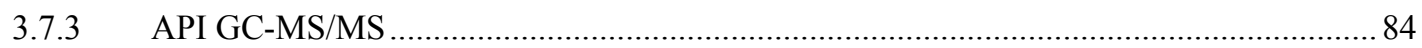

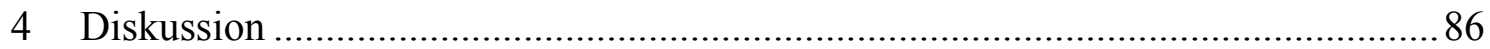

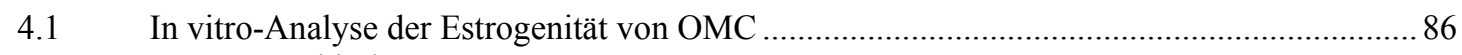

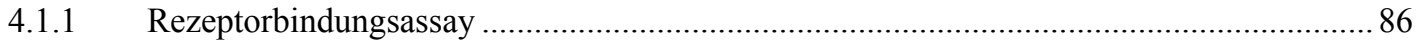

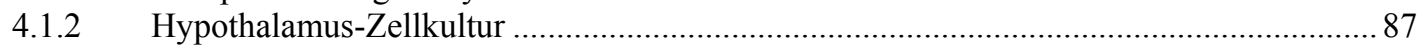

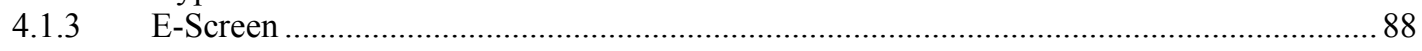

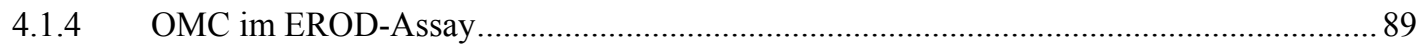

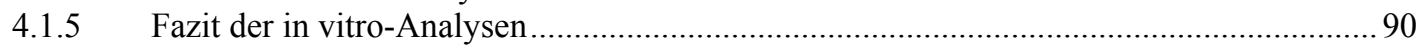

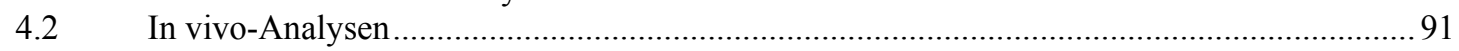

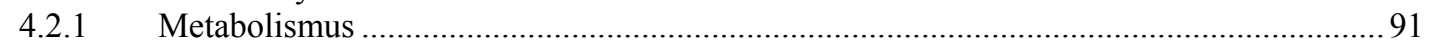

4.2.2 Expressionsmuster des ER alpha/beta-Systems.................................................... 91

4.2.3 Einfluss von OMC auf die HPG- und HPT-Achsen ............................................... 94

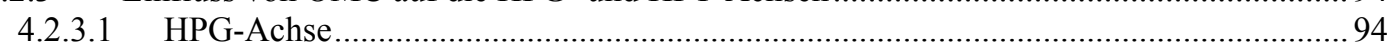




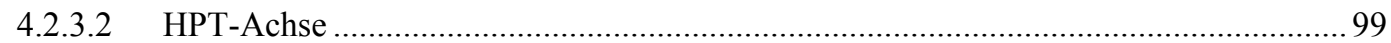

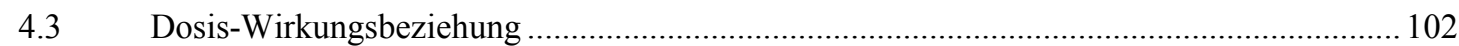

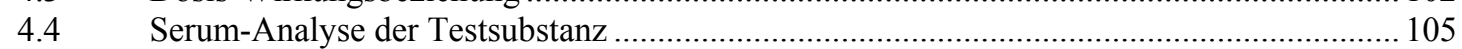

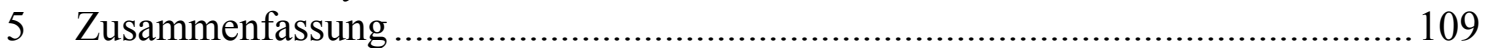

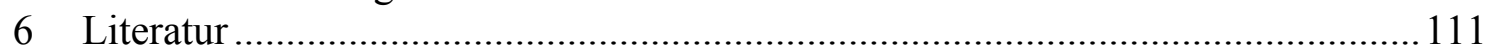




\section{Einleitung}

\subsection{Können komplexe chemische Moleküle in kosmetischen Produkten einen Einfluss auf endokrine Systeme haben?}

Das Thema einer möglichen Gefährdung des Menschen durch das Eingreifen von Umweltchemikalien in endokrine Systeme wurde erst durch Theo Colborn mit dem Buch „Our stolen future“ im Jahre 1994 medienwirksam in die Öffentlichkeit getragen. Grundlage dafür war eine Studie von 1993 (Colborn et al. 1993), in der Zusammenhänge zwischen Fortpflanzungsstörungen und der Belastung mit Xenobiotika diskutiert wurden. Schon früher wurden Beobachtungen epidemiologischer Studien mit der möglichen Exposition durch endokrin aktive Chemikalien in Verbindung gebracht. Dies wird in Abschnitt 1.1.2 diskutiert.

\subsubsection{Endokrin Aktive Chemikalien und Endokrine Disruptoren}

Unter dem Begriff „Endokrin Aktive Chemikalien“ (EAC) werden alle Substanzen zusammengefasst, welche die Fähigkeit besitzen, mit einem oder mehreren endokrinen Systemen zu interagieren. Dabei gibt es eine ganze Reihe verschiedener Möglichkeiten der Interaktion:

- Imitation einer hormonellen Wirkung als Agonist oder Antagonist des Hormonrezeptors, wobei die agonistische/antagonistische Aktivität einer Verbindung beeinflusst wird durch Metabolismus, Bindungsaffinität, Assoziationsund Dissoziationsrate (Kemppainen et al. 1999). Durch eine Veränderung der Konformation des Rezeptors wird die Stabilität des Rezeptors, die DNA-Bindung des Rezeptors, die Interaktion mit anderen Transkriptionsfaktoren, Begleitproteinen und Kofaktoren sowie die Phosphorylierung beeinflusst, wodurch es $\mathrm{zu}$ agonistisch/antagonistischen Mischfunktionen kommen kann (Landel et al. 1994).

- Hemmung einer hormonellen Wirkung. Dies kann durch Blockieren des Rezeptors, dessen Kofaktoren oder der Bindestelle im Genom geschehen (Kelce et al. 1995). Auch kann die Degradation des Rezeptors oder anderer an der Signalweiterleitung beteiligter Proteine induziert werden (Wormke et al. 2003). 
- Verstärkung der Produktion, der Freisetzung oder des Transportes sowie eine Veränderung der Metabolisierung eines endogenen Hormons (Morinaga et al. 2004; Thierfelder et al. 1995).

Eine Wertung des Einflusses wird hier noch nicht vorgenommen. Der in den letzten Jahren immer mehr gebräuchliche Begriff „Endokriner Disruptor“ (ED), welcher einen deutlichen negativen Unterton hat, wird von mehreren Institutionen unterschiedlich definiert.

Die US-Umweltschutzbehörde (EPA) definierte endokrine Disruptoren im Jahre 1995 als exogene Substanzen, welche die Synthese, Freisetzung, Transport, Metabolismus, Bindung, Aktivität oder Elimination natürlicher Hormone, die im Körper für die Aufrechterhaltung der Homöostase, der Reproduktion und der Regulation von Entwicklungsprozessen und des Verhaltens verantwortlich sind, beeinflussen (Kavlock et al. 1996).

Auf der im Jahre 1996 in Weybridge abgehaltenen Konferenz "European Workshop on the Impact of Endocrine Disruptors on Human Health and Wildlife" unter Federführung der EU-Kommission DG XII, der European Environment Agency und dem European Center for Environmental Health der WHO hat man sich auf folgende Definition für endokrine Disruptoren geeinigt: „Bei den endokrinen Disruptoren handelt es sich um körperfremde Verbindungen, die in das endokrine System eines gesunden Organismus oder das seiner Nachkommen eingreifen und zu signifikanten Gesundheitsstörungen führen. “ (Bruhn et al. 1999).

Die Definition der OECD (Organization for Economic Co-operation and Development) für endokrine Disruptoren lautet: Endokrine Disruptoren sind Fremdstoffe mit schädlichen Wirkungen auf die Gesundheit in einem unversehrten Organismus oder seiner Nachkommenschaft, die auf Änderungen von endokrinen Funktionen zurückgeführt werden können (OECD 1996).

\subsubsection{Einschätzung des Gefährdungspotentials möglicher EACs bzw. EDs für den Menschen}

Seit Anfang der 90er Jahre besteht ein großes öffentliches und wissenschaftliches Interesse am möglichen Einfluss von Xenobiotika auf den menschlichen Hormonhaushalt (Colborn et al. 1993; Vos et al. 2000). Es ist erwiesen, dass viele 
Xenobiotika in Prozesse der Entwicklung, Homöostase und Reproduktion eingreifen sowie die Entstehung und Proliferation von Karzinomen fördern können (Degen et al. 1999). Mehrere bekannte Beeinträchtigungen menschlicher Gesundheit wurden vor dem Hintergrund der Belastung des Menschen mit Xenobiotika diskutiert. Als Beispiele seien hier genannt:

Spermienqualität: Der Rückgang der Samenqualität (Spermien pro $\mathrm{ml}$ ) in den westlichen Industrienationen zwischen 1938 und 1990 um ca. 50 \% (Carlsen et al. 1992) war der Auslöser einer kontroversen Diskussion über die mögliche Beeinträchtigungen menschlicher Gesundheit durch hormonell aktive Substanzen (Golden et al. 1998).

Hodenkarzinome: Die altersstandardisierte Hodenkrebsrate nimmt stetig zu (Rösch et al. 1999). Die pränatale Exposition mit DES hat einen signifikanten Einfluss auf die Krebsinzidenz (Toppari et al. 1996). DES ist ein starkes synthetisches Estrogenanalogon, welches nach der Entdeckung im Jahre 1938, in den 50er bis 70er Jahren zur Prävention von Fehlgeburten verabreicht wurde.

Prostatakarzinom: Die Prostatakarzinom-Inzidenz hat sich zwischen 1961 und 1989 in den neuen Bundesländern verdoppelt (Möhner 1994), auch in den alten Bundesländern wurde ein Anstieg festgestellt (Schuz et al. 2000). Einige epidemiologische Studien zeigen eine deutlich höhere Prostatakrebsrate bei Anwendern von hormonell aktiven Pestiziden (Dich et al. 1998; Fleming et al. 1999; Keller-Byrne et al. 1997; Morrison et al. 1993; Parker et al. 1999).

Teratogenese männlicher Genitalien: Der Zusammenhang zwischen den Fehlbildungen männlicher Genitalien wie z.B. Kryptorchismus (Hodenhochstand) und Hypospadie (Fehlbildung der Harnröhre) mit der pränatalen Exposition durch exogene Chemikalien wie z.B. Pestiziden wurde von mehreren Autoren postuliert (GarciaRodriguez et al. 1996; Toppari et al. 1996).

Brustkrebs: In Deutschland ist ein Ansteigen der Rate der Brustkrebserkrankungen von 27 auf 45 Fälle pro 100.000 Einwohner im Zeitraum von 1991 bis 1995 verzeichnet worden. Estrogene haben einen Einfluss auf Brust- und Uteruskrebs (Lacey et al. 2005; Schairer et al. 2000). Schon 1993 wurde die Exposition durch das estrogene 
Dichlordiphenyltrichlorethan (DDT) mit dem Brustkrebsrisiko in Verbindung gebracht (Wolff et al. 1993).

Teratogenese weiblicher Genitalien: Bei der Pubertät der in utero mit DES (siehe oben) exponierten weiblichen Nachkommen wurden Langzeitfolgen der Behandlung ersichtlich. Es zeigte sich ein drastisch erhöhtes Vorkommen von vaginalen Adenokarzinomen (Herbst et al. 1971). Mehr als 90\% aller betroffenen Frauen entwickelten Anomalien des Reproduktionstraktes wie vaginale Adenosie (Herbst 1987; Holt et al. 1982).

Das Risiko eines modulierenden Effektes auf endokrine Systeme ist vorhanden, aber es kann für viele Substanzen noch nicht eingeschätzt werden. Einige der Xenobiotika, mit denen der Mensch sich umgibt, sind noch nicht auf ihre Toxizität hin untersucht. Für die meisten ist ein mögliches endokrines Potential noch völlig unerforscht. Gülden et al., legten eine Liste mit über 200 Substanzen vor, die als endokrine Disruptoren bezeichnet werden (Gülden et al. 1997). Allerdings ist bei vielen dieser Substanzen infolge mangelnder valider in vivo-Studien keine gesicherte Aussage möglich. Vergleiche der kristallographischen Daten des Estrogen Rezeptors (ER) mit der Struktur von 58.000 Industriechemikalien ergab 6.000 mögliche Liganden (Hong et al. 2002).

Gegenwärtig ist nicht auszuschließen, dass die Exposition gegenüber EACs bzw. EDs auch beim Menschen zu Störungen der hormonellen Regulation und damit zu gesundheitlichen Schädigungen führen kann (Gies et al. 2001). Inwieweit hormonelle Regelkreisläufe beim Menschen durch EACs bzw. EDs beeinflusst werden und ob dieser Einfluss advers ist, kann noch nicht abgeschätzt werden (Eertmans et al. 2003; Matthiessen 2000; Sharpe 2003; Sharpe et al. 2004). Hier besteht ein großer Bedarf bei der Identifikation sowie bei der Analyse der endokrinen Aktivität putativer EACs.

\subsubsection{Strategie zur Identifikation von EACs der OECD}

Das Problem einer möglichen endokrinen Disruption durch Xenobiotika ist auch von der europäischen Staatengemeinschaft erkannt worden.

In vitro-Tests erfassen die Effekte von Stoffen im zellulären oder molekularen Bereich oder auf bestimmte Organ- und Gewebetypen. Auf relativ einfache und kostengünstige Weise lässt sich mittels solcher Verfahren eine Wechselwirkung erkennen. Eine 
Extrapolation solcher Ergebnisse auf eventuelle Hormonwirkungen im Organismus ist allerdings nicht möglich, da hierbei die Resorption, Verteilung, Metabolisierung und Ausscheidung des Stoffes im Organismus nicht berücksichtigt werden können. Ohne eine Extrapolation der Ergebnisse auf die exponierte Risikogruppe ist auch eine Risikobewertung nicht möglich.

Die OECD hat dazu in den letzten Jahren einen immensen Aufwand in die Validierung des uterotrophen Assay investiert, um ein Test zur Erfassung der estrogenen und antiestrogenen Aktivität von Substanzen zu standardisieren (Kanno et al. 2003; Owens et al. 2003). Im uterotrophen Assay wird anhand des Uterusgewichtes von kastrierten, weiblichen Ratten die estrogene Aktivität von applizierten Substanzen quantifiziert. Das Modell des uterotrophen Assay vernachlässigt dabei allerdings wichtige Aspekte einer endokrinen Aktivität:

- Multiorgan-Effekte: Da ERs in allen Geweben des Organismus exprimiert werden (Couse et al. 1999), sind auch in allen Geweben ER-vermittelte Effekte möglich. Der uterotrophe Assay überprüft nur jedoch nur einen Parameter, das Uterusgewicht. In der weiteren Diskussion wird auch gezeigt, dass die Proliferation und die damit einhergehenden Veränderungen mechanistisch noch nicht ganz erfasst wurden.

- SERM-Effekte: Estrogene Chemikalien können organ- und gewebespezifische Auswirkungen entfalten. Substanzen, die in ihrem Muster von der Wirkung des endogenen Estradiols (E2) abweichen, werden deshalb als selective estrogen receptor modulator (SERM) bezeichnet. Das SERM-Konzept ist nach Untersuchungen der von Estradiol abweichenden Wirkung von Tamoxifen entstanden (Jordan et al. 1987). Obwohl die SERM-Wirkung noch nicht komplett verstanden ist (Matthews et al. 2003), scheint sie abhängig von der Präferenz einer Substanz zu den Rezeptoren ER alpha und beta sowie dem Expressionsmuster der beiden Subtypen zu sein (Watanabe et al. 1997). Eine weitere Rolle spielen die gewebespezifisch exprimierten Kofaktoren sowie die Beschaffenheit der Promotoren der ER-regulierten Gene (Weihua et al. 2003). SERM-Effekte können nur bei Untersuchungen mehrerer E2-regulierter Organe detektiert werden. 
- Nicht Estrogen-ähnliche bzw. nicht ER-vermittelte Effekte: Es gibt Berichte über multifunktionelle Xenobiotika. Ein Beispiel ist Vinclozolin, was neben einer antiandrogenen Aktivität (Kavlock et al. 2005) auch über den DioxinRezeptor Einfluss auf hormonelle Regulation ausübt (Wu et al. 2005). Multiple Effekte einer Substanz können über einen einzelnen Parameter nicht erfasst werden.

Damit ist diese Strategie nicht in der Lage, das Spektrum und das Potential von EACs vollständig zu erfassen.

\subsubsection{Ethylhexyl-methoxycinnamat (OMC)}

In den letzten Jahren ist zunehmend deutlich geworden, dass die erhöhte Exposition des Menschen mit UV-Strahlung mit gesundheitsschädlichen Nebenwirkungen einhergeht. Dazu gehören oberflächliche Entzündungsreaktionen wie Sonnenbrand oder Photoallergien. Des Weiteren können Tumore durch die UV-induzierte Schädigung der DNA entstehen.

Ethylhexyl-methoxycinnamat (aufgrund des 2003 gebräuchlichen Namens Octylmethoxycinnamat: OMC) kann aufgrund seines konjugierten $\pi$-Bindungssystems kurzwellige Strahlung (290-315nm (UVB) und 315-400nm (UVA)) absorbieren. Es ist weltweit eines der am häufigsten benutzten UV-Filter aus der Klasse der Zimtsäurederivate und wird hauptsächlich in Kosmetikprodukten wie Sonnenschutzcremes verwendet. Zusätzlich dazu wird OMC anderen Kosmetika wie Waschlotionen zum Produktschutz beigefügt.

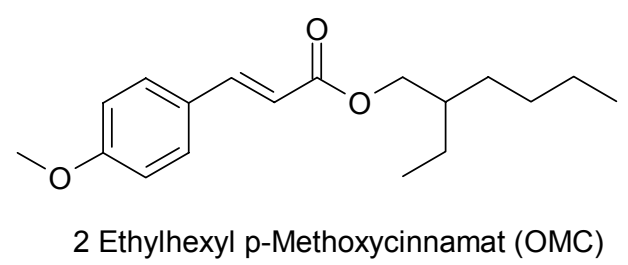

Abb. 1: Strukturformel von 2 Ethylhexyl p-methoxycinnamat (OMC). Summenformel: $\mathrm{C}_{18} \mathrm{H}_{26} \mathrm{O}_{3}$. Molekulargewicht: 290,4 g/mol. 
Laut Verordnung über kosmetische Mittel der Bundesrepublik (KosmetikV) sowie der EU (Council Directive 76/768/EEC) ist ein Gehalt an OMC in Kosmetikprodukten von bis zu 10 \% im europäischen Raum zugelassen.

Studien haben gezeigt, dass OMC in vivo und in vitro estrogene Eigenschaften besitzt. So zeigt die orale Applikation von OMC bei immaturen Ratten einen uterotrophen Effekt und die Estrogen-sensitive Zelllinie MCF-7 reagiert auf OMC mit vermehrter Proliferation (Schlumpf et al. 2001), vergleichbar mit der Wirkung von Estradiol. In einem in vitro Transaktivierungsassay induzierte OMC die ER alpha-vermittelte Genexpression (Schreurs et al. 2002). Auch die strukturell verwandte Substanz Zimtsäuremethylester induziert im Transaktivierungsassay das Reportergen bei einer Konzentration von $100 \mathrm{nM}$ genauso stark, wie dies für Estradiol ab einer Konzentration von $10 \mathrm{nM}$ zu beobachten ist (Mußler 1999). In dieser Arbeit wurde Zimtsäuremethylester als möglicher Ligand für die ERs aufgrund seiner strukturellen Homologie zu Estradiol herangezogen, wobei der Rauminhalt der Substanzen wie auch die elektrostatischen Verhältnisse innerhalb der Moleküle berücksichtigt wurden.

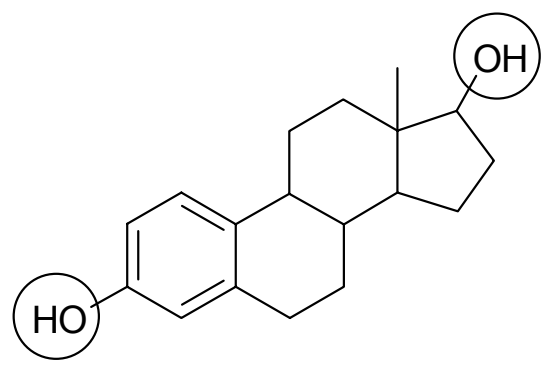

$17 ß-E s t r a d i o l$

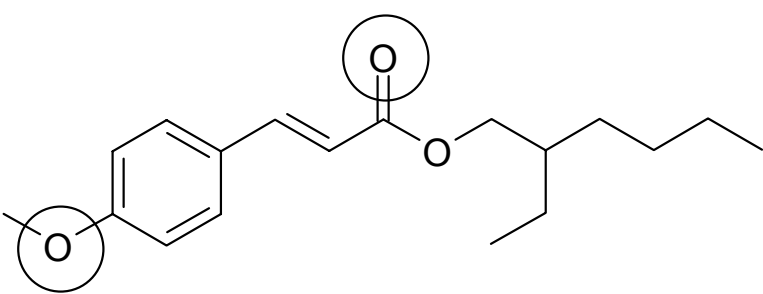

2 Ethylhexyl p-Methoxycinnamat

Abb. 2: Strukturformeln von 17 $\beta$-Estradiol und 2 Ethylhexyl p-methoxycinnamat. Die Positionen O3 und O17 des 17 $\beta$-Estradiol sowie die entsprechenden Positionen in der Struktur von 2 Ethylhexyl pmethoxycinnamat sind in der Abbildung mit einem Kreis gekennzeichnet.

Aus Abb. 2 ist ersichtlich, dass OMC eine mit E2 vergleichbare Größe hat, einzig der Ethylhexyl-Rest könnte ein sterisches Hindernis sein. Beide Substanzen verfügen über den aromatischen Ring sowie zwei Sauerstoffatome in vergleichbarer Position. Die beiden Sauerstoffatome interagieren über Wasserstoffbrückenbindungen mit den für die Aktivierung relevanten Aminosäuren im ER (Brzozowski et al. 1997). Die 
Untersuchungen auf der Grundlage von chemischen Strukturmerkmalen sind ungenau und müssen deshalb mit Programmen wie QSAR und SYBIL experimentell bestätigt werden (Gies et al. 2001).

Diese Ergebnisse zeigen, dass OMC Einfluss auf das estrogene System hat und somit als EAC und möglicherweise auch als ED anzusehen ist. Das endokrine Potential von OMC beim Menschen ist allerdings noch unbekannt

\subsection{Endogene Estrogene, Funktion und Wirkmechanismus}

Estrogene gehören zu den Steroidhormonen. Sie werden primär in den Granulosazellen der Ovarien und in der Plazenta während der Schwangerschaft produziert, in geringen Mengen auch in der Nebennierenrinde und in den Sertolizellen im Hoden. Bei der peripheren Estrogensynthese kann auch im Fettgewebe, im Muskel, in der Leber und im Gehirn Estrogen gebildet werden (Hess et al. 2000; Labrie et al. 1997; Sasano et al. 1997) Die Aktivität der Estrogene nimmt in der Reihenfolge Estradiol, Estriol und Estron ab (Cooke et al. 1988).

Im Zusammenspiel mit den anderen Steroidhormonen sind Estrogene an fast allen Prozessen im Körper beteiligt. Sie regulieren Wachstum und Entwicklung, die Reproduktion, die Homöostase des Metabolismus und haben einen Einfluss auf das Nerven- und Immunsystem (Reid et al. 2002).

Die Estrogen Rezeptoren (ER) spielen als Ligand-induzierbare Transkriptionsfaktoren eine Schlüsselrolle in der endokrinen Signaltransduktion. Bislang sind die beiden von unterschiedlichen Genloki exprimierten Rezeptoren ER alpha (Green et al. 1986) und beta (Kuiper et al. 1996) bekannt. Die ERs gehören zu der Steroid-RezeptorSuperfamilie, zu der auch der Glucocorticoid-Rezeptor, der MineralocoroticoidRezeptor, der Progesteron-Rezeptor und der Androgen-Rezeptor gehören (Mangelsdorf et al. 1995).

Der inaktive ER liegt, gebunden an Heat shock-Proteine, im Plasma des Zellkernes vor (Landel et al. 1995). Die Bindung des Liganden löst den Komplex auf und setzt den Rezeptor frei (Rachez et al. 2001). Als Homo- (ER alpha-alpha) oder Heterodimer (ER alpha-beta) kann der Rezeptor an spezifische DNA-Sequenzen, ein sogenanntes Estrogen response element, im Promotor des Zielgens binden (Paech et al. 1997). Danach werden in Abhängigkeit der Konformation Koaktivatoren (z.B. SRC-1) oder 
Korepressoren (z.B. SMRT) rekrutiert (Nilsson et al. 2001). Dabei ist die Position der Helix 12 des Rezeptors entscheidend für die agonistische bzw. antagonistische Funktion und somit die Induktion bzw. die Repression des Zielgens. Die Konformation des Rezeptors und damit die Position der Helix 12 wird durch die elektrostatischen Eigenschaften des Liganden bestimmt (Brzozowski et al. 1997).

Die Funktion und das Verhältnis der beiden ER-Subtypen zueinander sind noch nicht aufgeklärt. Die von Lindberg beschriebene Yin-Yang-Theorie geht davon aus, dass der ER beta eine modulierende Wirkung auf den ER alpha hat (Lindberg et al. 2003). Bei der Koexpression der beiden Subtypen reduziert ER beta die ER alpha-induzierte Genexpression, während bei alleiniger ER beta-Expression die Funktion von ER alpha übernommen werden kann (Liu et al. 2002). Zunehmend wird deutlich, dass diese einfache Regulation des ER alpha durch ER beta nicht die einzige Funktion der beiden Subtypen sein kann. Das Verhältnis der Rezeptoren scheint das Signal des Hormons Estrogen gewebsspezifisch in Proliferation und Differenzierung umzusetzen. So ist die Zellproliferation von HepG2-Zellen abhängig von der Interaktion des ER alpha mit dem Transkriptionsfaktor AF-1 (Flouriot et al. 2000). Die E2-induzierte Differenzierung im Maus-Ovidukt kann durch den ER-Antagonist ICI 182,780 blockiert werden, ist aber in ER alpha-knockout-Mäusen funktionsfähig (Okada et al. 2004). Ein zusätzliches Indiz dafür, dass eine Antagonisierung nicht die einzige Aufgabe des ER beta ist, ist die wachsende Anzahl bekannter Kofaktoren, die gewebsspezifisch exprimiert werden und eine unterschiedliche Affinität zu den beiden ER-Subtypen haben (Matthews et al. 2003).

Neben der rezeptorvermittelten Genexpression durch estrogene Substanzen gibt es noch andere Signaltransduktionswege, mit denen Estrogene über ERs interagieren können. Dazu gehört die Phosphorylierung von Proteinen über Kinasen (Watters et al. 2000), die Regulierung des Kalziumhaushaltes über cAMP, $\mathrm{IP}_{3}$ oder Phospholipase C (Qin et al. 2004) sowie die Modulierung des Methylierungsstatus der DNA (Nilsson et al. 2001). Auch können andere Transkriptionsfaktoren wie z.B. AP-1 oder SP-1 in ihrer Aktivität beeinflusst werden (Kushner et al. 2000; Wahli et al. 1991). 


\subsection{Zielsetzung und Methodik}

OMC ist als möglicher endokriner Disruptor in Verdacht geraten. Dabei wurde OMC als mögliches Estrogen beschrieben. Dies soll in in vitro-Assays bestätigt werden. Zusätzlich wird ein erweiterter Ansatz des von der OECD vorgeschlagenen, uterotrophen Assay verwendet, um ein umfassenderes Bild der endokrinen Wirkung von OMC zu erhalten. Dazu wird der Fokus von einem einzelnen Organ bzw. Parameter auf die Hypothalamus-Hypophyse-Gonaden-Achse (HPG) und HypothalamusHypophysen-Schilddrüsen-Achse (HPT) ausgeweitet, und es werden Parameter des Metabolismus untersucht. Aus den gewonnen Daten soll eine Dosis-Wirkungsbeziehung erstellt werden. Zuletzt soll die mögliche Metabolisierung von OMC untersucht werden.

- Untersuchung der Estrogenität von OMC mittels in vitro-Screening-Assays. Rezeptorbindungsassay, Hypothalamus-Zellkultur, Proliferationsassay (E-screen) und EROD-Assay.

- Erstellung des ER alpha/beta-Status nach Behandlung mit OMC in vivo im Tiermodell der ovariektomierten Ratte.

- Untersuchung der Estrogenität von OMC in vivo anhand bekannter estrogen regulierter Parameter. Der Fokus liegt dabei auf zwei wichtigen Achsen endokriner Regulation: der HPG- und HPT-Achse.

- Untersuchung der Effekte auf den Metabolismus anhand von Serum-Parametern.

- Eine Dosis-Wirkungsbeziehung für die in vivo erhaltenen Ergebnisse soll erstellt werden.

- Die mögliche Metabolisierung von OMC wird in vitro mit dem EROD, als Indiz für die Induktion der Biotransformation, sowie in vivo durch Serumanalysen untersucht.

Die Grundlagen der dabei verwendeten Methoden werden im Folgenden vorgestellt.

\subsubsection{In vitro-Untersuchung einer estrogenen Aktivität}

Anhand von in vitro-Assays können Substanzen als mögliche Kandidaten für eine estrogene oder antiestrogene Wirkung identifiziert werden. In vitro-Assays zeichnen sich durch eine schnelle Durchführbarkeit und geringe Kosten aus. Zudem bieten sie die Möglichkeit gezielt spezifische Endpunkte zu untersuchen. 


\subsubsection{Rezeptorbindungsassays}

Im RBA wird die Fähigkeit einer Substanz erfasst, mit radioaktiv markiertem Estradiol, um die Bindestellen am Estrogen Rezeptor zu konkurrieren. Die Grundlage für den RBA wurde 1966 von Toft und Gorski geschaffen, die ER-Protein isoliert und charakterisiert haben (Toft et al. 1966). In der Studie konnte gezeigt werden, dass DES im Gegensatz zu Testosteron in der Lage war, Estradiol von ER-Protein zu verdrängen. Damit ist der RBA in der Lage ER-Liganden zu identifizieren. Da ein estrogener Effekt in vivo hauptsächlich über die ERs vermittelt wird, wird dieser Assay weltweit als screening-Assay zur Identifikation möglicher EACs verwendet.

\subsubsection{Hypothalamus-Zellkultur}

Die murine Hypothalamus-Zelllinie GT1-7 sezerniert GnRH in das Kulturmedium. Die Sekretionsleistung ist abhängig von der Konzentration von Estradiol im Medium (Bowe et al. 2003), wobei Estradiol durch negative Rückkopplungsregulation die Sekretion hemmt. GnRH kann im Medium gemessen werden. Durch diesen Assay ist es möglich, den Einfluss der Testsubstanz auf die GnRH-Sekretion im Hypothalamus sowie auf die Rückkopplungsregulation zu untersuchen.

\subsubsection{Proliferationstest (E-screen) in der Zellkultur}

Der E-screen nutzt die Eigenschaft der Estrogen-sensitiven Mammakarzinom-Zelllinie MCF-7, auf estrogene Substanzen mit einer vermehrten Produktion von Wachstumsfaktoren und somit einer verstärkten Proliferation zu reagieren (Soto et al. 1991). Die Wachstumsrate als Parameter für Estrogenität, wird mit Hilfe eines Proliferationsassays bestimmt und mit der Wirkung eines Estrogens als Kontrolle verglichen. Obwohl vermehrt transgene Reportergenassays aufgrund ihrer höheren Spezifität bevorzugt werden, ist der Assay ein zuverlässiges screening-Instrument (Korach et al. 1995).

\subsubsection{EROD-Assay}

Das Gen Cypla1 codiert für mehrere Isoenzyme (z.B. AHH, EROD), die bei der Biotransformation von Xenobiotika in der Leber beteiligt sind. Die Aktivität eines dieser Isoenzyme, der Ethoxyresorufin-O-deethylase (EROD), wird in diesem Assay im 
Vergleich zu einer Positivkontrolle gemessen. Die Genexpression kann durch Substrate der Enzyme über den Arylhydrocarbon-Rezeptor (AhR) induziert werden (Denison et al. 2002). Es ist bekannt, dass Liganden über den AhR die Signaltransduktion der Estrogene als Antagonisten beeinflussen (Ebert et al. 2005; Zhou et al. 2003). Dies kann durch eine verstärkte Metabolisierung von E2, die Induktion von Repressorproteinen, das Blockieren von Bereichen des Promotors über sog. inhibitory response elements, die Konkurrenz um Kofaktoren sowie die induzierte Degradation des ER alpha geschehen (Safe et al. 2003).

\subsubsection{In vivo-Untersuchungen im erweiterten uterotrophen Assay}

In vitro-Assays sind hervorragende Instrumente zur Identifikation von aktiven Einzelverbindungen in Bezug auf spezifische Endpunkte und können auch bei der Aufklärung von Mechanismen helfen, doch eine Aussage über einen Effekt auf einen Organismus kann nur durch in vivo-Versuche erhalten werden (Gies et al. 2001). Die Pharmakodynamik und Pharmakokinetik von Estradiol setzen per se einen in vivoVersuch voraus, um die Absorption, Verteilung und Exkretion sowie die Auswirkung möglicher Metabolite zu erfassen. Dabei sollten Lebensstadien einbezogen werden, welche eine hohe Empfindlichkeit gegenüber den zu erwartenden Effekten aufweisen.

Die Organe des Reproduktionstraktes, Uterus, Cervix und Vagina, erfahren in der Ratte einen sehr schnellen Wechsel von Wachstum und Regression während des weiblichen Zyklus. Der uterotrophe Assay nutzt die Eigenschaft des Uterus, schnell und stark auf estrogene Substanzen mit einer Gewichtszunahme zu reagieren.

Primärer Auslöser des Wachstums sind ER-vermittelte Effekte des 17ß-Estradiols und des epidermalen Wachstumsfaktors EGF (Gardner et al. 1989; Mukku et al. 1985). Sekundär kommen zusätzliche Effekte durch Wachstumsfaktoren wie IGF-1 zum Tragen (Klotz et al. 2000). Die molekularen und zellulären Reaktionen auf dieses Signal können grob in zwei Phasen unterteilt werden: die frühe Phase bis 6 Stunden nach Administration und die späte Phase bis 24 Stunden nach Administration. Die frühe Phase ist gekennzeichnet durch die Aktivierung molekularer Prozesse wie vermehrte RNA-Synthese, die durch eine Reihe von sog. „Markergenen“ verfolgt werden kann. Die späte Phase ist gekennzeichnet durch vermehrtes Zellwachstum (Clark et al. 1983). 
Der weibliche Zyklus wird durch die intakte HPG-Achse reguliert. Aus der Abb. 3 ist ersichtlich, dass der gesamte Zyklus der Ratte nur 4 Tage dauert. Die Exposition des Uterus durch Estradiol und das damit verbundene Wachstum von Uterus- und Vaginalepithel tritt innerhalb von 2 Tagen ein (Allen et al. 1980). Daher ist eine Expositionszeit von mindestens 3 Tagen ausreichend, um eine estrogene Aktivität am Uterusgewicht zu erkennen. Eine hohe Sensitivität erhält man mit juvenilen oder ovariektomierten Ratten, da der endogene Estrogenspiegel sehr niedrig ist.

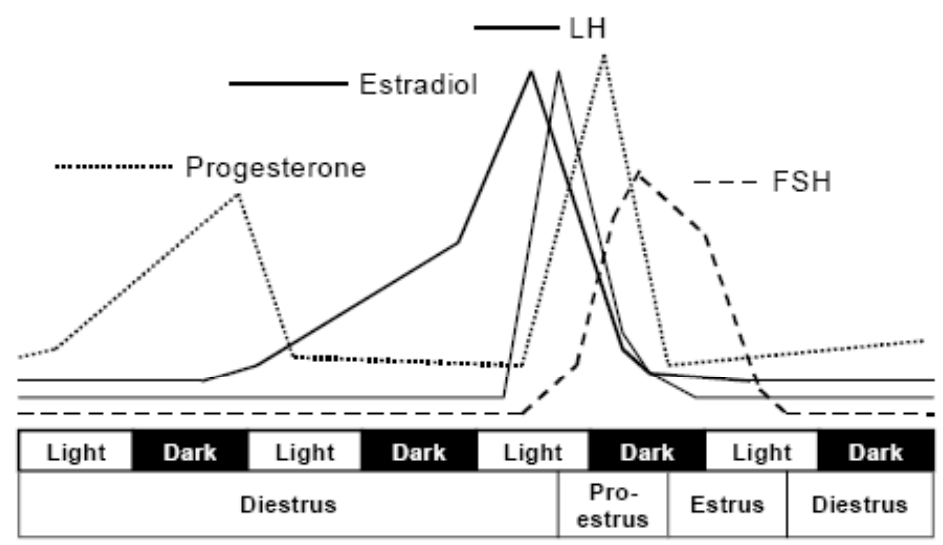

Abb. 3: Darstellung der Hormonkonzentrationen im 4tägigen Zyklus der Ratte bei regelmäßigem Tagesrhythmus von 12 Stunden Licht- und Dunkelperioden. Nach (Smith et al. 1975).

Damit stellt die ovariektomierte Ratte das ideale Modell zur Untersuchung von estrogenen Effekten in vivo dar.

- Bei dem klassischen uterotrophen Assay, der zurückzuführen ist auf die Untersuchungen von Allen et al. (Allen et al. 1937), werden die Uterusgewichte von juvenilen oder ovariektomierten Versuchstieren nach der Applikation der Testsubstanzen zu ihren Körpergewichten in Relation gesetzt und mit einer Kontrollgruppe verglichen. In der in der vorliegenden Arbeit verwendeten erweiterten Form des uterotrophen Assay werden zusätzliche Parameter herangezogen. Auswirkungen von estrogenen Substanzen können an vaginalen Abstrichen anhand des Erscheinungsbildes kategorisiert werden. Ovariektomierte Tiere zeigen ein dem Diestrus entsprechendes Erscheinungsbild. Die Behandlung mit Estrogenen verursacht das Erscheinungsbild von estrischen Ratten. Auf zellulärer Ebene können die durch 
Estrogene in den Geweben des Uterus eingeleiteten Veränderungen der Zellen des Endometriums und des Epithels mikroskopisch festgestellt werden [ausführlich beschrieben in (Yuan 1991)].

- Auf der Ebene der mRNA können durch ERs induzierte Gene, sog. Markergene, als analytische Parameter für eine Estrogenwirkung gemessen werden (Diel et al. 2000).

Das Gen des Komplement-Proteins C3 steht unter direkter Kontrolle dreier konjugierter estrogen response elements (ERE) und wird von den luminalen Epithelzellen des Uterus gebildet (Vik et al. 1991). Als Bestandteil des Komplementsystems übernimmt es wichtige Aufgaben bei der Inaktivierung von in den Organismus eingedrungenen Fremdstoffen und bildet so eine Verbindung zwischen dem Immunsystem und der estrogenen Regulation (Sundstrom et al. 1989).

Der insulin like growth factor 1, IGF-1, ist an der Entwicklung des menschlichen Organismus beteiligt. Im weiblichen Zyklus ist IGF-1 maßgeblich am Uteruswachstum beteiligt und wird im Zuge der oben beschriebenen Prozesse im Uterus durch Estrogene induziert (Murphy et al. 1987).

Eine bekannte splice-Variante des ER alpha ist TERP1, welcher die Exons 1 bis 4 fehlen (Friend et al. 1995). TERP1 unterliegt der Kontrolle eines im Intron 4 liegenden Promotors, welcher über ein ERE, in Abhängigkeit des hypophysären Kofaktors Pit-1, von den ERs reguliert wird (Schausi et al. 2003).

Die Rezeptoren ERR1, ERR2 und ERR3 (estrogen receptor related proteins) gehören zu der Superfamilie der nukleären Rezeptoren (NR) und weisen einen hohen Grad an struktureller Homologie zu den ERs auf (Giguere et al. 1988; Hong et al. 1999). Trotzdem reagieren diese Rezeptoren nicht auf Estradiol. ERR1, ERR2 und ERR3, sind im Gegensatz zu den ERs, konstitutiv aktive Transkriptionsfaktoren, welche durch Liganden inaktiviert werden können. Die ERRs interagieren mit dem estrogenen Signaltransduktionsweg, indem sie die gleichen response elements erkennen wie die ERs (Vanacker et al. 1999). Die Expression der ERRs 1 und 3 in weiten Teilen des zentralen Nervensystems (ZNS) (Bonnelye et al. 1997) lässt eine Rolle in der Funktion bzw. in der Entwicklung des ZNS vermuten. So spielt ERR1 eine Rolle in der Proliferation 
und Differenzierung bei der Entwicklung von Mäusen (Luo et al. 1997). Eine Regulation der Expression der ERRs durch Estrogene wurde von Liu et al. postuliert (Liu et al. 2003).

- Der Einfluss von Estrogenen auf den Metabolismus wurde im Zusammenhang mit Herzgefäßerkrankungen untersucht (Barrett-Connor et al. 1991). Die Exposition von Versuchstieren durch Estrogene senkt die SerumKonzentrationen von Cholesterol, high-density-lipoprotein (HDL) und lowdensity-lipoprotein (LDL) sowie das Körpergewicht (Washburn et al. 1993). Parallel dazu ändert sich die Serum-Konzentration des Fetthormons Leptin (Di Carlo et al. 2004). Leptin als Indikator für die Versorgungszustand eines Organismus hat einen regulatorischen Effekt auf die LH-Sekretion und somit auf die Reproduktion (Barb et al. 2005). Deshalb werden das Körpergewicht und zusätzlich die Serumspiegel von Leptin, Cholesterin, HDL und LDL gemessen

\subsubsection{Expressionsmuster des ER alpha/beta-Systems}

Estradiol vermittelt seine Wirkung primär über die ERs, reguliert gleichzeitig das Expressionsmuster der eigenen Rezeptoren, z.B. im Uterus, und modifiziert damit die eigene Signalwirkung. Die Wirkung des endogenen Estradiols dient als Standard für die Bewertung der estrogenen Aktivität. Davon abweichende Effekte werden als SERMWirkung angesehen. Um eine mögliche SERM-Wirkung der Testsubstanz zu überprüfen, wurde die Reaktion des ER alpha/beta-Systems auf den Standard Estradiol sowie auf die Testsubstanz anhand der Expression der beiden Subtypen untersucht.

\subsubsection{Parameter der HPG-Achse}

Die Regulation der weiblichen Reproduktion erfolgt auf drei Ebenen. Im Hypothalamus werden die releasing-Hormone, wie z.B. GnRH, aus den neurovaskulären Strukturen in den Portalkreislauf freigesetzt und gelangen so zum Hypophysenvorderlappen (Adenohypophyse). Der Einfluss einer Substanz auf die GnRH Sekretion kann in der Zellkultur an GT1-7-Zellen überprüft werden. In der Hypophyse werden wiederum glandotrope Hormone, die untergeordnete Drüsen regulieren, wie FSH und LH, oder Effekthormone, die direkt auf die Zellen des Zielorgans wirken, wie GH und Prolaktin, freigesetzt. FSH und LH wirken auf die Gonaden, Prolaktin auf die Brustdrüsen und GH 
hat vielfältige Aufgaben in der Entwicklung und der Homöostase. Die Wirkung von OMC auf diese Hormone kann anhand des Serumspiegels verfolgt werden. Zudem wird die alpha-Untereinheit der Hormone LH, FSH und TSH sowie die beta-Untereinheit des LH auf der Ebene der mRNA gemessen. Hypothalamus und Hypophyse unterliegen einer negativen Rückkopplungsregulation durch Estrogene und Progesteron der Gonaden.

\subsubsection{Parameter der HPT-Achse}

Der Stoffwechsel des Menschen steht ebenfalls unter der Regulation dreier Ebenen. So reguliert das aus den neurovaskulären Strukturen in den Portalkreislauf freigesetzte TRH im Hypophysenvorderlappen die Freisetzung von TSH aus den basophilen Zellen in den Blutkreislauf. TRH kann auf der mRNA-Ebene gemessen werden. In der Schilddrüse regt das TSH die Sekretion der Hormone T3 und T4 an. T3 und T4, als transportproteingebundenes (T3, T4) und freies Hormon (fT3, fT4) sowie TSH können im Serum gemessen werden können. Die Expression des TSH-Rezeptors wird auf der Proteinebene gemessen. Zudem wird die alpha-Untereinheit (s.o.) und die betaUntereinheit des TSH auf der Ebene der mRNA gemessen. Beide Hormone haben wiederum einen negativen Rückkopplungseffekt auf Hypophyse und Hypothalamus. Die Funktion der Schilddrüse wird anhand der Expression des Natrium/IodidSymporters (NIS) auf der Proteinebene sowie mit einem Schilddrüsenperoxidase (TPO)-Enzymaktivitätsassay überprüft. Zudem wird auf der Ebene der Zielorgane (z.B.

Leber) die Reaktion auf die Schilddrüsenhormone mit dem DeiodaseEnzymaktivitätsassay getestet.

\subsubsection{Dosis-Wirkungsbeziehung}

Im Verlauf einer Risikobewertung von Chemikalien für die menschliche Gesundheit (Human Health Risk Assessment of Chemicals) ist ein wichtiger Schritt die Evaluierung von in vivo-Daten und das Erstellen einer Dosis-Wirkungsbeziehung, aus welcher dann mit Hilfe des „Benchmark Approach“ Schwellenwerte extrapoliert werden. Diese Schwellenwerte geben die Dosis wieder, bei welcher die endokrine Aktivität der Substanz einsetzt. 
Die Risikobewertung von Chemikalien wird üblicherweise in vier Abschnitte unterteilt (Bostrom et al. 2002):

- Ermittlung eines Gefährdungspotentials:

Der erste Schritt der Risikobewertung für Chemikalien besteht in der Identifikation der möglichen Auswirkungen einer Exposition auf Organismen. Dabei ist die Relevanz für einen gefährdeten Lebensraum bzw. Population nicht von Bedeutung.

- Abschätzung der Dosis-Wirkungsbeziehung:

Sobald für eine Substanz ein mögliches Gefährdungspotential erkannt wurde, wird eine Dosis-Wirkungsbeziehung in einem Modellorganismus erstellt. Hierbei wird ein Modell gewählt, welches zur Untersuchung der in Punkt eins identifizierten Effekte optimal ist. Im Idealfall ergibt sich daraus ein Schwellenwert, bis zu dem keine Effekte im Organismus zu erwarten sind.

- Abschätzung der Exposition:

Daten, die in diesem Abschnitt gesammelt werden, stammen meist aus epidemiologischen Studien oder statistischen Auswertungen. Des Weiteren gehören Untersuchungen zur Kinetik der Chemikalien dazu.

- Abschließende Risikobeurteilung:

Abschließend werden die in den ersten drei Abschnitten gesammelten Daten ausgewertet und die $\mathrm{zu}$ erwartenden Risiken für die gefährdete Population werden formuliert.

Diese Arbeit beschäftigt sich im Schwerpunkt mit den ersten beiden Punkten des Ablaufes.

\subsubsection{Toxikokinetik}

Die Toxikokinetik beschäftigt sich mit Absorption, Verteilung, Metabolismus und Ausscheidung von Xenobiotika im Organismus.

Die Untersuchung der Absorption der oral applizierten Substanz erfolgt durch HPLCAnalyse der Tierseren. 
Untersuchungen zur Verteilung einer Substanz in Organismen werden traditionell mit radioaktiv markiertem Material durchgeführt (Halldin et al. 2001). Aufgrund der damit verbundenen Risiken wurde in dieser Arbeit die Verteilung nicht untersucht.

Die Leber ist das zentrale Organ für die Biotransformation von Xenobiotika. Bei oral applizierten Substanzen kommt oftmals der First-Pass-Effekt zum Tragen (Whitehead et al. 1980). Dabei werden Substanzen beim ersten Passieren der Leber, über die Pfortader nach Absorption im Magen-Darm-Trakt, degradiert oder transformiert (Phase I-Reaktionen), mit polaren Gruppen gekoppelt (Phase II-Reaktionen) und ausgeschieden. Xenobiotika die so metabolisiert werden induzieren in der Regel die Biosynthese der Enzyme der Biotransformation (Jeuken et al. 2003). Die Enzymaktivität eines der an der Phase I der Biotransformation beteiligten Enzyme wurde im EROD-Assay untersucht. Ob die Testsubstanz OMC über einen alternativen Weg metabolisiert wird, soll mittels der HPLC sowie der Massenspektrometrie überprüft werden. 


\section{Material und Methoden}

\subsection{Chemikalien und Verbrauchsmaterial}

Chemikalien wurden, wenn nicht anders im Text erwähnt, von den Firmen Gibco (Karlsruhe), Merck (Darmstadt), Roth (Karlsruhe), Sigma (Schnelldorf) und Bachem (Weil am Rhein) in analytischer Qualität bezogen. Verbrauchsmaterialien wurden von den Firmen American National Can. (Chicago, USA), Eppendorf (Hamburg), Greiner (Frickenhausen), Kimberley-Clark (USA), Nunc (Wiesbaden) und Sarstedt (Nümbrecht) bezogen.

\subsection{Testsubstanzen}

17ß-Estradiolvalerat (Estra-1,3,5(10)-trien-3,17-diol (17-beta)-, 17-pentanoat; E2V) wurde von Sigma (Schnelldorf) und Ethylhexyl-methoxycinnamat (Octylmethoxycinnamat, OMC, EUSOLEX 2292) wurde von Merck (Darmstadt) bezogen. E2V ist ein speziell für die orale Applikation entwickeltes E2-Derivat.

\subsection{In vitro-Methoden}

\subsubsection{Rezeptorbindungsassay}

In Rezeptorbindungsassays kann die Fähigkeit, einer Substanz radioaktiv markiertes Estradiol von Bindestellen an rekombinantem Estrogen Rezeptor-Protein zu verdrängen, quantifiziert werden. Die Rezeptorbindungsassays für die beiden ER-Subtypen alpha und beta wurden nach folgenden Schema in Glasscintillationsgefässen angesetzt:

ER alpha:

$5 \mu 1$ Probe/Standard in Ethanol (70\%)

$40 \mu 1$ ER alpha (730nM) Invitrogen (Panvera), Karlsruhe

$50 \mu 1 \mathrm{I}^{125}$ Estradiol-Tracer mit ca. $35.000 \mathrm{cpm}$

Perkin Elmer (NEN), Rodgau - Jügesheim

$350 \mu 1$ Assay-Puffer 
ER beta:

$5 \mu 1$

Probe/Standard in Ethanol (70 \%)

$20 \mu 1$ ER beta $(100 \mathrm{nM})$

Invitrogen (Panvera), Karlsruhe

$50 \mu 1 \mathrm{I}^{125}$ Estradiol-Tracer

Perkin Elmer (NEN), Rodgau - Jügesheim

$350 \mu 1$ Assay-Puffer

Als Standardkurve diente E2 (Merck, Darmstadt) in Konzentrationen von 1, 2,5, 5, 10, 25, 50 und $100 \times 10^{-8} \mathrm{M}$. Die Proben wurden gevortext und über Nacht bei $4^{\circ} \mathrm{C}$ inkubiert. Danach wurden die Proben auf Eis mit $500 \mu$ l Charcoal-Puffer versetzt und nach 15minütiger Inkubation bei 3000 Upm abzentrifugiert (Cryofuge 5000, Heraeus Christ, Hanau). Der Überstand wurde in ein Zählröhrchen dekantiert und im Gamma Counter (Wizard 1470, Perkin Elmer (Wallac), Rodgau - Jügesheim) für 10 min gezählt.

Assay-Puffer:

3,2 g TRIS

$0,504 \mathrm{~g}$ EDTA

1 g BSA (Fraction V)

Ad 900 ml, pH 7,4

$100 \mathrm{ml}$ Glycerol

Charcoal-Puffer:

$3,2 \mathrm{~g}$ TRIS

0,504 g EDTA

Ad 1000 ml, pH 7,4

5 g Dextran T70

5 g Charcoal
Paesel, Frankfurt

Merck, Darmstadt

Serva, Heidelberg

Sigma, Schnelldorf

Paesel, Frankfurt

Merck, Darmstadt

Pfizer (Pharmacia), Karlsruhe

Sigma, Schnelldorf

\subsubsection{Zellkultur}

Für den Proliferationsassay (E-screen) wurden MCF-7 Zellen (DSMZ, Braunschweig) benutzt. Der EROD-Assay wurde mit der Zelllinie H4IIE (ATCC, Manassas, VA, USA) durchgeführt. Die Zelllinien wurden in $75 \mathrm{~cm}^{2}$ Flaschen auf Permanent-Medium bei $37^{\circ} \mathrm{C}, 5 \% \mathrm{CO}_{2}$ und einer relativen Luftfeuchtigkeit von $95 \%$ inkubiert. Alle Medien 
wurden mit $1 \%$ Pen/Strep-Lösung (10.000 U Penicillin/ml, 10.000 $\mu$ g Streptomycin/ml in $0.85 \%$ Saline, Gibco, Karlruhe) versetzt. Im Abstand von 7 Tagen wurden die Zellen passagiert. Das Medium wurde vorsichtig vom Zellrasen abgesaugt. Die Zellen wurden 2 mal mit ca. $20 \mathrm{ml}$ PBS (Gibco, Karlsruhe) gewaschen und mit ca. $6 \mathrm{ml}$ TrypsinEDTA-Lösung (0,05 \% Trypsin, Gibco, Karlsruhe) bedeckt. Die Inkubationszeit bei $37^{\circ} \mathrm{C}$ betrug ca. $5 \mathrm{~min}$, der Fortschritt der Trypsinierung wurde unter dem Lichtmikroskop überprüft. Die Trypsin-EDTA-Lösung mit den abgelösten Zellen wurde in $15 \mathrm{ml}$ serumhaltiges Medium überführt, wodurch das Trypsin inaktiviert wurde. Anhaftende Zellen wurden durch leichte Stöße an die Kulturflasche abgelöst und mit ca. $10 \mathrm{ml}$ Medium aus der Flasche gespült. Die Zellsuspension wurde bei $1200 \mathrm{Upm}$ für 10 min bei RT zentrifugiert (Labofuge GL, Heraeus Christ, Hanau). Die Zellen wurden 2mal mit PBS gewaschen und die Zellzahl mit Hilfe einer Neubauer-Zählkammer (Brand, Wertheim) bestimmt. Die Zellen wurden mit ca. 20.000 Zellen pro ml Medium ausgesät. Die Kulturen wurden maximal bis Passage 20 benutzt, um sich verändernde Zelleigenschaften im Verlauf der Assays auszuschließen (Whyte et al. 2004). Deshalb wurden frühe Passagen der Zelllinie mit $1 \times 10^{6}$ Zellen in $1 \mathrm{ml} 10 \%$ DMSO in FKS in einem Styroporbehälter bei $-20^{\circ} \mathrm{C}$ über Nacht eingefroren und danach in einen Tank mit flüssigem Stickstoff überführt. Zum Start einer neuen Kultur wurden diese Aliquots in einem $37^{\circ} \mathrm{C}$ warmen Wasserbad angetaut und schnell in Permanent-Medium überführt. Nach zweimaligem Waschen mit Permanent-Medium wurden die Zellen in einer $75 \mathrm{~cm}^{2}$-Flasche ausgesät.

Permanent-Medium:

$\begin{array}{ll}500 \mathrm{ml} & \text { DMEM, Gibco, Karlsruhe } \\ 50 \mathrm{ml} & \text { FKS, Biochrom, Berlin } \\ 5 \mathrm{ml} & \text { Pyruvat (100mM), Gibco, Karlsruhe }\end{array}$

\subsubsection{Proliferationsassay (E-Screen)}

Zur Bestimmung der Proliferationsrate einer Zellpopulation wurde der Einbau von 5-Bromo-2'deoxyuridine (BrdU), einem Pyrimidin-Analogon, in die DNA gemessen.

Für den Proliferationsassay wurde das Cell Proliferation ELISA BrdU Kit (Roche, Mannheim) benutzt. Dafür wurden die MCF-7-Zellen in einer Zelldichte von 10.000 
Zellen/well in 96 well-Platten ausplattiert und für $24 \mathrm{~h}$ bei $37^{\circ} \mathrm{C}, 5 \% \mathrm{CO}_{2}$ und einer relativen Luftfeuchtigkeit von $95 \%$ inkubiert. Die Belastung der Zellen mit einer Verdünnungsreihe der in DMSO gelösten Substanz erfolgte für $24 \mathrm{~h}$ bei den gleichen Bedingungen. Die Durchführung des Assays erfolgte nach Angaben des Herstellers mit der Ausnahme, dass zur Reduzierung des Hintergrundes nach der Fixierung der Zellen mit $200 \mu \mathrm{l}$ Blocking Reagent für ELISA (Roche, Mannheim) für $30 \mathrm{~min}$ inkubiert wurde. Die Absorption der Proben wurde mit einem Spectra ELISA-Reader (Tecan, Crailsheim) bei $450 \mathrm{~nm}$ mit einer Referenzwellenlänge von $690 \mathrm{~nm}$ gemessen.

\subsubsection{Proliferationsassay (BrdU) mit H4IIE-Zellen}

Der Proliferationsassay mit H4IIE-Zellen wurde nach demselben Schema durchgeführt wie der E-Screen (2.3.2.1), wobei die Zellen mit einer Zelldichte von 5000 Zellen pro $\mathrm{ml}$ ausplattiert wurden.

\subsubsection{EROD-Assay}

Mit Dioxin verwandte Xenobiotika sind in der Lage, über den Arylhydrocarbon Rezeptor die Expression des Cypla1-Genes zu induzieren. Das Genprodukt wird posttranslational zu Enzymen mit verschiedenen Aktivitäten modifiziert, welche an der Phase I der Biotransformation beteiligt sind. $\mathrm{Zu}$ diesen Enzymen gehört die Ethoxyresorufin-O-deethylase (EROD). Mit Hilfe einer Substratreaktion kann die Enzymaktivität der EROD fluorometrisch bestimmt werden.

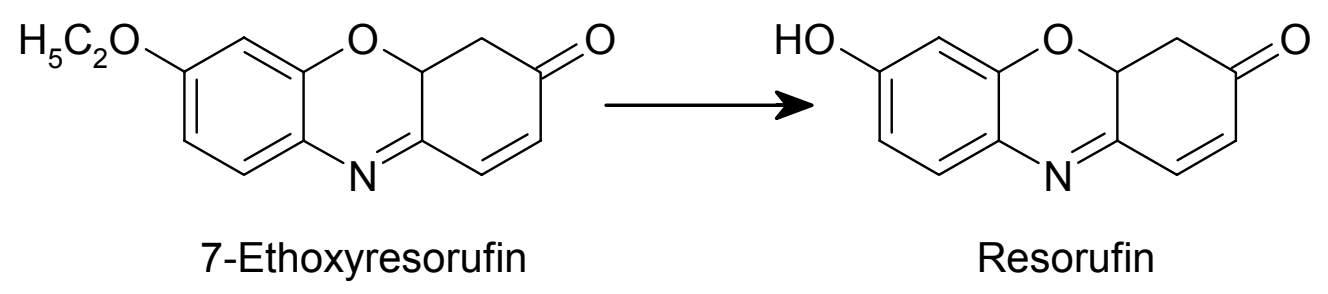

Abb. 4: Durch die EROD katalysierte Degradation von Ethoxyresorufin.

Die H4IIE-Zellen wurden in einer Dichte von 10.000 Zellen pro well in 96 well-Platten ausplattiert und für $48 \mathrm{~h}$ bei $37^{\circ} \mathrm{C}, 5 \% \mathrm{CO}_{2}$ und einer relativen Luftfeuchtigkeit von $95 \%$ inkubiert. Von den acht Replikaten wurden 6 für den EROD-Assay benutzt. Die 
Belastung der Zellen erfolgte mit einer Verdünnungsreihe der in DMSO gelösten Substanz in Permanent-Medium. Das zur Hemmung der Estrogen Rezeptoren verwendete ICI 182,780 wurde von Tocris (Avonmouth, UK) bezogen. Die Tierseren wurden mit Seren von Kontrolltieren verdünnt, da das zugesetzte Serum einen hemmenden Effekt hatte. Jeder Assay beinhaltete zusätzlich eine Lösungsmittelkontrolle in der niedrigsten Verdünnungsstufe des Lösungsmittels DMSO in den Testgruppen sowie als Positivkontrolle 3-Methylcholanthren (3-MC) $1 \times 10^{-6} \mathrm{M}$. Nach $48 \mathrm{~h}$ wurde das Medium abgesaugt und die Zellen mit $50 \mu$ Dicumarol (1:100 Verdünnung der $1 \mathrm{mM}$ Stammlösung in PBS) und $50 \mu$ Ethoxyresorufin (1:100 Verdünnung der $400 \mu \mathrm{M}$ Stammlösung in PBS) versetzt und für $30 \mathrm{~min}$ bei $37^{\circ} \mathrm{C}$

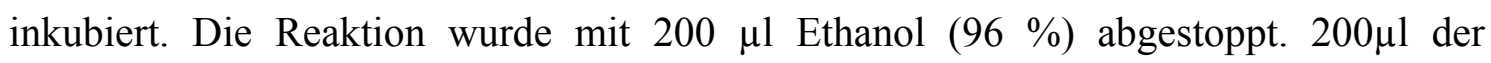
Lösungen wurden in eine spezielle 96 well-Platte für Fluoreszenz-Messungen (FluoroNunc F96, Nunc, Wiesbaden) überführt. Die Messung erfolgte in einem Synergy HT (BioTek, Bad Friedrichshall) Fluorometer bei $530 \mathrm{~nm}$ Anregung und $590 \mathrm{~nm}$ Emission.

Die Bestimmung der Produktkonzentration erfolgte anhand einer Standardkurve. Dazu wurde eine 2,5 $\mu \mathrm{M}$ Resorufinlösung in $70 \%$ Ethanol in PBS in 1:2 Verdünnungen zu sechs Standardpunkten verdünnt. Zwei Replikate desselben Ansatzes wurden für die Proteinbestimmung nach Bradford (Bradford 1976) benutzt. Dazu wurde das Medium vom Zellrasen entfernt und dieser mit 100 $\mu$ l Reporter Lysis Buffer (RLB) versetzt. Der Ansatz wurde für $30 \mathrm{~min}$ auf einem Schüttler bei RT inkubiert. $10 \mu \mathrm{l}$ des Lysates wurden in eine neue 96 well-Platte überführt, mit $200 \mu 1$ einer 1:5 Verdünnung des Bradford-Reagenzes (Protein Assay, BioRad, München) in $\mathrm{H}_{2} \mathrm{O}_{\text {bidest }}$ versetzt und für 5 min bei Raumtemperatur inkubiert. Die Extinktion bei $590 \mathrm{~nm}$ wurde mit dem Spectra ELISA-Reader (Tecan, Crailsheim) gemessen. Die Konzentrationsbestimmung erfolgte anhand einer Standardkurve mit 100, 200, 400, 600, 800 und $1000 \mu \mathrm{g} / \mathrm{ml}$ bovinem Plasma-Gammaglobulin (Std I, BioRad, München) in RLB.

Dicumarol

7-Ethoxyresorufin

Resorufin

RLB (Reporter Lysis Buffer)
Sigma, Schnelldorf

Fluka, Neu Ulm

Sigma, Schnelldorf

Promega, Mannheim 


\subsubsection{Hypophysen-Primärzellkultur}

Die Hypophysen von weiblichen, intakten, ca. 3 Monate alten Ratten wurden steril entnommen und sofort in Spinner-Medium auf Eis überführt. Mit Skalpellen wurden die Hypophysen im „Scherenschnitt“ zerkleinert und mit Spinner-Medium gespült, um Erythrozyten auszuwaschen. Die zerkleinerten Fragmente wurden in Spinner-Medium mit DNase (1 Spatelspitze auf $20 \mathrm{ml}$, Sigma, Schnelldorf) und Trypsin $(1 \mathrm{mg} / \mathrm{ml}$, Sigma, Schnelldorf) für ca. 2 Stunden verdaut. In Abständen von 30 min wurden die Fragmente mit einer abgeschnittenen Pipettenspitze trituriert. Nach 60 min wurde der Überstand abgenommen und durch einen Cell Strainer (BD Biosciences, Erembodegem, Belgien) in ca. $10 \mathrm{ml}$ Serum-Medium passiert. Der Bodensatz wurde mit frischem DNase-, und trypsinhaltigem Spinner-Medium versetzt und weiter verdaut. Sobald das Gewebe vollständig zersetzt war, wurde die restliche Zellsuspension durch den Cell Strainer passiert. Die Zellsuspension wurde 2-mal bei $1200 \mathrm{Upm}$ für $10 \mathrm{~min}$ bei RT abzentrifugiert (Labofuge GL, Heraeus Christ, Hanau) und mit Serum-Medium gewaschen. Mit Hilfe einer Neubauer-Zählkammer (Brand, Wertheim) wurde die Zellzahl bestimmt und auf 250.000 Zellen/ml verdünnt. Die Zellen wurden in 96 wellPlatten mit $250 \mu 1 /$ well ausplattiert und $96 \mathrm{~h}$ bei $37^{\circ} \mathrm{C}, 10 \% \mathrm{CO}_{2}$ und einer relativen Luftfeuchtigkeit von $95 \%$ inkubiert. Die Belastung der Zellen mit den Testsubstanzen erfolgte in steroidfreiem Permanent-Medium. Der Hälfte der Ansätze wurde nach $45 \mathrm{~h}$ Inkubation eine TRH-Lösung (Bachem, Weil am Rhein) in einer Endkonzentration von $1 \times 10^{-6} \mathrm{M}$ zugegeben. Nach insgesamt $48 \mathrm{~h}$ Inkubation wurden $200 \mu \mathrm{l}$ des Überstandes abgenommen und bei $-20^{\circ} \mathrm{C}$ eingefroren. Die verbleibenden $100 \mu 1$ wurden für den MTT-Test verwendet.

Spinner-Medium:

$500 \mathrm{ml}$ DMEM, Gibco, Karlsruhe

$7 \mathrm{ml} \quad 7,5 \%$ BSA, Gibco, Karlsruhe

$5 \mathrm{ml} \quad 1 \mathrm{M}$ HEPES, Gibco, Karlsruhe

$5 \mathrm{ml}$ Pyruvat (100mM), Gibco, Karlsruhe

$5 \mathrm{ml} \quad$ Glutamin (200mM), Gibco, Karlsruhe 
Serum-Medium:

$500 \mathrm{ml} \quad$ DMEM, Gibco, Karlsruhe

22,5 ml FKS steroidfrei, Biochrom, Berlin

$40 \mathrm{ml} \quad$ Pferdeserum

$5 \mathrm{ml} \quad$ Pyruvat (100mM), Gibco, Karlsruhe

Steroidfreies Permanent-Medium:

$500 \mathrm{ml} \quad$ DMEM w/o Phenol Red, Gibco, Karlsruhe

$50 \mathrm{ml} \quad$ FKS steroidfrei, Biochrom, Berlin

$5 \mathrm{ml} \quad$ Glutamin $(200 \mathrm{mM})$, Gibco, Karlsruhe

$5 \mathrm{ml} \quad$ Pyruvat (100mM), Gibco, Karlsruhe

\subsubsection{MTT-Test}

$\mathrm{Zu}$ den verbliebenen $100 \mu \mathrm{l}$ Medium wurden $10 \mu \mathrm{l}$ MTT-Lösung (5 mg/ml in PBS) hinzupipettiert. Die Zellen wurden für ca. 90 min bei $37^{\circ} \mathrm{C}$ inkubiert, bis in den Zellen unter dem Mikroskop dunkle Kristalle sichtbar wurden. Die Reaktion wurde durch Zugabe von $15 \mu$ einer 12,5 \%igen Glutaraldehyd-Lösung in PBS abgestoppt und für 15 min bei RT inkubiert. Danach wurde der Überstand abgesaugt und die Präzipitate mit $150 \mu 10,04 \mathrm{~N} \mathrm{HCl}$ in Isopropanol aufgelöst. Die Messung der Absorption erfolgte bei $590 \mathrm{~nm}$ mit einer Referenzwellenlänge von $690 \mathrm{~nm}$ mit einem Spectra ELISAReader (Tecan, Crailsheim).

MTT (3-(4,5-Dimethyl-2-thiazolyl)-2,5-diphenyl-2H-tetrazoliumbromid)

Sigma, Schnelldorf

Glutaraldehyd, $25 \%$ in $\mathrm{H}_{2} \mathrm{O}_{\text {bidest }}$

Sigma, Schnelldorf

\subsubsection{Hypothalamus-Zellkultur}

Die GT1-7-Zellen (von Richard Weiner, University of California, San Francisco, USA, zur Verfügung gestellt) wurden mit einer Zelldichte von 200.000 Zellen pro well in Permanent-Medium mit $15 \%$ FKS in 24 well-Platten ausplattiert und für $72 \mathrm{~h}$ bei $37^{\circ} \mathrm{C}$, $5 \% \mathrm{CO}_{2}$ und einer relativen Luftfeuchtigkeit von $95 \%$ inkubiert. Danach wurde das Medium entfernt und durch steroidfreies Permanent-Medium mit $2 \%$ FKS ersetzt. Die 
Belastung der Zellen erfolgte nach weiteren $16 \mathrm{~h}$ Inkubation in frischem steroidfreiem Permanent-Medium mit 2 \% FKS. Nach 6 h wurde der Überstand abgenommen und bei $-20^{\circ} \mathrm{C}$ eingefroren.

Permanent-Medium mit $15 \%$ FKS:

$500 \mathrm{ml}$ DMEM, Gibco, Karlsruhe

$75 \mathrm{ml} \quad$ FKS, Biochrom, Berlin

$5 \mathrm{ml} \quad$ Pyruvat (100mM), Gibco, Karlsruhe

Steroidfreies Permanent-Medium mit $2 \%$ FKS:

$500 \mathrm{ml} \quad$ DMEM w/o Phenol Red, Gibco, Karlsruhe

$10 \mathrm{ml} \quad$ FKS steroidfrei, Biochrom, Berlin

$5 \mathrm{ml} \quad$ Glutamin $(200 \mathrm{mM})$, Gibco, Karlsruhe

$5 \mathrm{ml} \quad$ Pyruvat (100mM), Gibco, Karlsruhe

\subsection{Tierexperimente}

Für die Tierexperimente lag eine Genehmigung der Bezirksregierung Braunschweig vor: Aktenzeichen 509.42502/01-36.03.: Steroidrezeptor-spezifische Wirkung von Endokrinen Disruptoren.

\subsubsection{Versuchstiere und Haltungsbedingungen}

Die Sprague-Dawley-Ratten wurden von der Firma Winkelmann (Borchen) bezogen. Für den Tierversuch wurden weibliche Ratten mit einem durchschnittlichen Körpergewicht von $280 \mathrm{~g}$ aus eigener Zucht verwendet. Das Haltungsfutter war eine sojafreie Spezialanfertigung (Ssniff, Soest). Die Tiere wurden in Makrolon Typ IVKäfigen in Gruppen von sechs Ratten pro Käfig gehalten. Die durchschnittliche Temperatur betrug $23^{\circ} \mathrm{C}$, die durchschnittliche Luftfeuchtigkeit betrug $55 \%$. Der Haltungsraum wurde täglich von 6:00 bis 18:00 Uhr beleuchtet. Sojafreies Futter und Trinkwasser stand ad libitum zur Verfügung. 


\subsubsection{Ovariektomie}

Nach kurzer Anästhesie mit $\mathrm{CO}_{2}$ wurden den Tieren die Flanken rasiert und desinfiziert. Unter leichter Ethernarkose wurde die Bauchdecke ca. $2 \mathrm{~cm}$ caudal der Rippenbögen geöffnet. Die Ovarien wurden freipräpariert, mit resorbierbarem Nahtmaterial (Vicryl, Ethicon, Norderstedt) abgebunden und mit einem Skalpell entfernt. Die Muskelschicht wurde mit resorbierbarem Nahtmaterial (Vicryl, Ethicon, Norderstedt) und die Haut mit nicht resorbierbarem Nahtmaterial (Supramid, Braun Aesculap, Tuttlingen) verschlossen. Zum Schutz der Nähte wurden diese zusätzlich mit Wundklammern (Michel Klammern, Martin Medizintechnik, Tuttlingen) gesichert. Die Tiere wurden bis zur vollständigen Erholung von der Narkose beobachtet.

\subsubsection{Sektion}

Unter $\mathrm{CO}_{2}$-Narkose wurden die Tiere mit einer Guillotine dekapitiert und ausgeblutet. Das Blut wurde bis zur Abtrennung des Serums auf Eis gelagert. Das Gehirn wurde mit einer Knochenzange freipräpariert, auf Trockeneis eingefroren und bei $-70^{\circ} \mathrm{C}$ gelagert. Die Hypophyse wurde aus der sella turcica herausgehoben. Mit einer spitzen Pinzette wurde die Neurohypophyse entfernt. Die Schilddrüsenlappen wurden mit einer Federstahlschere von der Trachea freipräpariert. Der Uterus wurde am Uterushals abgetrennt und geteilt. Ein Teil eines Leberlappens wurde entnommen. Die Organe wurden sofort in flüssigem Stickstoff tiefgefroren. Ein Horn des Uterus wurde in einer 4 \%igen Formalinlösung fixiert.

\subsubsection{Subakute Applikation der Testsubstanzen an ovariektomierten weiblichen Ratten}

Zwei Wochen vor Beginn der Applikation der Testsubstanzen wurden die Tiere ovariektomiert. Das Körpergewicht wurde vom Beginn des Experiments bis zur Dekapitation täglich jeweils nach der Gavagierung gemessen. Während des Versuches wurden die Tiere täglich auf Anzeichen einer toxischen Wirkung der Testsubstanzen untersucht. Die Applikation der Testsubstanzen erfolgte einmal täglich per gavage in 1 $\mathrm{ml}$ Olivenöl gelöst. Die Kontrollgruppe (KO) bekam $1 \mathrm{ml}$ reines Olivenöl. E2V wurde in einer Konzentration von $600 \mu \mathrm{g} / \mathrm{kg}$ Körpergewicht, OMC wurde in den Konzentrationen 10, 33, 100, 333 und $1000 \mathrm{mg} / \mathrm{kg}$ verabreicht. 
Kurz vor der Dekapitation wurden Vaginalabstriche gemacht. Dazu wurden 200-300 $\mu 1$ Saline in die Vaginalöffnung pipettiert und auf einen Objektträger gegeben. Die Auswertung des Erscheinungsbildes erfolgte unter dem Mikroskop. Dafür wurde die Morphologie der dominierenden Zellart/en bestimmt und mit dem Erscheinungsbild von Vaginalabstrichen von intakten Ratten verglichen. Den Tieren wurde ein „score“ zugeordnet, wobei diestrusartig der Wert 1, proestrusartig der Wert 2 und estrusartig der Wert 3 zugewiesen bekam.

\subsection{Messung von Serum-Parametern}

Zur Gewinnung des Serums wurde das Blut bei $2800 \mathrm{Upm}$ für $30 \mathrm{~min}$ zentrifugiert (Rotixa RP, Hettich, Tuttlingen). Das Serum wurde mit einer Pasteurpipette vorsichtig abgenommen und bei $-20^{\circ} \mathrm{C}$ eingefroren.

\subsubsection{Radioimmunoassay (RIA)}

Im Radioimmunoassay konkurriert das in einer Probe vorhandene Hormon mit dem radioaktiv markierten Hormon (Tracer) um die Bindungsstellen eines primären Antikörpers. Der Hormon-Antikörperkomplex wird dann ausgefällt, um ungebundenen Tracer zu entfernen. Die in der Probe verbleibende Menge an Radioaktivität ist umgekehrt proportional zu der Menge Hormon in der Probe. Die Bestimmung der Konzentration erfolgt über eine Standardkurve. Für die Messung von T3, fT3, T4, fT4 und Leptin wurden kommerziell erhältliche Kits nach Herstellerangaben verwendet:

T3: $\quad$ Active $($ T3, DSL, Sinsheim

T4: $\quad$ Active ${ }^{\circledR}$ Thyroxin, DSL, Sinsheim

fT3: $\quad$ RIAZENco FT3, ZenTech, Angleur, Belgien

fT4: $\quad$ RIAZENco FT4, ZenTech, Angleur, Belgien

Leptin: $\quad$ Rat Leptin RIA Kit, Linco Research, St.Charles, MO, USA

Die Hypophysenhormone LH, FSH, TSH, GH, Prolaktin sowie GnRH wurden mit Assays gemessen, die im Labor entwickelt wurden. Die Tracer wurden nach Hunter und Greenwood (Hunter et al. 1962) mit ${ }^{125} \mathrm{~J}$ markiert. Die Referenzpräparate, Jodierungspräparate und die primären Antikörper wurden vom National Hormone and 
Pituitary Program NHPP des NIH bezogen. Im Falle von Prolaktin und GnRH wurde laboreigenes Kaninchen-Antiserum benutzt.

Tab. 1: Eingesetztes Volumen der Seren, bzw. des Mediums in den Radioimmunoassays.

\begin{tabular}{|l|l|l|l|l|l|l|}
\hline & LH & FSH & TSH & GH & Prolaktin & GnRH \\
\hline Probenvolumen $(\mu 1)$ & 10 & 50 & 50 & 100 & 25 & 300 \\
\hline
\end{tabular}

Das jeweilige Probenvolumen wurde mit $1 \%$ BSA (Albumin bovine Fraction V, Serva, Heidelberg) in PBS auf $500 \mu \mathrm{l}$ aufgefüllt. Danach wurden $200 \mu \mathrm{l}$ einer 1:4000 Verdünnung des primären Antikörpers in PBS mit Kaninchenserum (1:300, bzw. 1:20000 bei GnRH) zugegeben und für $24 \mathrm{~h}$ bei $4^{\circ} \mathrm{C}$ inkubiert. $100 \mu \mathrm{l}$ des iodierten Tracers (ca. $20.000 \mathrm{cpm}$ ) wurden zugegeben und die Proben wurden erneut für $24 \mathrm{~h}$ bei $4^{\circ} \mathrm{C}$ inkubiert. Der Zweitantikörper (anti-Kaninchen IgG-Serum) wurde in einer 1:30 Verdünnung zum Ansatz gegeben. Nach einer Inkubation von $48 \mathrm{~h}$ bis $72 \mathrm{~h}$ bei $4^{\circ} \mathrm{C}$ wurden $2 \mathrm{ml}$ PBS zu den Proben gegeben und diese bei 3000 Upm für 60 Minuten (Cryofuge 5000, Heraeus-Christ, Osterode) abzentrifugiert. Der Überstand wurde abgenommen und im Gamma Counter (Wizard 1470, Perkin Elmer (Wallac), Rodgau Jügesheim) für 10 min gezählt. Die Bestimmung der Konzentrationen erfolgte anhand von Standardkurven.

\subsubsection{Metabolische Parameter}

Die metabolischen Parameter HDL, LDL und Cholesterol wurden mit kommerziell erhältlichen Kits der Firma Roche (Mannheim) auf einem Hitachi 902 Automatic analyzer gemessen. Folgende Kits wurden dafür verwendet:

Cholesterin: Cholesterin CHOD-PAP

HDL: $\quad$ HDL-Cholesterin 2nd generation

LDL: $\quad$ LDL-Cholesterin 2nd generation

\subsubsection{HPLC-Analyse}

Für die HPLC-Analyse wurde ein Aliquot des Serums direkt aufgereinigt oder über Nacht mit Helix pomatia-Glucuronidase inkubiert, um mögliche Glucuronide und Sulfate zu hydrolysieren. 


\subsubsection{Hydrolyse der Proben}

Zur Hydrolyse der Proben wurden $500 \mu 1$ Serum mit $500 \mu 1$ Hydrolyse-Puffer versetzt und über Nacht bei $37^{\circ} \mathrm{C}$ inkubiert. Danach wurden die Proben extrahiert.

Hydrolyse-Puffer:

$1 \mathrm{mg}$ Helix pomatia $\beta$-Glucuronidase

(Sigma, Schnelldorf)

$500 \mu 1$ 0,1M Ammoniumacetat-Puffer, pH 5

\subsubsection{Probenextraktion}

Die Proben wurden über Strata-X-Säulen (60 mg Bettmasse und $3 \mathrm{ml}$ Volumen, Phenomenex, Aschaffenburg) nach folgendem Schema vakuumextrahiert:

\begin{tabular}{|c|c|}
\hline Konditionierung & $3 \mathrm{ml}$ Methanol (100\%) \\
\hline Equilibrierung & $3 \mathrm{ml} \mathrm{H}_{2} \mathrm{O}_{\text {bidest }}$ \\
\hline Beladung & $1 \mathrm{ml}$ Probe \\
\hline Waschen & $3 \mathrm{ml}$ Methanol (5\%) \\
\hline Trocknen & $30 \mathrm{~s}$ Vakuum \\
\hline Eluieren & $3 \mathrm{ml}$ Methanol (100\%) \\
\hline
\end{tabular}

Die Proben wurden anschließend über Nacht in einer SpeedVac (SpeedVac Concentrator svc200H, Thermo Electron (Savant), Dreieich) lyophilisiert. Die lyophilisierten Proben wurden mit $500 \mu$ l Acetonitril (25\%) rekonstituiert und durch Filtrieren mit Millex-HV Filtern (Millipore, Schwalbach) von unlöslichen Verunreinigungen befreit.

\subsubsection{HPLC-Analyse}

Die für die HPLC-Analyse benutzen Parameter und Geräte sind im Folgenden aufgeführt: 
Vorsäule

Guard 7,5 x 4,6 mm

Jasco, Groß-Umstadt

SS Jour-Guard RP/C18 5,0 $\mu \mathrm{m}$

$\mathrm{P} / \mathrm{N}$ 69080, S/N 2110362.1

Säule

$\mathrm{NC} 250 \times 4,6 \mathrm{~mm}$

Bischoff, Leonberg

Hypersil-ODS 5,0 $\mu \mathrm{m}$

$\mathrm{P} / \mathrm{N} 2546$ 1805, S/N $2711 \mathrm{C} 30$

Autosampler 851-AS, Injektionsvolumen $100 \mu 1$

Jasco, Groß-Umstadt

UV-Detektor LC-95 UV/Vis Detector mit $306 \mathrm{~nm}$

Perkin-Elmer, Rodgau-Jügesheim

Pumpen HPLC Pump K-501 mit $1 \mathrm{ml} / \mathrm{min}$

Knauer, Berlin

Laufmittel A: $\mathrm{H}_{2} \mathrm{O}$ mit $0,085 \% \mathrm{H}_{3} \mathrm{PO}_{4}$

B: $100 \%$ Acetonitril

Gradient:

$0-5$ min:

$75 \% \mathrm{~A}$

$25 \% \mathrm{~B}$

10 min:

$20 \% \mathrm{~A}$

$80 \% \mathrm{~B}$

25 - 30 min:

$0 \% \mathrm{~A}$

$100 \% \mathrm{~B}$

35 min:

$75 \% \mathrm{~A}$

$25 \% \mathrm{~B}$

\subsubsection{HPLC-MS, GC MS und Elementaranalyse}

In Kooperation mit der Abteilung ,Zentrale Analytik und Massenspektrometrie“ des Instituts für Organische und Biomolekulare Chemie der Universität Göttingen wurden die Proben mit den dort vorhandenen Geräten untersucht.

\section{ESI DAD HPLC-MS}

Ausstattung LCQ: Ion Trap-Massenspektrometer (Fa. Finnigan) mit

- Elektrospray-Ionisation (ESI)

- Atmospheric Pressure Chemical Ionisation (APCI)

- MSn-Fähigkeit

- HPLC-UV-MS-Kopplung mit HPLC-Pumpe RHEOS 4000 (Fa. Flux Instruments)

- Diodenarray-Detektor (Thermo) und Autosampler (Jasco) 
API GC-MS/MS

Ausstattung TRACE MS:

GC-MS-Kopplung mit Gaschromatograph TRACE GC (Fa. ThermoFinnigan) mit Elektronenstoß-Ionisation

\subsection{Messung der RNA-Expression von Marker-Genen}

Aufgrund der Instabilität von RNA in Lösung wurden besondere Vorsichtsmassnahmen beim Umgang mit RNA getroffen. Es wurden nur RNase-freie Stammlösungen benutzt, wo dies nicht möglich war, wurde mit Velcorin (Dimethylpyrocarbonat, Bayer, Leverkusen) behandeltes Wasser $\left(\mathrm{H}_{2} \mathrm{O}_{\text {velc }}\right)$ zum Ansetzen der Lösungen benutzt. Dazu wurde $1 \mathrm{ml}$ Velcorin auf $11 \mathrm{H}_{2} \mathrm{O}_{\text {bidest }}$ gegeben, für $4 \mathrm{~h}$ inkubiert und autoklaviert. Alle Materialien wurden für $20 \mathrm{~min}$ bei $120^{\circ} \mathrm{C}$ autoklaviert oder für $12 \mathrm{~h}$ bei $240^{\circ} \mathrm{C}$ sterilisiert. Die Proben wurden auf Eis aufgetaut und unnötiges Auftauen wurde vermieden.

\subsubsection{Extraktion der gesamt-RNA aus Gewebe}

Die entnommenen Organe wurden bis zur Probenaufbereitung bei $-70^{\circ} \mathrm{C}$ gelagert. Mit Hilfe des RNeasy Minikits (Qiagen, Hilden) wurde die gesamt-RNA isoliert. Dazu wurde ein Fragment des Uterus in einem stickstoffgekühlten Teflongefäss in einem Mikro-Dismembrator (Braun, Melsungen) für $15 \mathrm{~s}$ bei $2500 \mathrm{Upm}$ zerkleinert. Ca. $50 \mathrm{mg}$ des Gewebepulvers wurden in $500 \mu$ RT-lysis-Puffer suspendiert. Die Schilddrüse wurde komplett in $400 \mu 1$ RT-lysis-Puffer mit einem Ultra Turrax (TP18/10, Janke \& Kunkel, Staufen) in ca. 30 s zerkleinert. Die Adenohypophyse wurde in $350 \mu 1$ RTlysis-Puffer an der Wand eines Eppendorf-Reaktionsgefäßes mit einer Kanüle (Braun, Melsungen) zerrieben. Das gefrorene Gehirn wurde auf der Arbeitsfläche des Gefriermikrotoms (Frigomobil 1206, Reichert-Jung, Bielefeld) mit Tissue-Tek (Sakura Fintek, Zoeterwoude, Niederlande) fixiert und in ca. $600 \mu \mathrm{m}$ dicke Scheiben geschnitten. Der mediobasale Hypothalamus (MBH) wurde nach den Angaben von Palkovits (Palkovits 1973) isoliert, wobei die Koordinaten mit Hilfe von Paxinos et al. (Paxinos et al. 1998) bestimmt wurden. Die entnommenen Gewebefragmente wurden in $500 \mu \mathrm{l}$ RT-lysis-Puffer homogenisiert. Die Suspension wurde für $15 \mathrm{~s}$ in einem Ultraschallbad (Bransonic 32 Sonicator Bath, Branson Instruments, Danbury, CT, USA) 
homogenisiert. Das Homogenat wurde über QIAshredder Säulen (Qiagen, Hilden) von groben Gewebestückchen befreit. Aus dem Eluat wurde mit dem RNeasy Kit nach Angaben des Herstellers die gesamt-RNA extrahiert. Reste von DNA wurden durch enzymatischen Verdau mit RNase-free DNase (Qiagen, Hilden; 27,3 Kunitz units je Probe) für 15 min aus der Aufreinigung entfernt. Das Elutionsvolumen betrug für $50 \mu 1$ für die Uterus- und Adenohypophysenextraktion und $35 \mu 1$ für die Schilddrüsenextraktion.

\subsubsection{Bestimmung der Konzentration und der Reinheit der RNA}

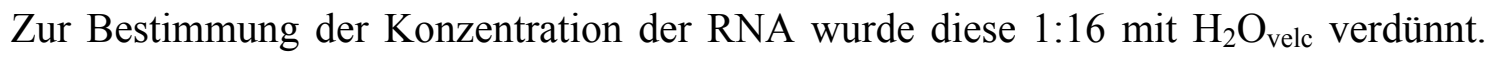
Die Extinktion bei $260 \mathrm{~nm}$ wurde in Quarzküvetten (Suprasil, Hellma, Müllheim) in einem Biophotometer (Eppendorf, Hamburg) gemessen. Eine $\mathrm{OD}_{260}$ von 1 entspricht einer RNA-Konzentration von ca. $40 \mu \mathrm{g} / \mathrm{ml}$ bei einer Schichtdicke von $1 \mathrm{~cm}$. Da organische Verunreinigungen wie z.B. Aminosäuren bei einer Wellenlänge von $280 \mathrm{~nm}$ absorbieren, kann durch den Quotienten $\mathrm{OD}_{260 \mathrm{~nm}} \mathrm{zu} \mathrm{OD}_{280 \mathrm{~nm}}$ der Grad der Verunreinigung durch Aminosäuren bestimmt werden. Bei einem Quotienten von 1,8 bis 2 kann die RNA als rein angesehen werden (Sambrook et al. 1989).

\subsubsection{Reverse Transkription (RT)}

Mit Hilfe der Reversen Transkription wurde die isolierte RNA in DNA umgeschrieben. Dazu wurde ein Kit mit einer murinen, retroviralen RT ohne RNase-Aktivität eingesetzt.

RT-Ansatz:

$3 \mu \mathrm{l} \mathrm{H}_{2} \mathrm{O}_{\text {Velc }}$

$1 \mu 1$ Random-Primer (Invitrogen, Karlsruhe; 1:30)

$10 \mu 1$ RNA Lösung mit einer Konzentration von 20 ng/ $\mu 1$

Zur Denaturierung von Sekundärstrukturen wurde der Ansatz für 10 min bei $70^{\circ} \mathrm{C}$ inkubiert und mit folgendem Mix versetzt: 
$1 \mu 1$ reverse Transkriptase

M-MLV Reverse Transcriptase RNase H Minus, Point Mutant, Promega, Mannheim

$4 \mu 1$ Puffer

$1 \mu 110$ mM dNTP-Mix Invitrogen, Karlsruhe

$0,1 \mu 1$ RNasin

Recombinant RNasin Ribonuclease Inhibitor, Promega, Mannheim

Zur Anlagerung der Primer wurde der Ansatz für 10 min bei $22^{\circ} \mathrm{C}$ inkubiert, die Gegenstrangsynthese erfolgte für $50 \mathrm{~min}$ bei $42^{\circ} \mathrm{C}$. Nach der Denaturierung für 10 Minuten bei $95^{\circ} \mathrm{C}$ wurden die Ansätze abzentrifugiert und bei $-20^{\circ} \mathrm{C}$ eingefroren.

\subsubsection{Herstellung der Standardkurven für die RT-PCR}

Bei der Herstellung der Standardkurven für die RT-PCR wurde zunächst eine StandardPCR mit einer cDNA durchgeführt, welche das Zielgen beinhaltet.

Reaktionsansatz:

$45 \mu 1$ PCR SuperMix (Invitrogen, Karlsruhe)

$25 \mathrm{nM}$ jedes Primers

$0,5 \mu 1 \mathrm{H}_{2} \mathrm{O}_{\text {Velc }}$

$4 \mu 1 \mathrm{cDNA}$

Programm:

1. $95^{\circ} \mathrm{C}-180$ Sekunden

2. $95^{\circ} \mathrm{C}-30$ Sekunden

3. $60^{\circ} \mathrm{C}-90$ Sekunden

4. $72^{\circ} \mathrm{C}-30$ Minuten

5. $\quad 4^{\circ} \mathrm{C}-$ Pause

Wiederholung der Schritte 2 und 339 mal.

Das PCR Produkt wurde mit dem GFX PCR DNA and Gel Band Purification Kit (Amersham Biosciences, Freiburg) nach Angaben des Herstellers aufgereinigt und auf einem 1,5 \%igen Agarosegel überprüft. Danach wurde das Produkt in eine zweite PCR 
(Ansatz und Programm wie oben) mit modifizierten Primern eingesetzt, wodurch das Amplifikat durch einen T7-Promotor am 5'-Ende erweitert wurde (Schenborn et al. 1985).

T7-Promotor Sequenz: 5'-ATT GTA ATA CGA CTC ACT ATA GGG AGG-3'

Das Produkt wurde ebenfalls aufgereinigt und in eine in vitro-Transkription (T7MEGAshortscript, Ambion, Huntington, UK) eingesetzt:

Reaktionsansatz:

$1 \mu 1$ Transkriptionspuffer

$1 \mu 1$ ATP, GTP, CTP und UTP (75 nM)

$1 \mu 1$ T7-MEGAshortscript Enzym Mix

$4 \mu 1$ DNA

Der Ansatz wurde bei $37^{\circ} \mathrm{C}$ über Nacht inkubiert. Danach wurde dem Ansatz 0,5 $\mu 1$ DNase zugegeben und dieser für 15 min bei $37^{\circ} \mathrm{C}$ inkubiert. Die Reaktion wurde durch die Zugabe von 57,5 $\mu 1$ Wasser und 7,5 $\mu 1$ Stopplösung (5 M Ammoniumacetat, $10 \mathrm{mM}$ EDTA) abgestoppt. Das Produkt wurde mit einer Phenol-Chloroform-Extraktion aufgereinigt. Dem Ansatz wurde $75 \mu \mathrm{l}$ puffergesättigtes Phenol/Chloroform (5:1) zugegeben und kurz gevortext. Durch eine Zentrifugation bei $13.000 \mathrm{Upm}$ für $5 \mathrm{~min}$ (Microcentrifuge MC-13, Amicon, Witten) wurden die Phasen getrennt. Die wässrige Phase wurde abgenommen, mit $75 \mu$ Chloroform/Isoamylalkohol (24:1) versetzt und kurz gevortext. Nach erneuter Zentrifugation wurde die wässrige Phase abgenommen. Es folgte eine Ethanolpräzipitation nach Shapiro (Shapiro 1981). Dazu wurden die Proben mit $150 \mu \mathrm{l}$ Ethanol (100 \%) versetzt und zum Ausfällen der RNA über Nacht bei $-20^{\circ} \mathrm{C}$ inkubiert. Die Proben wurden bei $13.000 \mathrm{Upm}$ für $15 \mathrm{~min}$ (Microcentrifuge MC13, Amicon, Witten) abzentrifugiert. Das Pellet wurde zweimal mit $200 \mu 170 \%$ Ethanol gewaschen, für ca. 15 min bei RT getrocknet und anschließend in $25 \mu 1$ $\mathrm{H}_{2} \mathrm{O}_{\text {bidest }}$ aufgelöst.

Die so hergestellte RNA wurde zu 10 Standardpunkten verdünnt und analog zu den Proben in cDNA umgeschrieben. 6 - 8 Punkte konnten für die Analyse benutzt werden. 
Tab. 2: Primer-, und Sondensequenzen aller verwendeten RT-PCR Systeme und die dazugehörige Accession-Nummer der NCBI Datenbank.

\begin{tabular}{|c|c|c|}
\hline Gen & $\begin{array}{l}\text { Sequenzen der forward- und reverse-Primer } \\
\text { sowie der Sonde }\end{array}$ & $\begin{array}{l}\text { Accession- } \\
\text { Nr. }\end{array}$ \\
\hline ER alpha & $\begin{array}{l}\text { 5'-AAGCTGGCCTGACTCTGCAG-3' } \\
\text { 5'-GCAGGTCATAGAGAGGCACGA-3' } \\
\text { 5'-CGTCTGGCCCAGCTCCTCCTCATC-3' }\end{array}$ & X61098 \\
\hline ER beta & $\begin{array}{l}\text { 5'-CTCTGTGTGAAGGCCATGAT-3' } \\
\text { 5'-GGAGATACCACTCTTCGCAATC-3' } \\
\text { 5'-ACGCGGTGACAGATGCCCTG-3' }\end{array}$ & U57439 \\
\hline ERR 1 & $\begin{array}{l}\text { 5'-TCCCAGGCTTCTCCTCACTGTC-3' } \\
\text { 5'-TCATCTAGGACCAGGTCCTCAGC-3' } \\
\text { 5'-CCCAGCGCTCACTGCCACTGC-3' }\end{array}$ & ВC039774 \\
\hline ERR 3 & $\begin{array}{l}\text { 5'-AACAAAGATCGACACATTGATTCC-3' } \\
\text { 5'-CCAGTCCGTTCTGATGGCC-3' } \\
\text { 5'-CCCTGGTGGGTCTTCCGACGC-3' }\end{array}$ & AF117254 \\
\hline TERP1 & $\begin{array}{l}\text { 5'-TTGAACAGCGACCAGGCTTT-3' } \\
\text { 5'-AGTTAGGAGCAAACAGGAGCTTCC-3' } \\
\text { 5'-ATGATTGGTCTGGTCTGGCGCTCCA-3' }\end{array}$ & L38931 \\
\hline $\begin{array}{l}\text { alpha- } \\
\text { Untereinheit }\end{array}$ & $\begin{array}{l}\text { 5'-TCTTGGACCTTGCGGGAGT-3' } \\
\text { 5'-GGTGCCCCCATCTATCAGTG-3' } \\
\text { 5'-TGCCCTGGAGAAGCAACAGCCCAT-3' }\end{array}$ & J00757 \\
\hline LH beta & $\begin{array}{l}\text { 5'-ACCTTCACCACCAGCATCTGT-3' } \\
\text { 5'-AGCTCACGGTAGGTGCACACT-3' } \\
\text { 5'-CTGCCTTGCCTCCCGTGCCTCA-3' }\end{array}$ & NM_012858 \\
\hline TSH beta & $\begin{array}{l}\text { 5'-GATGTACGTGGACAGGAGAGAGTGT-3' } \\
\text { 5'-GACATCCTGAGAGAGTGCGTACTTG-3', } \\
\text { 5'-TCAACACCACCATCTGCGCTGGG-3' }\end{array}$ & BC058488 \\
\hline C3 & $\begin{array}{l}\text { 5'-CTGTACGGCATAGGGATATCACG-3' } \\
\text { 5'-ATGCTGGCCTGACCTTCAAGA-3' } \\
\text { 5'-TGCCATCCTCACAACACTTCCGCAG-3' }\end{array}$ & X52477 \\
\hline IGF-1 & $\begin{array}{l}\text { 5'-TGTCGTCTTCACATCTCTTCTACCTG-3' } \\
\text { 5'-CCACACACGAACTGAAGAGCGT-3', } \\
\text { 5'-TTACCAGCTCGGCCACAGCCGGAC-3' }\end{array}$ & M15481 \\
\hline $\mathrm{TRH}$ & $\begin{array}{l}\text { 5'-TTCTGGATTCCTGGTTCTCAGATG-3' } \\
\text { 5'-GGATGTTGCCTCTTGGTGACA-3' } \\
\text { 5'-AGCACCCTGGCAGGCGATCCTTC-3' }\end{array}$ & NM_013046 \\
\hline
\end{tabular}




\subsubsection{Semi-quantitative Real-time RT-PCR}

Die RT-PCR (Heid et al. 1996), eine Variante der Standard-PCR (Mullis et al. 1987), wurde nach dem TaqMan-Prinzip von Roche (Livak et al. 1995) durchgeführt. Dabei kommt eine genspezifische Sonde zum Einsatz, welche am 5'-Ende ein Reporterfluoreszenzfarbstoff (6-Carboxy-fluorescein, FAM) und am 3'-Ende ein Quencherfarbstoff (6-Carboxy-tetramethyl-rhodamin, TAMRA) trägt. Wenn der Reporterfarbstoff durch Licht der Wellenlänge $488 \mathrm{~nm}$ angeregt wird, strahlt er Licht der Wellenlänge $518 \mathrm{~nm}$ ab, welches wiederum von einem räumlich benachbarten Quencherfarbstoffmolekül aufgenommen wird (Fluoreszenz-Resonanz-EnergieTransfer). Während der PCR wird die Sonde durch die 5'-3'-Exonukleaseaktivität der eingesetzten Taq-Polymerase (AmpliTaq DNA Polymerase) degradiert, wodurch die beiden Moleküle, FAM und TAMRA, räumlich getrennt werden. Dies unterbricht den Fluoreszenz-Resonanz-Energie-Transfer und ermöglicht es, das Fluoreszenzsignal des Reporterfarbstoffes $\mathrm{zu}$ messen. Die Signalstärke ist dabei proportional zur Produktkonzentration.

Die Reaktionen wurden nach folgendem Schema angesetzt:

Reaktionsansatz:

$12,5 \mu 1$ Puffer mit 3,5 mM MgCl 2

0,25 U Uracil-N-glycosylase

$300 \mathrm{nM}$ beide Primer.
qPCR Core Kit, Eurogentec, Seraing, Belgien

Eurogentec, Seraing, Belgien

Eurogentec, Seraing, Belgien

Ausnahmen: ER $\alpha$ mit $50 \mathrm{nM}$ sense und $900 \mathrm{nM}$ antisense Primer.

C3 mit 900 nM beide Primer.

$225 \mathrm{nM}$ Sonde

$2-4 \mu \mathrm{cDNA}$

Ad $25 \mu 1$ mit $\mathrm{H}_{2} \mathrm{O}_{\text {Velc }}$

Die Ansätze wurden in 96-well Platten pipettiert (96 Well Multiply-PCR-Plate, Sarstedt, Nümbrecht) und mit optischen Deckelketten (0,2 ml Biosphere, Sarstedt, Nümbrecht) verschlossen. Jeder Ansatz beinhaltete eine Standardkurve aus 6 bis 8 Punkten in Doppelbestimmung sowie Negativkontrollen ohne cDNA. 
Die Messungen wurden mit einem ABI Prism 7700 Sequence Detection System (Perkin Elmer, Rodgau-Jügesheim) mit folgendem Programm durchgeführt:

PCR Programm:

1. $\quad 94^{\circ} \mathrm{C}-180 \mathrm{~s}$

2. $94^{\circ} \mathrm{C}-30 \mathrm{~s}$

3. $60^{\circ} \mathrm{C}-90 \mathrm{~s}$

4. $\quad 72^{\circ} \mathrm{C}-10 \mathrm{~min}$

Wiederholung der Schritte 2 und 339 mal.

\subsubsection{Erstellen der TaqMan-Systeme ERR1 und ERR3}

Als Grundlage für die Systeme dienten die Gensequenzen (Accession-Nummer: BC039774 und AF117254), die der Datenbank GenBank entnommen wurden. Diese wurden auf die für das Protein kodierende Sequenz begrenzt. Mit Hilfe des Programms PrimerExpress (Ver. 1.5 Applied Biosystems, Darmstadt) wurden die Primer und die Sonde für das TaqMan-Prinzip abgeleitet. Das Programm wurde mit den für das TaqMan-Prinzip vorgegebenen Parametern programmiert:

- Oligo-Länge 20-30 Basen, GC-Gehalt 40-60 \%.

- Schmelzpunkt der Sonde etwa $5^{\circ} \mathrm{C}$ unter dem der Primer.

- Nicht mehr als 3 gleiche Basen hintereinander.

- Am 5'-Ende kein G.

- Keine Komplementarität zwischen der Sonde und den Primern.

Die Primer wurden zur Erhöhung der Spezifität auf unterschiedliche Exons der mRNA gelegt. Die Sonde wurde auf die Schnittstelle zwischen den Exons platziert.

Die in der PCR erhaltenen Amplifikate wurden sequenziert (SEQLAB Sequence Laboratories, Göttingen).

\subsection{Proteinchemie}

Alle Arbeitsschritte bei der Aufarbeitung der Schilddrüsen wurden auf Eis ausgeführt. 


\subsubsection{Extraktion des Gesamtproteins aus Schilddrüsen}

Zwei Schilddrüsenlappen wurden in $500 \mu$ l Homogenisationspuffer mit einem Ultra Turrax (TP18/10, Janke \& Kunkel, Staufen) zerkleinert. Die Suspension wurde dann für 1 min mit einem Ultraschallgerät (Sonifier B12, Branson Instruments, Danbury, CT; USA) beschallt. Die Zelltrümmer wurden mit $13.000 \mathrm{Upm}$ bei $4{ }^{\circ} \mathrm{C}$ für $10 \mathrm{~min}$ abzentrifugiert (Centrifuge 4515R, Eppendorf, Hamburg). Der Überstand wurde bei $-70^{\circ} \mathrm{C}$ eingefroren.

Homogenisationspuffer:

250mM Saccharose

10mM TRIS HCl, pH7

$5 \mathrm{mM} \mathrm{NaCl}$

$1 \mathrm{mM}$ EDTA

1 Tablette Protease Inhibitor Cocktail (Complete Mini, EDTA frei, Roche, Mannheim) pro $10 \mathrm{ml}$

\subsubsection{Inkubation der Proben mit Triton X-100}

Da es sich bei den zu markierenden Proteinen um Membranproteine handelt, wurden die Extrakte zusätzlich mit dem Detergenz Triton X-100 behandelt. Dazu wurde der Extrakt mit $0,5 \%$ Triton $\mathrm{X}-100$ versetzt und für $1 \mathrm{~h}$ bei $4^{\circ} \mathrm{C}$ inkubiert.

\subsubsection{Proteinkonzentrationsbestimmung der Extrakte}

Die Proteinkonzentration wurde anhand des Bradford-Assays (Bradford 1976) bestimmt. Dazu wurden $10 \mu 1$ des Extraktes in einer 96 well-Platte mit $200 \mu 1$ einer 1:5 Verdünnung des Bradford Reagenzes (Protein Assay, BioRad, München) in $\mathrm{H}_{2} \mathrm{O}_{\text {bidest }}$ versetzt und für 5 min bei Raumtemperatur inkubiert. Die Extinktion bei $590 \mathrm{~nm}$ wurde mit dem Spectra ELISA-Reader (Tecan, Crailsheim) gemessen. Die Konzentrationsbestimmung erfolgte anhand einer Standardkurve mit 100, 200, 400, 600, 800 und $1000 \mu \mathrm{g} / \mathrm{ml}$ bovinem Plasma-Gammaglobulin (Std I, BioRad, München). 


\subsubsection{Polyacrylamid-Gelelektrophorese (PAGE)}

Die Polyacrylamid-Gelelektrophorese erfolgte nach Lämmli (Laemmli 1970) in der Mini Protean 3-Zelle (BioRad, München). Die Gele setzten sich wie folgt zusammen:

Tab. 3: Zusammensetzung von Sammel-, und Trenngel für die PAGE.

\begin{tabular}{|l|l|l|}
\hline & Sammelgel & Trenngel \\
\cline { 2 - 3 } & $5 \%$ & $7,5 \%$ \\
\hline $30 \%$ Acrylamid $(\mathrm{ml})$, Roth, Karlsruhe & 0,833 & 3,75 \\
\hline Gel-Puffer $(\mathrm{ml})$ & 0,625 & 5,625 \\
\hline $\mathrm{H}_{2} \mathrm{O}_{\text {bidest }}(\mathrm{ml})$ & 3,462 & 5,343 \\
\hline $10 \%$ SDS $(\mu \mathrm{l})$ & 50 & 150 \\
\hline $10 \%$ APS $(\mu \mathrm{l})$ & 25 & 120 \\
\hline TEMED $(\mu \mathrm{l})$, BioRad, München & 5 & 12 \\
\hline
\end{tabular}

Die angegebenen Volumina sind ausreichend für 2 Mini-Gele. Zuerst wurden die Glasplatten mit Ethanol (96 \%) gründlich gereinigt und in den Gießstand (BioRad, München) eingesetzt. Die Gelkassette wurde mit der Trenngellösung bis $1 \mathrm{~cm}$ unter den Rand des Kammes gefüllt und mit $\mathrm{H}_{2} \mathrm{O}_{\text {bidest }}$ überschichtet. Nach ca. 40 min wurde das Wasser abgegossen, die Gelkassette mit $\mathrm{H}_{2} \mathrm{O}_{\text {bidest }}$ gereinigt und mit einem Filterpapier getrocknet. Die Sammelgellösung wurde bis unter den Rand der Glasplatten eingefüllt und der Kamm luftblasenfrei eingesetzt. Nach ca. 40 min wurde das Gel mit $\mathrm{H}_{2} \mathrm{O}_{\text {bidest }}$ gespült. Der Zusammenbau der Gelkammer erfolgte nach Angaben des Herstellers.

Die Proben wurden mit Homogenisationspuffer auf eine Proteinkonzentration von 3,5 mg/ml gebracht und mit einem 4-fach Ladepuffer (Roti-Load, Roth, Karlsruhe) versetzt. Danach wurden die Proben für $5 \mathrm{~min}$ auf $95^{\circ} \mathrm{C}$ erhitzt (Thermomixer 4536, Eppendorf, Hamburg) und nach einer kurzen Abkühlung auf Eis mit einer Hamiltonspritze auf das Gel aufgetragen. Die Laufzeit betrug ca. $35 \mathrm{~min}$ bei $200 \mathrm{~V}$. 
Lauf-Puffer:

144 g Glycin

$30 \mathrm{~g}$ TRIS

$10 \mathrm{~g}$ SDS

Ad 11 mit $\mathrm{H}_{2} \mathrm{O}_{\text {bidest, }}$ pH 8,9

\subsubsection{Fast Blot}

Das Gel wurde in einer Semi dry-Blotkammer (FastBlot, BioRad, München) auf eine Nitrocellulose-Membran ( $0,2 \mu \mathrm{m}$ Porengröße, Sartorius, Göttingen) geblottet (Towbin et al. 1979). Der Aufbau der Apparatur erfolgte nach den Angaben des Herstellers mit jeweils drei Lagen GB003 Gel Blotting-Papier (Schleicher\&Schuell, Dassel) unter Verwendung des SDS-haltigen Fast Blot-Puffers. Der Transfer erfolgte für $30 \mathrm{~min}$ bei ca. $3 \mathrm{~mA}$ pro $\mathrm{cm}^{2}$ Gelfläche.

Fast Blot-Puffer:

5,8 g TRIS Base

2,9 g Glycin

$0,375 \mathrm{~g}$ SDS

$200 \mathrm{ml}$ Methanol

Ad 11 mit $\mathrm{H}_{2} \mathrm{O}_{\text {bidest }}$

\subsubsection{Ponceau S-Färbung}

Auf der Membran konnte nach dem Fast Blot mit Hilfe der Ponceau S-Färbung (Salinovich et al. 1986) das Gesamtprotein markiert werden, um den erfolgreichen Transfer der Proteine sowie die gleichmäßige Beladung des Geles zu überprüfen. Dazu wurde die Membran für 15 min in der Ponceau S-Färbelösung (0,1 \% Ponceau S in 5 \% Essigsäure, Sigma, Schnelldorf) bei Raumtemperatur auf einem Schüttler mit $150 \mathrm{Upm}$ (Unimax1010, Heidolph, Schwabach) inkubiert. Die Beladung des Geles wurde anhand der Bandenintensität im Bereich von 30 bis $100 \mathrm{kDa}$ kontrolliert. Dazu wurde die Nitrocellulose-Membran gescannt. Mit Hilfe eines Analyseprogramms (Kodak ds 1D, Kodak, New Haven, USA) konnte die Bandenintensität der einzelnen 
Probenauftragungen berechnet werden. Vor der Markierung mit Antikörpern wurde die Membran in ca. 10-15 min in PBS vollständig entfärbt.

\subsubsection{Antikörper-Markierung}

Die Membran wurde für $1 \mathrm{~h}$ bei RT in TPBS (PBS mit $1 \%$ Tween-20) mit $7 \%$ Trockenmilchpulver (Amersham, Freiburg) auf einem Schüttler mit 150 Upm (Unimax1010, Heidolph, Schwabach) geblockt (Batteiger et al. 1982) und auf dem Schüttler dreimal für 5 min in TPBS gewaschen. Anschließend wurde die Membran über Nacht bei $4^{\circ} \mathrm{C}$ mit dem Erstantikörper in TPBS inkubiert und dann erneut auf dem Schüttler dreimal für $5 \mathrm{~min}$ in TPBS gewaschen. Als Zweitantikörper für die Natrium/ Iodid-Symporter (NIS) Markierung diente ein polyklonaler Ziege-anti-Kaninchen Antikörper, der mit der Meerrettichperoxidase gekoppelt ist (GAR HRP). Im Falle des Thyrotropin-Rezeptors (TSHR) wurde ein Signalverstärker (Envision, DAKO) eingesetzt, welcher über ein Filament mit multiplen Meerrettichperoxidase-Enzymen gekoppelt ist. Die Inkubation mit dem Zweitantikörper erfolgte für $1 \mathrm{~h}$ bei RT auf dem Schüttler. Nachdem die Membran dreimal für $5 \mathrm{~min}$ in TPBS gewaschen wurde, erfolgte die Farbreaktion in einer DAB-Lösung (Envision, DAKO) für 45-60 s. Die Membran wurde gescannt und densitometrisch ausgewertet.

Tab. 4: Verwendete Erst-, und Zweitantikörper.

\begin{tabular}{|l|l|l|l|}
\hline $\begin{array}{l}\text { Antikörper } \\
\text { Vnd }\end{array}$ & Wirt & Hersteller & Typ \\
\hline $\begin{array}{l}\text { TSHR } \\
1 / 500\end{array}$ & $\begin{array}{l}\text { Ziege, } \\
\text { polyklonal }\end{array}$ & $\begin{array}{l}\text { Santa Cruz Biotech., Santa } \\
\text { Cruz, CA, USA }\end{array}$ & affinitätsaufgereinigt \\
\hline $\begin{array}{l}\text { NIS } \\
1 / 2500\end{array}$ & $\begin{array}{l}\text { Kaninchen, } \\
\text { polyklonal }\end{array}$ & $\begin{array}{l}\text { Acris Antibodies, } \\
\text { Hiddenhausen }\end{array}$ & Ig-Fraktion \\
\hline GAR HRP & Ziege, & Dianova, Hamburg & $\begin{array}{l}\text { anti-Kaninchen, } \\
\text { affinitätsaufgereinigt }\end{array}$ \\
\hline Envision & k.A. & $\begin{array}{l}\text { DAKO } \\
\text { Hamburg }\end{array}$ & $\begin{array}{l}\text { anti- Kaninchen/Ziege, } \\
\text { affinitätsaufgereinigt }\end{array}$ \\
\hline
\end{tabular}




\subsection{Histologie}

Querschnitte des Uterus der behandelten Tiere wurden auf Veränderungen in der Morphologie untersucht. Dazu wurden $3 \mu \mathrm{m}$ dicke Schnitte mit Haematoxylin - Eosin gefärbt und unter dem Mikroskop (Axiophot, Zeiss, Oberkochen) untersucht.

\subsubsection{Herstellung von Paraffinblöcken}

Ein Horn des Uterus wurde für $24 \mathrm{~h}$ einer Formalinlösung fixiert. Danach wurde das Horn in drei Fragmente geschnitten, proximal, medial und distal, und für eine Stunde in Einbettkassetten (Sarstedt, Nümbrecht) in Leitungswasser gewässert. Die Proben wurden mit einer Einbettmaschine (TP1020, Leica, Wetzlar) mit folgendem Programm dehydriert und mit Paraffin infiltriert:

Tab. 5: Programm zur Dehydratisierung der Proben in der Einbettmaschine.

\begin{tabular}{|l|l|l|l|}
\hline Lösung & Zeit & Lösung & Zeit \\
\hline $50 \%$ Ethanol & $1 \mathrm{~h}$ & Ethanol absolut & $1 \mathrm{~h} 20 \mathrm{~min}$ \\
\hline $75 \%$ Ethanol & $1 \mathrm{~h} 20 \mathrm{~min}$ & Ethanol absolut & $1 \mathrm{~h} 20 \mathrm{~min}$ \\
\hline $75 \%$ Ethanol & $1 \mathrm{~h} 20 \mathrm{~min}$ & Xylol & $1 \mathrm{~h} 20 \mathrm{~min}$ \\
\hline $96 \%$ Ethanol & $1 \mathrm{~h} 20 \mathrm{~min}$ & Xylol & $1 \mathrm{~h} 20 \mathrm{~min}$ \\
\hline $96 \%$ Ethanol & $1 \mathrm{~h} 20 \mathrm{~min}$ & Paraffin & $1 \mathrm{~h}$ \\
\hline Ethanol absolut & $1 \mathrm{~h} 20 \mathrm{~min}$ & Paraffin & $1 \mathrm{~h}$ \\
\hline
\end{tabular}

Alle drei Fragmente einer Probe wurden in einen Paraffinblock mit dem Querschnitt zur Schnittkante mit einer Paraffinausgießstation (EG 1140C, Leica, Wetzlar) eingebettet.

Formalinlösung:

4 \% Paraformaldehydlösung in 0.01 M Phosphatpuffer (PBS) pH 7,6

\subsubsection{Herstellung von Paraffinschnitten}

Mit einem Mikrotom (RM2135, Leica, Wetzlar) wurden $3 \mu \mathrm{m}$ dicke Schnitte angefertigt und auf beschichteten Objektträgern (Superfrost plus, Menzel, Braunschweig) fixiert. Die Objektträger wurden über Nacht getrocknet und waren dann unbegrenzt lagerbar. 


\subsubsection{Haematoxylin - Eosin - Färbung (HE)}

Die HE-Färbung ermöglicht die morphologische Betrachtung der Schnitte. Dabei werden Zellkerne dunkelblau und das Cytoplasma rot-blau gefärbt. Für die Färbung wurden die Schnitte in einer Reihe von Lösungen inkubiert:

Tab. 6: Ablauf der Haematoxylin-Eosin-Färbung.

\begin{tabular}{|l|l|}
\hline Lösung & Zeit \\
\hline Xylol & $3 \times 10 \mathrm{~min}$ \\
\hline Ethanol, absolut & $3 \times 2 \mathrm{~min}$ \\
\hline Ethanol, 96\% & $2 \times 2 \mathrm{~min}$ \\
\hline Ethanol, 75\% & 2 min \\
\hline $\mathrm{H}_{2} \mathrm{O}_{\text {bidest }}$ & 2 min \\
\hline Haematoxylin & 2 min \\
\hline Leitungswasser & $5-10 \mathrm{~min}$ \\
\hline Eosin & $1-2 \mathrm{~min}$ \\
\hline Ethanol, 75\% & 2 min \\
\hline Ethanol, 96\% & $2 \times 2 \mathrm{~min}$ \\
\hline Ethanol, absolut & $3 \times 2 \mathrm{~min}$ \\
\hline Xylol & $3 \times 5 \mathrm{~min}$ \\
\hline
\end{tabular}

Haematoxylin Lösung (Haematoxylin Mayer, Merck, Darmstadt)

$0,25 \%$ Eosin gelb (Merck, Darmstadt) in $80 \%$ Ethanol

Sofort nach der letzten Xylol-Lösung wurde ein Tropfen DePeX (Serva, Heidelberg) auf die Objektträger gegeben und mit einem Deckgläschen luftblasenfrei versiegelt. Die Proben härteten über Nacht im Abzug aus.

\subsection{5'Deiodase Typ I/II-Assay}

Mit diesem Assay können die Enzymaktivitäten der 5'-Deiodasen Typ I (5'DI) und Typ II (5'DII) bestimmt werden. Deiodasen werden gewebe- und entwicklungspezifisch von zwei Genen exprimiert und katalysieren die Abspaltung des Jods von T4 zur 
Bereitstellung von T3 sowie den Abbau des T3 im Zielgewebe. Die Aktivität der Deiodasen kann durch die Abspaltung von radioaktiv markiertem Jod von reversem T3 bestimmt werden. 6-n- Propyl-2-tiouracil (PTU) ist ein spezifischer Inhibitor der 5'DI. Durch den Einsatz von PTU kann die Aktivität der 5'DII bestimmt werden. Aus der Differenz berechnet sich die spezifische Aktivität der 5'DI.

Ein Fragment der bei $-70^{\circ} \mathrm{C}$ gefrorenen Leber wurde mit einem Homogenisator (Microdismembrator ${ }^{\mathrm{TM}}$, Braun, Melsungen) für $15 \mathrm{~s}$ bei $2500 \mathrm{Upm}$ homogenisiert, wobei das benutzte Material auf Trockeneis gekühlt wurde. Eine Spatelspitze des Gewebepulvers wurde in $500 \mu 1$ Homogenisationspuffer suspendiert. Die Suspension wurde für $15 \mathrm{~s}$ in einem Ultraschallbad (Bransonic 32 Sonicator Bath, Branson Instruments, Danbury, CT, USA) homogenisiert. Danach wurden die Proben bei $3000 \mathrm{Upm}$ für $10 \mathrm{~min}$ bei $4^{\circ} \mathrm{C}$ (Cryofuge 5000, Heraeus-Christ, Osterode) abzentrifugiert.

Die Proteinkonzentration wurde im Bradford-Assay bestimmt (siehe 2.7.3). In den Assay wurden $20 \mu \mathrm{g}$ Protein in $40 \mu \mathrm{l}$ Homogenisationspuffer eingesetzt. Für die Bestimmung der Gesamtaktivität (5'DI/II) wurde dem Ansatz $10 \mu 1 \mathrm{H}_{2} \mathrm{O}_{\text {dest}}$, für die Bestimmung der Einzelaktivität (5'DI) wurde dem Ansatz $10 \mu 1 \quad 10$ mM PTU zugegeben.

Der im Assay verwendete Tracer wurde über Sephadex LH20-Säulen filtriert, um Abbauprodukte zu entfernen. Dazu wurden die Säulen mit zunächst $3 \mathrm{ml}$ 0,1 N HCl equilibriert. Eine adäquate Menge des Tracers wurde aufgetragen. Die Säulen wurden mit $3 \mathrm{ml} \mathrm{0,1} \mathrm{N} \mathrm{HCl} \mathrm{und} 3 \mathrm{ml}$ Wasser gespült. Der Tracer wurde mit $1 \mathrm{ml} \mathrm{EtOH} / \mathrm{NH}_{4} \mathrm{OH}$ (49:1) eluiert. Das Eluat wurde abzentrifugiert und unter leichtem Stickstoffstrom in einem handwarmen Wasserbad eingedampft. Der Tracer wurde in Substrat-Mix resuspendiert, so dass $50 \mu 1$ Tracer-Substratmix etwa $5000 \mathrm{cpm}$ ergeben.

Die Reaktion wurde durch Zugabe von $50 \mu \mathrm{l}$ Tracer-Substrat-Mix zu $50 \mu 1$ Proteinextrakt gestartet und nach $60 \mathrm{~min}$ bei $37^{\circ} \mathrm{C}$ durch Zugabe von $50 \mu$ l StoppLösung gestoppt. Die Proben wurden mit $400 \mu 110 \%$ Trichloressigsäure versetzt und bei 3000 Upm für 5 min (Cryofuge 5000, Heraeus-Christ, Osterode) zentrifugiert. Derweil wurden AG 50W-X2-Säulen (Bio-Rad, München) 2 mal mit $2 \mathrm{ml} 10 \%$ Essigsäure equilibriert. Die Proben wurden auf die Säulen aufgetragen und mit $2 \mathrm{ml}$ 10 \% Essigsäure in Zählröhrchen eluiert. Die Messung erfolgte im Gamma-Counter (Wizard 1470, Perkin Elmer (Wallac), Rodgau - Jügesheim) für 10 min. 
Homogenisationspuffer:

$250 \mathrm{mM}$

Saccharose

$20 \mathrm{mM}$

HEPES

$1 \mathrm{mM}$

EDTA

$\mathrm{pH} 7,4$

10 mM PTU-Lösung:

$\begin{array}{lc}1,7 \mathrm{~g} & \text { PTU (MP Biomedicals, Irvine (CA), USA) } \\ 80 \mathrm{ml} & 40 \mathrm{mM} \mathrm{NaOH} \\ \text { unter Zugabe von } & 0,1 \mathrm{M} \mathrm{NaOH} \text { lösen } \\ \text { anschließend 1:10 mit } 40 \mathrm{mM} \mathrm{NaOH} \text { verdünnen }\end{array}$

Substrat-Mix (pro Probe):

$\begin{array}{ll}10 \mu \mathrm{l} & 1 \mathrm{M} \mathrm{KPO}_{4} \text {-Puffer } \\ 2 \mu \mathrm{l} & 1 \mathrm{M} \mathrm{DTT} \\ 0,41 \mu \mathrm{l} & 40 \mathrm{mM} \mathrm{NaOH} \\ 1 \mu \mathrm{l} & 0,1 \mathrm{M} \text { reverses T3 } \\ 36,59 \mu \mathrm{l} & \mathrm{H}_{2} \mathrm{O}_{\text {dest }}\end{array}$

$\mathrm{KPO}_{4}$-Puffer:

A:

$43,55 \mathrm{~g} \quad \mathrm{~K}_{2} \mathrm{HPO}_{4}$

$0,93 \mathrm{~g} \quad$ EDTA-Na-Dihydrat

auffüllen auf $250 \mathrm{ml} \mathrm{mit} \mathrm{H}_{2} \mathrm{O}_{\text {dest }}$

B:
$34,03 \mathrm{~g} \quad \mathrm{~K}_{2} \mathrm{HPO}_{4}$
$0,93 \mathrm{~g} \quad$ EDTA-Na-Dihydrat

auffüllen auf $250 \mathrm{ml} \mathrm{mit} \mathrm{H}_{2} \mathrm{O}_{\text {dest }}$

Lösung A mit Lösung B titrieren auf pH 6,8 
Stopp-Lösung:

$10 \mathrm{~g}$ BSA

$10 \mathrm{ml}$ 0,1 M PTU-Lösung auffüllen auf $100 \mathrm{ml} \mathrm{mit} \mathrm{H}_{2} \mathrm{O}_{\text {dest }}$

Tracer:

$\mathrm{L}^{-3,3} 3^{`} 5^{`}-\left[{ }^{125} \mathrm{I}\right]$-Triiodothyronine ([$\left.{ }^{125} \mathrm{I}\right]$-Reverse $\left.\mathrm{T}_{3}\right), 11.9 \mathrm{MBq} / \mathrm{ml}$ (Kat.Nr.:NEX 109250UC, Perkin Elmer, Rodgau-Jügesheim)

\subsection{Schilddrüsenperoxidase (TPO)-Assay}

Die Schilddrüsenperoxidase (TPO), ein membranintegrales Enzym in der apikalen Membran des Schilddrüsenepithels, katalysiert die Oxidation von Iodid sowie den Einbau des Jods in Tyrosinreste des Thyreoglobulins.

Für den Assay wurde ein Lappen der Schilddrüse in $1 \mathrm{ml}$ Extraktionspuffer mit dem Ultra Turrax (TP18/10, Janke \& Kunkel, Staufen) in ca. 30 s zerkleinert. Die groben Trümmer wurden bei $1000 \mathrm{Upm}$ für $10 \mathrm{~min}$ bei $4^{\circ} \mathrm{C}$ (Cryofuge 5000, Heraeus-Christ, Osterode) abzentrifugiert. Der Überstand wurde abgenommen und bei 3000 Upm für $60 \mathrm{~min}$ bei $4^{\circ} \mathrm{C}$ (Cryofuge 5000, Heraeus-Christ, Osterode) zentrifugiert. Das Pellet wurde in $100 \mu 1200 \mathrm{mM}$ Kaliumphosphat-Puffer resuspendiert und für $15 \mathrm{~s}$ in einem Ultraschallbad (Bransonic 32 Sonicator Bath, Branson Instruments, Danbury, CT, USA) homogenisiert.

Die Proteinkonzentration wurde im Bradford-Assay bestimmt (siehe 2.7.3). Der Assay wurde nach folgendem Schema angesetzt:

Reaktionsansatz:

$250 \mu 1$ $100 \mu \mathrm{M}$ Kaliumphosphat-Puffer (pH 7,4)

$200 \mu 1$ 100 mM Guaiacol (Sigma, Schnelldorf; in $\mathrm{H}_{2} \mathrm{O}$ )

$50 \mu \mathrm{g}$ Membranprotein

auf 487,5 $\mu 1$ mit $\mathrm{H}_{2} \mathrm{O}$ auffüllen

Der Start der Reaktion erfolgte durch die Zugabe von $12,5 \mu 130 \% \mathrm{H}_{2} \mathrm{O}_{2}$. Die Reduktion von $\mathrm{H}_{2} \mathrm{O}_{2}$ wurde photometrisch bei $470 \mathrm{~nm}$ für 90 Sekunden verfolgt. 


\subsection{Statistische Auswertung}

Die Rohdaten wurden zunächst dem Grubbs-Test für Ausreißer unterzogen (Burke 2001). Dazu wurde der Z-Wert, der sich für jeden Wert aus folgender Formel berechnet:

$$
\mathrm{Z}=\left|\bar{x}-x_{i}\right| / \mathrm{s}
$$

wobei $\bar{x}$ den Mittelwert der Gruppe, $x_{i}$ den Einzelwert und $s$ die Standardabweichung darstellt, mit dem kritischen Z-Wert $\left(Z_{\text {critical }}\right)$ für das $95 \%$ Konfidenzintervall verglichen. Der Messwert wurde entfernt wenn $Z>Z_{\text {critical }}$.

Danach wurden die Ergebnisse mit dem Programm Prism, (Ver.4, GraphPad, San Diego CA, USA) ausgewertet. Bei zwei Gruppen wurde der student's t-Test, bei mehreren Gruppen wurde der Kruskal-Wallis-Test (One-Way analysis of variance (ANOVA), nicht-parametrisch) benutzt. War die Varianz des kompletten Datensatzes im ANOVA signifikant, wurden die Einzelvarianzen mit Dunn's Multiple Comparisons-Post Test berechnet. Ein Wert wurde als signifikant bezeichnet, wenn $p<0,05$ (in allen Abbildungen mit * markiert).

Die Ergebnisse sind als Mittelwert und Standardfehler des Mittelwertes angegeben. Wenn keine abweichenden Einheiten angegeben sind, wurden die Messwerte auf den Mittelwert der Kontrollgruppe prozentrelativiert (\% rel).

Bei der Erstellung der Dosis-Wirkungsbeziehung wurde das Programm PROAST (ver. 02R) benutzt welches eine Gruppe von verschachtelten Modellen benutzt (Slob 2002) um die Daten darzustellen:
1. $\mathrm{y}=\mathrm{a}$
2. $y=a \exp (b x)$
3. $y=a \exp \left(b x^{d}\right)$
4. $y=a(c-(c-1) \exp (b x))$
5. $y=a\left(c-(c-1) \exp \left(b x^{d}\right)\right)$

Mit einer Bestimmung der Wahrscheinlichkeit (likelihood ratio test) wurde das Modell gewählt, welches bei einer maximalen Anzahl von Parametern einen signifikant besseren Deckungsgrad mit den Daten erzielt als das vorhergehende Modell. Mit einer vorher festgelegten kritischen Effektgröße (CES) kann aus dem ermittelten Modell die 
dazugehörige kritische Effektdosis (CED) berechnet werden, wobei $C E S=f(C E D) / f(0)-1$. Eine sehr detaillierte Darstellung der zugrunde liegenden mathematischen Zusammenhänge findet man in (Woutersen et al. 2001). 


\section{Ergebnisse}

\subsection{Rezeptorbindungsassay}

Die Testsubstanz OMC wurde auf die Fähigkeit zur Verdrängung von markiertem Estradiol von Bindestellen an rekombinantem ER alpha- oder beta-Protein im Vergleich zu Estradiol als Positivkontrolle untersucht. Abb. 5 zeigt die Verdrängung von Estrogen vom ER alpha, Abb. 6 zeigt die Verdrängung vom ER beta.

Im Rezeptorbindungsassay zeigte OMC keine deutliche Verdrängung von markiertem Estradiol am ER alpha. Die Positivkontrolle, nicht markiertes Estradiol, zeigte eine Verdrängung ab ca. $1 \times 10^{-9} \mathrm{M}$.

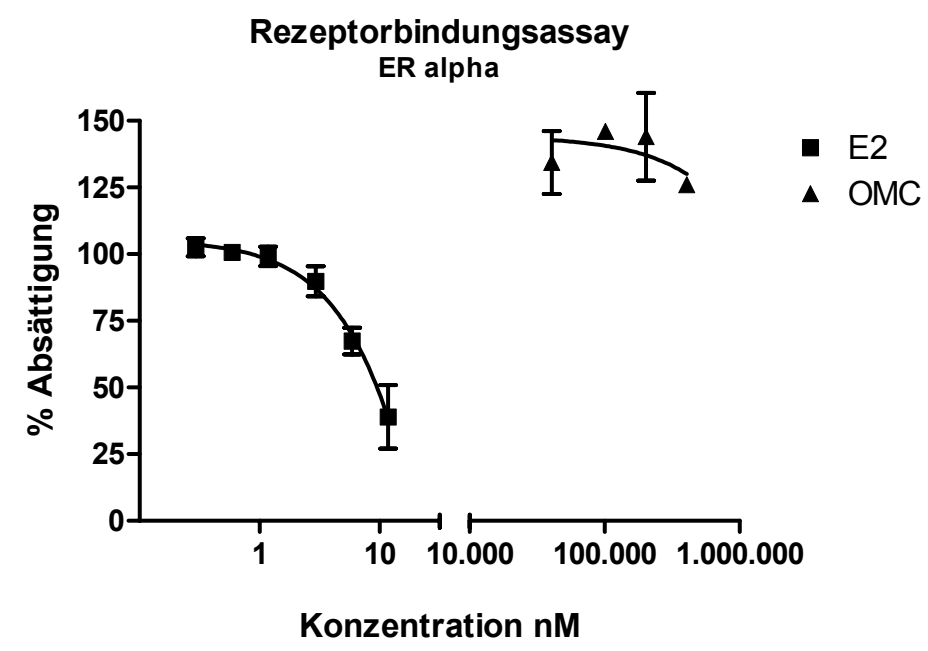

Abb. 5: Verdrängung von Estradiol im ER alpha-RBA. Es wurde die Verdrängung von radioaktiv markiertem E2 durch OMC bzw. ,kaltes“ E2 in den angegebenen Konzentrationen gemessen.

Bei dem Rezeptorbindungsassay für den ER beta ist für OMC nur eine leichte Tendenz ab einer Konzentration von ca. $2 \times 10^{-4} \mathrm{M}$ zu sehen. Estradiol verdrängte den Tracer ab einer Konzentration von $1 \times 10^{-9} \mathrm{M}$. 


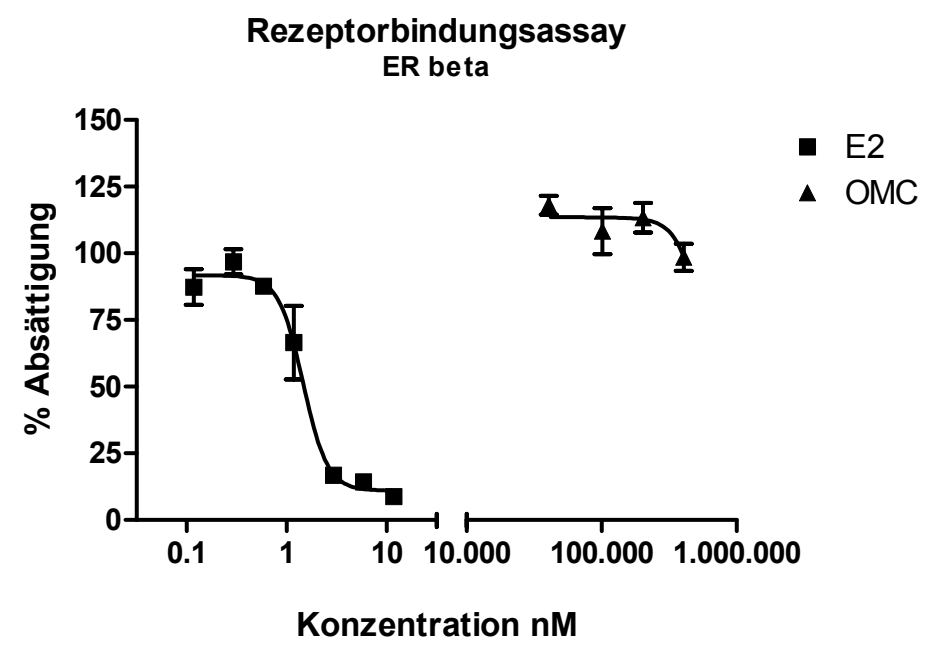

Abb. 6: Verdrängung von Estradiol im ER beta-RBA. Es wurde die Verdrängung von radioaktiv markiertem E2 durch OMC bzw. „,kaltes“ E2 in den angegebenen Konzentrationen gemessen.

\subsection{Proliferationsassay (E-Screen)}

OMC hat keinen Einfluss auf das Wachstum der MCF-7-Zellen im Proliferationsassay gezeigt. Die Positivkontrolle E2 erreichte $164 \%$ der Kontrollgruppe. Bei der Koinkubation von OMC mit E2 trat auch kein wachstumshemmender Effekt auf, es zeigte sich keine Abweichungen von der Positivkontrolle.

BrdU-Assay

MCF-7-Zellen

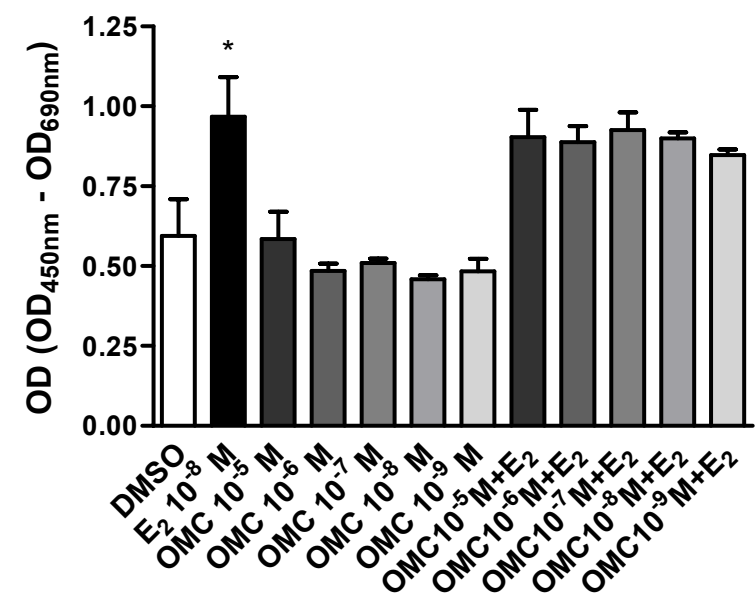

Abb. 7: Einfluss von OMC auf den BrdU-Einbau in genomische DNA. Die Absorption des Substrates bei $450 \mathrm{~nm}$ wurde gemessen. * = signifikant gegen Kontrolle (DMSO). 


\subsection{Hypothalamus-Zellkultur}

Die Inkubation der GT1-7 Zellen mit E2 senkte die Sekretion von GnRH auf ca. 54 \% im Vergleich zur Kontrollgruppe. Dieser Effekt ist allerdings nicht signifikant. Die Koinkubation mit dem ER-Antagonisten ICI 182.780 hob den hemmenden Effekt von E2 auf. ICI 182.780 allein hatte keine signifikante Auswirkung auf die Sekretion. OMC hingegen stimulierte die Sekretion signifikant auf $449 \%$, wobei diese Reaktion der Zellen auf die Testsubstanz durch ICI 182.780 hemmbar war.

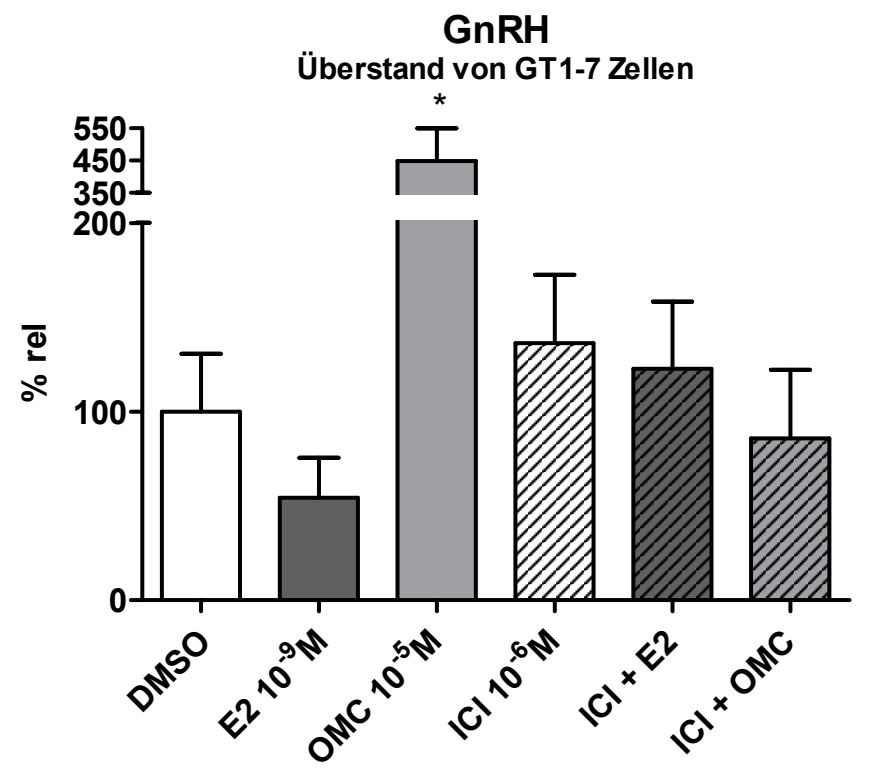

Abb. 8: GnRH-Konzentration im Überstand von belasteten GT1-7 Zellen. Die Messwerte sind in Relation zur Kontrollgruppe angegeben. * = signifikant gegen Kontrolle (DMSO).

\subsection{EROD-Assay}

Die Substanz OMC sowie E2 als Standard wurden im EROD-Assay auf ihren Einfluss auf die Cyp1a1-Expression getestet. Dabei wurden die Möglichkeit der Induktion sowie die Möglichkeit der Hemmung einer Induktion berücksichtigt. Die basale ERODAktivität lag in diesem Assay bei etwa 5 bis $18 \mathrm{U}$. Mit dem Agonisten 3MC erreichten die Zellen eine Aktivität von etwa 75 bis 90 U. Im EROD-Assay auf eine agonistische Wirkung (Abb. 9) zeigte keine der getesteten Konzentrationen von OMC eine deutliche Erhöhung der EROD-Aktivität. Im EROD-Assay auf eine antagonistische Wirkung hemmt OMC die Induktion der EROD-Aktivität durch 3MC ab einer Konzentration von 
$3 \times 10^{-5} \mathrm{M}$. Die maximale Hemmung durch OMC bei einer Konzentration von $1 \times 10^{-4} \mathrm{M}$ lag bei ca. $80,5 \%$.
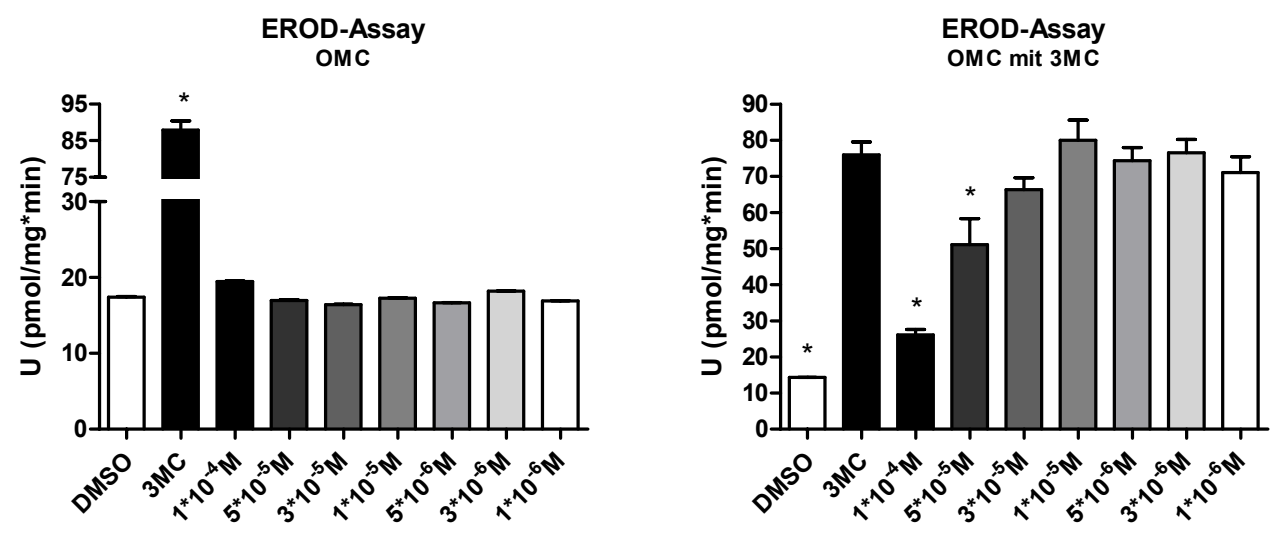

Abb. 9: Induktion und Hemmung der Induktion der EROD-Aktivität durch OMC. Links ist die Inkubation mit OMC dargestellt. * = signifikant gegen Kontrolle (DMSO). Rechts ist die Koinkubation mit $3 \mathrm{MC}\left(1 \times 10^{-6} \mathrm{M}\right)$ dargestellt. * = signifikant gegen Positivkontrolle $3 \mathrm{MC}\left(1 \times 10^{-6} \mathrm{M}\right)$.

Die Tierseren der OMC-1000 Gruppe wurden im EROD-Assay auf agonistische und antagonistische (Koinkubation mit 3MC) Aktivität getestet (Abb. 10), um eine mögliche Veränderung der Aktivität durch eine in vivo-Metabolisierung zu überprüfen. Die maximale Induktion der Positivkontrolle 3MC erreichte nur eine Aktivität von ca. $40 \mathrm{U}$. Weder bei dem Test auf eine induzierende Wirkung noch bei dem Test auf eine hemmende Wirkung auf die Induktion durch 3MC konnte ein Effekt der Testseren festgestellt werden.
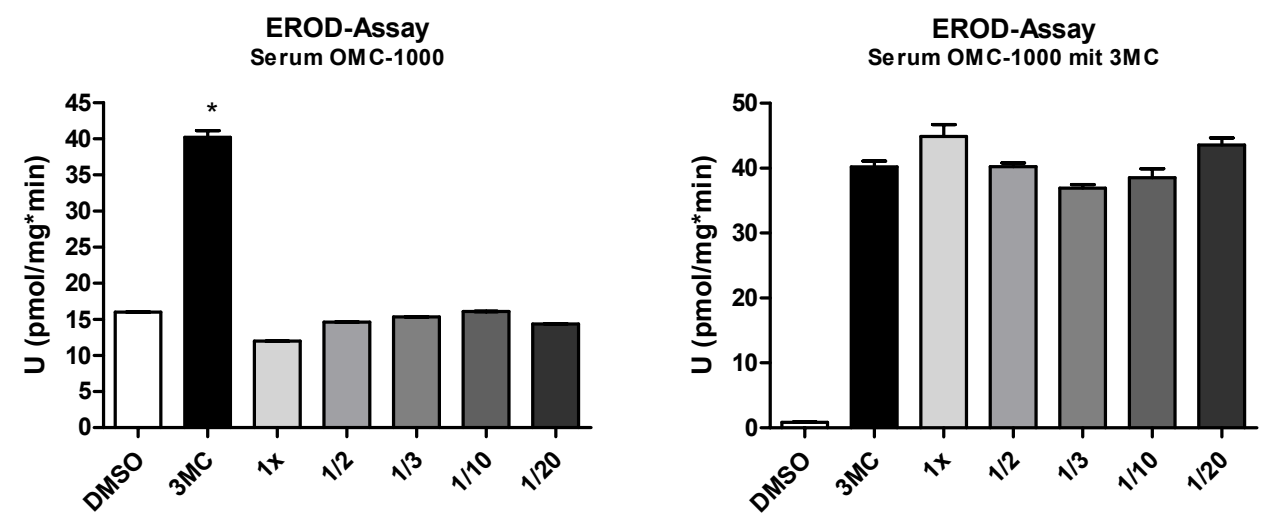

Abb. 10: Induktion und Hemmung der Induktion der EROD-Aktivität durch Tierseren. Links ist die Inkubation mit OMC-1000 Serum, rechts die Koinkubation mit $3 \mathrm{MC}\left(1 \times 10^{-6} \mathrm{M}\right)$ dargestellt. * = signifikant gegen Kontrolle (DMSO). 
E2 hatte bei hohen Konzentrationen ab $1 \times 10^{-6} \mathrm{M}$ einen hemmenden Effekt auf die Reaktivität des AhR-Systems (Abb. 11). Die maximale Hemmung der Induktion durch $3 \mathrm{MC}$ bei einer Konzentration von $1 \times 10^{-5} \mathrm{M}$ lag bei ca. $30 \%$.

EROD-Assay

E2 mit 3MC

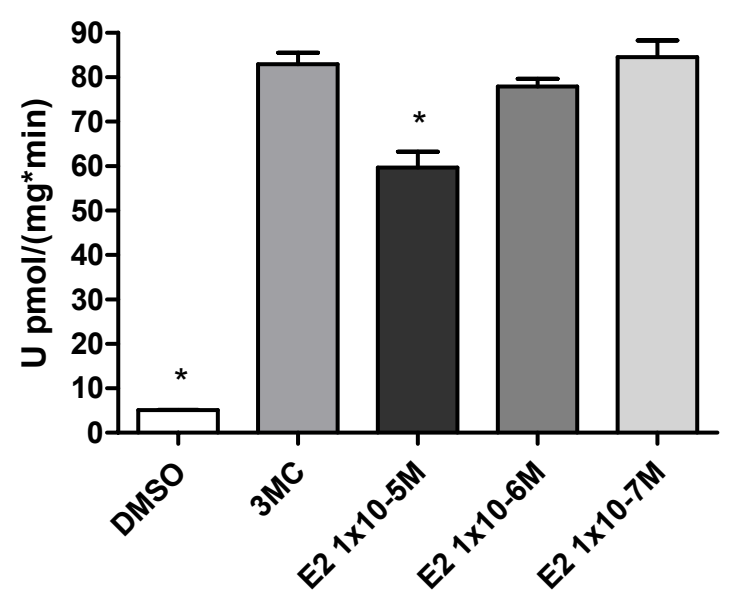

Abb. 11: Hemmung der Induktion der EROD-Aktivität durch E2. Koinkubation mit E2 und 3MC $\left(1 \times 10^{-6} \mathrm{M}\right) .{ }^{*}=$ signifikant gegen Positivkontrolle $3 \mathrm{MC}\left(1 \times 10^{-6} \mathrm{M}\right)$.

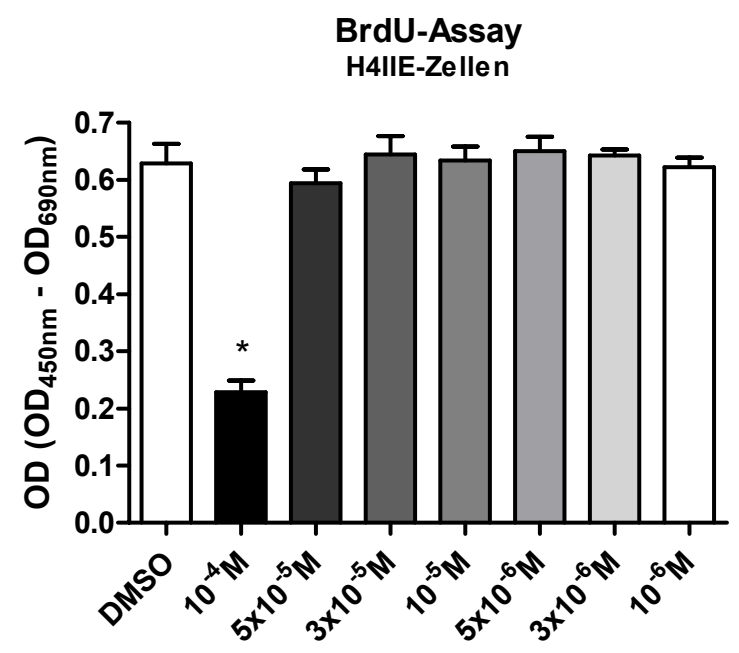

Abb. 12: Einfluss von OMC auf den BrdU-Einbau in genomische DNA. Die Absorption des Substrates bei $450 \mathrm{~nm}$ wurde gemessen. * = signifikant gegen Kontrolle (DMSO).

Die Möglichkeit, dass OMC die Proliferation der H4IIE-Zellen, die im EROD-Assay benutzt wurden, beeinflusst, wurde mit dem BrdU-Assay überprüft (Abb. 12). Die 
Testsubstanz zeigte nur bei der höchsten eingesetzten Konzentration von $1 \times 10^{-4} \mathrm{M}$ eine deutliche Hemmung der Proliferation der Zellen. Die maximale Hemmung lag bei ca. $63 \%$.

Für beide Testsubstanzen E2 und OMC wurde versucht, die hemmende Wirkung auf die Induktion mit 3MC mit dem ER-Antagonisten ICI 182,780 zu blockieren (Abb. 13). ICI 182,780 allein hatte keinen induzierenden Effekt auf die EROD-Aktivität, auch wurde die Induktion durch 3MC nicht durch ICI 182,780 gehemmt. Bei der Inkubation der Zellen mit E2 und 3MC zeigte sich wieder die hemmende Wirkung von E2 auf die EROD-Aktivität. Die Zugabe von ICI 182,780 hatte keinen Effekt auf die hemmende Wirkung von E2. Beide Ansätze unterschieden sich nicht signifikant.

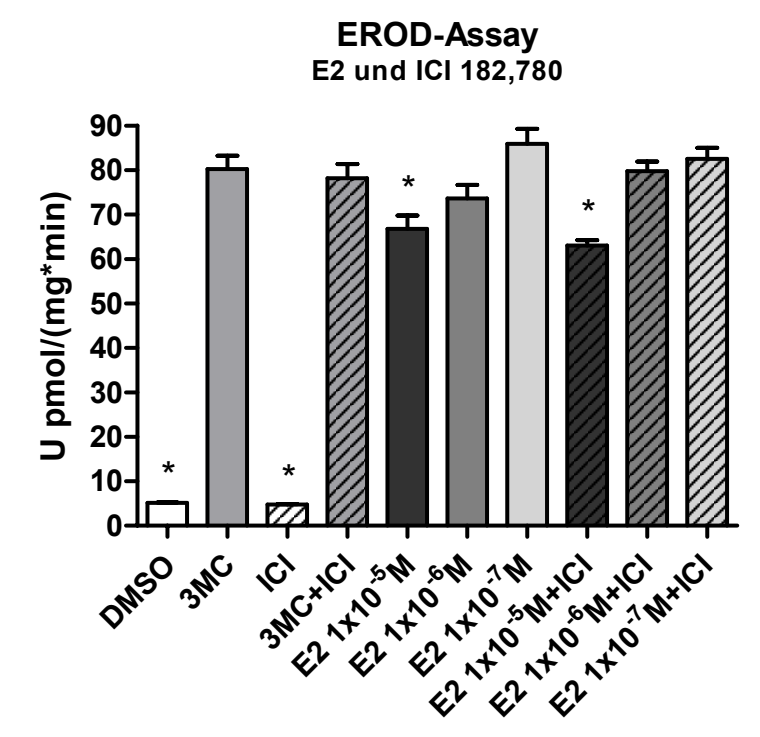

Abb. 13: Einfluss von ICI 182,780 auf die hemmenden Effekte von E2 auf die EROD-Aktivität. $*=$ signifikant gegen Positivkontrolle $3 \mathrm{MC}\left(1 \times 10^{-6} \mathrm{M}\right)$.

Bei dem Versuch, die hemmende Wirkung von OMC mit ICI 182,780 zu inhibieren, kam es ebenfalls zu keinen sichtbaren Unterschieden zwischen der Inkubation der Zellen mit OMC mit und ohne ICI 182,780 (Abb. 14). 


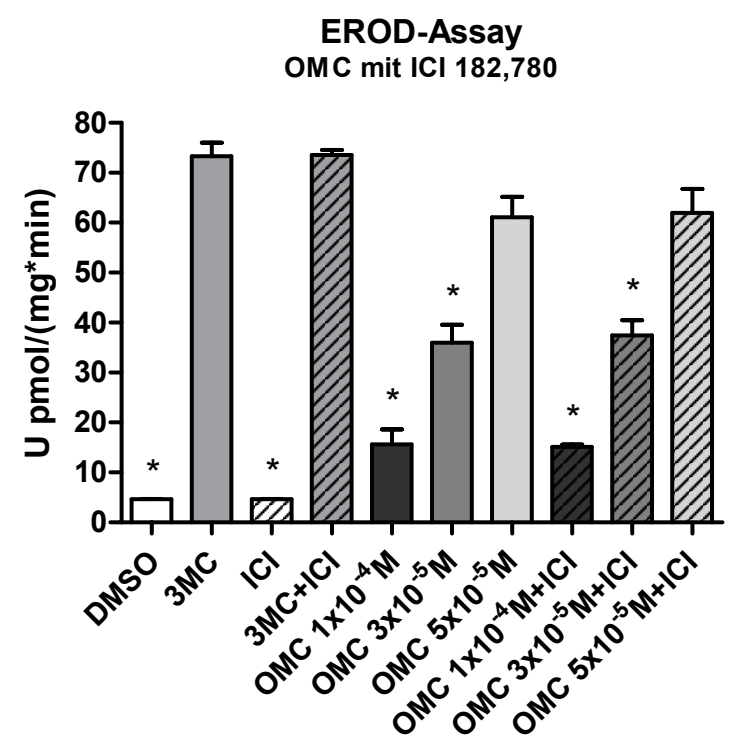

Abb. 14: Einfluss von ICI 182,780 auf die hemmenden Effekte von OMC auf die EROD-Aktivität. $*$ = signifikant gegen Positivkontrolle $3 \mathrm{MC}\left(1 \times 10^{-6} \mathrm{M}\right)$.

\subsection{Tierversuchsdaten}

Es folgen die Ergebnisse, die aus dem Tierversuch „Subakute Applikation der Testsubstanzen an ovariektomierten weiblichen Ratten“ gewonnen wurden.

\subsubsection{Vaginalabstrich}

Anhand der Morphologie und des dominierenden Zelltypus wurde der Vaginalabstrich der ovariektomierten Ratten mit dem Erscheinungsbild des Vaginalabstriches von intakten Ratten verglichen (Abb. 15). Die Tiere der Kontrollgruppe zeigten ein dem Diestrus entsprechendes Erscheinungsbild, welches charakterisiert wird durch große Mengen an Leukozyten und keine Epithelzellen. Die Tiere der E2V-Gruppe zeigten das Erscheinungsbild von estrischen Ratten, erkennbar durch große polygonale Epithelzellen, welche meist kernlos waren, und wenige Leukozyten. Die Tiere der Behandlungsgruppen OMC-10 bis OMC-100 wiesen keine Unterschiede zur Kontrollgruppe auf. In der OMC-333-Gruppe traten vermehrt kernhaltige ovale Epithelzellen auf. Dies verstärkte sich noch in der OMC-100 Gruppe. Auch traten vereinzelt polygonale Epithelzellen auf. 


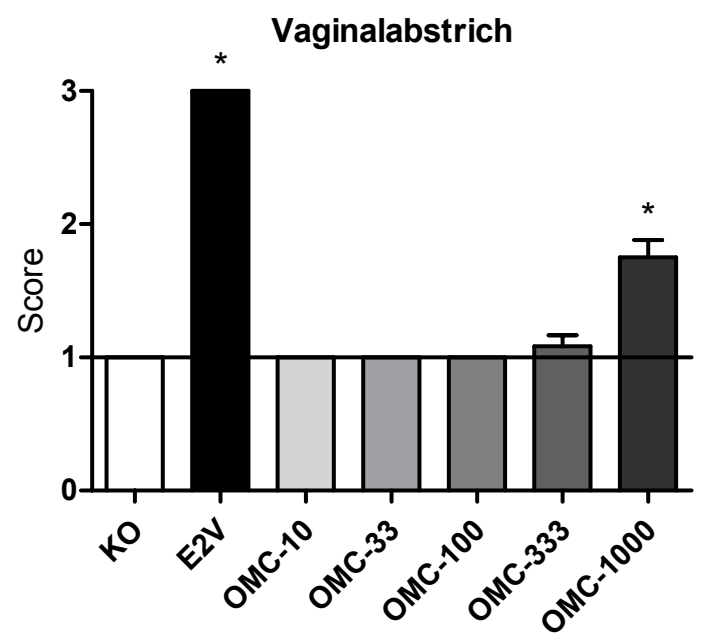

Abb. 15: Erscheinungsbild der Vaginalabstriche der Behandlungsgruppen nach 5tägiger Behandlung. Den Tieren wurde ein ,score“ zugeordnet, wobei diestrusartig der Wert 1, proestrusartig der Wert 2 und estrusartig der Wert 3 zugewiesen wurde.* = signifikant gegen Kontrollgruppe.

\subsubsection{Tier-, und Organgewichte}

Estrogene haben einen starken Effekt auf die Entwicklung des Körpergewichtes. Abb. 16 zeigt den Verlauf des Körpergewichtes der Versuchstiere während der Behandlung. Die Tiere der Kontrollgruppe verloren am zweiten Tag etwas an Gewicht. Für den Rest des Behandlungszeitraumes blieb das Tiergewicht stabil. Die Kontrollsubstanz E2 zeigte einen Einfluss auf das Gewicht der Tiere. Am zweiten Tag war das Gewicht deutlich verringert und sank bis zum fünften Tag leicht ab. Der Verlauf der Tiergewichte in allen OMC-Behandlungsgruppen zeigte einen geringen Abfall der Gewichte am zweiten Tag. Danach stabilisierte sich das Gewicht der Tiere und zeigte bis zum Versuchsende keine deutliche Abweichung vom Tiergewicht zu Versuchsbeginn. 


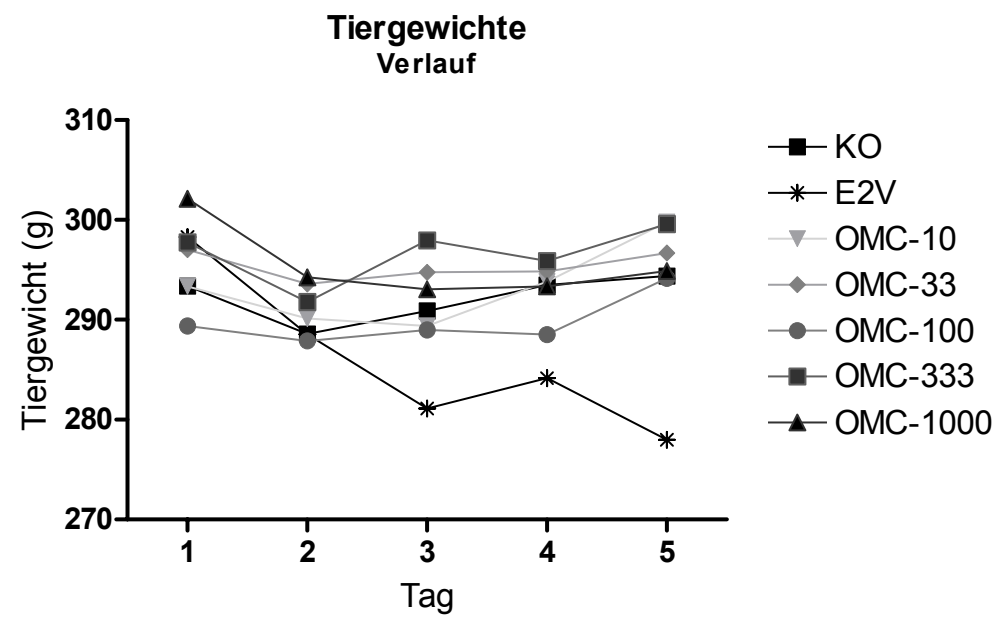

Abb. 16: Verlauf der Tiergewichte der Behandlungsgruppen über den Behandlungszeitraum.

Das durchschnittliche Gewicht der Tiere am fünften Tag der OMCBehandlungsgruppen (Abb. 17) unterschied sich nicht von dem Gewicht der Tiere der Kontrollgruppe. In der E2V-Gruppe war das Gewicht ca. 16 g oder 5,5 \% niedriger als in der Kontrollgruppe. Diese Änderung ist nicht signifikant.

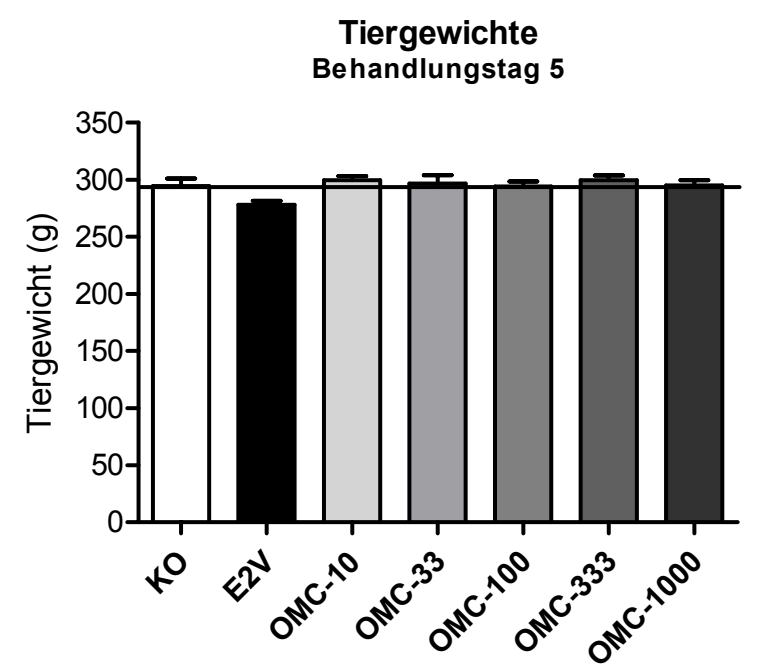

Abb. 17: Tiergewichte der Behandlungsgruppen am 5ten Tag des Behandlungszeitraumes.

Der Uterus reagiert auf Estrogene sehr stark mit Proliferation, dementsprechend war das Gewicht der Uteri der E2V-Gruppe im Vergleich zur Kontrollgruppe signifikant auf 353 \% erhöht (Abb. 18). Die Tiere der Gruppen OMC-10 bis OMC-100 zeigten noch keine Reaktion. In der Gruppe OMC-333 kam es zu einer leichten, nicht signifikanten 
Erhöhung. Erst in der OMC-1000-Gruppe zeigte sich eine signifikante Erhöhung des Uterusgewichtes. Die maximale Induktion auf 155 \% im Vergleich zur Kontrollgruppe erreichte allerdings nicht das Niveau der E2V-Gruppe.

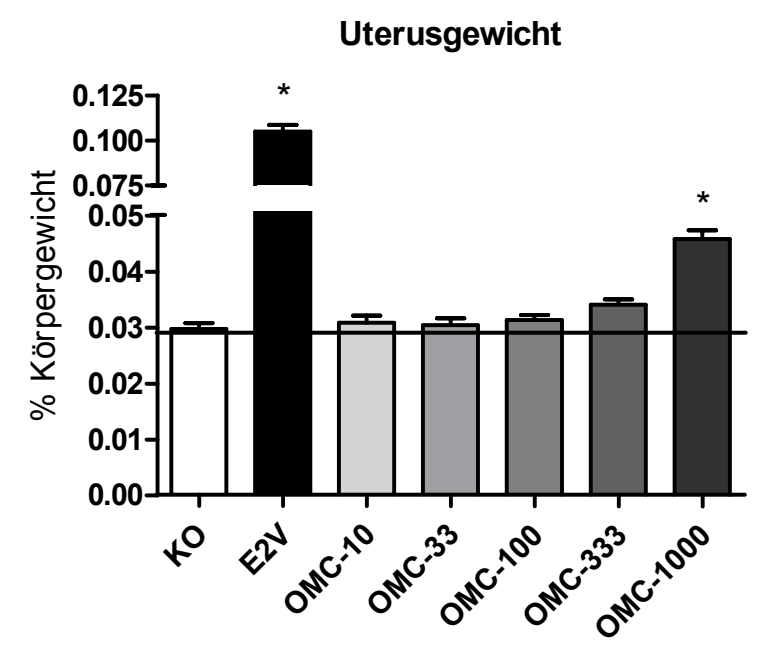

Abb. 18: Uterusgewicht der Behandlungsgruppen nach 5tägiger Behandlung. Das Uterusgewicht wurde auf das Körpergewicht der einzelnen Tiere bezogen. * = signifikant gegen Kontrollgruppe.

\subsubsection{Uterus-Morphologie}

In Abb. 19 sind typische Querschnitte von drei Tieren der Kontrollgruppe (A), der E2VGruppe (B) und der OMC-1000 Gruppe (C) abgebildet. Die Zellkerne der Zellen des Endometriums der Kontrollgruppe waren oval bis kugelförmig, während sie nach E2VBehandlung eine spindelförmige Form annahmen. Die Zellen des Epithels des Endometriums der Kontrollgruppe waren i.d.R. nicht mehr als doppelt so lang wie breit und der Zellkern lag zentral. Unter E2V-Einfluss streckten sich die Epithelzellen in Längsrichtung, wobei die Zellkerne an der basalen Seite verblieben. Die Zellen des Endometriums der OMC-1000-Tiere unterschieden sich in der Form des Kernes nicht von denen der Kontrolltiere. Die Zellen des Epithels hingegen waren leicht gestreckt. Auf der apikalen Seite befand sich ein größerer Anteil des Cytosols, der Zellkern lag auf der basalen Seite. 


\section{Ergebnisse}
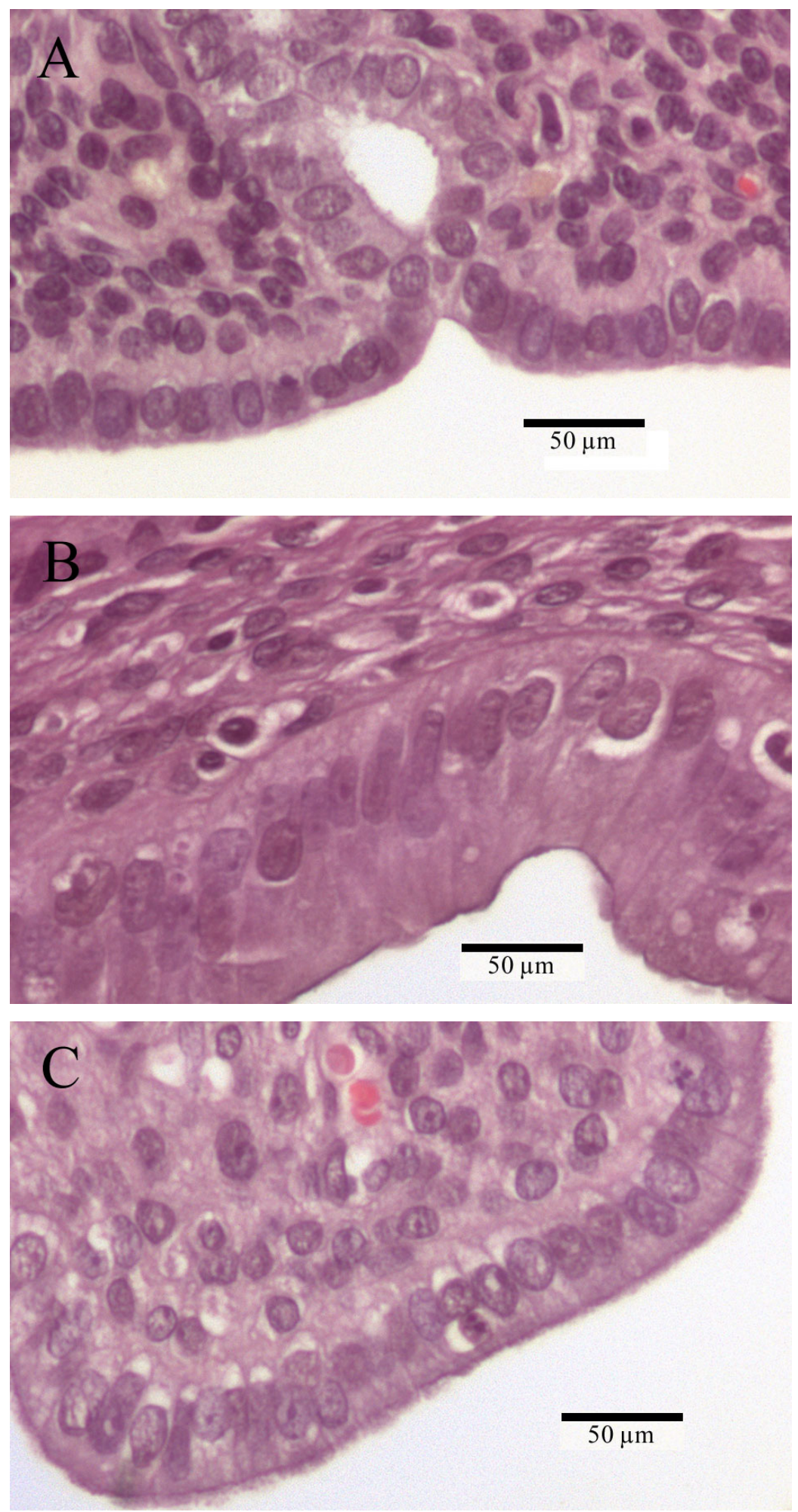

Abb. 19: Beispiele für die Morphologie der Uteri aus Kontrollgruppe (A), E2V(B)- und OMC-1000(C) Gruppe nach 5tägiger Behandlung. Haematoxylin-Eosin-Färbung der Querschnitte. 
Als messbare Parameter für die Quantifizierung des estrogenen Effektes auf die Morphologie des Uterus wurden der Durchmesser der Uteri sowie der Durchmesser des Lumens bestimmt. Die Behandlung der Tiere mit E2V führte zu einer deutlichen Erhöhung des Durchmessers des Uterus auf 152 \% sowie des Lumens auf $180 \%$ im Vergleich zur Kontrollgruppe. In der OMC-1000 Gruppe kam es zu einer Erhöhung des Uterusdurchmessers auf 132 \%, während der Lumendurchmesser auf 131 \% erhöht wurde.
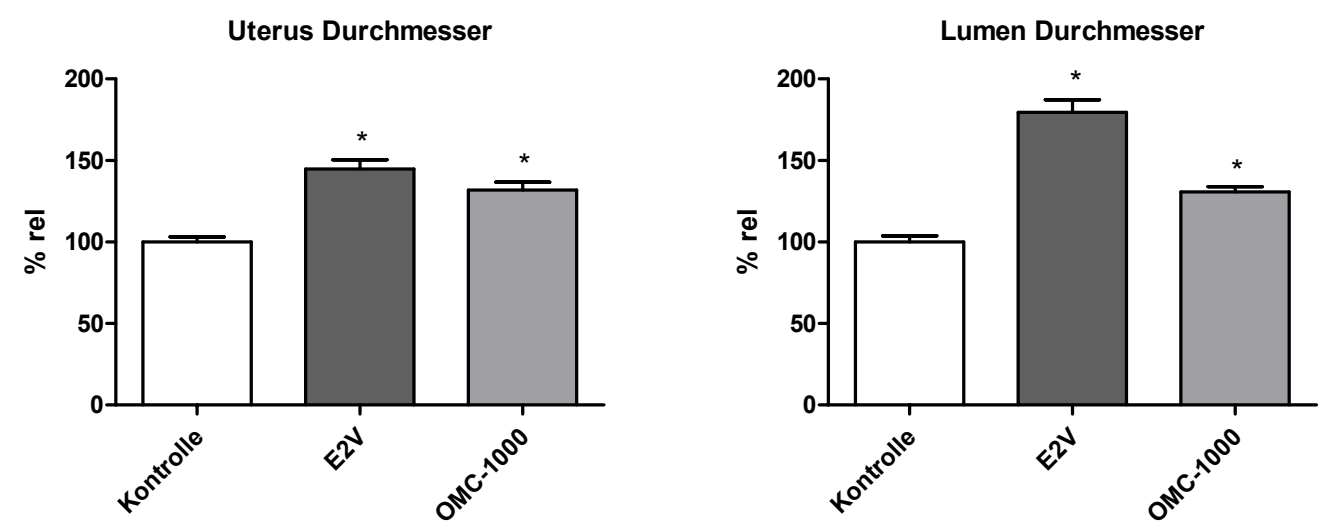

Abb. 20: Uterus- und Lumendurchmesser nach 5tägiger Behandlung. Links ist der Uterusdurchmesser, rechts ist der Lumendurchmesser dargestellt. Die Werte wurden auf die Kontrollgruppe relativiert. * = signifikant gegen Kontrollgruppe.

Das Verhältnis von Lumendurchmesser zu Uterusdurchmesser (prozentrelativierte Werte) änderte sich von 1 in der Kontrollgruppe auf 1,27 durch die E2V-Behandlung, wie in Abb. $21 \mathrm{zu}$ sehen ist. Das Verhältnis in der OMC Behandlungsgruppe blieb gleich. In der Auftragung Lumendurchmesser gegen Uterusdurchmesser ist der Unterschied der Wirkung von E2V und OMC auf die Morphologie des Uterus deutlich zu sehen. Der Lumendurchmesser der OMC behandelten Tiere stieg im Vergleich zu den E2V behandelten Tiere nicht so stark wie der Uterusdurchmesser. 

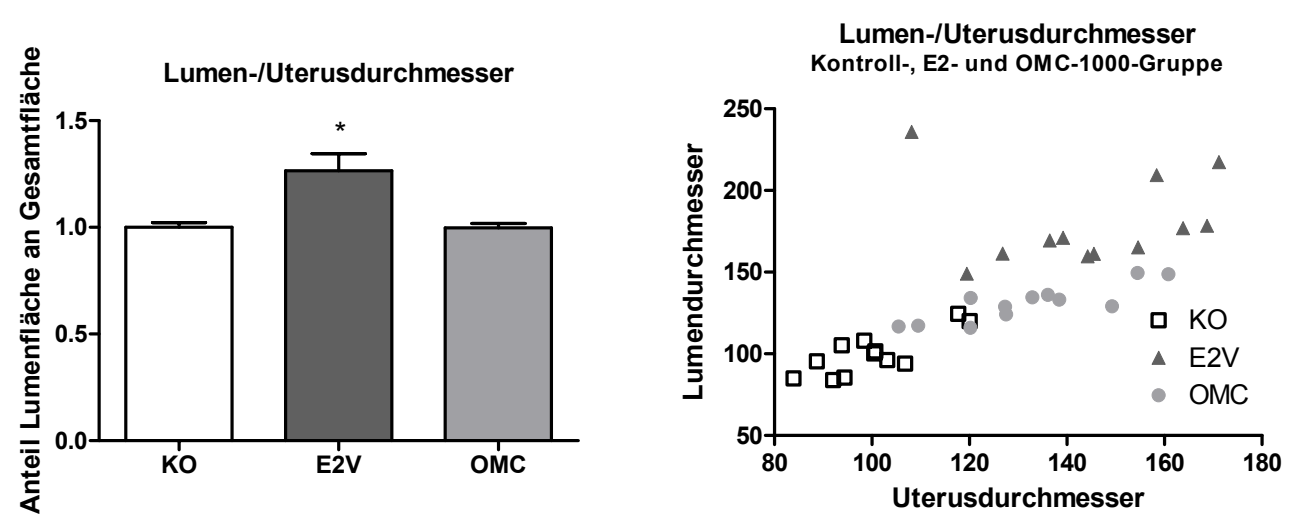

Abb. 21: Quotient des Lumen- und Uterusdurchmessers. Links ist der Quotient der Behandlungsgruppen zur Kontrolle dargestellt. Die Werte wurden auf die Kontrolle relativiert. * = signifikant gegen Kontrollgruppe. Rechts ist ein scatterplot der Werte der einzelnen Tiere dargestellt.

\subsubsection{Serum-Analyse}

\subsubsection{Hypophysen-Hormone}

Im RIA wurden die Serumspiegel der Hypophysenhormone Prolaktin, GH, FSH, LH und TSH gemessen. Die mit E2V behandelten Tiere wiesen einen deutlich erhöhten Serumspiegel von Prolaktin auf (307 \% der Kontrollgruppe), die Serumspiegel von GH und FSH waren unverändert. Der LH-Spiegel sank leicht, die Änderung ist aber nicht signifikant (Abb. 22). Die Behandlung mit OMC führte bei den Hormonen Prolaktin, GH, FSH und LH zu keinen Veränderungen der Serumspiegel. 

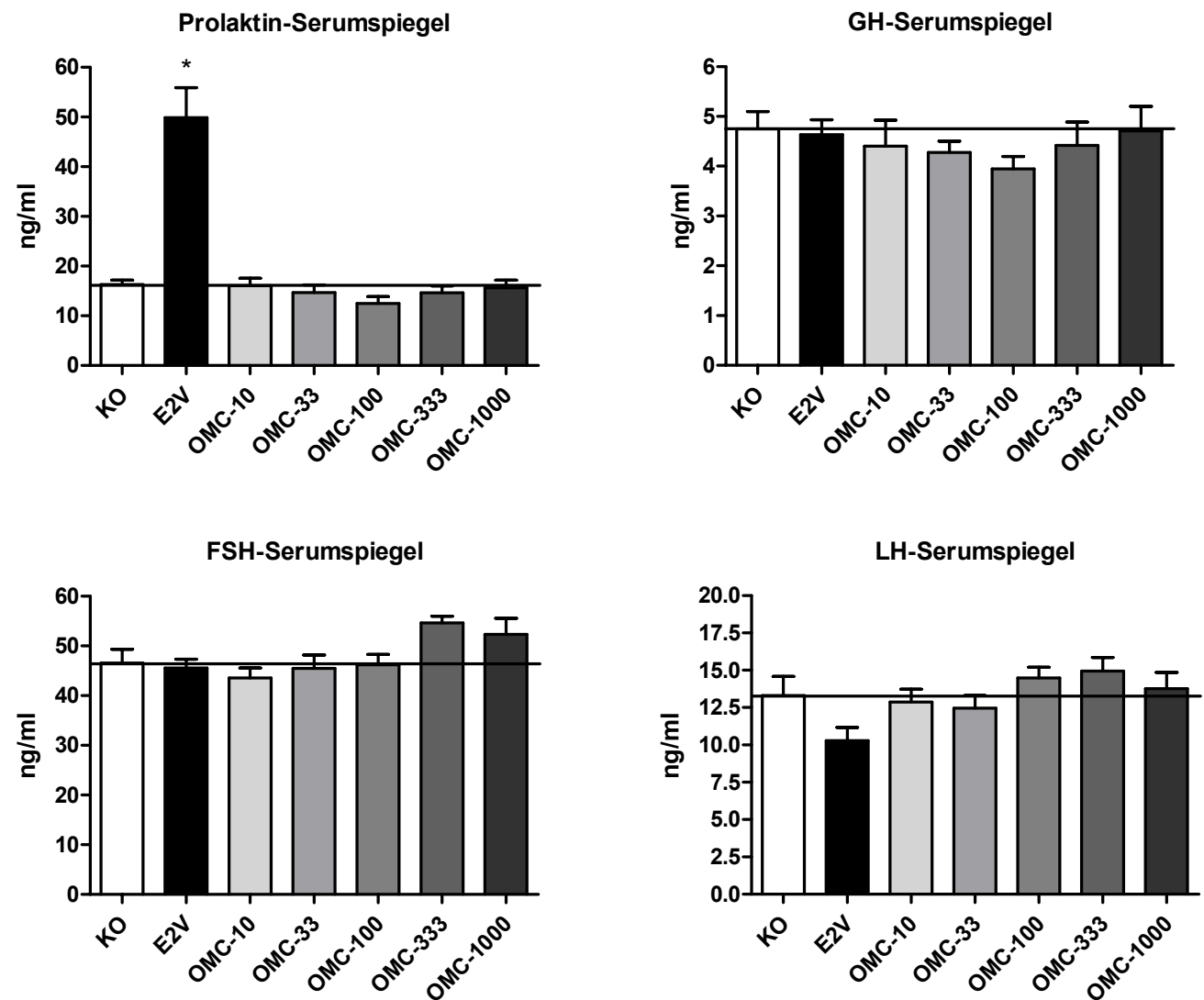

Abb. 22: Serumspiegel der Hypophysenhormone Prolaktin, GH, FSH und LH nach 5tägiger Behandlung. * = signifikant gegen Kontrollgruppe.

Abb. 23 zeigt, dass die Behandlung mit E2V in einem leichten, aber nicht signifikanten Anstieg des Serumspiegels von TSH resultierte. In den OMC-Gruppen führt die Behandlung zu einem Absinken der Hormonwerte auf bis zu $38 \%$ in der OMC-1000Gruppe. 
TSH Serumspiegel

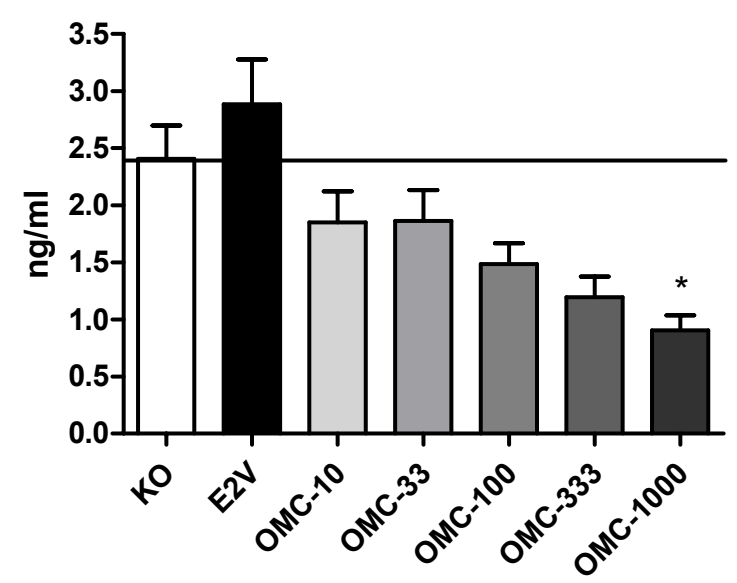

Abb. 23: Serumspiegel des Hypophysenhormons TSH nach 5tägiger Behandlung. * = signifikant gegen Kontrollgruppe.

\subsubsection{Schilddrüsen-Hormone}

Die Funktion der Schilddrüse wurde anhand der Serumwerte der Schilddrüsenhormone untersucht. Abb. 24 zeigt die Serumspiegel des Hormons T3 insgesamt (T3) sowie in freier Form (fT3). Die Behandlung mit E2V hatte einen leichten, senkenden Effekt auf die Serumspiegel von T3 und fT3 auf $83 \%$ bzw. $88 \%$ der Kontrollgruppe, der allerdings nicht signifikant ist. Der Serumspiegel beider Formen des T3 wurde in den OMC-Behandlungsgruppen erniedrigt. Im Falle des gesamten T3 in der OMC-1000Gruppe signifikant auf 63 \%. Bei dem freien T3 ist die Änderung in der OMC-333Gruppe und in der OMC-1000-Gruppe signifikant (80\% und $75 \%$ ).
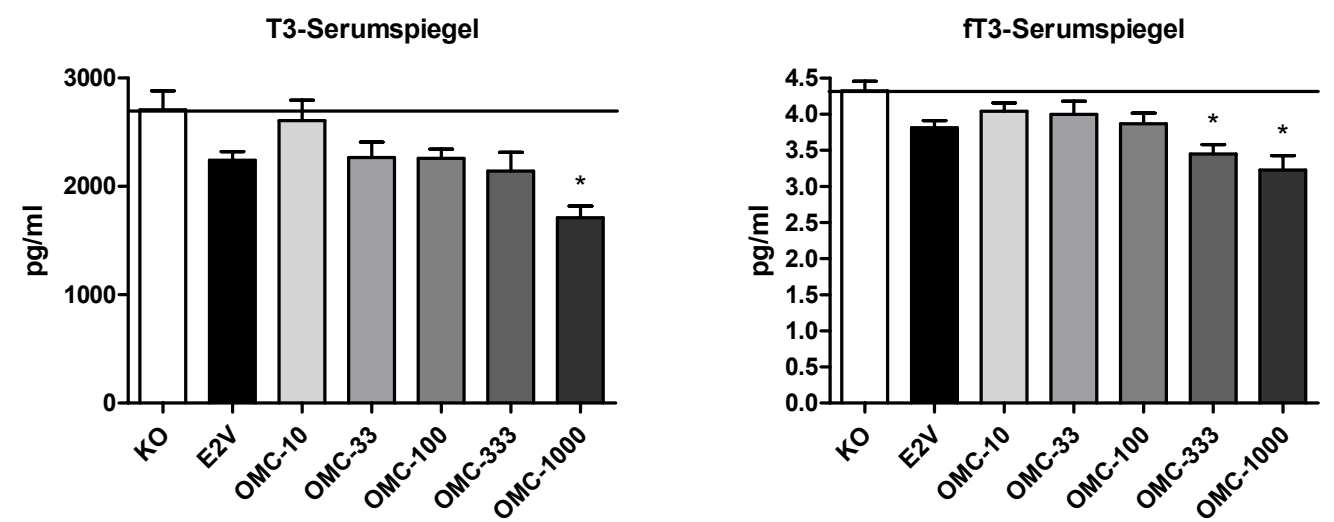

Abb. 24: Serumspiegel der Hypophysenhormone T3 und fT3 der Behandlungsgruppen nach 5tägiger Behandlung. * = signifikant gegen Kontrollgruppe. 
Der Serumspiegel des gesamten T4 zeigte nach der OMC-Behandlung einen Abfall, welcher bei OMC-333 und bei OMC-1000 signifikant war (75\% und $59 \%$, Abb. 25). Die E2V-Behandlung hatte allerdings keinen Effekt auf den T4 Spiegel. Auf das freie T4 hatte OMC keinen signifikanten Einfluss. Der leichte Anstieg des fT4 Spiegels auf $125 \%$ der Kontrollgruppe in der E2V-Gruppe war nicht signifikant.
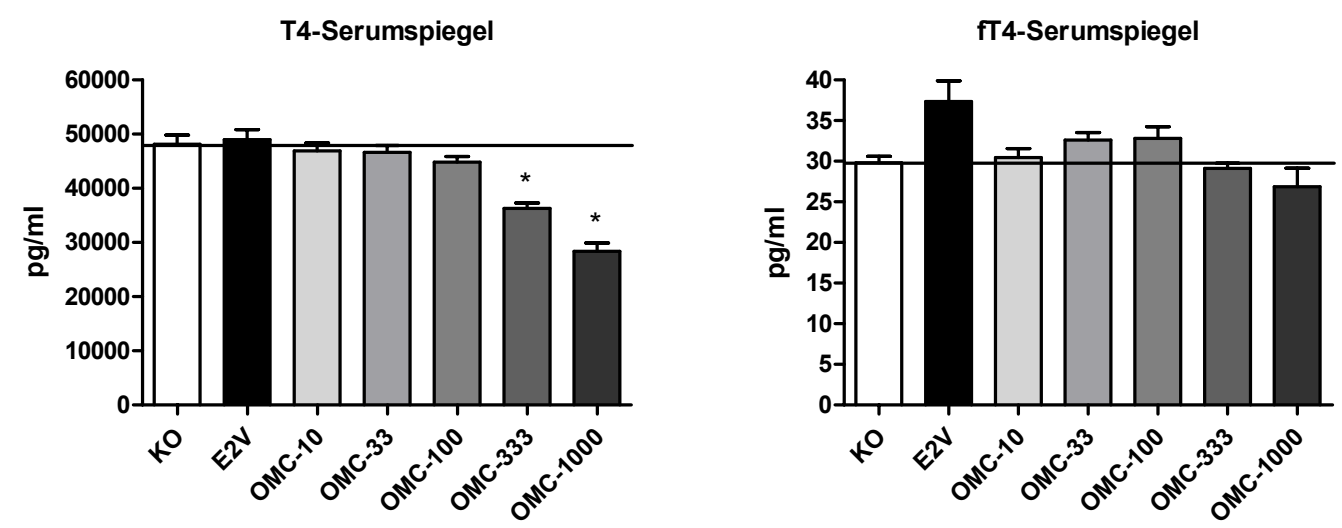

Abb. 25: Serumspiegel der Hypophysenhormone T4 und fT3 der Behandlungsgruppen nach 5tägiger Behandlung. * = signifikant gegen Kontrollgruppe.

Die vier Formen des Schilddrüsenhormons stehen in einem definierten Verhältnis zueinander. In Abb. 26 sind die Verhältnisse von freiem zu gesamt-T3 bzw. T4 sowie die Verhältnisse von T3 und fT3 zu T4 und fT4 dargestellt. Der Effekt von E2V und OMC auf die fT3- und T3-Serumspiegel hatte keinen signifikanten Einfluss auf das Verhältnis von freiem T3 zu gesamt-T3. Das Verhältnis von fT4 zu T4 stieg nach E2V Behandlung und nach OMC-Behandlung dosisabhängig, obwohl E2V und OMC einen unterschiedlichen Effekt auf den Serumspiegel von fT4 und T4 hatten. Das Verhältnis von freiem $\mathrm{T} 3 \mathrm{zu}$ freiem $\mathrm{T} 4$ nahm nach E2V- sowie nach OMC-Behandlung dosisabhängig ab. Das gesamt-T3 nahm nach E2V-Behandlung im Verhältnis zum gesamt T4 leicht (auf $81 \%$ ) aber nicht signifikant ab, während in den OMCBehandlungsgruppen keine Tendenz zu beobachten war. 

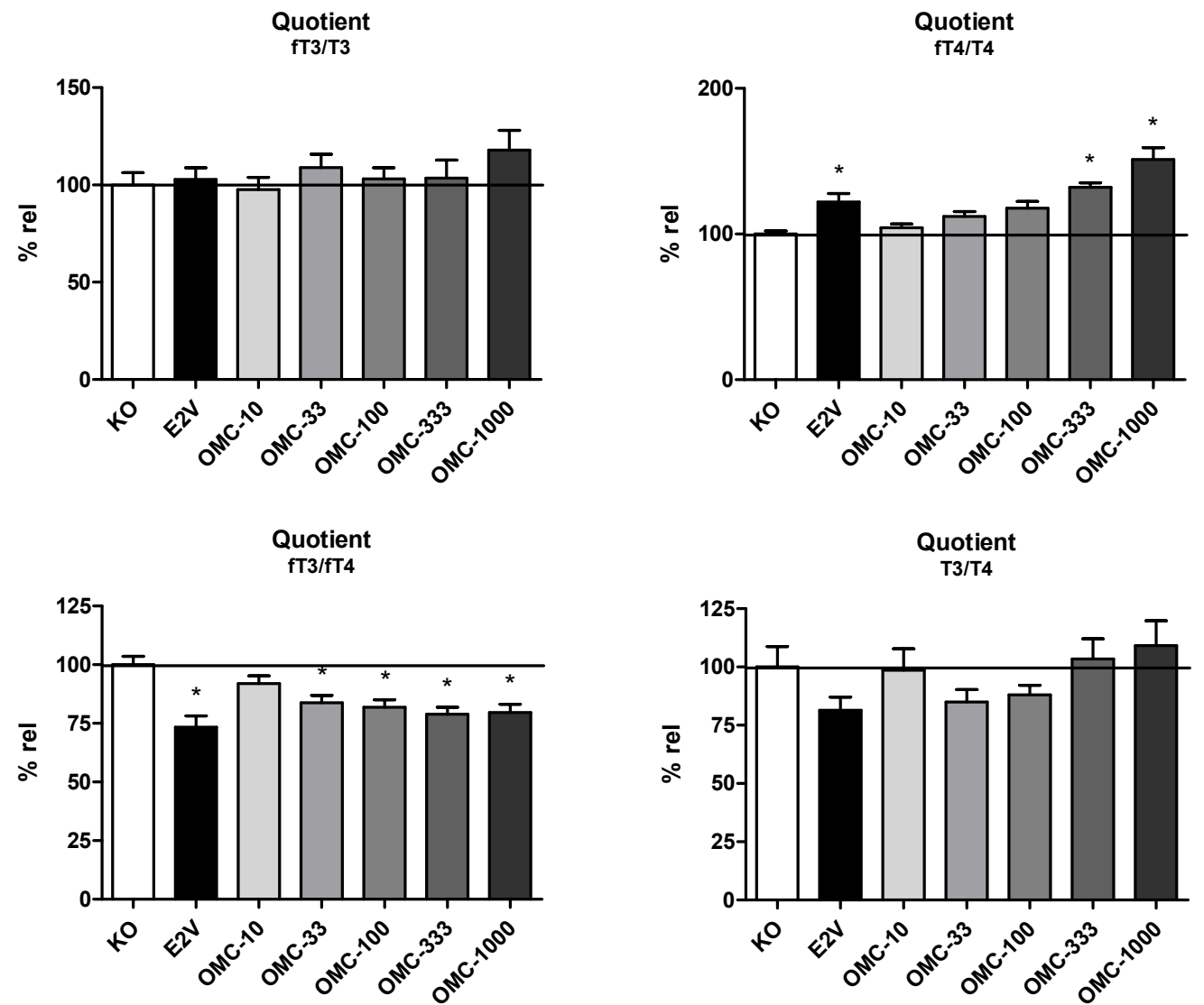

Abb. 26: Verhältnisse der Schilddrüsenhormone zueinander. Die Werte wurden auf die Kontrollgruppe relativiert. * = signifikant gegen Kontrollgruppe.

\subsubsection{Metabolische Parameter}

EV hat einen regulierenden Einfluss auf metabolische Parameter. Deshalb wurden im Serum die Werte des Fettgewebshormons Leptin, des Cholesterins und der Lipoproteine HDL und LDL gemessen (Abb. 27). Die Behandlung mit E2V hatte auf alle vier Parameter einen signifikanten, senkenden Effekt. Leptin: 46 \%, Cholesterin 36 \%, HDL: $39 \%$ und LDL: $16 \%$ der jeweiligen Kontrollgruppen. In den OMC-Gruppen zeigte sich ein signifikanter, senkender Effekt auf die Parameter Cholesterin und LDL in der OMC1000-Gruppe auf $78 \%$ und $48 \%$. Die Parameter Leptin und HDL waren von der Behandlung mit $\mathrm{OMC}$ unbeeinflusst. 
Leptin-Serumspiegel

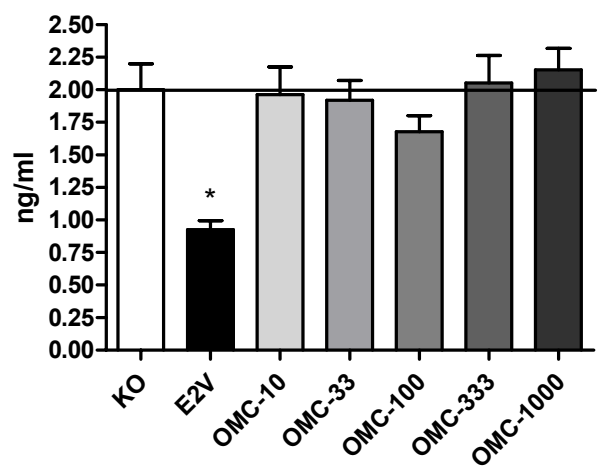

HDL-Serumspiegel

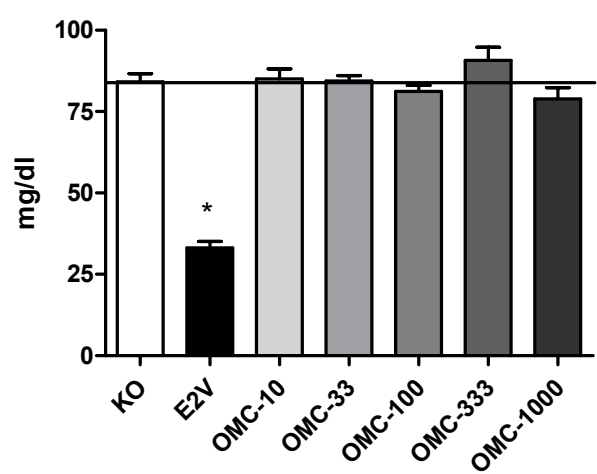

Cholesterin-Serumspiegel

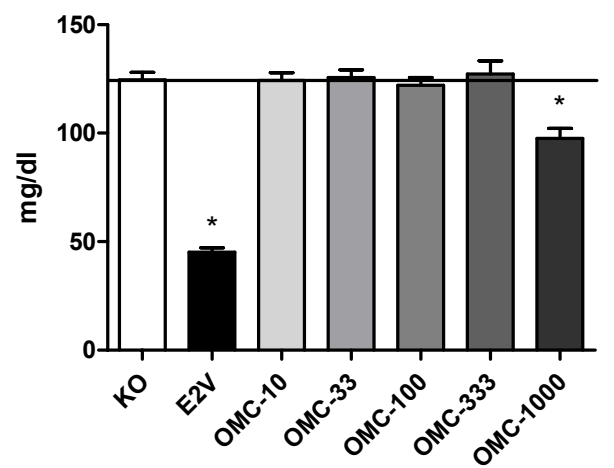

LDL-Serumspiegel

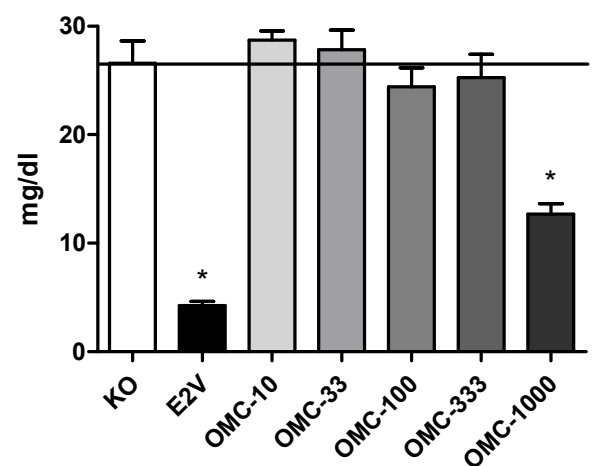

Abb. 27: Leptin-, Cholesterol-, HDL- und LDL-Serumwerte der Behandlungsgruppen nach 5tägiger Behandlung. * = signifikant gegen Kontrollgruppe.

\subsubsection{Genexpressionsanalyse (RT-PCR)}

Mit Hilfe der Genexpressionsanalyse wurde der Status des estrogenen Signaltransduktionsweges im Bezug auf die beiden Estrogen Rezeptoren auf der Ebene der mRNA untersucht. Zudem wurde der Einfluss der Testsubstanz auf die Expression von Markergenen untersucht.

\subsubsection{Mediobasaler Hypothalamus (MBH)}

In Abb. 28 ist die Expression der Estrogen Rezeptoren alpha und beta im Hypothalamus dargestellt. Nach E2V-Behandlung wurde die Expression des ER alpha auf $135 \%$ und des ER beta auf $134 \%$ leicht, aber nicht signifikant erhöht. In den OMCBehandlungsgruppen ist keine tendenzielle Änderung aufgetreten. 
ER alpha-Expression im MBH

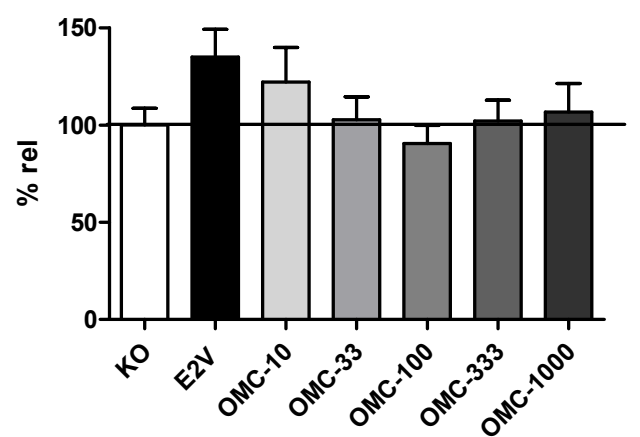

ER beta-Expression im MBH

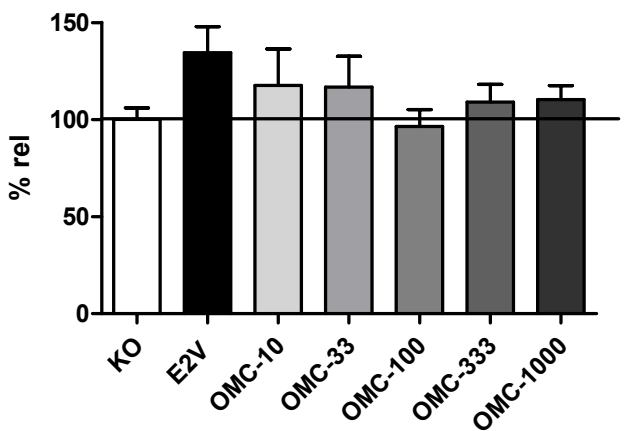

Abb. 28: ER alpha- und ER beta-Genexpression im MBH nach 5tägiger Behandlung. Die Werte wurden auf die Kontrollgruppe relativiert.

In Abb. 29 ist die Genexpression der Rezeptoren ERR1 und ERR3 dargestellt. Die Genexpression des ERR1 im MBH wurde nicht signifikant verändert. Auch zeigte sich in den Behandlungsgruppen keine eindeutige Tendenz. Die ERR3-Expression wurde nach E2V-Behandlung nicht-signifikant auf $120 \%$ erhöht. Die Behandlungsgruppen OMC-10 bis OMC-333 zeigten keine Veränderung. Die OMC-1000-Gruppe zeigten einen mit der E2V-Gruppe vergleichbaren Anstieg auf $121 \%$, der ebenfalls nicht signifikant war.
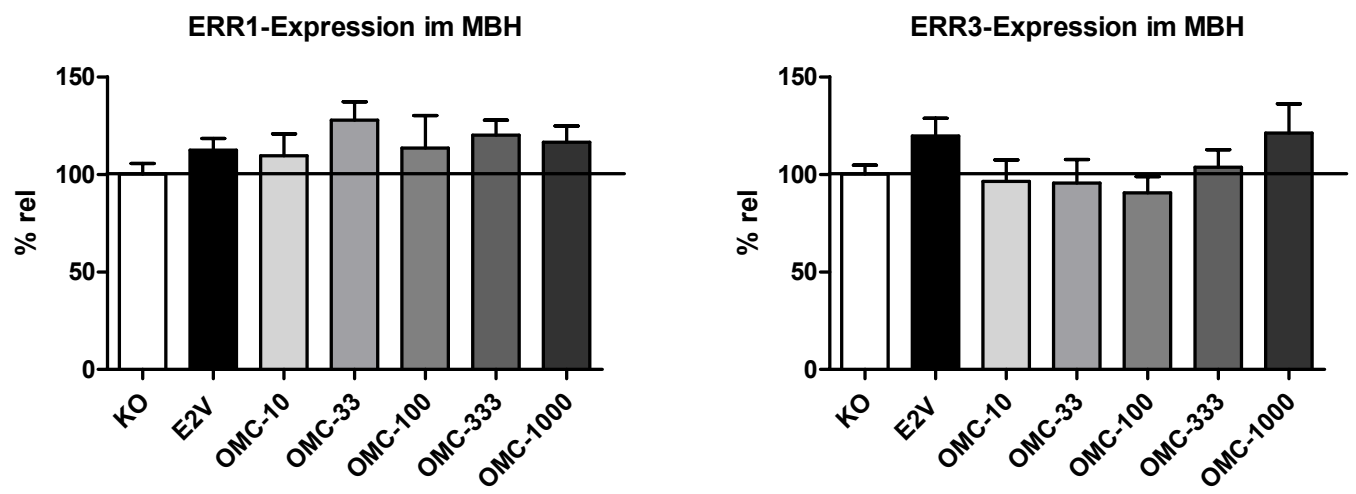

Abb. 29: ERR1- und ERR3-Genexpression im MBH nach 5tägiger Behandlung. Die Werte wurden auf die Kontrollgruppe relativiert.

Auf der Ebene der mRNA war die Expression des TRH durch die Behandlung mit E2V unbeeinflusst (Abb. 30). Die OMC-Behandlung führte ebenfalls $\mathrm{zu}$ keiner dosisabhängigen Veränderung. 
TRH-Expression im MBH

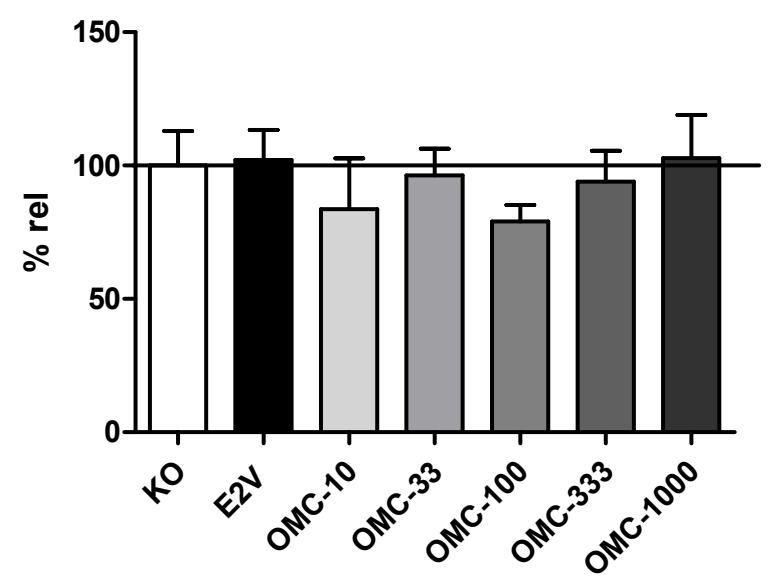

Abb. 30: Prä-Pro-TRH-Genexpression im MBH nach 5tägiger Behandlung. Die Werte wurden auf die Kontrollgruppe relativiert.

\subsubsection{Hypophyse}

In Abb. 31 sind die Expressionsmuster der ERs in der Hypophyse dargestellt. Während E2V keinen Einfluss auf die Genexpression des ER alpha in der Hypophyse hatte, war bei den OMC-Behandlungsgruppen eine dosisabhängige Hemmung $\mathrm{zu}$ sehen, die allerdings keine Signifikanz erreichte. Die Genexpression des ER beta wurde durch die E2V-Behandlung signifikant auf $46 \%$ der Kontrollgruppe gesenkt. In den OMCBehandlungsgruppen zeigte sich keine eindeutige Tendenz. Es schien sich aber um eine Induktion der Genexpression zu handeln. Die maximale Induktion in der OMC-1000Gruppe lag bei $221 \%$ der Kontrollgruppe.
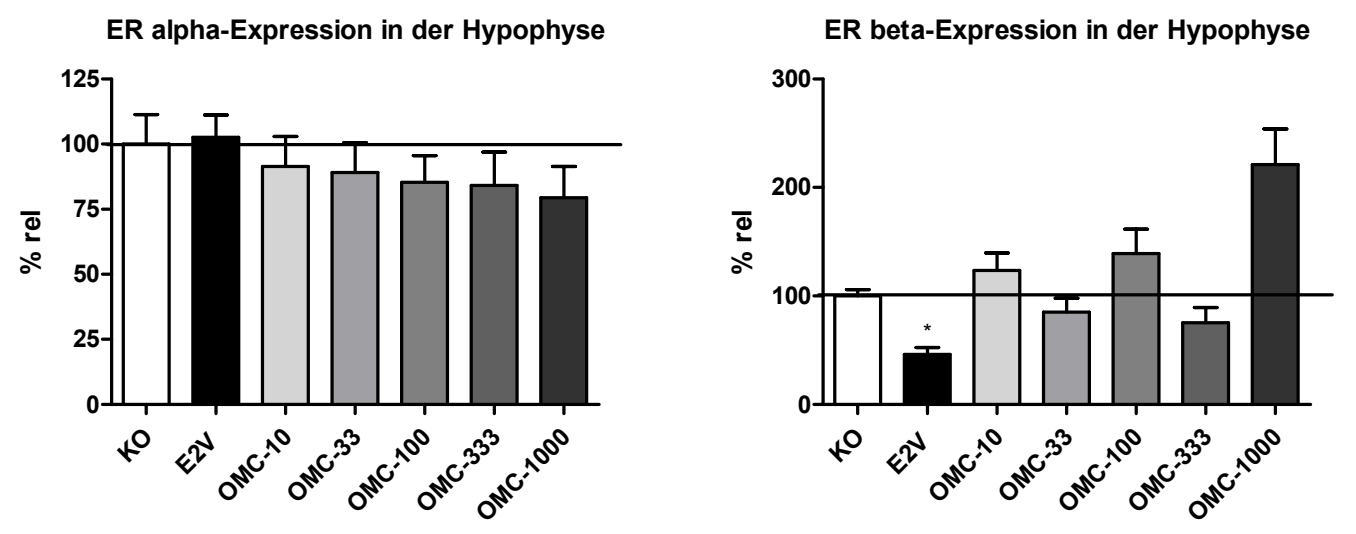

Abb. 31: ER alpha- und ER beta-Genexpression in der Hypophyse nach 5tägiger Behandlung. Die Werte wurden auf die Kontrollgruppe relativiert. * = signifikant gegen Kontrollgruppe. 
TERP1 ist eine splice-Variante des ER alpha, welche durch ERs über ein estrogen response element (ERE) in Abhängigkeit des hypophysenspezifischen Transkriptionsfaktors Pit-1 reguliert wird. Die Genexpression in der E2V-Gruppe wurde auf $5750 \%$ der Expression der Kontrollgruppe erhöht (Abb. 32). Die Genexpression von TERP1 in den OMC-Behandlungsgruppen war in den Gruppen OMC-100 und OMC-333 leicht erhöht und erreichte eine signifikante Änderung in der OMC-1000Gruppe. Die maximale Expression der OMC-1000-Gruppe betrug $631 \%$.

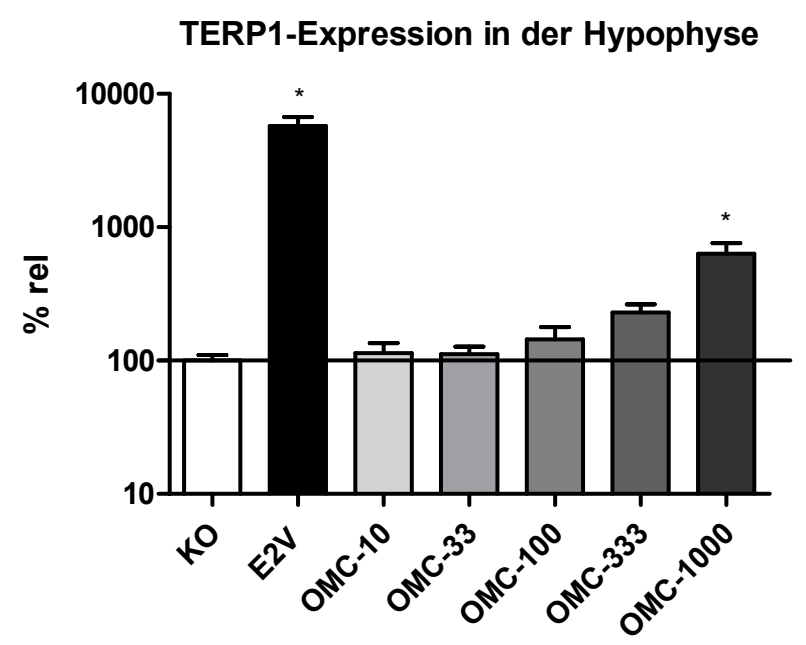

Abb. 32: TERP1-Genexpression in der Hypophyse nach 5tägiger Behandlung. Die Werte wurden auf die Kontrollgruppe relativiert. * = signifikant gegen Kontrollgruppe.

Die Genexpression der alpha-Untereinheit der Hypophysenhormone LH, FSH und TSH wurde durch die E2V-Behandlung nicht-signifikant auf $86 \%$ gesenkt, während die Genexpression der beta-Untereinheit des LH signifikant auf $77 \%$ gesenkt wurde (Abb. 33). Die Genexpression der LH beta- und alpha-Untereinheit war durch die OMCBehandlung unbeeinflusst. 

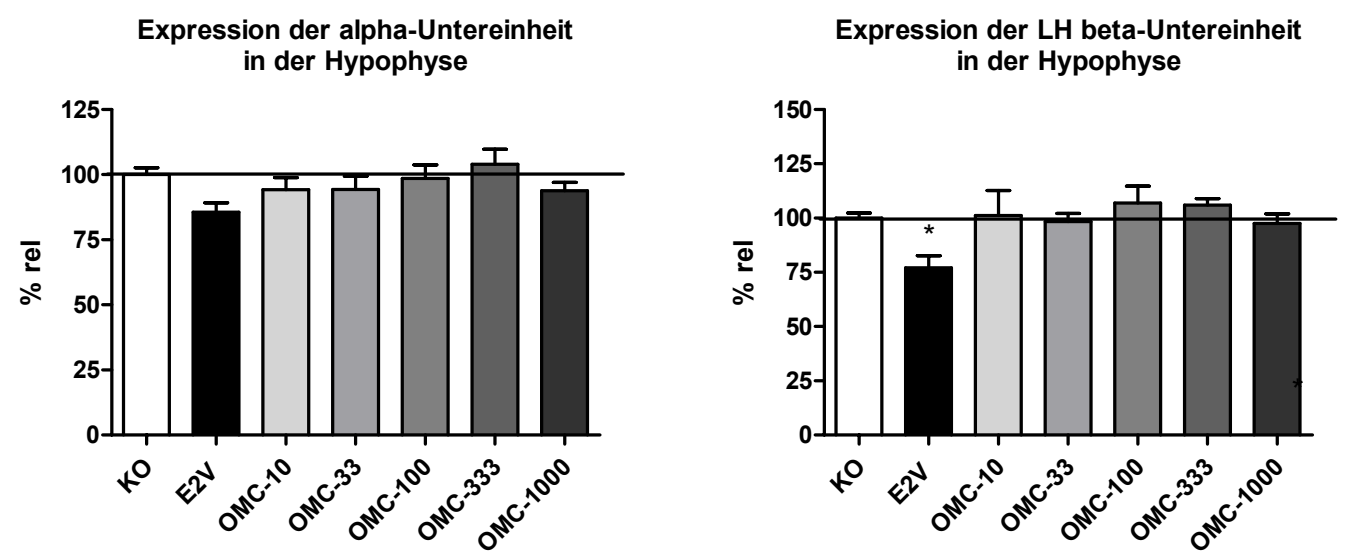

Abb. 33: Genexpression der alpha-Untereinheit und der LH beta-Untereinheit in der Hypophyse nach 5tägiger Behandlung. Die Werte wurden auf die Kontrollgruppe relativiert. * = signifikant gegen Kontrollgruppe.

In Abb. 34 ist die Genexpression der Untereinheit TSH beta in der Hypophyse dargestellt. Die Behandlung mit E2V führte zu einem Absenken der Expression der TSH beta-mRNA signifikant auf $77 \%$. In den OMC-Behandlungsgruppen war keine Tendenz zu erkennen. Erst in der OMC-1000-Gruppe wurde die Genexpression signifikant auf $67 \%$ gesenkt.

TSH beta-Expression in der Hypophyse

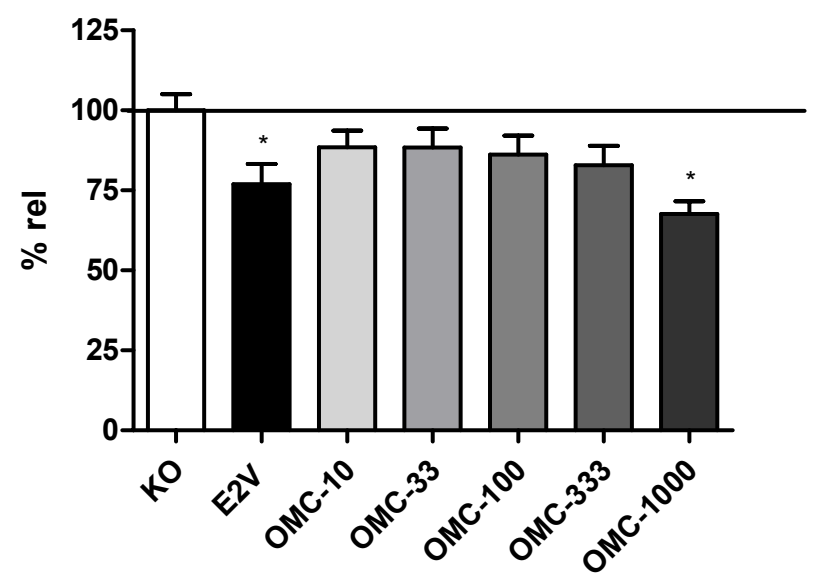

Abb. 34:Genexpression der TSH beta-Untereinheit in der Hypophyse nach 5tägiger Behandlung. Die Werte wurden auf die Kontrollgruppe relativiert. * = signifikant gegen Kontrollgruppe.

\subsubsection{Uterus}

Alle Behandlungsgruppen zeigten eine geringere Genexpression des ER alpha (Abb. 35) im Vergleich zur Kontrollgruppe. Keine der Änderungen war signifikant. Die 
Genexpression in den OMC-Behandlungsgruppen wurde allerdings nicht dosisabhängig reguliert. Der ER beta wird im Uterus organspezifisch durch Estrogene über einen noch nicht aufgeklärten Mechanismus reprimiert. In Abb. 35 ist zu sehen, dass die ER betaGenexpression durch die E2V-Behandlung auf 12 \% der Expression der Kontrollgruppe reprimiert wurde. Die OMC-Behandlungsgruppen zeigten eine dosisabhängige, leicht ansteigende Induktion der ER beta-Genexpression. In der OMC-1000-Gruppe stieg die Genexpression auf $144 \%$ an.
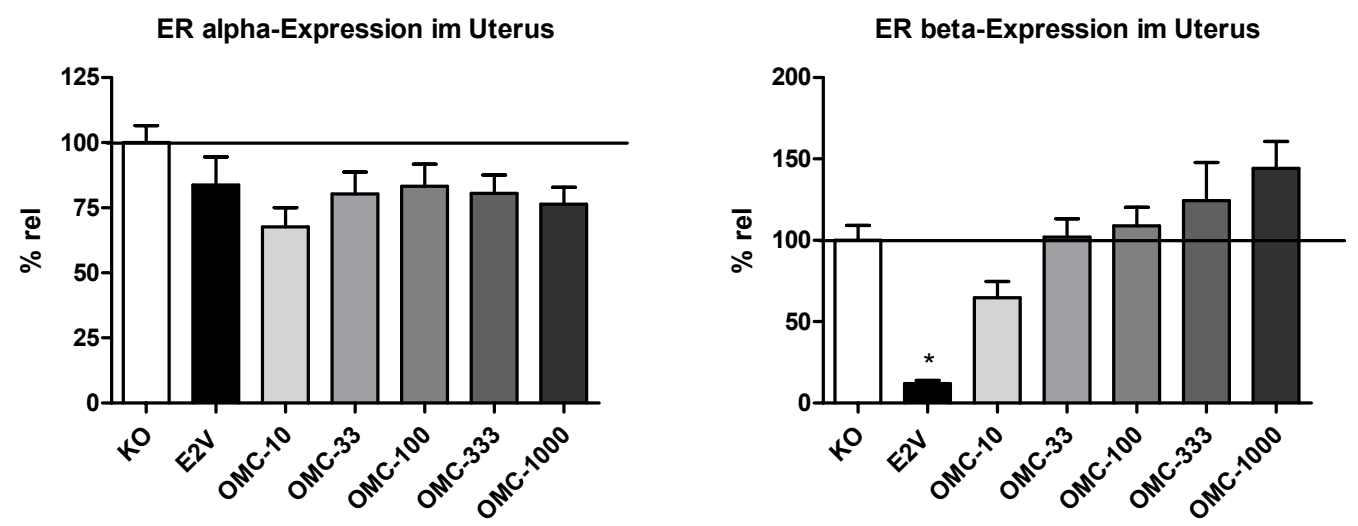

Abb. 35: ER alpha- und ER beta- Genexpression im Uterus nach 5tägiger Behandlung. Die Werte wurden auf die Kontrollgruppe relativiert. * = signifikant gegen Kontrollgruppe.

Das Komplement-Protein 3 kann durch estrogene Substanzen über ein ERE reguliert werden. In der E2V-Gruppe wurde die Genexpression des C3 (Prä-Pro-C3, im folgenden C3) signifikant gegenüber der Kontrollgruppe erhöht (Abb. 36). Die maximale Induktion durch E2V lag bei $16830 \%$. Die Genexpression in den OMCBehandlungsgruppen OMC-10 bis OMC-333 war unverändert. In der OMC-1000Gruppe war die Expression der C3-mRNA signifikant auf 1378 \% angestiegen. Die Genexpression des an der Proliferation des Uterus beteiligten IGF-1 wurde unter E2VEinfluss auf 1094 \% der Kontrollgruppe erhöht. Die Behandlung mit OMC zeigte keine signifikante Änderung der IGF-1 Genexpression. Auch war keine eindeutige Tendenz in der Dosis-Wirkungsbeziehung zu erkennen. 

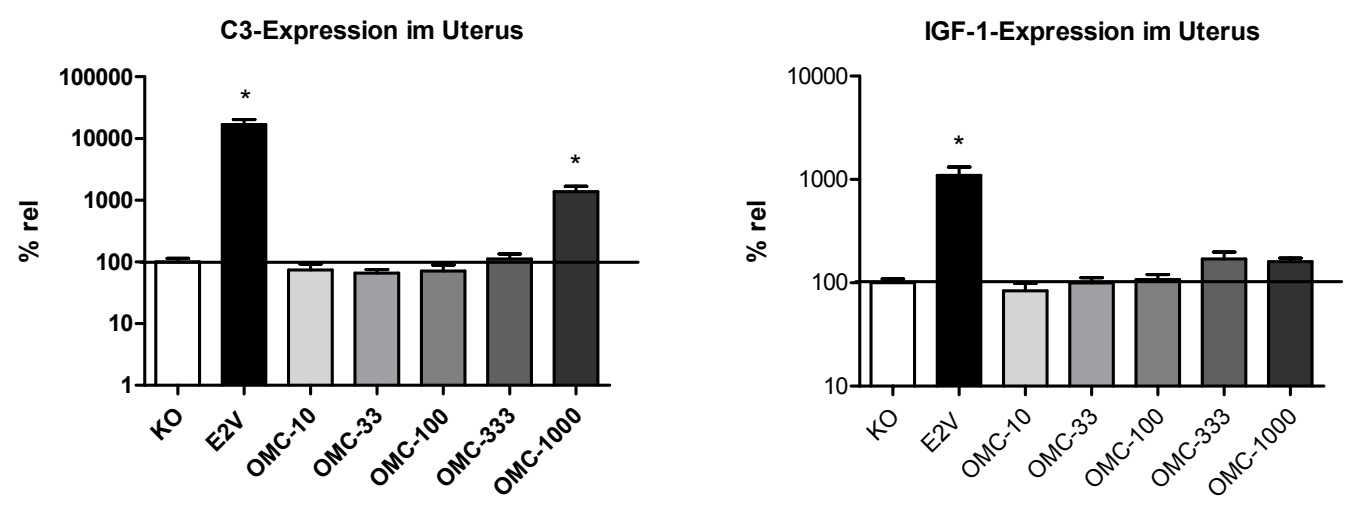

Abb. 36: C3- und IGF-1-Genexpression im Uterus nach 5tägiger Behandlung. Die Werte wurden auf die Kontrollgruppe relativiert. * = signifikant gegen Kontrollgruppe.

\subsubsection{Analyse der Proteinexpression (Western)}

Auf der Proteinebene wurde die Expression des Natrium/Iodid-Symporters und des Thyrotropin-Rezeptors untersucht.

\subsubsection{Natrium/lodid-Symporter (NIS)-Expression}

Die Expression des NIS war auf der Proteinebene durch die Behandlung mit OMC unverändert (Abb. 37).

\section{Proteinexpression des Natrium/lodid-Symporters \\ in der Schilddrüse}

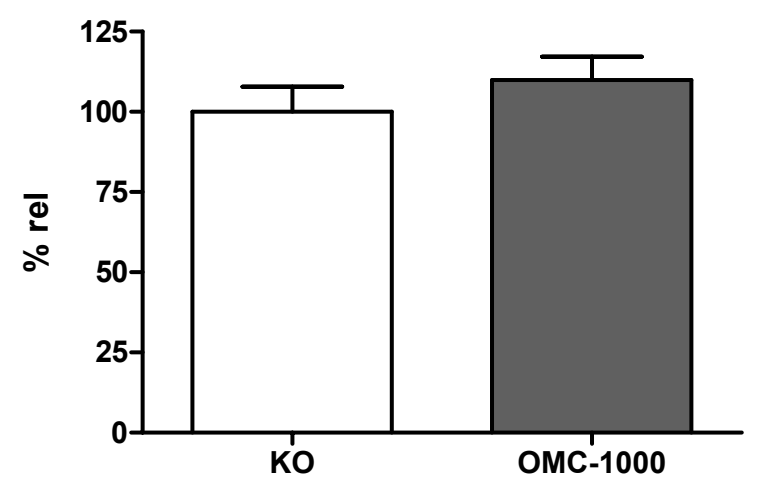

Abb. 37: Proteinexpression des Natrium/Iodid-Symporters (NIS) in der Schilddrüse nach 5tägiger Behandlung. Die Werte wurden auf die Kontrollgruppe relativiert. 


\subsubsection{Thyrotropin-Rezeptor (TSHR)-Expression}

Die Behandlung mit OMC steigerte die Expression des TSHR in der Schilddrüse signifikant auf $144 \%$ im Vergleich zu Kontrollgruppe (Abb. 38).

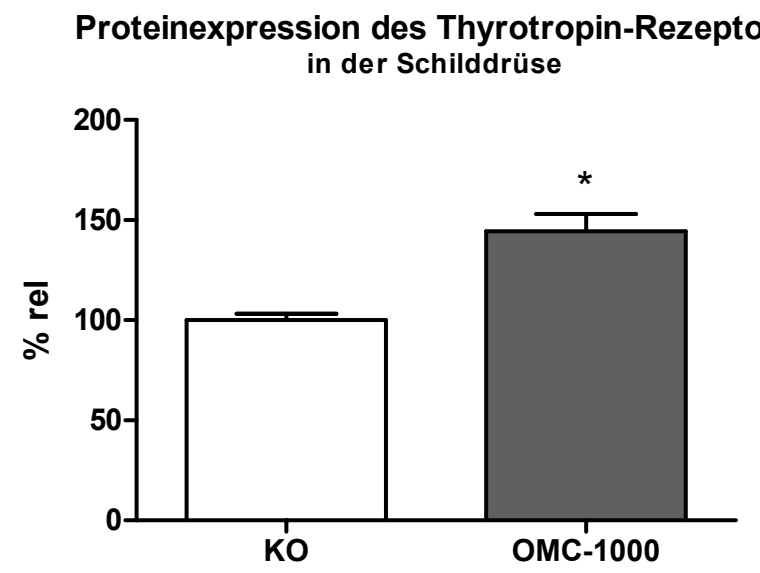

Abb. 38: Proteinexpression des Thyrotropin-Rezeptors (TSHR) in der Schilddrüse nach 5tägiger Behandlung. Die Werte wurden auf die Kontrollgruppe relativiert. * = signifikant gegen Kontrollgruppe.

\subsubsection{Typ I und II 5'Deiodase- und Schilddrüsenperoxidase-Aktivität}

Die Typ I 5'Deiodase (5'DI)-Aktivität wurde durch die Behandlung mit E2V nicht beeinflusst (Abb. 39). Nach der Applikation von OMC war eine dosisabhängige Reduktion der Aktivität der 5'DI zu erkennen. Diese erreichte ein signifikantes Niveau in den Behandlungsgruppen OMC-333 und OMC-1000 mit $72 \%$ bzw. $64 \%$ der Aktivität der Kontrollgruppe.

Die Aktivität der Typ II 5'Deiodase lag größtenteils unterhalb des messbaren Bereichs (Daten nicht gezeigt). 


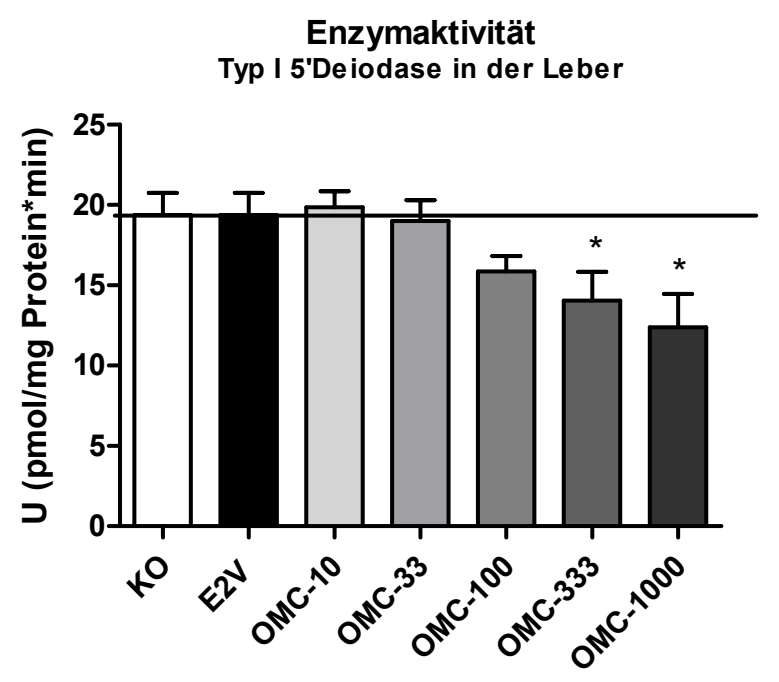

Abb. 39: 5'DI-Aktivität in der Leber nach 5tägiger Behandlung. $*=$ signifikant gegen Kontrollgruppe.

Die Schilddrüsenperoxidase (TPO)-Aktivität wurde durch E2V nicht beeinflusst. In den OMC-Behandlungsgruppen war ebenfalls keine signifikante Veränderung und keine Tendenz zu erkennen.

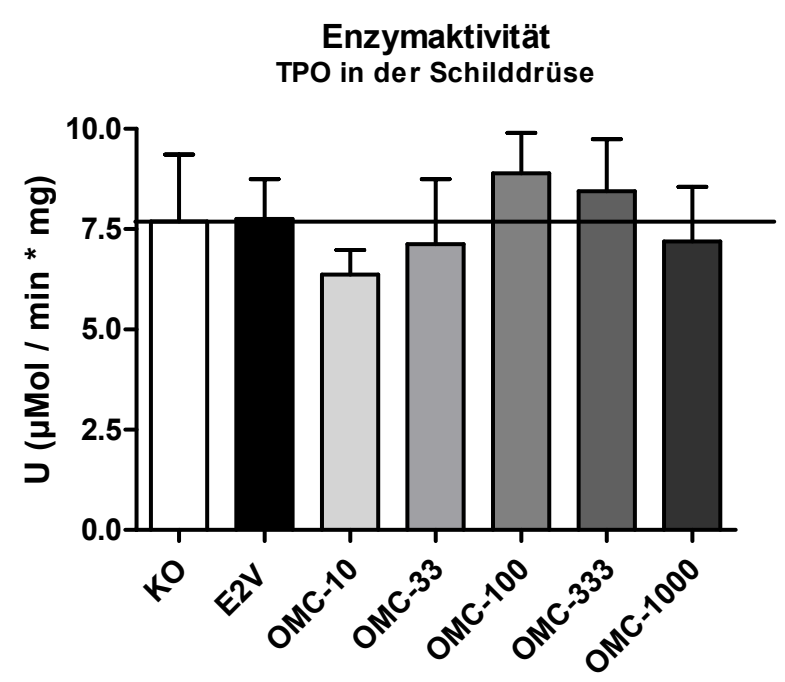

Abb. 40: Aktivität der Schilddrüsenperoxidase (TPO) nach 5tägiger Behandlung. 


\subsubsection{Hypophysen-Primärzellkultur}

Die Behandlung von isolierten Hypophysenzellen mit E2 stimulierte die Sekretion von TSH (Abb. 41). Der Gehalt im Medium stieg signifikant auf $138 \quad \%$ der Lösungsmittelkontrolle. OMC hatte den gleichen Effekt in den Konzentrationen $1 \times 10^{-5} \mathrm{M}$ und $1 \times 10^{-6} \mathrm{M}$, wobei die TSH-Konzentration signifikant auf $130 \%$ und $123 \%$ der Kontrollgruppe anstieg. In der Konzentration $1 \times 10^{-7} \mathrm{M}$ hatte OMC keinen Einfluss auf die TSH-Sekretion. Bei gleichzeitiger Stimulation mit TRH hatte E2 keinen Einfluss auf die Sekretion von TSH. Allerdings zeigte OMC in der Konzentration $1 \times 10^{-5} \mathrm{M}$ weiterhin einen stimulierenden Effekt, auf $123 \%$ der Kontrollgruppe, auf die TSH-Sekretion ins Medium.
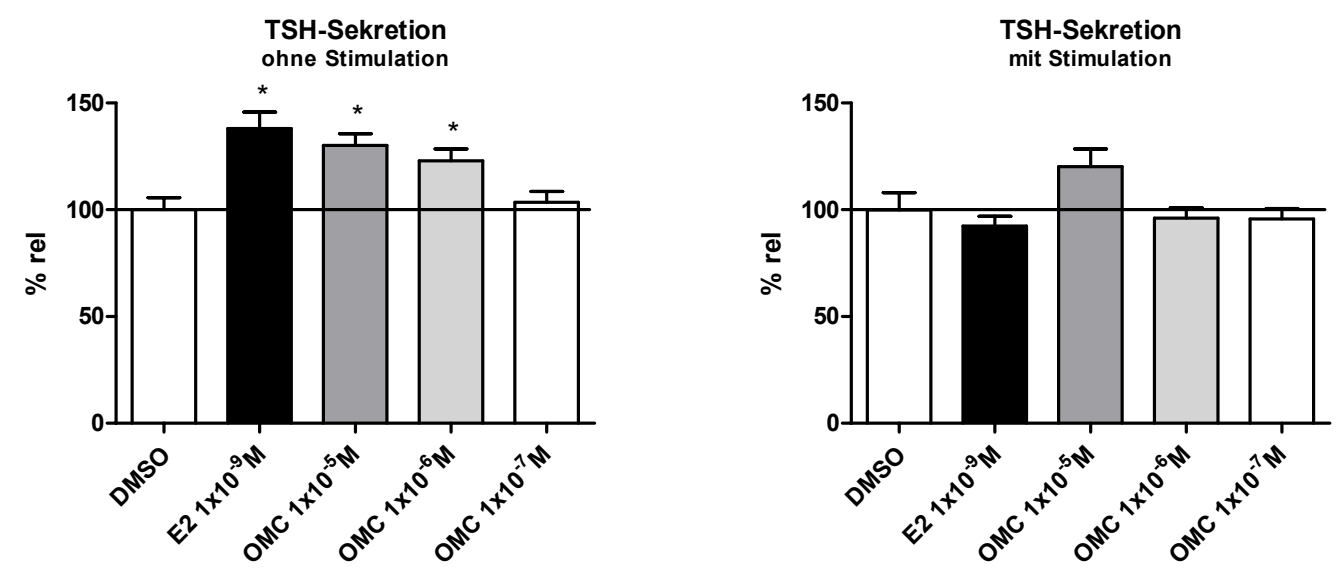

Abb. 41: Hypophysenprimärzellkultur. Inkubation der Zellen links ohne TRH-Stimulation und rechts mit TRH-Stimulation. Die Werte wurden auf die Kontrollgruppe relativiert. * = signifikant gegen Kontrollgruppe.

Der ER alpha und beta-Antagonist ICI 182,780 allein hatte keinen Einfluss auf die TSH-Sekretion von Hypophysenzellen in der verwendeten Konzentration von $1 \times 10^{-6} \mathrm{M}$ (Abb. 42). Die Induktion durch die E2-Behandlung konnte durch ICI 182,780 vollständig inhibiert werden. Auch die Induktion der TSH-Sekretion durch die OMCBehandlung bei einer Konzentration von $1 \times 10^{-5} \mathrm{M}$ und $1 \times 10^{-6} \mathrm{M}$ wurde durch die Koinkubation mit ICI 182,780 vollständig aufgehoben. 
TSH-Sekretion

Einfluss der Koinkubation mit ICI 182,780

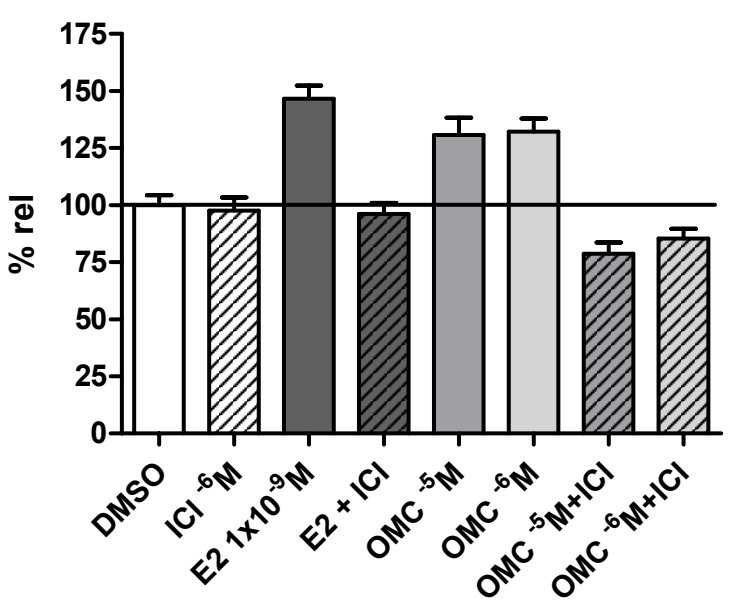

Abb. 42: Einfluss von ICI 182,780 auf die TSH-Sekretion von TSH in der Hypophysenprimärzellkultur. Die Werte wurden auf die Kontrollgruppe relativiert.

Im MTT-Test zeigte OMC keinen Einfluss auf die Viabilität der Zellen in den in der Hypophysenzellkultur getesteten Konzentrationen.

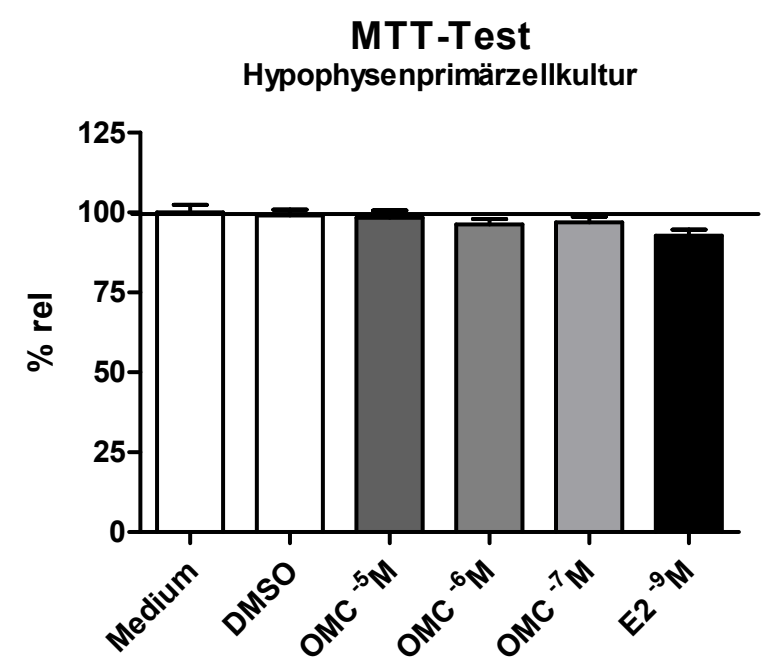

Abb. 43: MTT-Test. 


\subsection{Dosis-Wirkungsbeziehung}

Aus den gewonnen Daten wurden die Parameter mit einer dosisabhängigen Veränderung in OMC-Behandlungsgruppen mit Hilfe des PROAST-Programms ausgewertet. In einer nicht-linearen Regression wurden die Modelle ermittelt, welche zur weiteren Berechnung von Schwellenwerten benutzt wurden.

\subsubsection{Hypothalamus}

OMC hatte auf keine im Hypothalamus gemessenen Parameter einen Einfluss.

\subsubsection{Hypophyse}

Für die TERP1-Genexpression in der Hypophyse, den TSH-Serumspiegel und die TSH beta-Genexpression in der Hypophyse wurden folgende Gleichungen ermittelt:

- $\mathrm{F}(\mathrm{x})=90,44 * \exp \left(0,002636^{*} \mathrm{x}^{\wedge} 0,9391\right)$

- $\mathrm{F}(\mathrm{x})=1,909 *(0,4362-(0,4362-1) \exp (-0,007765 \mathrm{x}))$

- $\mathrm{F}(\mathrm{x})=91,92 *(0,6533-(0,6533-1) \exp (-0,001594 \mathrm{x}))$
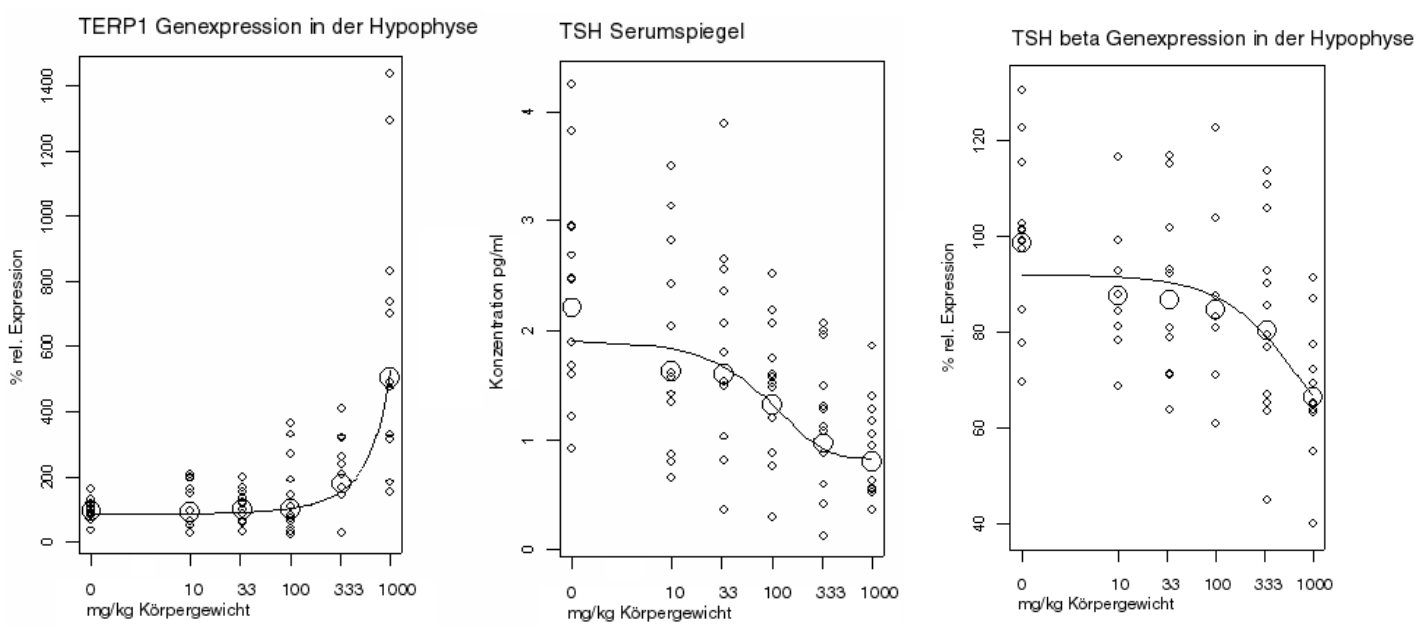

Abb. 44: Dosis-Wirkungsbeziehung der TERP1-Genexpression, des TSH-Serumspiegels und der TSH beta-Genexpression. Nicht-lineare Regression der Daten. Kleine Kreise entsprechen den Einzelmesswerten, große Kreise entsprechen dem Gruppenmittelwert.

\subsubsection{Uterus}

Für das Uterusgewicht, die Vaginalzytologie, die C3-Genexpression und die ER betaGenexpression im Uterus wurden folgende Gleichungen ermittelt: 
- $\mathrm{F}(\mathrm{x})=0,02958 * \exp \left(0,0004227 * \mathrm{x}^{\wedge} 1\right)$

- $\mathrm{F}(\mathrm{x})=0,9999 * \exp \left(0,0004805^{*} \mathrm{x}^{\wedge} 1\right)$

- $\mathrm{F}(\mathrm{x})=92,57 * \exp (0,002116 \mathrm{x})$

- $\mathrm{F}(\mathrm{x})=82,88 *(1,839-(1,839-1) \exp (-0,001236 \mathrm{x}))$
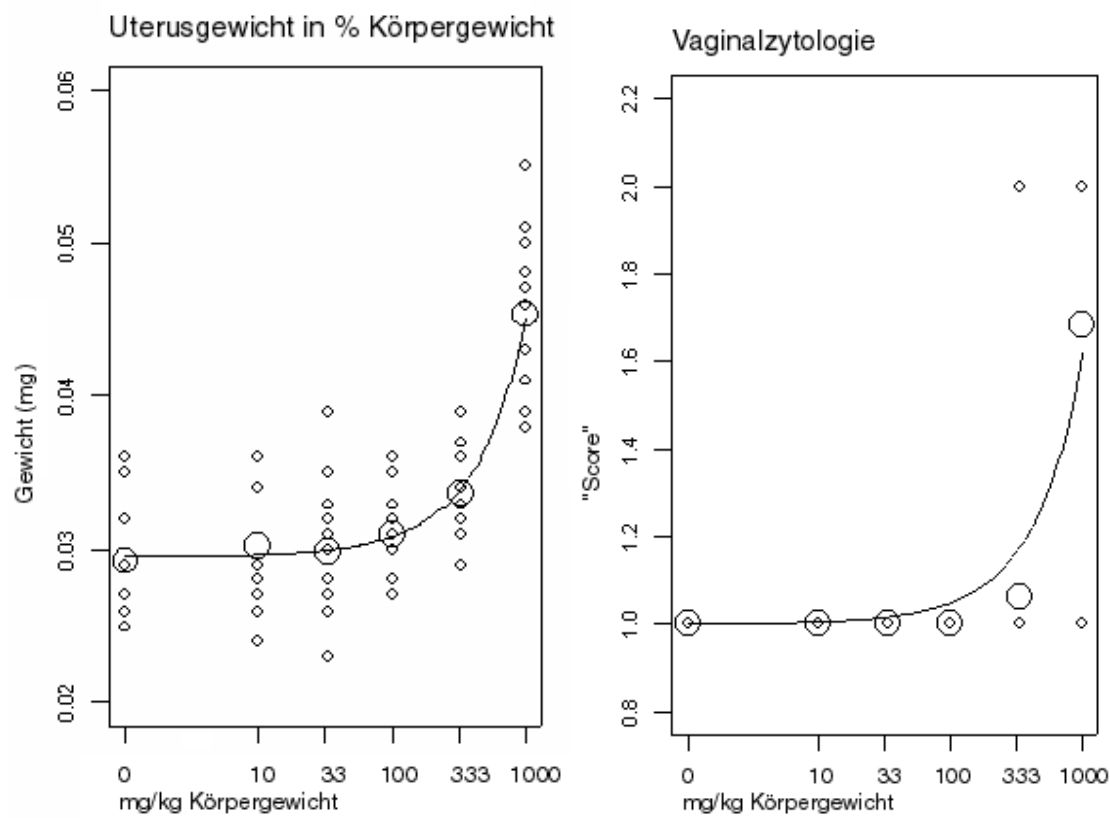

C3 Genexpression im Uterus

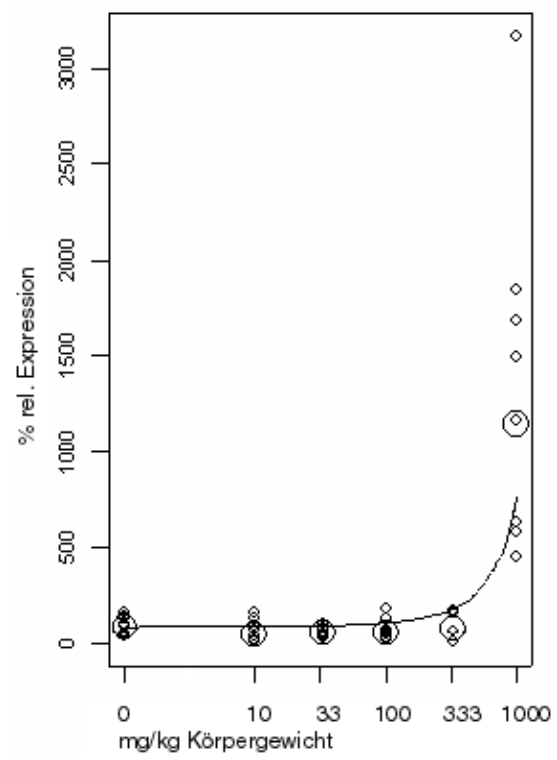

ER beta Genexpression im Uterus

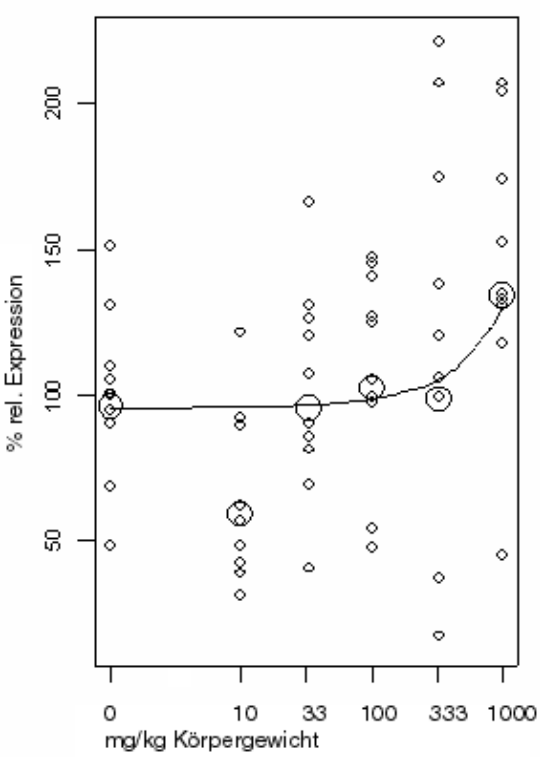

Abb. 45: Dosis-Wirkungsbeziehung des Uterusfeuchtgewichtes, der Vaginalzytologie und der C3und ER beta-Genexpression. Nicht-lineare Regression der Daten. Kleine Kreise entsprechen den Einzelmesswerten, große Kreise entsprechen dem Gruppenmittelwert. 


\subsubsection{Schilddrüse}

Für den T3- und den freien T3-Serumspiegel wurden folgende Gleichungen ermittelt:

- $\mathrm{F}(\mathrm{x})=2546,63 *(0,6460-(0,4660-1) \exp (-0,002923 \mathrm{x}))$

- $\mathrm{F}(\mathrm{x})=4,155^{*}(0,7574-(0,7574-1) \exp (-0,004069 \mathrm{x}))$

T3 Serumspiegel

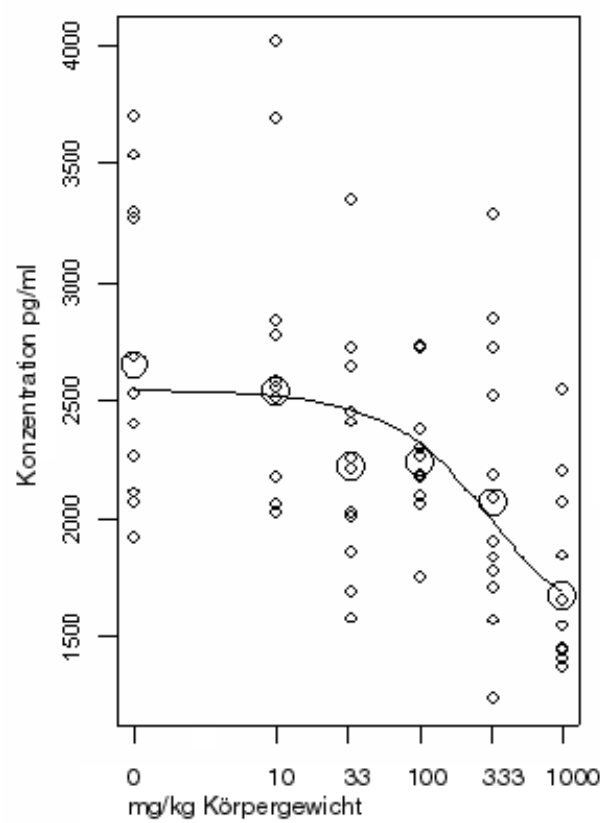

fT3 Serumspiegel

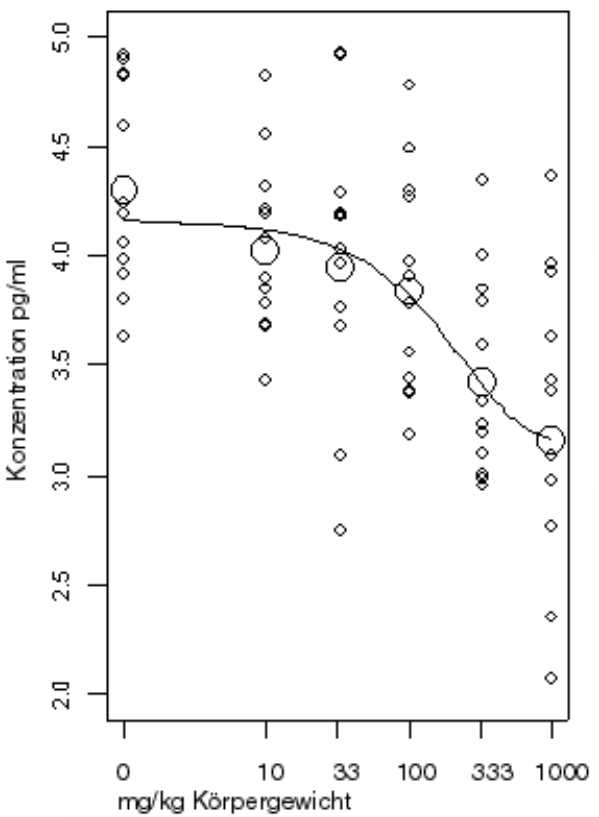

Abb. 46: Dosis-Wirkungsbeziehung der T3- und fT3-Serumspiegel. Nicht-lineare Regression der Daten. Kleine Kreise entsprechen den Einzelmesswerten, große Kreise entsprechen dem Gruppenmittelwert.

Für den T4- und den freien T4-Serumspiegel wurden folgende Gleichungen ermittelt:

- $\mathrm{F}(\mathrm{x})=47432,57 * \exp \left(-0,000562 * \mathrm{x}^{\wedge} 0,9999\right)$

- $\mathrm{F}(\mathrm{x})=29,5536^{*} \exp \left(0,000115^{*} \mathrm{x}^{\wedge} 0,9999\right)$ 

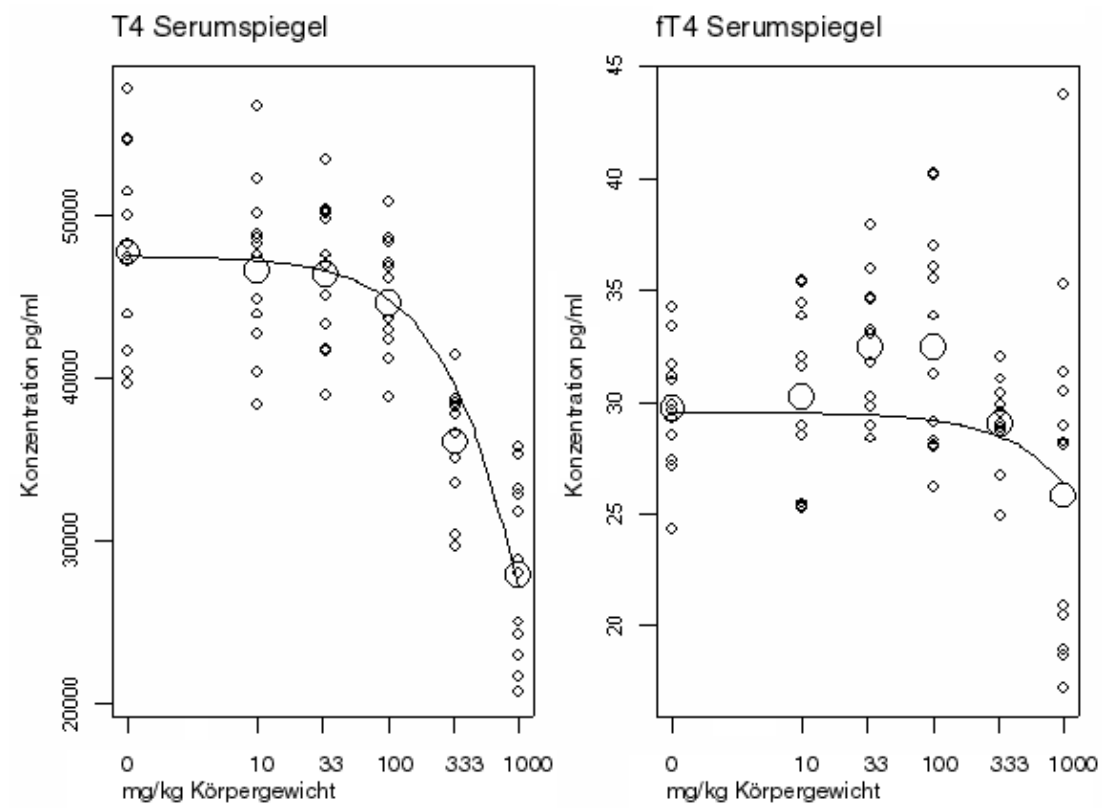

Abb. 47: Dosis-Wirkungsbeziehung der T4- und fT4-Serumspiegel. Nicht-lineare Regression der Daten. Kleine Kreise entsprechen den Einzelmesswerten, große Kreise entsprechen dem Gruppenmittelwert.

\subsubsection{Leber}

Für die 5'DI-Aktivität in der Leber wurde folgende Gleichung ermittelt:

- $\mathrm{F}(\mathrm{x})=19,39 *(0,5543-(0,5543-1) \exp (-0,007475 \mathrm{x}))$

$5^{\prime}$ dl Aktivität in der Leber

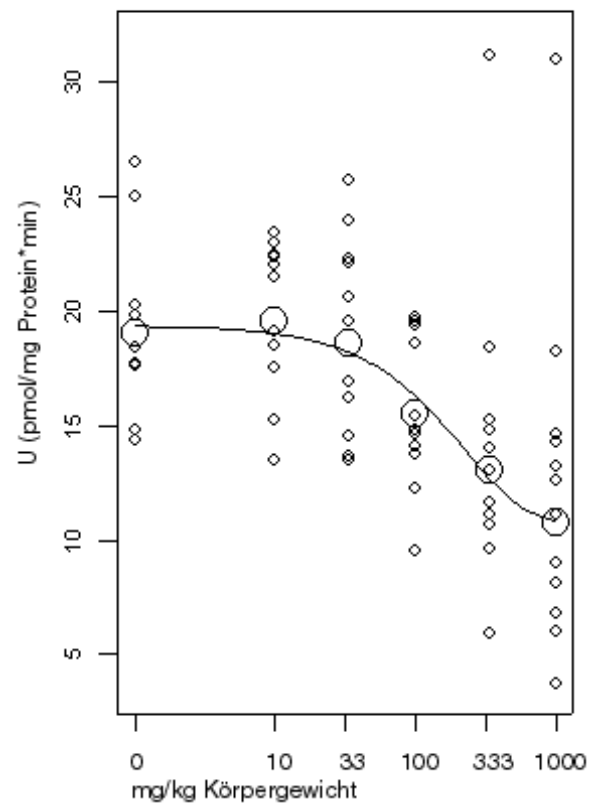

Abb. 48: Dosis-Wirkungsbeziehung der 5'DI-Aktivität. Nicht-lineare Regression der Daten. Kleine Kreise entsprechen den Einzelmesswerten, große Kreise entsprechen dem Gruppenmittelwert. 


\subsubsection{Zusammenfassung}

Die folgende Tabelle (Tab. 7) fasst die Änderungen der im in vivo-Versuch erhaltenen Ergebnisse mit den NOAEL/LOAEL-Werten und den CED-Werten für die jeweiligen CES-Werte von einer Standardabweichung und einem Standardfehler des Mittelwertes der Kontrollgruppe zusammen.

Tab. 7: Zusammenfassung der Ergebnisse der Dosis-Wirkungsbeziehung.

\begin{tabular}{|c|c|c|c|c|}
\hline Parameter & Estradiol & $\mathrm{OMC}$ & $\begin{array}{l}\text { NOAEL/LOAEL } \\
\text { mg/kg Körpergewicht }\end{array}$ & $\begin{array}{l}\text { CED (SD/SEM) } \\
\text { mg/kg Körpergewicht }\end{array}$ \\
\hline $\mathrm{MBH}, \mathrm{ER} \mathrm{a} / \mathrm{b}$ & $\Uparrow$ & $\Leftrightarrow$ & - & - \\
\hline MBH, ERR 1/3 & 介 & $\Leftrightarrow$ & - & - \\
\hline MBH, TRH & $\Leftrightarrow$ & $\Leftrightarrow$ & - & - \\
\hline Hypophyse, Terp1 & 介 & 介 & $333 / 1000$ & $146 / 53$ \\
\hline Hypophyse, alpha-Untereinheit & $\Downarrow$ & $\Leftrightarrow$ & - & - \\
\hline Hypophyse, LH beta & $\Downarrow$ & $\Leftrightarrow$ & - & - \\
\hline Hypophyse, TSH beta & $\Downarrow$ & $\Downarrow$ & $333 / 1000$ & $439 / 98$ \\
\hline Serum, Prolaktin & $\Uparrow$ & $\Leftrightarrow$ & - & - \\
\hline Serum, GH, FSH & $\Leftrightarrow$ & $\Leftrightarrow$ & - & - \\
\hline Serum, LH & $\Downarrow$ & $\Leftrightarrow$ & - & - \\
\hline Serum, TSH & $\Uparrow$ & $\Downarrow$ & $333 / 1000$ & $176 / 31$ \\
\hline Vaginalzytologie & 介 & $\Uparrow$ & $333 / 1000$ & k.A., da quantal \\
\hline Uterusfeuchtgewicht & $\Uparrow$ & $\Uparrow$ & $333 / 1000$ & $268 / 81$ \\
\hline Uterus, C3 & 介 & $\Uparrow$ & $1000 /-$ & $182 / 66$ \\
\hline Uterus, ER beta & $\Downarrow$ & 介 & $1000 /-$ & $816 / 276$ \\
\hline Serum, T3 & $\Downarrow$ & $\Downarrow$ & $333 / 1000$ & $343 / 69$ \\
\hline Serum, fT3 & $\Leftrightarrow$ & $\Downarrow$ & $100 / 333$ & $143 / 34$ \\
\hline Serum, T4 & $\Leftrightarrow$ & $\Downarrow$ & $100 / 333$ & $234 / 65$ \\
\hline Serum, fT4 & $\Uparrow$ & $\Downarrow$ & $1000 /-$ & $848 / 238$ \\
\hline Leber, 5’Deiodase Typ I & $\Leftrightarrow$ & $\Downarrow$ & $100 / 333$ & $145 / 39$ \\
\hline
\end{tabular}

In der Tabelle sind die Tendenzen der durch die E2V- und OMC-Behandlung verursachten Effekte zusammengefasst. NOAEL und LOAEL wurden aus der Analyse mittels ANOVA abgeleitet. Der Schwellenwert (CED) wurde für die Effektgrößen (CES) einer Standardabweichung (SD) sowie eines Standardfehlers des Mittelwertes (SEM) der Kontrollgruppe angegeben. Die Daten aus der Vaginalzytologie sind nicht mit dem Programm PROAST ausgewertet worden, da es sich um quantale Daten handelt. 
Die statistische Analyse ergab „no observed adverse effect level“ (NOAEL)- und „lowest observed adverse effect level“ (LOAEL)-Werte, wobei NOAEL die höchste Dosis ist, welche keinen signifikanten Effekt aufweist, und LOAEL die niedrigste Dosis ist, welche einen signifikanten Effekt aufweist. Aus den Modellen der nicht-linearen Regression wurden für die jeweiligen kritischen Effektgrößen (CES) die dazugehörigen kritischen Effektdosen (CED) ermittelt, wobei CES $=\mathrm{f}(\mathrm{CED}) / \mathrm{f}(0)-1$.

\subsection{HPLC-Analyse}

\subsubsection{HPLC}

Die Chromatogramme der Seren mit OMC behandelten Tiere ergaben einen Peak, welcher nicht im Kontrollserum vorkam und die gleiche Retentionszeit aufwies wie der OMC-Standard (Abb. 50). Unter der Annahme, dass es sich hierbei um die Testsubstanz handelte, wurde anhand einer Standardkurve die OMC-Serumkonzentration der Versuchstiere bestimmt (Abb. 49). Das Detektionslimit (Signal zu Hintergrund 3:1) lag bei 3,5 $\mu \mathrm{g} / \mathrm{ml}$, das Quantifizierungslimit (Signal $\mathrm{zu}$ Hintergrund 10:1) lag bei $15,3 \mu \mathrm{g} / \mathrm{ml}$. In der OMC-1000-Gruppe wurden Konzentrationen von $296 \mu \mathrm{g} / \mathrm{ml}$ gemessen. Das entspricht bei einem Molekulargewicht von 290,4 g/mol für OMC einer Konzentration von 1,02 mM. Die nicht-lineare Regression der Uterusgewichte im Bezug zu den Serumkonzentration zeigt eine signifikante Korrelation.
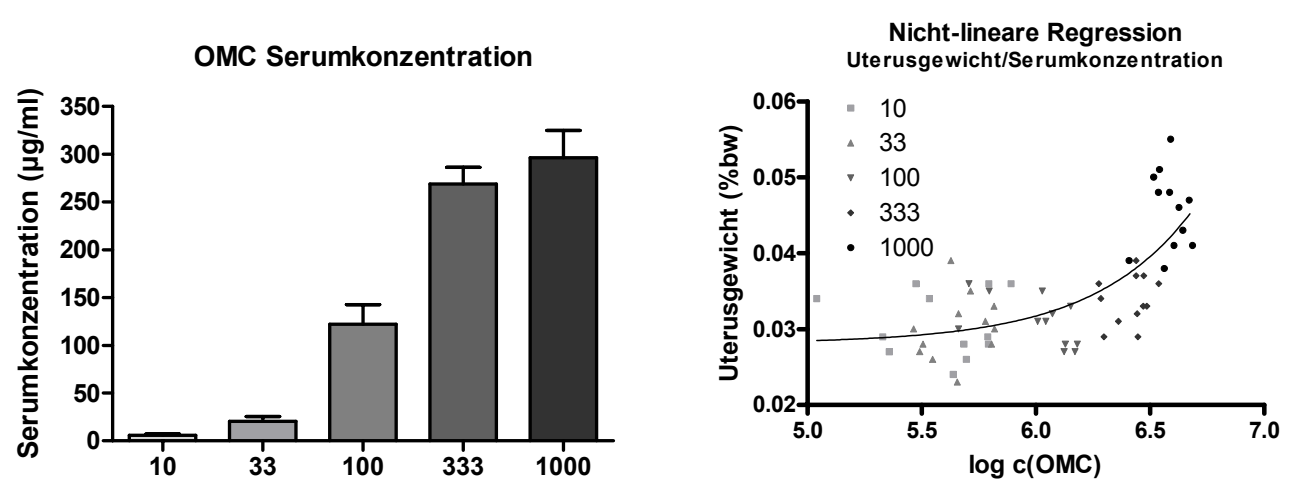

Abb. 49: Serumkonzentrationen von OMC. Links ist die Serumkonzentration der OMCBehandlungsgruppen aufgetragen. Die rechte Grafik zeigt die Korrelation der Uterusgewichte und der Serumkonzentration in einer nicht-linearen Regression. 


\subsubsection{ESI DAD HPLC-MS}

Das Chromatogramm der Seren der Tiere aus den OMC-Behandlungsgruppen wies, zusätzlich zum Substanzpeak von OMC bei der Retentionszeit 12,73 min, zwei Peaks bei den Retentionszeiten 11,12 min und 12,35 min auf (Abb. 50). Es war nicht möglich, diese Peaks aus dem Serum durch die Hydrolyse mit Helix pomatia-Glucuronidase zu eliminieren (Daten nicht gezeigt). Deshalb wurde versucht, die Massen der möglichen Metabolite mit Hilfe der ESI DAD HPLC-MS zu bestimmen (Abb. 50). Die positive Ionisierung der Serumproben erbrachte keine auswertbaren Ergebnisse (Daten nicht gezeigt). In der negativen Ionisierung (ESI (-)) wurde für den Substanzpeak mit der Retentionszeit von 12,35 min die Masse $320 \mathrm{~g} / \mathrm{mol}$ und für den Substanzpeak mit der Retentionszeit von 12,73 min die Masse $306 \mathrm{~g} / \mathrm{mol}$ gemessen (in der MS Messung bei 12,17 min und 12,50 min). Für den Peak bei 11,25 min konnte keine Masse bestimmt werden.

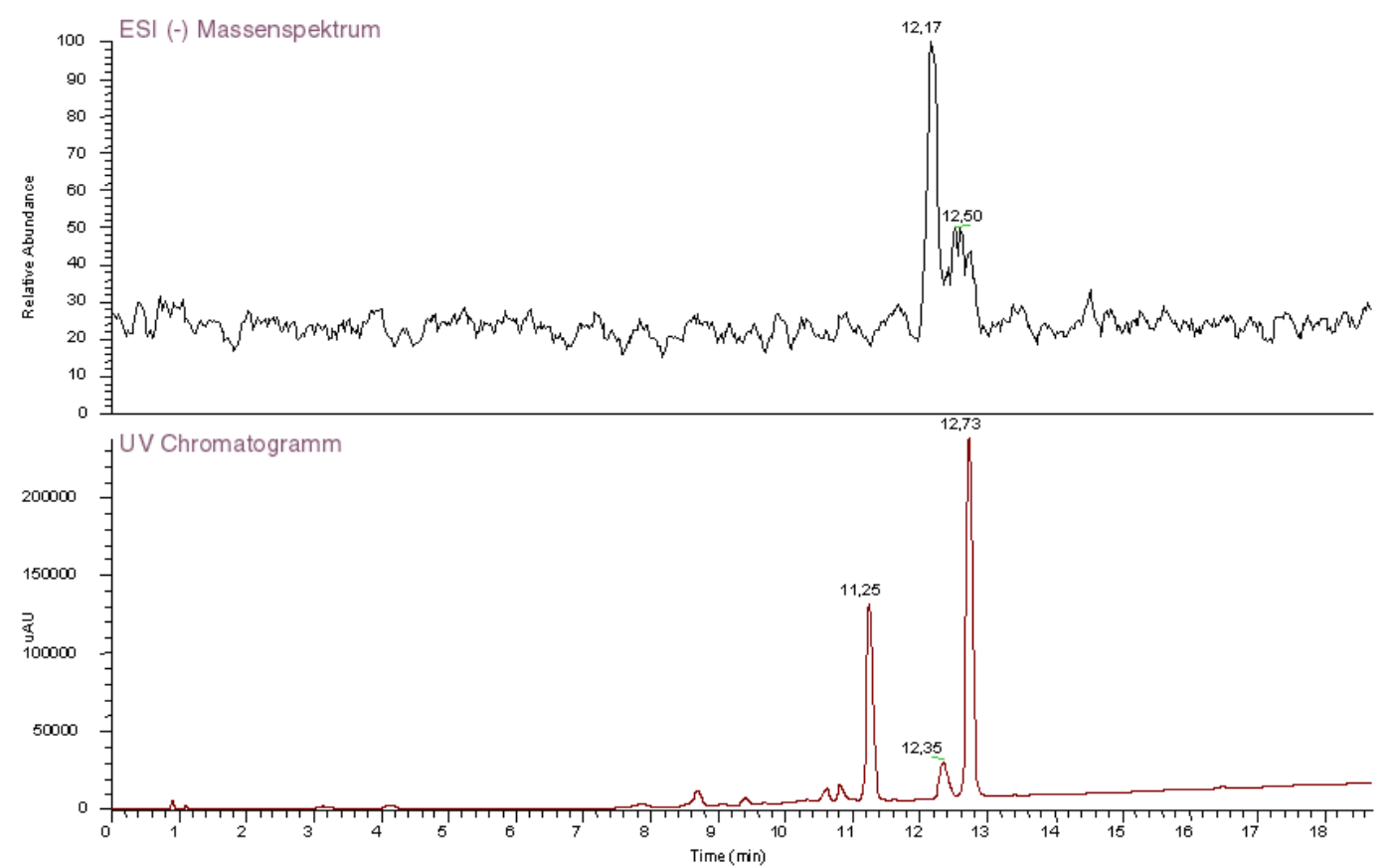

Abb. 50: MS- und UV-Chromatogramme des Serums eines OMC-1000-Tieres. Oben: ESI (-) MS Chromatogramm. Unten: HPLC DAD-Chromatogramm.

\subsubsection{API GC-MS/MS}

Mit dieser Methode erhaltene Muster aus Fragmenten sind substanzspezifisch und können anhand von Datenbanken der Substanz zugeordnet werden. OMC als Standard 
in wasserfreiem Methanol konnte mit dieser Methode mit einer Wahrscheinlichkeit von 0,9554 aus Datenbanken identifiziert werden. Im Serum der OMC-1000-Gruppe konnte allerdings kein OMC nachgewiesen werden. Der Metabolit mit derselben Retentionszeit wie der Standard konnte mit dieser Methode nicht identifiziert werden (Daten nicht gezeigt). Zudem wurden diverse Bruchstücke der Reinsubstanz identifiziert. In Abb. 51 sind einige Beispiele abgebildet.<smiles>COC(=O)c1ccc(OC)cc1</smiles>

Methyl 4-methoxybenzoate<smiles>CCCCC(CC)C(=O)O</smiles>

2-Ethylhexanoat<smiles>COC(=O)CCc1ccc(OC)cc1</smiles>

Benzenepropanoat, 4-methoxymethylester Methyl p-methoxycinnamat<smiles>COC(=O)/C=C/c1ccc(OC)cc1</smiles>

Abb. 51: Formeln der Fragmente, die mittels API GC MS/MS im Serum gefunden wurden. 


\section{Diskussion}

In dieser Arbeit konnte gezeigt werden, dass OMC als EAC und darüber hinaus sogar als ED anzusehen ist. Die in vitro- und in vivo-Analysen zeigen deutlich, dass sich die Aktivität von OMC dabei von der Wirkung von E2 unterscheidet. OMC ist kein reines Estrogen, sondern zeigt eine SERM-Aktivität..

Die Ergebnisse zeigen zudem, dass der uterotrophe Assay nicht ausreicht, um eine multiorgane SERM-Wirkung, wie sie in diesem Fall gefunden wurde, zu untersuchen. Es wurden zudem zusätzliche nicht ER-vermittelte Effekte auf die Hypophyse in der HPT-Achse aufgedeckt.

Aus den Daten der in vivo-Untersuchungen wurden Dosis-Wirkungsbeziehungen erstellt, auf deren Grundlage eine Risikoabschätzung durchgeführt werden konnte.

Bei der Analyse der Metabolisierung von OMC hat sich gezeigt, dass OMC nicht über einen klassischen Weg der Biotransformation metabolisiert wurde.

\subsection{In vitro-Analyse der Estrogenität von OMC}

OMC ist in 2001 durch die Arbeit von Schlumpf et al. in den Verdacht geraten, eine endokrin aktive Chemikalie zu sein (Schlumpf et al. 2001). OMC verursachte bei immaturen Ratten einen uterotrophen Effekt und induzierte das Wachstum von MCF-7Zellen im E-screen. In einem in vitro-Transaktivierungsassay induzierte OMC die ER alpha-vermittelte Genexpression (Schreurs et al. 2002).

Die in dieser Arbeit erhaltenen in vitro-Daten zur estrogenen Aktivität von OMC ergeben dagegen ein sehr heterogenes Bild und geben erste Hinweise auf eine differenzierte, von E2 deutlich unterschiedliche Wirkung von OMC.

\subsubsection{Rezeptorbindungsassay}

Die Ergebnisse im Rezeptorbindungsassay zeigen bei den eingesetzten Konzentrationen nur eine geringe Verdrängung von E2 am ER beta und keine Verdrängung am ER alpha. Bei höheren Konzentrationen ist das Risiko einer unspezifischen Verdrängung zu hoch, weshalb OMC bei höheren Konzentrationen nicht getestet wurde.

In einer aktuellen Arbeit (Gomez et al. 2005) zeigt OMC eine schwache Transaktivierung in einem Reportergenassay über den ER alpha bei einer Konzentration von $1 \times 10^{-5} \mathrm{M}$ bis $1 \times 10^{-6} \mathrm{M}$, während über den ER beta keine Transaktivierung 
stattfindet. Der Transaktivierungsassay scheint sensitiver $\mathrm{zu}$ sein als der Rezeptorbindungsassay, was auch von Korach und McLachlan postuliert wurde (Korach et al. 1995). Die Ergebnisse aus dem Reportergenassay von Gomez et al. sind somit $\mathrm{zu}$ den Ergebnissen aus dem Rezeptorbindungsassay in dieser Arbeit entgegengesetzt.

\subsubsection{Hypothalamus-Zellkultur}

Der Hypothalamus reagiert im intakten Organismus auf einen steigenden Estrogenspiegel mit einer erhöhten GnRH-Sekretion (positive Rückkopplung) als auch mit einem Absenken der GnRH-Sekretion (negative Rückkopplung) in Abhängigkeit verschiedener Faktoren wie dem Zeitpunkt der Untersuchung, der Behandlungsdauer, der Kastrationsdauer und der E2-Dosis. Die negative Rückkopplungsreaktion zeigt sich auch in vitro in der Zellkultur an GT1-7-Zellen (Bowe et al. 2003).

Mit einer Belastungszeit von 6 Stunden konnte in der vorliegenden Arbeit für E2, bei einer Konzentration von $1 \times 10^{-9} \mathrm{M}$, diese Rückkopplungsreaktion gezeigt werden. Nach der Behandlung mit E2 wurde in der Hypothalamus-Zellkultur eine Hemmung der Sekretion auf $54 \%$ der Kontrollgruppe erreicht. In der Literatur wurde eine vergleichbare Repression der Genexpression von Pro-GnRH auf $50 \%$ der Kontrollgruppe in Zytotrophoblasten (Zellen der Plazenta), bei einer Belastung durch $1 \times 10^{-8}$ M E2, beschrieben (Wong et al. 2004).

Die hypothalamische Zelllinie GT1-7 reagiert auf OMC, bei einer Konzentration von $1 \times 10^{-5} \mathrm{M}$, im Gegensatz zur Positivkontrolle E2, mit einer vermehrten GnRH-Sekretion ins Kulturmedium. Die Sekretion steigt auf fast $450 \%$ an. Die GnRH-Produktion in GnRH-Neuronen in vivo sowie die estrogene Induktion und Repression ist abhängig von der Position im Hypothalamus, von der Tageszeit sowie von hormonellen Einflüssen (Herbison 1998). In vitro wurde gezeigt, dass der Promotor durch Estrogene reguliert wird (Dong et al. 1996; Roy et al. 1999; Wierman et al. 1992). Eine Arbeit zeigte, dass diese Regulation in Abhängigkeit zur intrazellulären ER alpha-Konzentration steht (Chen et al. 2001). Andere Arbeiten hingegen zeigten, dass in GnRH-Neuronen keine Steroidhormon-Rezeptoren exprimiert werden (Herbison et al. 1995; Lehman et al. 1993; Skinner et al. 2001). Allerdings wurde die mRNA beider ERs in GnRH-Neuronen gefunden (Skynner et al. 1999). Neuere Arbeiten konnten auch das Protein beider 
Rezeptoren in $80 \%$ der GnRH-Neuronen der Ratte detektieren (Hrabovszky et al. 2001; Legan et al. 2003). Bei der Untersuchung der Rolle des ER beta bei der GnRHRegulation stellte sich heraus, dass der ER beta auf den GnRH-Promotor eine konstitutive Aktivität entfaltet, die durch ER-Liganden gehemmt werden konnte (Pak et al. 2006). Auch in vitro konnte eine konstitutive Aktivität des ER beta auf einen minimalen Promotor mit einem ERE und einer AP-1-Bindestelle (ein Koaktivator) festgestellt werden (Pak et al. 2005). Die Autoren vermuten darin den Mechanismus der negativen Rückkopplung der GnRH-Sekretion durch Steroidhormone. Die konstitutive ER beta-Aktivität welche über EREs auf die GnRH-Genexpression ausgeübt wird, wird durch ER-Liganden gehemmt. Diese Hypothese wird auch dadurch gestützt, dass der LH-Serumspiegel in ER beta-knockout-Mäusen erhöht ist und nicht durch eine Behandlung mit E2 supprimiert wird (Dorling et al. 2003). Die Induktion der GnRHSekretion in GT1-7-Zellen könnte demnach ein SERM-Effekt der Testsubstanz OMC auf den ER beta sein, wobei die konstitutive Aktivität gesteigert und nicht gehemmt wird. Ein indirekter Effekt über die Regulation der ER beta-Genexpression wurde durch die fehlende Modulation der ER beta-Expression durch OMC ausgeschlossen. Es ist ausgeschlossen, dass ein SERM-Effekt auf den ER alpha die Expression des GnRH induziert, da der GnRH-Promotor nicht über klassische EREs verfügt, sondern über neue ER beta-spezifische half-site EREs (Pak et al. 2006).

Dieses Ergebnis lässt eine Wirkung von OMC innerhalb der HPG-Achse vermuten, die nicht dem Bild entspricht, das E2 verursacht.

\subsubsection{E-Screen}

Der E-screen, ein etablierter screening-Assay (Soto et al. 1991), zeigt hier für OMC keinen estrogenen Effekt auf das Wachstum der MCF-7-Zellen im Bereich von 1x10 ${ }^{-5}$ $\mathrm{M}$ bis $1 \times 10^{-9} \mathrm{M}$. Schlumpf et al., hingegen konnten bei Konzentrationen von $1 \times 10^{-5} \mathrm{M}$ bis $5 \times 10^{-6} \mathrm{M}\left(\mathrm{EC} 50=2,5 \times 10^{-6} \mathrm{M}\right)$ eine deutliche Zunahme im Wachstum der Zellen messen. Auf die Positivkontrolle E2 reagiert der in der vorliegenden Arbeit verwendete Assay einwandfrei, auch eine Wiederholung brachte kein anderes Ergebnis. Die Induktion der Proliferation von MCF-7-Zellen durch Estrogene ist abhängig von der IGF-1-Induktion über den ER alpha (Zhang et al. 2005). Das wird dadurch bestätigt, dass in ER alpha-knockout-Mäusen die IGF-1-vermittelten Effekte supprimiert sind 
(Klotz et al. 2002). Eine ER alpha-negative MCF-7-Zelllinie reagiert nicht mit Proliferation auf E2, wird aber nach Transfektion mit ER alpha-Expressionsvektoren rezeptiv (Oesterreich et al. 2001). Im E-screen hat die Testsubstanz OMC in den eingesetzten Konzentrationen über den ER alpha keine estrogene Aktivität entfaltet.

\subsubsection{OMC im EROD-Assay}

Auf die EROD-Aktivität hat OMC einen antagonistischen Effekt ab einer Konzentration von $3 \times 10^{-5} \mathrm{M}$. Ein agonistischer Effekt konnte dagegen nicht festgestellt werden. Auf die Expression von AhR regulierten Markergenen wie Cypla1 und AhR-Repressor hat OMC ebenfalls keinen Effekt (Daten nicht gezeigt). Eine Beeinflussung des estrogenen Signaltransduktionsweges über den AhR, wie von Wormke et al. beschrieben (Wormke et al. 2003), kann ausgeschlossen werden, da dies nur bei AhR-Agonisten der Fall ist.

Der BrdU-Test hat ergeben, das OMC zwar einen wachstumshemmenden Effekt ausübt, allerdings tritt der hemmende Effekt auf die EROD-Aktivität schon bei geringeren Konzentrationen auf. In der optischen Begutachtung der Zellen konnte zudem keine morphologische Veränderung festgestellt werden, die auf Toxizität hindeutet. Die Hemmung der EROD-Aktivität ist also eindeutig auf eine antagonistische Wirkung von OMC zurückzuführen.

Ein hemmende Effekt von Estradiol auf die EROD-Aktivität in Hepatozyten der Regenbogenforelle (Oncorhynchus mykiss) bei einer Konzentration von $1 \times 10^{-8} \mathrm{M}$ ist schon von Navas und Segner beschrieben worden (Navas et al. 2000). Auch in MCF-7Zellen führt eine Inkubation mit E2 $(1 \mathrm{nM})$ zum Verlust der Induktionsfähigkeit der EROD-Aktivität durch TCDD (Spink et al. 2003). Für die in der vorliegenden Arbeit benutzten Rattenhepatomzellen H4IIE wurde der Effekt erstmals von Lai et al., beschrieben (Lai et al. 2004) und bestätigt damit die Ergebnisse aus dem EROD-Assay.

Das Detergenz Octylphenol induziert die Expression von Vitellogenin, einem Marker für estrogene Effekte in Fischen, in Hepatozyten über die Estrogen Rezeptoren und „estrogen response elements“ (Navas et al. 2000). Es hat aber bei gleicher Konzentration keinen hemmenden Effekt auf die EROD-Aktivität. Das zeigt, das ERAgonisten nicht per se einen hemmenden Effekt auf die EROD-Aktivität ausüben.

Die Koinkubation der H4IIE-Zellen mit OMC bzw. E2, 3MC und ICI 182,780 im EROD-Assay ergab keine Aufhebung der Hemmung durch E2 und OMC. 
Parallel dazu konnte der hemmende Effekt von Nonylphenol auf die TCDD induzierte EROD-Aktivität mit Tamoxifen, einem spezifischen Antagonisten für die ERs, ebenfalls nicht aufgehoben werden (Jeong et al. 2001). Des Weiteren konnte die Gruppe aber zeigen, dass E2 zu einer verminderten Fähigkeit des AhRs, an sein response element zu binden, führt. Der Rezeptor muss demnach zusätzlich über eine separate Bindestelle für Estrogen und estrogenartige Substanzen verfügen, die allerdings von der E2-Bindestelle der ERs abweichende Eigenschaften besitzt, da nicht alle Estrogene an dieser Stelle binden können.

OMC ist $\mathrm{zu}$ E2 vermutlich strukturell ausreichend homolog, im Gegensatz zur Homologie von Octylphenol zu Estradiol, um den gleichen, nicht ER-vermittelten Effekt auf die Aktivität des AhR auszuüben. Es ist wahrscheinlich, dass OMC an dieser separaten Stelle an den AhR bindet und eine Transaktivierung über AhR-response elements verhindert.

\subsubsection{Fazit der in vitro-Analysen}

Die Daten aus dem RBA, dem E-screen und der Hypothalamus-Zellkultur zeigen, dass OMC nicht in der Lage ist, an den ER alpha zu binden oder über den ER alpha einen Effekt auf einen biologischen Endpunkt auszuüben. Die Ergebnisse der drei Assays sind in sich schlüssig, stehen allerdings in einem Gegensatz zu veröffentlichten Daten. Der Transaktivierungsassay von Gomez et al. in HeLa-Zellen zeigt eine Bindung an ER alpha aber nicht an ER beta. In einem Transaktivierungsassay in HEK293-Zellen induziert OMC einen ER alpha-regulierten Reporter (Schreurs et al. 2002). OMC kann denselben Reporter in vivo allerdings nicht aktivieren. Zuletzt zeigen Schlumpf et al. in dem gleichen E-screen mit MCF-7-Zellen, der in dieser Arbeit verwendet wurde eine Induktion des Zellwachstums (Schlumpf et al. 2001). Eine mögliche Erklärung ist der jeweilige Zellkontext in dem die Substanz getestet wurden. Die verwendeten Zelllinien HeLa, HEK293 und MCF-7 verfügen über eine individuelle Ausstattung an Rezeptoren und deren Isoformen sowie Kofaktoren, wodurch auch die Diskrepanz zwischen den in vitro- und in vivo-Daten der Arbeit Schreurs et al. erklärt wird. Der Unterschied zwischen dem Proliferationsassay der Gruppe Schlumpf et al. und dem hier verwendeten begründet sich möglicherweise in einer Veränderung der Zelllinie MCF-7 
während der Subkultivierung in den jeweiligen Labors. Mit fortlaufender Passage verändert sich der Zellkontext und die Zellen können altern (Shi et al. 2004).

\subsection{In vivo-Analysen}

Es besteht ein Konsens, auf der Grundlage von in vitro-Tests keine abschließenden Bewertungen einer Substanz in Hinblick auf die endokrine Aktivität vorzunehmen. Zur Analyse von endokrinen Effekten putativer EACs wurden deshalb in vivoUntersuchungen mit standardisierten Testverfahren durchgeführt.

\subsubsection{Metabolismus}

Die Behandlung der Tiere mit E2 führt über einen längeren Zeitraum zu einem Absinken des Tiergewichtes. Bei einer Behandlung durch E2V an nur 5 Tagen zeigen die Daten diesen Abfall nicht sehr deutlich. Dennoch zeigt die Serumanalyse deutlich den Einfluss von E2V auf den Metabolismus der Tiere. Das Fetthormon Leptin als Indikator des allgemeinen Ernährungszustandes des Organismus sinkt stark ab. Parallel dazu sinken die Serumwerte von Cholesterin, HDL und LDL.

Die OMC Tiere zeigen keinen Effekt der Behandlung auf das Körpergewicht, und auch bei den Serumwerten hat die Behandlung nur einen leichten, nicht signifikanten Einfluss auf Cholesterin und LDL in der OMC-1000-Gruppe. Die Regulation des Metabolismus und die estrogene Regulation der Reproduktion sind eng miteinander verknüpft (D'Eon et al. 2005). Erstaunlich ist, dass der Leptinspiegel im Serum nicht auf OMC reagiert, da Leptin eine Verbindung zwischen Metabolismus und estrogener Regulation darstellt, und durch Estrogene reguliert wird (Mayes et al. 2004). Die Reaktion der Parameter Cholesterin und LDL auf die Behandlung mit OMC könnte deshalb durchaus ein sekundärer Effekt sein und hätte dann nichts mit einer estrogenen Wirkung von $\mathrm{OMC} z u$ tun. Eine Möglichkeit ist die indirekte Beeinflussung des Metabolismus über die HPT-Achse die in Abschnitt 4.2.3.2 diskutiert wird.

\subsubsection{Expressionsmuster des ER alpha/beta-Systems}

Die Messung der Genexpression der ERs im MBH ergab, dass beide ERs durch E2V hochreguliert wurden. Der Effekt ist mit 35 \% allerdings nicht signifikant. Das System 
wird durch eine größere Menge an Rezeptor-Protein sensitiver einem estrogenen Signal gegenüber.

Die Expression beider Subtypen des ER im Hypothalamus ist abhängig von der E2Konzentration im Serum und wird während des Zyklus nur schwach reguliert (Hatoya et al. 2003). Die Schwankung in der ER-Expression ist eine Anpassung der Sensitivität. OMC ist nicht in der Lage, auf die Expression der ERs einen mit E2V vergleichbaren Einfluss auszuüben.

In der Hypophyse reagierte das System mit einer deutlichen Reduktion der ER betaExpression auf die Behandlung mit E2V, während die ER alpha-Expression unverändert blieb. Dies deckt sich mit den Ergebnissen einer anderen Arbeitsgruppe, die zudem noch ein Absinken der ER alpha-Proteinkonzentation zeigen konnte (Schreihofer et al. 2000). Nach Ovariektomie weiblicher Ratten steigt die ER beta-Expression in der Hypophyse (Tena-Sempere et al. 2004). Die Veränderung kann durch die Behandlung mit Estrogenen aufgehoben werden, allerdings nicht mit dem ER beta-Agonisten Diarylpropionitril. Das zeigt, dass die ER beta-Expression in der Hypophyse über den ER alpha reguliert wird.

Die Behandlung der Tiere mit OMC hingegen scheint, obwohl die Daten eine starke Schwankung zeigen, eine Hochregulation der ER beta-Expression zu bewirken. Hier zeigt sich in vivo ein Anzeichen für die fehlende Fähigkeit der Testsubstanz OMC, über den ER alpha einen transaktivierenden Einfluss auf E2-regulierte Gene auszuüben, da die über den ER alpha vermittelte Hemmung der Expression des ER beta in kastrierten Ratten nicht von OMC eingeleitet wird. Dies Ergebnis stützt die in dieser Arbeit erhaltenen in vitro-Daten. OMC scheint kein ER alpha-Agonist zu sein, hat hier aber eine SERM-Aktivität auf die möglicherweise ER alpha-vermittelte Genexpression von ER beta.

Es gibt einen prä-ovulatorischen Schub von LH, FSH und Prolaktin im Serum von intakten Ratten. Dies wird durch ein Ansteigen der E2-Konzentration im Serum verursacht, wodurch es zu einer vermehrten Produktion von Prolaktin in laktotrophen Zellen und von LH und FSH in gonadotrophen Zellen kommt (Fink 1988). Der molekulare Mechanismus dieser positiven Rückkopplung ist allerdings noch unverstanden, da eine E2-Administration in vivo zu einer Hemmung der LH-Sekretion 
führt (Nedvidkova et al. 1998). Schreihofer et al. vermuten in der negativen Regulation der ER alpha-Proteinkonzentration sowie der ER beta-Genexpression in Verbindung mit der Hochregulation von TERP1 einen Mechanismus zur Hemmung der positiven Rückkopplung in der Hypophyse die zu dem prä-ovulatorischen Schub von LH, FSH und Prolaktin führt (Schreihofer et al. 2000). TERP1 erreicht dabei eine äquimolare Konzentration zum ER alpha und hemmt die Funktion beider ERs durch die Bildung von inaktiven Heterodimeren (Resnick et al. 2000).

Die von E2V abweichende Regulation der ER beta-Expression innerhalb dieses Mechanismus zur Hemmung der positiven Regulation in der Hypophyse könnte auf eine Beeinträchtigung der Regulation des weiblichen Zyklus durch OMC hindeuten. Es ist durchaus möglich, dass OMC auch die Reproduktionsfähigkeit dadurch beeinträchtigt. In der vorliegenden Arbeit wurde OMC an kastrierten weiblichen Ratten getestet. Um diese Hypothese zu untersuchen sind weitere Versuche an intakten Tieren notwendig.

Die ER alpha-Expression im Uterus wurde durch die E2V-Behandlung nicht reguliert. Allerdings wurde die ER beta-Expression durch E2V auf einen Bruchteil der Expression der Kontrollgruppe gesenkt (12\%). Wie in der Hypophyse steigt die ER betaExpression im Uterus nach Ovariektomie an und kann durch Administration von E2 gesenkt werden (Murata et al. 2003), wodurch die Ergebnisse dieser Arbeit bestätigt werden. Die Tendenz der Genexpression von ER beta nach der OMC-Behandlung ist hier deutlicher als in der Hypophyse, und zeigt einen leichten Anstieg. Ein Quotient von ER alpha zu ER beta steigt nach E2V Behandlung auf das 9- bis 10-fache an, während er nach OMC-Behandlung leicht sinkt.

Es gibt viele Hinweise auf einen regulierenden Einfluss des ER beta auf die ER alphaFunktion. Andererseits ist es durchaus denkbar, dass die ER-Subtypen eine unterschiedliche Funktion haben. Die starke negative Regulation des ER beta durch die Behandlung mit E2 stützt beide Hypothesen. Entweder wird der hemmende Effekt von ER beta aufgehoben oder die Funktion des ER alpha wird durch die Erhöhung seines Anteils gefördert. Nach einer E2-Applikation kommt es $\mathrm{zu}$ einer Induktion der Proliferation und einer ganzen Reihe von ER-vermittelten Effekten.

Die Regulation der ER beta-Expression im Uterus zeigt, dass die Signaltransduktionskaskade der estrogenen Regulation durch OMC in einer ganz 
anderen Weise beeinflusst wird als bei E2V. Die Aktivität des ER alpha wird durch die Induktion der ER beta-Expression gehemmt oder aber die Funktion des ER alpha wird durch die Erhöhung des ER beta-Anteils geschwächt. Auch hier lässt sich vermuten, dass die Reproduktionsfähigkeit durch OMC durch die Störung der natürlichen E2induzierten Ereignisse im Uterus beeinträchtigt sein könnte.

\subsubsection{Einfluss von OMC auf die HPG- und HPT-Achsen}

\subsubsection{HPG-Achse}

Im Zusammenspiel mit Progesteron sind Estrogene an der Regulation von Wachstum und Entwicklung, der Reproduktion, der Homöostase des Metabolismus beteiligt. Die Funktionen der Reproduktion werden über die HPG-Achse kontrolliert.

In der Hypophyse werden als Reaktion auf GnRH die Hormone LH und FSH sezerniert. Bei der LH-Sekretion ist bekannt, dass die Werte bei kastrierten Ratten höher liegen als bei intakten Tieren (Maeda et al. 1989) und nach E2-Applikation sinken (Cagampang et al. 1991). Den gleichen Effekt hat man bei der Regulation von FSH gefunden (Shupnik et al. 1988). Beide Effekte sind eine Reaktion auf die in Abschnitt 4.1.2 beschriebenen negativen Rückkopplung durch E2. Das in dem Tierversuch verwendete E2V ist ein mit Valerat gekoppeltes Derivat. Dieses speziell für die orale Applikation entwickelte Präparat hat im Gegensatz zu dem in Injektionsversuchen verwendeten Präparat E2Benzoat einen sehr schwachen Effekt auf die Hypophysenhormone LH und FSH (Seidlova-Wuttke et al. 2005). Der Unterschied in der Suppression der LH-Sekretion der beiden E2-Derivate ist auch in einem weiteren, separaten Experiment bestätigt worden (Hubertus Jarry; unveröffentlichte Daten). Des Weiteren sind keine Unterschiede von E2V zu E2 bekannt. OMC hat keinen signifikanten Effekt auf die Sekretion von LH und FSH, allerdings ist auch keine Induktion festzustellen, wie man aus der Hypothalamus-Zellkultur erwartet hätte. Die Expression der Hypophysenhormone zeigt eine deutlichere Suppression bei der alpha-Untereinheit von LH, FSH und TSH sowie bei der LH beta-Untereinheit in der E2V-Behandlungsgruppe. Auch hier kann für OMC kein Effekt auf die Hormonproduktion auf der Ebene der mRNA festgestellt werden. Die wahrscheinlichste Erklärung ist, dass die Testsubstanz 
OMC eine $\mathrm{zu}$ schwache Aktivität besitzt, um in den verwendeten Dosen einen signifikanten Effekt auf die Hypophysenhormone auszuüben.

Die TERP1-Genexpression in der Hypophyse wird durch OMC deutlich induziert. Der Promotor wird über ein intaktes ERE, in Abhängigkeit des hypophysären Kofaktors Pit1, reguliert. Zellkulturexperimente mit COS-7-Zellen, die keinen ER alpha besitzen, und mit MMQ-Zellen, welche den ER alpha exprimieren, haben gezeigt, dass eine Transaktivierung durch die Belastung mit E2 in vitro abhängig vom ER alpha ist (Schausi et al. 2003). Auch konnte in ER alpha-knockout-Mäusen die Genexpression von TERP1 nicht durch E2 induziert werden (Schreihofer et al. 2002). Das System der knockout-Mäuse hat aber Nachteile, die eine Interpretation schwierig machen. Der Organismus der Tiere kann sich während der gesamten Entwicklung auf den fehlenden Rezeptor einstellen und kompensiert dies über eine Redundanz innerhalb der komplexen Systeme. Diese Annahme wird gestützt allein durch die Lebensfähigkeit vieler knockout-Tiere. Auch entfallen modulierende Effekte durch synergistische und antagonistische Interaktionen durch die Elimination eines ER-Subtyps. Zudem ist es möglich, dass die Tiere eine rudimentäre Form des Proteins exprimieren (Harris et al. 2002).

Es konnte ebenfalls gezeigt werden, dass auch ER beta-Agonisten wie Diarylpropionitril in der Lage sind die Expression von TERP1 in vivo zu stimulieren (Tena-Sempere et al. 2004). Der ER alpha ist dabei für die Induktion unerlässlich. Da ER alpha und beta funktionelle Heterodimere und somit Transkriptionsfaktoren bilden, ist es denkbar, dass die ligandenabhängige Aktivierung über den ER beta stattfindet. Es ist möglich, dass OMC wie Diarylpropionitril die Genexpression von TERP1 reguliert ohne ein ER alpha-Agonist zu sein.

TERP-1 ist ein wichtiger Regulator der E2-Wirkung in der Hypophyse. Die Modulation durch TERP1 ist eine biphasische Rückkopplungsregulation. Bei niedrigen Konzentrationen titriert TERP1 Korepressorproteine und verstärkt die Ligandeninduzierte ER-Aktivität, während bei hohen Konzentrationen eine direkte ProteinProtein-Wechselwirkung mit den ERs sowie mit dem Steroid-Rezeptor-Koaktivator (SRC-1), die Rezeptoren inaktiviert (Schreihofer et al. 1999). OMC aktiviert durch die 
Induktion der TERP1-Expression diesen Rückkopplungsmechanismus in der Hypophyse vergleichbar mit E2V.

Das Erscheinungsbild der Vaginalabstriche gibt Hinweise auf den Zustand des Vaginalepithels (Yuan 1991). Die Tiere der E2V-Gruppe erreichen den Zustand von intakten estrischen Tieren, während die OMC-Tiere zwar eine deutliche Veränderung des Erscheinungsbildes im Vergleich zu Kontrollgruppe aufweisen, allerdings nicht den Zustand der E2V-Gruppe erreichen. Diese Diskrepanz könnte auf die im Vergleich geringe estrogene Aktivität von OMC zurückzuführen sein.

Die Administration von E2 an ovariektomierten Tieren führt $\mathrm{zu}$ einem Zuwachs des Uterusdurchmessers sowie der Schichtdicke des Endothels (Cardenas et al. 2004). Zudem sind Veränderungen in der Form der Zellen des Endometriums zu beobachten (Yuan 1991).

In der Positivkontrollgruppe sind die typischen Reaktionen auf die Behandlung mit E2V $\mathrm{zu}$ beobachten. Die Behandlung mit OMC allerdings erzeugt nur ein schwaches Längenwachstum des Epithels. Auch zeigen die Zellen des Endometriums keinerlei Anzeichen einer Polarisierung. Sehr auffällig erschien die Fläche des Lumens der OMC-1000-Gruppe im Verhältnis zur Lumenfläche der E2V-Gruppe. Deshalb wurde zusätzlich zu den klassischen Parametern, der Schichtdicke des Epithels und des Uterusdurchmessers, auch der Anteil des Lumen an der Gesamtfläche des Uterus gemessen. Dabei fällt auf, dass der Uterusdurchmesser mit $132 \%$ der Kontrollgruppe fast so stark zugenommen hat wie in der E2V-Gruppe mit $152 \%$ der Kontrollgruppe. Beim Lumendurchmesser allerdings zeigt die E2V-Gruppe einen stärkeren Zuwachs. Der Anteil des Lumens an der Uterusfläche nimmt unter E2V-Behandlung stärker zu als unter OMC-Behandlung. Das Endometrium scheint den Dickenzuwachs des Uterus zu kompensieren, weshalb auch die Zellen des Endometriums der OMC-1000-Tiere keine Anzeichen für eine Polarisierung und somit Streckung des Gewebes zeigen. Dieses Phänomen wurde bislang noch nicht in der Literatur beschrieben. Eine Erklärung hierfür könnte die Funktion der ER-Subtypen in Bezug auf die Veränderung des Uterus sein. Wenn die Funktion des ER alpha die Induktion der Proliferation und die Funktion des ER beta die Differenzierung ist (siehe 1.2), dann deutet dieser Befund auf eine vermehrte Proliferation im Uterus und somit auf eine stärkere Aktivität des ER alpha 
hin. In Abschnitt 4.2.2 wurde die Induktion der ER beta-Genexpression im Uterus diskutiert. Dies hätte bei einem Estrogen eine stärkere Aktivität des beta-Rezeptors zur Folge und widerspricht dem Befund aus der Histologie des Uterus. Zudem zeigen die in vitro-Daten eher eine ER beta-Präferenz der Substanz OMC. Diese Widersprüche lassen sich nur durch das SERM-Konzept erklären. Ein Beispiel dafür ist der SERM Tamoxifen, welcher als Agonist der ERs im Uterus und als Antagonist in der Mamma agiert. Diese Erklärung würde auch die Ergebnisse anderer Labore mit den Ergebnissen dieser Arbeit in Einklang bringen.

Die Administration von E2V führt über die ERs zu einer Induktion des Uterusgewichts. Die Funktion der ERs bei der Reaktion des Uterus auf die Hormone Estradiol und Progesteron wurden in ER-knockout-Mäusen intensiv untersucht. Die Uteri von ER alpha- und ER alpha/beta-knockout-Mäusen sind als immatur beschrieben worden (Couse et al. 1999; Lubahn et al. 1993). Die Entwicklung des Organs ist dabei nicht eingeschränkt, nur das post-pubertäre Wachstum ist defekt. Der Uterus von ER alphaund ER alpha/beta-knockout-Mäusen reagiert nicht auf E2 im uterotrophen Assay mit Wachstum bzw. der Induktion von Markergenen (Couse et al. 1995). Im Gegensatz dazu reagieren die Uteri von ER beta-knockout-Mäusen normal auf die Behandlung mit E2. Die Tiere sind auch trotz einer starken Subfertilität in der Lage eine normale Schwangerschaft auszutragen (Krege et al. 1998). Die Funktion des Reproduktionstraktes scheint also von der Aktivität des ER alpha abzuhängen, obwohl hier auch wieder auf die Unzulänglichkeiten von knockout-Tieren per se hingewiesen werden muss (s.o.). Die Daten einer Behandlung von ovariektomierten Ratten mit einem ER beta-selektiven Agonisten zeigen eine schwache, nicht signifikante, aber dosisabhängige Induktion des Uterusgewichts innerhalb von vier Dosierungen (Frasor et al. 2003). Allerdings wird das von den Autoren als ein Ausbleiben einer Reaktion bezeichnet. Die leichte Induktion des Uterusgewichtes deutet auf eine ER alphaagonistische Aktivität von OMC hin. Dies widerspricht den in vitro-Daten, die eine ER beta-agonistische Aktivität vorhergesagt haben. Eine Erklärung hierfür bietet das SERM-Konzept (s.o.). OMC zeigt in vivo eine Wirkung auf uterine Zellen, während der E-screen mit Brusttumorzellen und die Hypothalamus-Zellkultur mit immortalisierten GnRH-Neuronen arbeitet. 
IGF-1 ist Bestandteil der Signaltransduktionskaskade, die zu der Erhöhung des Uterusgewichts führt. So führt die Zugabe von exogenem EGF und IGF-1 zu der Erhöhung des Uterusgewichtes (Sahlin et al. 1994) und zur Induktion der Zellteilung (Ignar-Trowbridge et al. 1993). Eine Behandlung mit E2 führt bei ovariektomierten Ratten zu einer Induktion der EGF- und IGF-1-Expression und in der Aktivierung des IGF-1-Rezeptor-Signaltransduktionswegs (Richards et al. 1996). In IGF-1-knockoutMäusen führt die Administration von E2 zu keiner Induktion des Uterusgewichts im uterotrophen Assay (Adesanya et al. 1999). Anhand von ER alpha-knockout-Mäusen konnte gezeigt werden, dass ein funktionierender ER alpha für die IGF-1-Induktion benötigt wird (Klotz et al. 2000).

In der vorliegenden Arbeit reagiert die IGF-1-Genexpression in der E2V-Gruppe deutlich mit einer Induktion. In den OMC-Behandlungsgruppen ist allerdings keine signifikante Induktion zu erkennen. Die höchste Induktion liegt in der OMC-333Gruppe bei $170 \%$. Selbst schwache Estrogene zeigen in der Regel eine 3-fache Induktion. Dieser Befund korreliert nicht mit dem Zuwachs des Uterusgewichts, der eindeutig eine dosisabhängige Induktion zeigt. Da das Uteruswachstum von der IGF-1Induktion abhängig ist zeigt sich hier ein Indiz für einen nicht-estrogenen Effekt von OMC.

Das Komplement-Protein C3 wird über drei EREs in der Promotorsequenz durch die ERs reguliert. Die Behandlung mit E2V führte $\mathrm{zu}$ einer starken Induktion der Genexpression. Die Behandlung mit OMC induziert die uterine C3-Genexpression nur in der OMC-1000-Gruppe.

Der selektive ER alpha-Ligand Propylpyrazoletriol induziert die C3-Genexpression, erreicht aber nicht das Maximum der Induktion der E2-Positivkontrolle, während die C3-Expression eine nur ca. 40 \%ige Induktion durch den ER beta-selektiven Liganden Diarylpropionitril zeigt (Frasor et al. 2003). Das ist mit der 10-fachen Induktion von C3 durch Propylpyrazoletriol bzw. OMC in der OMC-1000-Gruppe nicht zu vergleichen. Die Regulation der C3-Expression in vivo scheint hauptsächlich ER alpha-vermittelt. OMC könnte durchaus SERM-Eigenschaften besitzen, die eine Induktion im Uterus zulassen, während in anderen Organen ER-regulierte Systeme nicht aktiviert werden. 
Dass der uterotrophe Effekt allein auf eine Bindung und somit Transaktivierung des ER beta zurückzuführen ist, scheint ausgeschlossen. Das wird allein dadurch gestützt, dass ER alpha- und ER alpha/beta-knockout-Mäuse im Gegensatz zu ER beta-knockoutMäusen nicht auf E2 im uterotrophen Assay reagieren (Couse et al. 1995). Auch ein synergistischer Effekt zwischen ER beta als ligandaktivierter Transkriptionsfaktor und ER alpha scheint unwahrscheinlich. OMC zeigt in der HPG-Achse das Bild eines SERMs, dessen Eigenschaften denen von E2V ähneln aber auch Unterschiede aufweisen.

\subsubsection{HPT-Achse}

Die HPT-Achse kann durch Estrogene durch einen direkten Einfluss auf die hypophysäre TSH-Sekretion einen regulierenden Einfluss auf den Stoffwechsel haben. In der Hypophysenprimärzellkultur wird die TSH-Sekretion durch E2 $\left(1 \times 10^{-11}\right.$ bis $1 \times 10^{-9} \mathrm{M}$ ) und somit die Konzentration im Medium signifikant induziert (Miller et al. 1977).

Dieser direkte Einfluss durch E2 bei einer Konzentration von $1 \times 10^{-9} \mathrm{M}$ konnte in der vorliegenden Arbeit in der Zellkultur gezeigt werden. Die Testsubstanz OMC zeigt bei Konzentrationen von $1 \times 10^{-6}$ bis $1 \times 10^{-5} \mathrm{M}$ einen mit E2 vergleichbaren Effekt auf die hypophysäre TSH-Sekretion. In einem weiteren Experiment wurde gezeigt, dass der stimulierende Effekt von E2 sowie der von OMC durch den ER-Antagonisten ICI 182,780 komplett gehemmt werden kann. Dies zeigt die Abhängigkeit der estrogenen Regulation der TSH-Sekretion von den ERs.

Der stimulierende Effekt von E2 auf die TSH-Sekretion in der Hypophyse tritt auch in vivo auf. In der E2V-Gruppe ist eine leichte Induktion der TSH-Sekretion zu erkennen. Dies deckt sich mit anderen Arbeiten, die ebenfalls eine Induktion der TSH-Sekretion durch Estrogene in vivo beschrieben haben (Kim et al. 2002; Schmutzler et al. 2004). In den OMC-Behandlungsgruppen tritt allerdings eine Hemmung der Sekretion auf. Obwohl OMC in vitro die TSH-Sekretion durch einen estrogenen Mechanismus induziert, scheint es hier einen in vivo-Effekt zu geben, der die estrogene Regulation blockiert und sogar einen gegenteiligen Effekt verursacht. 
Bei der Genexpression der Untereinheiten des TSH, TSH beta sowie der alphaUntereinheit, zeigt sich ein hemmender Effekt sowohl bei E2V als auch bei OMC. Aus dem Ergebnis der TSH-Serumspiegel wäre dieses Ergebnis für OMC zu erwarten gewesen, steht aber im Widerspruch zu dem stimulierenden Effekt von E2(V) auf die TSH-Sekretion in der Hypophyse, in vitro und in vivo.

Aufgrund einer Induktion der Genexpression der beiden Untereinheiten des TSH durch TRH in Zellkultur-Experimenten könnte die Regulation auf der Transkriptionsebene ein wichtiger Faktor der hypothalamische Regulation der HPT-Achse sein (Shupnik et al. 1986). Die Genexpression der TSH beta-Untereinheit spielt dabei eine dominierende Rolle im Gegensatz zur alpha-Untereinheit, die scheinbar auf die TSH-Sekretion keinen Einfluss hat (Gurr et al. 1983). Dabei gibt es eine zeitliche Diskrepanz zwischen der Genexpression der Untereinheiten sowie der Sekretion von TSH durch Zellen der Hypophyse. Eine andere Arbeitsgruppe beschrieb eine deutliche Abweichung zwischen der Genexpression der Untereinheiten und der TSH-Sekretion nach der E2-Behandlung (Lippman et al. 1986). Die Autoren vermuten den Grund dieser Diskrepanz in der posttranslationalen Glykosylierung sowie in der Sekretion aus zellulären Speichern.

Um einen möglichen Einfluss der Testsubstanz OMC sowie der Positivkontrolle E2V auf die TRH-Sekretion im Hypothalamus zu untersuchen, wurde die Genexpression des TRH im MBH gemessen. Dabei hat sich gezeigt, dass die TRH-Expression weder durch E2 noch durch OMC beeinflusst wurde. Es gibt also keinen hypothalamischen Einfluss von OMC der die Modulation der TSH-Sekretion erklären könnte.

Die Applikation von E2V hat einen negativen Einfluss auf den gesamt-T3Serumspiegel, der sich allerdings nur schwach auf die Konzentration des freien, aktiven fT3 auswirkt. Im Gegenzug wird allerdings die Konzentration des freien T4 erhöht, welches in den Zielorganen der Schilddrüsenhormone durch die Abspaltung eines JodAtoms in das aktive T3 umgewandelt wird. Das fT3/fT4-Verhältnis sinkt, doch das fT4/T4-Verhältnis steigt. Mit E2 behandelte Tiere zeigen einen erhöhten Stoffwechsel, eine verringerte Nahrungsaufnahme und verlieren an Körpergewicht (Young 1986).

Die Testsubstanz OMC zeigt einen stärkeren hemmenden Effekt auf die T3-Produktion als E2V, der sich auch stärker auf die Konzentration des freien, aktiven fT3 auswirkt. 
Die Konzentration des gesamt-T4 ist ebenfalls gesenkt, was sich in der Konzentration des freien T4 allerdings nicht bemerkbar macht. In den Verhältnissen der Hormone zueinander ergibt sich daraus, trotz der von E2V abweichenden Effekte auf die Konzentrationen der einzelnen Hormone, kein abweichendes Bild für OMC. Dennoch zeigt OMC einen starken hemmenden Effekt auf die Produktion und Sekretion der Schilddrüsenhormone ins Serum. Die Produktion der Schilddrüsenhormone ist in der Signaltransduktionskaskade der HPT-Achse der Hypophyse nachgeschaltet, so dass anzunehmen ist, dass der starke hemmende Effekt von OMC durch den verringerten TSH-Serumspiegel verursacht wird.

Durch Untersuchungen in der Schilddrüse sollte sichergestellt werden, dass OMC keinen direkten Effekt auf die Schilddrüse hat.

Der Natrium/Iodid-Symporter (NIS) transportiert das Jod, welches für die Synthese der Schilddrüsenhormone gebraucht wird, in die Schilddrüsenzellen und ist somit ein Schlüsselenzym für die T3/T4-Produktion (Carrasco 1993). Die Untersuchung der NIS Expression auf der Proteinebene hat allerdings keine Veränderung in der Expression ergeben, so dass ein Effekt auf den NIS als Ursache für die niedrigen T3/T4Serumspiegel ausgeschlossen werden kann.

Das durch den NIS in die Schilddrüsenzellen transportierte Iodid wird durch die Schilddrüsenperoxidase (TPO) organifiziert. Dabei wird das Iodid über eine radikalische Reaktion innerhalb der Follikel in das dort gespeicherte Thyreoglobulin eingebaut. Die Behandlung der Tiere mit OMC hat keinen Einfluss auf die TPOAktivität. Die Synthese der Schilddrüsenhormone wird also auch nicht durch eine Veränderung der TPO-Aktivität in der Schilddrüse beeinflusst.

Auf der Proteinebene konnte gezeigt werden, dass die Behandlung mit OMC zu einer Induktion des TSH-Rezeptors (TSHR) führt. In einer Schilddrüsenzelllinie (FRTL-5), welche mit einem TSHR-Promotor-Reporter Konstrukt transfiziert wurden, konnten Ikuyama et al. zeigen, dass die Promotor Aktivität mit zunehmender TSHKonzentration abnahm. Dies wurde in Leberzellen nicht erreicht. Zudem wurde eine positive Regulation des TSHR-Promotors durch die Koexpression des Transkriptionsfaktors TTF-1 nachgewiesen (Ikuyama et al. 1997). TSH inhibiert die Expression des Transkriptionsfaktors TTF-1, wodurch die TSHR-Expression durch 
TSH noch zusätzlich gehemmt wird (Saito et al. 1997). Damit reagiert die Schilddrüse in der OMC-1000-Gruppe auf einen sinkenden TSH-Serumspiegel mit der Induktion des TSHR um die Sensitivität der Schilddrüse zu erhöhen.

Die Leber exprimiert die 5'Deiodase, welche für die Degradierung und somit Exkretion der Schilddrüsenhormone verantwortlich ist. Ein Absinken der Schilddrüsenhormone T3 und T4 könnte durch eine erhöhte Expression bzw. Aktivität der 5'DeiodaseAktivität in der Leber ausgelöst werden. Der 5'Deiodase-Assay hat für die OMC Behandlungsgruppen allerdings eine deutlich gehemmte Aktivität ergeben. TSH ist ein Regulator der 5'Deiodase-Genexpression (Morimura et al. 2005). Das erklärt die Hemmung der 5'Deiodase durch die Behandlung mit OMC als eine Reaktion auf eine geringere Genexpression durch geringere TSH-Serumspiegel.

Die niedrigen T3 und T4 Serumspiegel müssten eine geringere negative Rückkopplung auf die TSH-Sekretion zur Folge haben und dadurch die TSH-Sekretion in der Hypophyse stimulieren. Dies ist nicht der Fall. Die Hemmung der TSH-Sekretion in der Hypophyse durch OMC zeigt somit eine Störung des Rückkopplungsmechanismus durch die Schilddrüsenhormone.

Die Erklärung des von der estrogenen Wirkung von E2V abweichenden Effektes von OMC in der Hypophyse kann nicht eine fehlende estrogene Aktivität von OMC sein, da OMC in der Zellkultur durchaus eine estrogene Modulation der TSH-Sekretion gezeigt hat, die auch durch ICI 182,780 hemmbar war.

OMC hat in der Hypophyse eine nicht-estrogene, endokrine Aktivität auf die HPTAchse, dessen Mechanismus mit den zur Verfügung stehenden Mitteln nicht aufgeklärt werden konnte.

\subsection{Dosis-Wirkungsbeziehung}

Auf der Basis einer Dosis-Wirkungsbeziehung konnten Schwellenwerte definiert werden, mit denen ein wirkungsvoller Gesundheitsschutz bei Belastungen durch EACs betrieben werden könnte. Gerade UV-Filter werden von der Legislative der EU auf einer Positivliste geführt, die den Gebrauch und die maximal einzusetzenden Konzentrationen regelt. Da allerdings die endokrinen Aktivitäten für einige Substanzen 
unbekannt oder noch nicht bewertet sind, ist diese nicht mehr zeitgemäß und muss angepasst werden.

Für die Analyse der Ergebnisse wurde der benchmark approach gewählt, da er im Gegensatz zum klassischen NOAEL/LOAEL-Ansatz klare Vorteile besitzt (Crump 1984). Die CED-Werte sind für einen CES von einer Standardabweichung (SD) und für einen CES von einem Standardfehler des Mittelwertes (SEM) angegeben. Dadurch werden die individuellen Schwankungen der Tiere in Bezug auf den jeweiligen Parameter berücksichtigt.

Die ermittelten CED(SD)-Werte liegen im Bereich von 143 bis $848 \mathrm{mg} / \mathrm{kg}$ Körpergewicht, während die CED(SEM)-Werte im Bereich von 31 bis $238 \mathrm{mg} / \mathrm{kg}$ Körpergewicht liegen. Dabei sind keine deutlichen Unterschiede in der Sensitivität von estrogenartig regulierten oder nicht-estrogenartig regulierten Parametern auszumachen. Auch scheint es nicht so zu sein, dass ein Organ schneller oder sensitiver reagiert als andere.

Im Vergleich mit den ermittelten NOAEL- und LOAEL-Werten zeigt sich, dass die Mehrheit der CED-Werte gut damit korreliert. Allerdings ist bei einigen Parametern aufgrund einer fehlenden Signifikanz der Effekte ein Ableiten der LOAEL-Werte unmöglich (z.B. C3-Genexpression im Uterus). Darin zeigt sich, dass es möglich ist, mit dem benchmark approach Schwellenwerte unabhängig vom Studiendesign oder den Dosierungen zu berechnen. Die klassische NOAEL/LOAEL-Methode benötigt eine große Tierzahl pro Gruppe um diese Nachteile zu kompensieren, wodurch oftmals die Anzahl der Dosierungen eingeschränkt wird. Die Dosiswirkungsbeziehung wird dadurch i.d.R. schlechter. Der Vorteil dieser Methode ist ausführlich im FOBIG-Report beschrieben (Kalberlah et al. 2003).

Die ausführliche Analyse der Risikoabschätzung ist in Klammer et al. dargestellt (Klammer et al. 2005). Für eine Risikoabschätzung wird zunächst eine Extrapolation der aus dem Tierversuch erhaltenen CEDs auf den Menschen vorgenommen. Das geschieht über sog. Unsicherheitsfaktoren (UF). Diese berücksichtigen die Intra- und Interspeziesvarianzen der Auswirkungen einer Behandlung sowie die Unterschiede in der Aufnahme der Substanz und der Expositionsdauer. Ein Unsicherheitsfaktor von 1440 ist hier angebracht, der sich aus dem Faktor 10 für Intraspeziesvarianzen, 48 für Interspeziesvarianzen und 3 für die Expositionsdauer zusammensetzt. Der Quotient 
CED/UF entspricht der maximalen akzeptablen Dosis bzw. Exposition des Menschen. Die Exposition des Menschen kann experimentell untersucht werden. Eine transdermale Absorption von OMC wurde beim Menschen schon nachgewiesen, aber noch nicht in einer transepidermalen Absorptionsrate quantifiziert (Janjua et al. 2004). Die transepidermale Absorption von OMC in Tierversuchen liegt bei 1,6 \% (Jimenez et al. 2004). Unter Berücksichtigung der von der EU beschriebenen Richtwerten zur Berechnung der Exposition mit UV-Filtern (Council Directive 95/17EC) ergibt sich eine systemische Exposition von $0,96 \mathrm{mg} / \mathrm{kg}$ Körpergewicht (Klammer et al. 2005). Aus den in dieser Arbeit ermittelten Schwellenwerten von 30 bis $850 \mathrm{mg} / \mathrm{kg}$ Körpergewicht ergibt sich eine maximal akzeptable Exposition von 0,02 mg/kg Körpergewicht. Dieser Wert wird durch die systemische Exposition von 0,96 mg/kg Körpergewicht deutlich überschritten.

Daraus folgt, dass nicht ausgeschlossen werden kann, dass bei sensitiven bzw. extensiv exponierten Bevölkerungsgruppen das Risiko einer endokrinen Aktivität von OMC besteht.

Durch die Bestimmung der CED-Werte für die biochemischen und biologischen Effekte von Xenobiotika sind für epidemiologische Untersuchungen präzisere Aussagen über die gesundheitlichen Auswirkungen der exponierten Bevölkerungsgruppen möglich. Man vermutet aus einer ganzen Reihe von epidemiologischen Studien zu Störungen der menschlichen Gesundheit (Abschnitt 1.1.2) sowie auch aus Störungen von Ökosystemen (hier nicht weiter aufgeführt), dass die endokrine Aktivität von Xenobiotika einen Anteil an Phänomenen hat, wie z.B. Spermienqualität, Karzinomen und Teratogenese.

In dieser Arbeit konnte gezeigt werden, dass die Chemikalie OMC, die durch die Benutzung als UV-Filter den Menschen und auch Lebensräume in der Umwelt belastet, als endokrin aktive Chemikalie und aufgrund der kontroversen estrogenen Effekte sowie der Schilddrüseneffekte als endokriner Disruptor anzusehen ist. Diese Studie unterstützt die Hypothesen aus vielen epidemiologischen Studien, dass Xenobiotika die Gesundheit der belasteten Personen über eine endokrine Disruption beeinflussen. OMC ist ein möglicher Kandidat, der zu Störungen der menschlichen Gesundheit beitragen kann. Auch wenn die aus der Dosis-Wirkungsbeziehung ermittelten Schwellenwerte im Vergleich mit der anzunehmenden Exposition keine akute Gefährdung ableiten lässt, 
muss eine besondere Vorsicht bei der Bewertung hormoneller Aktivität in Bezug auf folgende Aspekte bedacht werden:

- Hormonell regulierte Systeme sind in bestimmten Lebensstadien, z. B. pränatal, besonders empfindlich. Kinder sind aufgrund der sensitiven Entwicklungsvorgänge eine besondere Risikogruppe.

- Es gibt Hinweise, dass Dosis-Wirkungsbeziehungen bei hormonellen Effekten nicht immer monoton steigend sind, d. h. unterhalb eines Bereiches ohne Wirkung treten wiederum Effekte auf (U-Form). Derartige Beziehungen werden in der Pharmakologie häufig beobachtet. Es wird vermutet, dass solche Kurven multiple Wirkungsmechanismen wie Homöostase oder die Aktivierung von kompensatorischen oder schützenden Reaktionen zugrunde liegen (Davis et al. 1990).

- Synergistische Wirkungen, d. h. mehr als additive, sich gegenseitig verstärkende Wirkungen könnten bei hormonell wirksamen Stoffen verbreitet sein. Eine aktuelle Studie konnte dies auch schon für UV-Filter belegen (Heneweer et al. 2005).

Die Beurteilung des estrogenen Effektes von Xenobiotika als advers oder nicht advers ist umstritten. Der Effekt von OMC auf die Schilddrüse ist allerdings als advers einzustufen. In diesem Fall sollte man von dem Gebrauch grundsätzlich Abstand nehmen.

\subsection{Serum-Analyse der Testsubstanz}

Ein wichtiger Faktor bei der Evaluation der endokrinen Aktivität einer Substanz in vivo ist die Absorption. Mit Hilfe der HPLC wurden die Seren der Tiere untersucht. Im Serum der mit OMC-behandelten Tiere wurde ein Peak gefunden, der die gleiche Retentionszeit wie der Standard aufwies. Zusätzlich traten allerdings noch zwei weitere Peaks in den Chromatogrammen auf, die eine dosisabhängige Konzentration zeigten und im Serum der Kontrolltiere nicht vorkamen.

Die weitere Analyse der Seren in der ESI DAD HPLC-MS hat allerdings ergeben, dass der Peak, der zunächst als OMC identifiziert wurde, eine Molmasse von $306 \mathrm{~g} / \mathrm{mol}$ $(\mathrm{OMC}+16)$ besitzt im Gegensatz zu 290,4 g/mol für OMC. Zusätzlich dazu wurde ein Metabolit mit der Molmasse $320 \mathrm{~g} / \mathrm{mol}(\mathrm{OMC}+30)$ sowie ein nicht weiter bestimmbarer 
Metabolit gefunden. Die API GC-MS/MS nutzt eine andere Form der Probenvorbereitung für die Analyse. Damit konnte gezeigt werden, dass in den Seren der Tiere der OMC-1000 Gruppe kein OMC mehr detektierbar war. Der Peak von $\mathrm{OMC}+16$ konnte auf der Basis der verfügbaren Bibliotheken nicht identifiziert werden. Der OMC+30 Peak ist durch die API im Gegensatz zur ESI leider durch eine Spaltung der Substanz vor der Injektion in den MS entfernt worden und kann so mit dieser Methode nicht bestimmt werden. Es gibt noch andere, spezielle Methoden der Induktion (z.B. APCI), die möglicherweise eine Bestimmung der unbekannten Metabolite erlauben. Diese standen für diese Arbeit nicht zur Verfügung. Es konnten aber auch Bruchstücke der Ausgangssubstanz OMC im Serum detektiert werden. Das ist ein Indiz für eine Degradation der Substanz in vivo durch Spaltung im Bereich des Esters. Dies wird möglicherweise durch eine Monooxigenierung oder Epoxidierung der Doppelbindung eingeleitet $(\mathrm{OMC}+16)$.

Unter der Annahme, dass das Absorptionsspektrum durch das Einbringen eines Sauerstoffatoms nicht stark verändert wird, kann man annehmen, dass die Serumkonzentration von $1 \mathrm{mM}$, die anhand der OMC+16 Peaks ermittelt wurde, auf OMC übertragbar ist. Auch wenn die zusätzlichen nicht identifizierten Metabolite nicht berücksichtigt werden können, kann man eine Größenordnung der Konzentration des resorbierten OMC von $\mathrm{mM}$ annehmen.

Viele in den Organismus eingebrachte Xenobiotika werden unterliegen der Biotransformation, die in einer Aktivierung (bzw. Giftung), einer Inaktivierung (bzw. Entgiftung) oder einer Verbesserung der Ausscheidungsfähigkeit resultieren kann. Die Konsequenz dieser Metabolisierungsreaktion ist es fast immer eine Ausscheidung des Stoffes. Dies kann durch den Abbau der Verbindung und der Verwertung im Intermediärstoffwechsel, den Abbau mit verbesserter Ausscheidungsfähigkeit der Stoffwechselprodukte oder die Verbindung mit endogenen Stoffen, um die Ausscheidungsfähigkeit der Syntheseprodukte zu erhöhen, geschehen.

Da weder das EROD-System induziert wurde noch die Peaks mit HP zu entfernen waren, ist anzunehmen, dass das Cyp1a1-System der Biotransformation nicht für die Metabolisierung verantwortlich sein kann.

Es gibt allerdings noch weitere Gene die für Cyp-Isoenzyme kodieren. Die Anzahl der Gensequenzen pro Genom schwankt bei Mammalia zwischen 50 (Homo Sapiens: 57) 
und 100 (Mus musculus: 102) (Estabrook 2003). Das Cytochrom P450-CYP 3A4Isoenzym baut z.B. Medikamente $a b$, die bei Bluthochdruck verschrieben werden (Verapamil, Nifedipin). Es ist durchaus denkbar, dass ein anderes System hier für die Metabolisierung von OMC verantwortlich ist.

Die Tiere für die in vivo-Analyse wurden ca. 4 Stunden nach der letzten Applikation dekapitiert. Nach der relativ kurzen Zeit verschwindet OMC komplett aus dem Serum. Die Tiere wurden per Schlundsonde gefüttert. Die Substanz passiert über die Pfortader zuerst die Leber. Es ist durchaus denkbar, dass ein First-Pass-Effekt für die Umsetzung von OMC verantwortlich ist. Dabei wird das absorbierte OMC bei dem ersten Passieren der Leber komplett metabolisiert. Dies erklärt die Ergebnisse der Serumanalyse. Allerdings wirft es neue Fragen über die eigentlich wirksame Substanz in vivo auf. Diese Ergebnisse lassen die Hypothese zu, dass der Effektor nicht das applizierte OMC ist, sondern einer oder mehrere der Metaboliten sind. Diese Annahme wird dadurch gestützt, dass Zimtsäuremethylester im Transaktivierungsassay bei einer Konzentration von $100 \mathrm{nM}$ ein Reportergen genauso stark induziert wie Estradiol ab einer Konzentration von $10 \mathrm{nM}$ (Mußler 1999). Der estrogene Effekt in vivo kann durchaus auf ein Zimtsäurederivat aus der Degradation von OMC stammen. Das wäre zumindest auch eine Erklärung für die Diskrepanz zwischen den Ergebnissen aus den in vitroVersuchen und dem in vivo-Versuch.

Der EROD-Assay mit Serum aus dem Tierversuch (Pool der Seren der OMC-1000Gruppe) hat keinerlei hemmende Effekte gezeigt. Dies könnte bedeuten, dass die Serum Konzentrationen der Metabolite zu gering sind, um die Aktivität zu hemmen. Die Konzentration von $(\mathrm{OMC}+16)$, wenn übertragbar, liegt aber im Bereich von $1 \mathrm{mM}$. Die Hemmung durch OMC trat im EROD schon ab etwa $10 \mu \mathrm{M}$ auf. Deshalb kann hier ausgeschlossen werden, dass der Metabolit $\mathrm{OMC}+16$ eine estrogene Wirkung hat, da sonst die EROD-Aktivität gehemmt worden wäre. Abschließend könnte diese Hypothese nicht geklärt werden, da für die Analyse keine Methode zur Verfügung stand.

Die Untersuchung der Estrogenität von OMC hat ein stark von E2 abweichendes Bild der endokrinen Aktivität ergeben. Ein screening-Modell, welches mit dem Uterusgewicht nur einen einzelnen biologischen Endpunkt der estrogenen Aktivität in 
der HPG-Achse berücksichtigt, ist für die Identifikation von Estrogenen nur bedingt nützlich, da ER-spezifische und SERM-Effekte wie in diesem Fall übersehen werden können. OMC ist nicht nur ein ED der estrogenen Signalwege, es besitzt eine zusätzliche Aktivität auf die Hypophyse in der HPT-Achse. Dies stützt die Forderung nach einer umfassenden Untersuchung der endokrinen Disruption durch Xenobiotika. 


\section{Zusammenfassung}

Viele Beeinträchtigungen der menschlichen Gesundheit sind vor dem Hintergrund der Belastung durch Xenobiotika diskutiert worden. Da das von der OECD vorgeschlagene Modell des uterotrophen Assay aus mehreren Gründen unzureichend ist, wurde in dieser Arbeit die endokrine Aktivität des als Estrogen in Verdacht geratenen OMC mittels in vitro-Versuchen sowie im erweiterten uterotrophen Assay untersucht. Die Ergebnisse zeigen, dass OMC ein stark von E2 abweichendes Bild der endokrinen Aktivität ergeben hat:

- OMC besitzt estrogene Eigenschaften, diese scheinen allerdings ER betavermittelt zu sein. Zudem deuten die Ergebnisse aus der HypothalamusZellkultur auf eine von E2 abweichende SERM-Aktivität im Hypothalamus hin.

- Die metabolischen Parameter der Tiere werden durch OMC nicht in einer eindeutig estrogenen Weise beeinflusst. Obwohl die Serumfettwerte reguliert sind, scheint eine estrogene Regulation ausgeschlossen, da das E2-regulierte Leptin keine Veränderung zeigt.

- Bei der Untersuchung des ER alpha/beta-Expressionsystems wurde in vivo keine Aktivität im Hypothalamus gefunden. Die Regulation des Systems in der Hypophyse stellt ein Feedbacksystem dar, das durch OMC von E2V abweichend reguliert wurde. OMC ist hier entweder ein ER alpha-SERM oder besitzt noch unbekannte Aktivität am ER beta-Promotor. Im Uterus wird die Funktion des ER alpha/beta-Expressionsystems durch die von E2V abweichende Veränderung durch OMC gestört.

- In vivo zeigt $\mathrm{OMC}$ in der HPG-Achse keinen Einfluss auf die Hypophysenhormone. Dies kann auf Unterschiede zwischen den in vivo und in vitro-Testsystemen zurückzuführen sein oder auf die Dosis. TERP1 wurde in der Hypophyse induziert. Ein synergistischer Effekt über ER beta kann nicht ausgeschlossen werden und unterstützt die SERM-Hypothese. Anhand der Vaginalzytologie ist zu erkennen, das OMC die Estrogen vermittelten Veränderungen einleitet. Trotz der Unterschiede in der Uterusmorphologie scheint OMC im Uterus eine SERM-Aktivität als ER alpha-Agonist zu 
entfalten. Uterusgewicht, IGF-1- und C3-Expression zeigen für OMC SERMEigenschaften, die von den E2V-Eigenschaften abweichen.

- OMC hat in vitro einen estrogenen Effekt auf die TSH-Sekretion. Allerdings gibt es in vivo einen Effekt von OMC auf die Hypophyse, welcher die HPTAchse nachhaltig von E2V abweichend moduliert. Die untergeordneten Parameter (T3, T4, TSHR und 5'DI) reagieren auf die hypophysäre Repression der TSH-Sekretion, allerdings wird der Rückkopplungsmechanismus von T3/T4 auf die TSH-Sekretion in den OMC-Gruppen gehemmt.

- Die Analyse der Dosis-Wirkungsbeziehungen der einzelnen Parameter erlaubt die Extrapolation der Ergebnisse auf eine Risikogruppe. Die Belastung mit OMC (systemische Exposition) ist im Vergleich zu den CEDs bzw. der maximal akzeptablen Exposition relativ hoch. Demnach kann eine Beeinträchtigung von sensitiven bzw. extensiv exponierten Gruppen der Bevölkerung nicht ausgeschlossen werden. Der Effekt auf die Schilddrüse ist im Gegensatz zu einer estrogenen Wirkung als advers einzustufen. In solchen Fällen sollte von dem Gebrauch eines EDs grundsätzlich Abstand genommen werden.

- Die Serumanalyse hat gezeigt, dass OMC in vivo metabolisiert wird. Dies geschieht nicht über den klassischen Cyp1a1-Weg. Die Identifikation der Metabolite hat sich als schwierig herausgestellt, deswegen kann keine Aussage über biologische Effekte der Metabolite gemacht werden.

Es hat sich gezeigt, dass zur Untersuchung von EACs bzw. EDs der estrogenen Signalwege ein Ansatz nötig ist, der über die klassischen Ziele einer hormonellen Wirkung von Estrogenen wie z.B. dem Uterusgewicht hinausgeht. Dieser Ansatz sollte ein umfassenderes, mehrere Organe oder Achsen beinhaltendes Spektrum abdecken. So konnte für OMC eine möglicherweise rezeptorspezifische und/oder SERM-Wirkung gezeigt werden. Zudem wurde eine zusätzliche Wirkung auf die Hypophyse in der HPTAchse gefunden. Der in dieser Arbeit vorgestellte Ansatz zur Untersuchung von OMC kann dabei noch erweitert werden. Eine ausführlichere Untersuchung der Hypothalamus-Hypophyse-Leber-Achse und Hypothalamus-Hypophyse-KnochenAchse sowie des Immunsystems wäre denkbar. 


\section{Literatur}

Adesanya, O.O., Zhou, J., Samathanam, C., Powell-Braxton, L., Bondy, C.A. (1999). Insulin-like growth factor 1 is required for G2 progression in the estradiolinduced mitotic cycle. Proc Natl Acad Sci U S A 96(6):3287-3291.

Allen, E., Smith, G.M., Garnder, W.U. (1937). Accentuation of the growth effect of theelin on genital tissues of the ovarietcomized mouse by arrest of mitosis with colchicines. Amer J Anat 61:321-341.

Allen, K.E., Clark, E.R., Jordan, V.C. (1980). Evidence for the metabolic activation of non-steroidal antioestrogens: a study of structure-activity relationships. $\mathrm{Br} \mathrm{J}$ Pharmacol 71(1):83-91.

Barb, C.R., Hausman, G.J., Czaja, K. (2005). Leptin: a metabolic signal affecting central regulation of reproduction in the pig. Domest Anim Endocrinol 29(1):186-192.

Barrett-Connor, E., Bush, T.L. (1991). Estrogen and coronary heart disease in women. Jama 265(14):1861-1867.

Batteiger, B., Newhall, W.J.t., Jones, R.B. (1982). The use of Tween 20 as a blocking agent in the immunological detection of proteins transferred to nitrocellulose membranes. J Immunol Methods 55(3):297-307.

Bonnelye, E., Vanacker, J.M., Dittmar, T., Begue, A., Desbiens, X., Denhardt, D.T., et al. (1997). The ERR-1 orphan receptor is a transcriptional activator expressed during bone development. Mol Endocrinol 11(7):905-916.

Bostrom, C.E., Gerde, P., Hanberg, A., Jernstrom, B., Johansson, C., Kyrklund, T., et al. (2002). Cancer risk assessment, indicators, and guidelines for polycyclic aromatic hydrocarbons in the ambient air. Environ Health Perspect 110 Suppl 3:451-488.

Bowe, J., Li, X.F., Sugden, D., Katzenellenbogen, J.A., Katzenellenbogen, B.S., O'Byrne, K.T. (2003). The effects of the phytoestrogen, coumestrol, on gonadotropin-releasing hormone (GnRH) mRNA expression in GT1-7 GnRH neurones. J Neuroendocrinol 15(2):105-108.

Bradford, M.M. (1976). A rapid and sensitive method for the quantitation of microgram quantities of protein utilizing the principle of protein-dye binding. Anal Biochem 72:248-254. 
Bruhn, T., Gülden, M., Ludewig, S., Seibert, H. (1999). Einstufung von Schadstoffen als endokrin wirksame Substanzen.: Umweltbundesamt.

Brzozowski, A.M., Pike, A.C., Dauter, Z., Hubbard, R.E., Bonn, T., Engstrom, O., et al. (1997). Molecular basis of agonism and antagonism in the oestrogen receptor. Nature 389(6652):753-758.

Burke, S. (2001). Missing Values, Outliers, Robust Statistics \& Non-parametric Methods. LCGC Europe Online Supplement:19-24.

Cagampang, F.R., Maeda, K.I., Tsukamura, H., Ohkura, S., Ota, K. (1991).

Involvement of ovarian steroids and endogenous opioids in the fasting-induced suppression of pulsatile LH release in ovariectomized rats. $J$ Endocrinol 129(3):321-328.

Cardenas, H., Pope, W.F. (2004). Attenuation of estrogenic effects by dihydrotestosterone in the pig uterus is associated with downregulation of the estrogen receptors. Biol Reprod 70(2):297-302.

Carlsen, E., Giwercman, A., Keiding, N., Skakkebaek, N.E. (1992). Evidence for decreasing quality of semen during past 50 years. Bmj 305(6854):609-613.

Carrasco, N. (1993). Iodide transport in the thyroid gland. Biochim Biophys Acta 1154(1):65-82.

Chen, Z., Zheng, H., Dong, K.W. (2001). Identification of negative and positive estrogen response elements in human GnRH upstream promoter in the placental JEG-3 cells. Mol Cell Endocrinol 184(1-2):125-134.

Clark, J.H., Markaverich, B.M. (1983). The agonistic and antagonistic effects of short acting estrogens: a review. Pharmacol Ther 21(3):429-453.

Colborn, T., vom Saal, F.S., Soto, A.M. (1993). Developmental effects of endocrinedisrupting chemicals in wildlife and humans. Environ Health Perspect 101(5):378-384.

Cooke, B.A., King, R.J.B., van der Molen, H.J. (1988). Hormones and their action. Part I:Elsevier.

Couse, J.F., Bunch, D.O., Lindzey, J., Schomberg, D.W., Korach, K.S. (1999). Prevention of the polycystic ovarian phenotype and characterization of ovulatory capacity in the estrogen receptor-alpha knockout mouse. Endocrinology 140(12):5855-5865. 
Couse, J.F., Curtis, S.W., Washburn, T.F., Lindzey, J., Golding, T.S., Lubahn, D.B., et al. (1995). Analysis of transcription and estrogen insensitivity in the female mouse after targeted disruption of the estrogen receptor gene. Mol Endocrinol 9(11):1441-1454.

Couse, J.F., Korach, K.S. (1999). Estrogen receptor null mice: what have we learned and where will they lead us? Endocr Rev 20(3):358-417.

Crump, K.S. (1984). A new method for determining allowable daily intakes. Fundam Appl Toxicol 4(5):854-871.

D'Eon, T.M., Souza, S.C., Aronovitz, M., Obin, M.S., Fried, S.K., Greenberg, A.S. (2005). Estrogen regulation of adiposity and fuel partitioning. Evidence of genomic and non-genomic regulation of lipogenic and oxidative pathways. $J$ Biol Chem 280(43):35983-35991.

Davis, J.M., Svendsgaard, D.J. (1990). U-shaped dose-response curves: their occurrence and implications for risk assessment. J Toxicol Environ Health 30(2):71-83.

Degen, G.H., Foth, H., Kahl, R., Kappus, H., Neumann, H.G., Oesch, F., et al. (1999). Hormonell aktive Substanzen in der Umwelt: Xenoöstrogene. 24: DGPT Forum.

Denison, M.S., Pandini, A., Nagy, S.R., Baldwin, E.P., Bonati, L. (2002). Ligand binding and activation of the Ah receptor. Chem Biol Interact 141(1-2):3-24.

Di Carlo, C., Tommaselli, G.A., Sammartino, A., Bifulco, G., Nasti, A., Nappi, C. (2004). Serum leptin levels and body composition in postmenopausal women: effects of hormone therapy. Menopause 11(4):466-473.

Dich, J., Wiklund, K. (1998). Prostate cancer in pesticide applicators in Swedish agriculture. Prostate 34(2):100-112.

Diel, P., Schulz, T., Smolnikar, K., Strunck, E., Vollmer, G., Michna, H. (2000). Ability of xeno- and phytoestrogens to modulate expression of estrogen-sensitive genes in rat uterus: estrogenicity profiles and uterotropic activity. J Steroid Biochem Mol Biol 73(1-2):1-10.

Dong, K.W., Chen, Z.G., Cheng, K.W., Yu, K.L. (1996). Evidence for estrogen receptor-mediated regulation of human gonadotropin-releasing hormone promoter activity in human placental cells. Mol Cell Endocrinol 117(2):241-246.

Dorling, A.A., Todman, M.G., Korach, K.S., Herbison, A.E. (2003). Critical role for estrogen receptor alpha in negative feedback regulation of gonadotropin- 
releasing hormone mRNA expression in the female mouse. Neuroendocrinology 78(4):204-209.

Ebert, B., Seidel, A., Lampen, A. (2005). Induction of phase-1 metabolizing enzymes by oltipraz, flavone and indole-3-carbinol enhance the formation and transport of benzo[a]pyrene sulfate conjugates in intestinal Caco-2 cells. Toxicol Lett 158(2):140-151.

Eertmans, F., Dhooge, W., Stuyvaert, S., Comhaire, F. (2003). Endocrine disruptors: effects on male fertility and screening tools for their assessment. Toxicol In Vitro 17(5-6):515-524.

Estabrook, R.W. (2003). A passion for P450s (rememberances of the early history of research on cytochrome P450). Drug Metab Dispos 31(12):1461-1473.

Fink, G. (1988). Oestrogen and progesterone interactions in the control of gonadotrophin and prolactin secretion. J Steroid Biochem 30(1-6):169-178.

Fleming, L.E., Bean, J.A., Rudolph, M., Hamilton, K. (1999). Cancer incidence in a cohort of licensed pesticide applicators in Florida. J Occup Environ Med 41(4):279-288.

Flouriot, G., Brand, H., Denger, S., Metivier, R., Kos, M., Reid, G., et al. (2000). Identification of a new isoform of the human estrogen receptor-alpha (hERalpha) that is encoded by distinct transcripts and that is able to repress hERalpha activation function 1. Embo $J$ 19(17):4688-4700.

Frasor, J., Barnett, D.H., Danes, J.M., Hess, R., Parlow, A.F., Katzenellenbogen, B.S. (2003). Response-specific and ligand dose-dependent modulation of estrogen receptor (ER) alpha activity by ERbeta in the uterus. Endocrinology 144(7):3159-3166.

Friend, K.E., Ang, L.W., Shupnik, M.A. (1995). Estrogen regulates the expression of several different estrogen receptor mRNA isoforms in rat pituitary. Proc Natl Acad Sci U S A 92(10):4367-4371.

Garcia-Rodriguez, J., Garcia-Martin, M., Nogueras-Ocana, M., de Dios Luna-delCastillo, J., Espigares Garcia, M., Olea, N., et al. (1996). Exposure to pesticides and cryptorchidism: geographical evidence of a possible association. Environ Health Perspect 104(10):1090-1095. 
Gardner, R.M., Verner, G., Kirkland, J.L., Stancel, G.M. (1989). Regulation of uterine epidermal growth factor (EGF) receptors by estrogen in the mature rat and during the estrous cycle. $J$ Steroid Biochem 32(3):339-343.

Gies, A., Gottschalk, C., Greiner, P., Heger, W., Kolossa, M., Rechenberg, B., et al. (2001). Nachhaltigkeit und Vorsorge bei der Risikobewertung und beim Risikomanagement von Chemikalien. Teil II: Umweltchemikalien, die auf das Hormonsystem wirken - Belastungen, Auswirkungen, Minderungsstrategien -: Umweltbundesamt.

Giguere, V., Yang, N., Segui, P., Evans, R.M. (1988). Identification of a new class of steroid hormone receptors. Nature 331(6151):91-94.

Golden, R.J., Noller, K.L., Titus-Ernstoff, L., Kaufman, R.H., Mittendorf, R., Stillman, R., et al. (1998). Environmental endocrine modulators and human health: an assessment of the biological evidence. Crit Rev Toxicol 28(2):109-227.

Gomez, E., Pillon, A., Fenet, H., Rosain, D., Duchesne, M.J., Balaguer, P., et al. (2005). Estrogenic activity of cosmetic components in reporter cell lines: Parabens, UV screens, and musk. J Toxicol Environ Health A 68(4):239-251.

Green, S., Walter, P., Kumar, V., Krust, A., Bornert, J.M., Argos, P., et al. (1986). Human oestrogen receptor cDNA: sequence, expression and homology to v-erbA. Nature 320(6058):134-139.

Gülden, M., Turan, A., Seibert, H. (1997). Substanzen mit endokriner Wirkung in Oberflächengewässern. Berlin: Umweltbundesamt.

Gurr, J.A., Kourides, I.A. (1983). Regulation of thyrotropin biosynthesis. Discordant effect of thyroid hormone on alpha and beta subunit mRNA levels. J Biol Chem 258(17):10208-10211.

Halldin, K., Berg, C., Bergman, A., Brandt, I., Brunstrom, B. (2001). Distribution of bisphenol A and tetrabromobisphenol A in quail eggs, embryos and laying birds and studies on reproduction variables in adults following in ovo exposure. Arch Toxicol 75(10):597-603.

Harris, H.A., Katzenellenbogen, J.A., Katzenellenbogen, B.S. (2002). Characterization of the biological roles of the estrogen receptors, ERalpha and ERbeta, in estrogen target tissues in vivo through the use of an ERalpha-selective ligand. Endocrinology 143(11):4172-4177. 
Hatoya, S., Torii, R., Kumagai, D., Sugiura, K., Kawate, N., Tamada, H., et al. (2003). Expression of estrogen receptor alpha and beta genes in the mediobasal hypothalamus, pituitary and ovary during the canine estrous cycle. Neurosci Lett 347(2):131-135.

Heid, C.A., Stevens, J., Livak, K.J., Williams, P.M. (1996). Real time quantitative PCR. Genome Res 6(10):986-994.

Heneweer, M., Muusse, M., van den Berg, M., Sanderson, J.T. (2005). Additive estrogenic effects of mixtures of frequently used UV filters on pS2-gene transcription in MCF-7 cells. Toxicol Appl Pharmacol 208(2):170-177.

Herbison, A.E. (1998). Multimodal influence of estrogen upon gonadotropin-releasing hormone neurons. Endocr Rev 19(3):302-330.

Herbison, A.E., Horvath, T.L., Naftolin, F., Leranth, C. (1995). Distribution of estrogen receptor-immunoreactive cells in monkey hypothalamus: relationship to neurones containing luteinizing hormone-releasing hormone and tyrosine hydroxylase. Neuroendocrinology 61(1):1-10.

Herbst, A.L. (1987). The effects in the human of diethylstilbestrol (DES) use during pregnancy. Princess Takamatsu Symp 18:67-75.

Herbst, A.L., Ulfelder, H., Poskanzer, D.C. (1971). Adenocarcinoma of the vagina. Association of maternal stilbestrol therapy with tumor appearance in young women. N Engl J Med 284(15):878-881.

Hess, R.A., Bunick, D., Lubahn, D.B., Zhou, Q., Bouma, J. (2000). Morphologic changes in efferent ductules and epididymis in estrogen receptor-alpha knockout mice. J Androl 21(1):107-121.

Holt, L.H., Herbst, A.L. (1982). DES-related female genital changes. Semin Oncol 9(3):341-348.

Hong, H., Tong, W., Fang, H., Shi, L., Xie, Q., Wu, J., et al. (2002). Prediction of estrogen receptor binding for 58,000 chemicals using an integrated system of a tree-based model with structural alerts. Environ Health Perspect 110(1):29-36.

Hong, H., Yang, L., Stallcup, M.R. (1999). Hormone-independent transcriptional activation and coactivator binding by novel orphan nuclear receptor ERR3. $J$ Biol Chem 274(32):22618-22626. 
Hrabovszky, E., Steinhauser, A., Barabas, K., Shughrue, P.J., Petersen, S.L., Merchenthaler, I., et al. (2001). Estrogen receptor-beta immunoreactivity in luteinizing hormone-releasing hormone neurons of the rat brain. Endocrinology 142(7):3261-3264.

Hunter, W.M., Greenwood, F.C. (1962). Preparation of iodine-131 labelled human growth hormone of high specific activity. Nature 194:495-496.

Ignar-Trowbridge, D.M., Teng, C.T., Ross, K.A., Parker, M.G., Korach, K.S., McLachlan, J.A. (1993). Peptide growth factors elicit estrogen receptordependent transcriptional activation of an estrogen-responsive element. Mol Endocrinol 7(8):992-998.

Ikuyama, S., Ohe, K., Takayanagi, R., Kohn, L.D., Nawata, H. (1997). Cloning and characterization of the $4.2 \mathrm{~kb}$ region of the rat thyrotropin receptor promoter. Endocr J 44(2):247-256.

Janjua, N.R., Mogensen, B., Andersson, A.M., Petersen, J.H., Henriksen, M., Skakkebaek, N.E., et al. (2004). Systemic absorption of the sunscreens benzophenone-3, octyl-methoxycinnamate, and 3-(4-methyl-benzylidene) camphor after whole-body topical application and reproductive hormone levels in humans. J Invest Dermatol 123(1):57-61.

Jeong, H.G., Kim, J.Y., Choi, C.Y., You, H.J., Hahm, K. (2001). Suppression of CYP1A1 expression by 4-nonylphenol in murine Hepa-1c1c7 cells. Cancer Lett 165(1):95-101.

Jeuken, A., Keser, B.J., Khan, E., Brouwer, A., Koeman, J., Denison, M.S. (2003). Activation of the Ah receptor by extracts of dietary herbal supplements, vegetables, and fruits. J Agric Food Chem 51(18):5478-5487.

Jimenez, M.M., Pelletier, J., Bobin, M.F., Martini, M.C. (2004). Influence of encapsulation on the in vitro percutaneous absorption of octyl methoxycinnamate. Int J Pharm 272(1-2):45-55.

Jordan, V.C., Robinson, S.P. (1987). Species-specific pharmacology of antiestrogens: role of metabolism. Fed Proc 46(5):1870-1874.

Kalberlah, F., Hassauer, M. (2003). Vergleich der Verfahren zur Ableitung gesundheitsbezogener Wirkungsschwellen (Benchmark - NOAEL). 
Abschlussbericht Forschungs- und Entwicklungsvorhaben FKZ 20165 201/01. Freiburg/Berlin: Forschungs- und Beratungsinstitut Gefahrstoffe GmbH.

Kanno, J., Onyon, L., Peddada, S., Ashby, J., Jacob, E., Owens, W. (2003). The OECD program to validate the rat uterotrophic bioassay. Phase 2: dose-response studies. Environ Health Perspect 111(12):1530-1549.

Kavlock, R., Cummings, A. (2005). Mode of action: inhibition of androgen receptor function--vinclozolin-induced malformations in reproductive development. Crit Rev Toxicol 35(8-9):721-726.

Kavlock, R.J., Daston, G.P., DeRosa, C., Fenner-Crisp, P., Gray, L.E., Kaattari, S., et al. (1996). Research needs for the risk assessment of health and environmental effects of endocrine disruptors: a report of the U.S. EPA-sponsored workshop. Environ Health Perspect 104 Suppl 4:715-740.

Kelce, W.R., Stone, C.R., Laws, S.C., Gray, L.E., Kemppainen, J.A., Wilson, E.M. (1995). Persistent DDT metabolite p,p'-DDE is a potent androgen receptor antagonist. Nature 375(6532):581-585.

Keller-Byrne, J.E., Khuder, S.A., Schaub, E.A. (1997). Meta-analyses of prostate cancer and farming. Am J Ind Med 31(5):580-586.

Kemppainen, J.A., Langley, E., Wong, C.I., Bobseine, K., Kelce, W.R., Wilson, E.M. (1999). Distinguishing androgen receptor agonists and antagonists: distinct mechanisms of activation by medroxyprogesterone acetate and dihydrotestosterone. Mol Endocrinol 13(3):440-454.

Kim, H.S., Shin, J.H., Moon, H.J., Kang, I.H., Kim, T.S., Kim, I.Y., et al. (2002). Comparative estrogenic effects of p-nonylphenol by 3-day uterotrophic assay and female pubertal onset assay. Reprod Toxicol 16(3):259-268.

Klammer, H., Schlecht, C., Wuttke, W., Jarry, H. (2005). Multi-organic risk assessment of estrogenic properties of octyl-methoxycinnamate in vivo A 5-day sub-acute pharmacodynamic study with ovariectomized rats. Toxicology 215(1-2):90-96.

Klotz, D.M., Hewitt, S.C., Ciana, P., Raviscioni, M., Lindzey, J.K., Foley, J., et al. (2002). Requirement of estrogen receptor-alpha in insulin-like growth factor-1 (IGF-1)-induced uterine responses and in vivo evidence for IGF-1/estrogen receptor cross-talk. J Biol Chem 277(10):8531-8537. 
Klotz, D.M., Hewitt, S.C., Korach, K.S., Diaugustine, R.P. (2000). Activation of a uterine insulin-like growth factor I signaling pathway by clinical and environmental estrogens: requirement of estrogen receptor-alpha. Endocrinology 141(9):3430-3439.

Korach, K.S., McLachlan, J.A. (1995). Techniques for detection of estrogenicity. Environ Health Perspect 103 Suppl 7:5-8.

Krege, J.H., Hodgin, J.B., Couse, J.F., Enmark, E., Warner, M., Mahler, J.F., et al. (1998). Generation and reproductive phenotypes of mice lacking estrogen receptor beta. Proc Natl Acad Sci U S A 95(26):15677-15682.

Kuiper, G.G., Enmark, E., Pelto-Huikko, M., Nilsson, S., Gustafsson, J.A. (1996). Cloning of a novel receptor expressed in rat prostate and ovary. Proc Natl Acad Sci U S A 93(12):5925-5930.

Kushner, P.J., Agard, D., Feng, W.J., Lopez, G., Schiau, A., Uht, R., et al. (2000). Oestrogen receptor function at classical and alternative response elements. Novartis Found Symp 230:20-26; discussion 27-40.

Labrie, F., Belanger, A., Cusan, L., Candas, B. (1997). Physiological changes in dehydroepiandrosterone are not reflected by serum levels of active androgens and estrogens but of their metabolites: intracrinology. J Clin Endocrinol Metab 82(8):2403-2409.

Lacey, J.V., Jr., Brinton, L.A., Lubin, J.H., Sherman, M.E., Schatzkin, A., Schairer, C. (2005). Endometrial carcinoma risks among menopausal estrogen plus progestin and unopposed estrogen users in a cohort of postmenopausal women. Cancer Epidemiol Biomarkers Prev 14(7):1724-1731.

Laemmli, U.K. (1970). Cleavage of structural proteins during the assembly of the head of bacteriophage T4. Nature 227(5259):680-685.

Lai, K.P., Wong, M.H., Wong, C.K. (2004). Modulation of AhR-mediated CYP1A1 mRNA and EROD activities by 17beta-estradiol and dexamethasone in TCDDinduced H411E cells. Toxicol Sci 78(1):41-49.

Landel, C.C., Kushner, P.J., Greene, G.L. (1994). The interaction of human estrogen receptor with DNA is modulated by receptor-associated proteins. Mol Endocrinol 8(10):1407-1419. 
Landel, C.C., Kushner, P.J., Greene, G.L. (1995). Estrogen receptor accessory proteins: effects on receptor-DNA interactions. Environ Health Perspect 103 Suppl 7:2328.

Legan, S.J., Tsai, H.W. (2003). Oestrogen receptor-alpha and -beta immunoreactivity in gonadotropin-releasing hormone neurones after ovariectomy and chronic exposure to oestradiol. J Neuroendocrinol 15(12):1164-1170.

Lehman, M.N., Karsch, F.J. (1993). Do gonadotropin-releasing hormone, tyrosine hydroxylase-, and beta-endorphin-immunoreactive neurons contain estrogen receptors? A double-label immunocytochemical study in the Suffolk ewe. Endocrinology 133(2):887-895.

Lindberg, M.K., Moverare, S., Skrtic, S., Gao, H., Dahlman-Wright, K., Gustafsson, J.A., et al. (2003). Estrogen receptor (ER)-beta reduces ERalpha-regulated gene transcription, supporting a "ying yang" relationship between ERalpha and ERbeta in mice. Mol Endocrinol 17(2):203-208.

Lippman, S.S., Amr, S., Weintraub, B.D. (1986). Discordant effects of thyrotropin (TSH)-releasing hormone on pre- and posttranslational regulation of TSH biosynthesis in rat pituitary. Endocrinology 119(1):343-348.

Liu, D., Zhang, Z., Gladwell, W., Teng, C.T. (2003). Estrogen stimulates estrogenrelated receptor alpha gene expression through conserved hormone response elements. Endocrinology 144(11):4894-4904.

Liu, M.M., Albanese, C., Anderson, C.M., Hilty, K., Webb, P., Uht, R.M., et al. (2002). Opposing action of estrogen receptors alpha and beta on cyclin D1 gene expression. J Biol Chem 277(27):24353-24360.

Livak, K.J., Flood, S.J., Marmaro, J., Giusti, W., Deetz, K. (1995). Oligonucleotides with fluorescent dyes at opposite ends provide a quenched probe system useful for detecting PCR product and nucleic acid hybridization. PCR Methods Appl 4(6):357-362.

Lubahn, D.B., Moyer, J.S., Golding, T.S., Couse, J.F., Korach, K.S., Smithies, O. (1993). Alteration of reproductive function but not prenatal sexual development after insertional disruption of the mouse estrogen receptor gene. Proc Natl Acad Sci U S A 90(23):11162-11166. 
Luo, J., Sladek, R., Bader, J.A., Matthyssen, A., Rossant, J., Giguere, V. (1997).

Placental abnormalities in mouse embryos lacking the orphan nuclear receptor ERR-beta. Nature 388(6644):778-782.

Maeda, K.I., Tsukamura, H., Uchida, E., Ohkura, N., Ohkura, S., Yokoyama, A. (1989).

Changes in the pulsatile secretion of LH after the removal of and subsequent resuckling by pups in ovariectomized lactating rats. J Endocrinol 121(2):277283.

Mangelsdorf, D.J., Thummel, C., Beato, M., Herrlich, P., Schutz, G., Umesono, K., et al. (1995). The nuclear receptor superfamily: the second decade. Cell 83(6):835839.

Matthews, J., Gustafsson, J.A. (2003). Estrogen signaling: a subtle balance between ER alpha and ER beta. Mol Interv 3(5):281-292.

Matthiessen, P. (2000). Is endocrine disruption a significant ecological issue? Ecotoxicol 9:21-24.

Mayes, J.S., Watson, G.H. (2004). Direct effects of sex steroid hormones on adipose tissues and obesity. Obes Rev 5(4):197-216.

Miller, W.L., Knight, M.M., Gorski, J. (1977). Estrogen action in vitro: regulation of thyroid stimulating and other pituitary hormones in cell cultures. Endocrinology 101(5):1455-1460.

Möhner, M. (1994). Atlas der Krebsinzidenz in der DDR 1961-1989. Berlin:Ullstein Mosby.

Morimura, T., Tsunekawa, K., Kasahara, T., Seki, K., Ogiwara, T., Mori, M., et al. (2005). Expression of type 2 iodothyronine deiodinase in human osteoblast is stimulated by thyrotropin. Endocrinology 146(4):2077-2084.

Morinaga, H., Yanase, T., Nomura, M., Okabe, T., Goto, K., Harada, N., et al. (2004). A benzimidazole fungicide, benomyl, and its metabolite, carbendazim, induce aromatase activity in a human ovarian granulose-like tumor cell line (KGN). Endocrinology 145(4): 1860-1869.

Morrison, H., Savitz, D., Semenciw, R., Hulka, B., Mao, Y., Morison, D., et al. (1993). Farming and prostate cancer mortality. Am J Epidemiol 137(3):270-280.

Mukku, V.R., Stancel, G.M. (1985). Receptors for epidermal growth factor in the rat uterus. Endocrinology 117(1):149-154. 
Mullis, K.B., Faloona, F.A. (1987). Specific synthesis of DNA in vitro via a polymerase-catalyzed chain reaction. Methods Enzymol 155:335-350.

Murata, T., Narita, K., Honda, K., Matsukawa, S., Higuchi, T. (2003). Differential regulation of estrogen receptor alpha and beta mRNAs in the rat uterus during pregnancy and labor: possible involvement of estrogen receptors in oxytocin receptor regulation. Endocr $J$ 50(5):579-587.

Murphy, L.J., Murphy, L.C., Friesen, H.G. (1987). Estrogen induces insulin-like growth factor-I expression in the rat uterus. Mol Endocrinol 1(7):445-450.

Mußler, B. (1999). Etablierung von in vitro Methoden zur Erfassung von endokrinen Disruptoren, Dissertation. Universität Kaiserslautern.

Navas, J.M., Segner, H. (2000). Modulation of trout 7-ethoxyresorufin-O-deethylase (EROD) activity by estradiol and octylphenol. Mar Environ Res 50(1-5):157162.

Nedvidkova, J., Haluzik, M., Pacak, K., Schreiber, V., Starka, L. (1998). Estrogenic effect of estradiol-sulfamate on the male rat anterior pituitary. J Steroid Biochem Mol Biol 67(4):359-362.

Nilsson, S., Makela, S., Treuter, E., Tujague, M., Thomsen, J., Andersson, G., et al. (2001). Mechanisms of estrogen action. Physiol Rev 81(4):1535-1565.

OECD. (1996). European Workshop on the impact of endocrine disruptors on human health

and wildlife; Report of Proceedings 2-4 December; Weybridge UK: Organisation for Economic Co-operation and Development.

Oesterreich, S., Zhang, P., Guler, R.L., Sun, X., Curran, E.M., Welshons, W.V., et al. (2001). Re-expression of estrogen receptor alpha in estrogen receptor alphanegative MCF-7 cells restores both estrogen and insulin-like growth factormediated signaling and growth. Cancer Res 61(15):5771-5777.

Okada, A., Ohta, Y., Brody, S.L., Watanabe, H., Krust, A., Chambon, P., et al. (2004). Role of foxj1 and estrogen receptor alpha in ciliated epithelial cell differentiation of the neonatal oviduct. J Mol Endocrinol 32(3):615-625.

Owens, W., Koeter, H.B. (2003). The OECD program to validate the rat uterotrophic bioassay: an overview. Environ Health Perspect 111(12):1527-1529. 
Paech, K., Webb, P., Kuiper, G.G., Nilsson, S., Gustafsson, J., Kushner, P.J., et al. (1997). Differential ligand activation of estrogen receptors ERalpha and ERbeta at AP1 sites. Science 277(5331):1508-1510.

Pak, T.R., Chung, W.C., Lund, T.D., Hinds, L.R., Clay, C.M., Handa, R.J. (2005). The androgen metabolite, 5alpha-androstane-3beta, 17beta-diol, is a potent modulator of estrogen receptor-beta1-mediated gene transcription in neuronal cells. Endocrinology 146(1):147-155.

Pak, T.R., Chung, W.C., Roberts, J.L., Handa, R.J. (2006). Ligand-independent effects of estrogen receptor beta on mouse gonadotropin releasing hormone $(\mathrm{GnRH})$ promoter activity. Endocrinology.

Palkovits, M. (1973). Isolated removal of hypothalamic or other brain nuclei of the rat. Brain Res 59:449-450.

Parker, A.S., Cerhan, J.R., Putnam, S.D., Cantor, K.P., Lynch, C.F. (1999). A cohort study of farming and risk of prostate cancer in Iowa. Epidemiology 10(4):452455.

Paxinos, G., Watson, C. (1998). The Rat Brain in Stereotaxic Coordinates. London:Academic Press.

Qin, C., Samudio, I., Ngwenya, S., Safe, S. (2004). Estrogen-dependent regulation of ornithine decarboxylase in breast cancer cells through activation of nongenomic cAMP-dependent pathways. Mol Carcinog 40(3):160-170.

Rachez, C., Freedman, L.P. (2001). Mediator complexes and transcription. Curr Opin Cell Biol 13(3):274-280.

Reid, G., Denger, S., Kos, M., Gannon, F. (2002). Human estrogen receptor-alpha: regulation by synthesis, modification and degradation. Cell Mol Life Sci 59(5):821-831.

Resnick, E.M., Schreihofer, D.A., Periasamy, A., Shupnik, M.A. (2000). Truncated estrogen receptor product-1 suppresses estrogen receptor transactivation by dimerization with estrogen receptors alpha and beta. J Biol Chem 275(10):71587166.

Richards, R.G., DiAugustine, R.P., Petrusz, P., Clark, G.C., Sebastian, J. (1996). Estradiol stimulates tyrosine phosphorylation of the insulin-like growth factor-1 
receptor and insulin receptor substrate-1 in the uterus. Proc Natl Acad Sci USA 93(21):12002-12007.

Rösch, C., Vetter, E., Götz, D., Steinbicker, V. (1999). Pilotstudie: Prävalenz genitaler Fehlbildungen - Datenbasis - Auswertung - Ursachenhypothese.

Roy, D., Angelini, N.L., Belsham, D.D. (1999). Estrogen directly respresses gonadotropin-releasing hormone $(\mathrm{GnRH})$ gene expression in estrogen receptoralpha (ERalpha)- and ERbeta-expressing GT1-7 GnRH neurons. Endocrinology 140(11):5045-5053.

Safe, S., Wormke, M. (2003). Inhibitory aryl hydrocarbon receptor-estrogen receptor alpha cross-talk and mechanisms of action. Chem Res Toxicol 16(7):807-816.

Sahlin, L., Norstedt, G., Eriksson, H. (1994). Estrogen regulation of the estrogen receptor and insulinlike growth factor-I in the rat uterus: a potential coupling between effects of estrogen and IGF-I. Steroids 59(7):421-430.

Saito, T., Endo, T., Nakazato, M., Kogai, T., Onaya, T. (1997). Thyroid-stimulating hormone-induced down-regulation of thyroid transcription factor 1 in rat thyroid FRTL-5 cells. Endocrinology 138(2):602-606.

Salinovich, O., Montelaro, R.C. (1986). Reversible staining and peptide mapping of proteins transferred to nitrocellulose after separation by sodium dodecylsulfatepolyacrylamide gel electrophoresis. Anal Biochem 156(2):341-347.

Sambrook, J., Fritsch, E.F., Maniatis, T. (1989). Molecular Cloning: a laboratory manual. New York:Cold Spring Harbour Laboratory press.

Sasano, H., Uzuki, M., Sawai, T., Nagura, H., Matsunaga, G., Kashimoto, O., et al. (1997). Aromatase in human bone tissue. J Bone Miner Res 12(9):1416-1423.

Schairer, C., Lubin, J., Troisi, R., Sturgeon, S., Brinton, L., Hoover, R. (2000). Estrogen-progestin replacement and risk of breast cancer. Jama 284(6):691-694.

Schausi, D., Tiffoche, C., Thieulant, M.L. (2003). Regulation of the intronic promoter of rat estrogen receptor alpha gene, responsible for truncated estrogen receptor product-1 expression. Endocrinology 144(7):2845-2855.

Schenborn, E.T., Mierendorf, R.C., Jr. (1985). A novel transcription property of SP6 and T7 RNA polymerases: dependence on template structure. Nucleic Acids Res 13(17):6223-6236. 
Schlumpf, M., Cotton, B., Conscience, M., Haller, V., Steinmann, B., Lichtensteiger, W. (2001). In vitro and in vivo estrogenicity of UV screens. Environ Health Perspect 109(3):239-244.

Schmutzler, C., Hamann, I., Hofmann, P.J., Kovacs, G., Stemmler, L., Mentrup, B., et al. (2004). Endocrine active compounds affect thyrotropin and thyroid hormone levels in serum as well as endpoints of thyroid hormone action in liver, heart and kidney. Toxicology 205(1-2):95-102.

Schreihofer, D.A., Resnick, E.M., Soh, A.Y., Shupnik, M.A. (1999). Transcriptional regulation by a naturally occurring truncated rat estrogen receptor (ER), truncated ER product-1 (TERP-1). Mol Endocrinol 13(2):320-329.

Schreihofer, D.A., Rowe, D.F., Rissman, E.F., Scordalakes, E.M., Gustafsson, J.J., Shupnik, M.A. (2002). Estrogen receptor-alpha (ERalpha), but not ERbeta, modulates estrogen stimulation of the ERalpha-truncated variant, TERP-1. Endocrinology 143(11):4196-4202.

Schreihofer, D.A., Stoler, M.H., Shupnik, M.A. (2000). Differential expression and regulation of estrogen receptors (ERs) in rat pituitary and cell lines: estrogen decreases ERalpha protein and estrogen responsiveness. Endocrinology 141(6):2174-2184.

Schreurs, R., Lanser, P., Seinen, W., van der Burg, B. (2002). Estrogenic activity of UV filters determined by an in vitro reporter gene assay and an in vivo transgenic zebrafish assay. Arch Toxicol 76(5-6):257-261.

Schuz, J., Schon, D., Batzler, W., Baumgardt-Elms, C., Eisinger, B., Lehnert, M., et al. (2000). Cancer registration in Germany: current status, perspectives and trends in cancer incidence 1973-93. J Epidemiol Biostat 5(2):99-107.

Seidlova-Wuttke, D., Jarry, H., Christoffel, J., Rimoldi, G., Wuttke, W. (2005). Effects of bisphenol-A (BPA), dibutylphtalate (DBP), benzophenone-2 (BP2), procymidone (Proc), and linurone (Lin) on fat tissue, a variety of hormones and metabolic parameters: a 3 months comparison with effects of estradiol (E2) in ovariectomized (ovx) rats. Toxicology 213(1-2):13-24.

Shapiro, D.J. (1981). Quantitative ethanol precipitation of nanogram quantities of DNA and RNA. Anal Biochem 110(1):229-231. 
Sharpe, R.M. (2003). The 'oestrogen hypothesis'- where do we stand now? Int J Androl 26(1):2-15.

Sharpe, R.M., Irvine, D.S. (2004). How strong is the evidence of a link between environmental chemicals and adverse effects on human reproductive health? Bmj 328(7437):447-451.

Shi, Q., Aida, K., Vandeberg, J.L., Wang, X.L. (2004). Passage-dependent changes in baboon endothelial cells--relevance to in vitro aging. DNA Cell Biol 23(8):502509.

Shupnik, M.A., Gharib, S.D., Chin, W.W. (1988). Estrogen suppresses rat gonadotropin gene transcription in vivo. Endocrinology 122(5):1842-1846.

Shupnik, M.A., Greenspan, S.L., Ridgway, E.C. (1986). Transcriptional regulation of thyrotropin subunit genes by thyrotropin-releasing hormone and dopamine in pituitary cell culture. J Biol Chem 261(27):12675-12679.

Skinner, D.C., Caraty, A., Allingham, R. (2001). Unmasking the progesterone receptor in the preoptic area and hypothalamus of the ewe: no colocalization with gonadotropin-releasing neurons. Endocrinology 142(2):573-579.

Skynner, M.J., Sim, J.A., Herbison, A.E. (1999). Detection of estrogen receptor alpha and beta messenger ribonucleic acids in adult gonadotropin-releasing hormone neurons. Endocrinology 140(11):5195-5201.

Slob, W. (2002). Dose-response modeling of continuous endpoints. Toxicol Sci 66(2):298-312.

Smith, M.S., Freeman, M.E., Neill, J.D. (1975). The control of progesterone secretion during the estrous cycle and early pseudopregnancy in the rat: prolactin, gonadotropin and steroid levels associated with rescue of the corpus luteum of pseudopregnancy. Endocrinology 96(1):219-226.

Soto, A.M., Justicia, H., Wray, J.W., Sonnenschein, C. (1991). p-Nonyl-phenol: an estrogenic xenobiotic released from "modified" polystyrene. Environ Health Perspect 92:167-173.

Spink, D.C., Katz, B.H., Hussain, M.M., Pentecost, B.T., Cao, Z., Spink, B.C. (2003). Estrogen regulates $\mathrm{Ah}$ responsiveness in MCF-7 breast cancer cells. Carcinogenesis 24(12):1941-1950. 
Sundstrom, S.A., Komm, B.S., Ponce-de-Leon, H., Yi, Z., Teuscher, C., Lyttle, C.R. (1989). Estrogen regulation of tissue-specific expression of complement C3. $J$ Biol Chem 264(28):16941-16947.

Tena-Sempere, M., Navarro, V.M., Mayen, A., Bellido, C., Sanchez-Criado, J.E. (2004). Regulation of estrogen receptor (ER) isoform messenger RNA expression by different ER ligands in female rat pituitary. Biol Reprod 70(3):671-678.

Thierfelder, W., Mehnert, W.H., Laußmann, D., Arndt, D., Reineke, H.H. (1995). Der Einfluss umweltrelevanter östrogener oder östrogenartiger Substanzen auf das Reproduktionssystem. Bundesgesundheitsblatt 38:337-341.

Toft, D., Gorski, J. (1966). A receptor molecule for estrogens: isolation from the rat uterus and preliminary characterization. Proc Natl Acad Sci U S A 55(6):15741581.

Toppari, J., Larsen, J.C., Christiansen, P., Giwercman, A., Grandjean, P., Guillette, L.J., Jr., et al. (1996). Male reproductive health and environmental xenoestrogens. Environ Health Perspect 104 Suppl 4:741-803.

Towbin, H., Staehelin, T., Gordon, J. (1979). Electrophoretic transfer of proteins from polyacrylamide gels to nitrocellulose sheets: procedure and some applications. Proc Natl Acad Sci U S A 76(9):4350-4354.

Vanacker, J.M., Pettersson, K., Gustafsson, J.A., Laudet, V. (1999). Transcriptional targets shared by estrogen receptor- related receptors (ERRs) and estrogen receptor (ER) alpha, but not by ERbeta. Embo J 18(15):4270-4279.

Vik, D.P., Amiguet, P., Moffat, G.J., Fey, M., Amiguet-Barras, F., Wetsel, R.A., et al. (1991). Structural features of the human C3 gene: intron/exon organization, transcriptional start site, and promoter region sequence. Biochemistry 30(4):1080-1085.

Vos, J.G., Dybing, E., Greim, H.A., Ladefoged, O., Lambre, C., Tarazona, J.V., et al. (2000). Health effects of endocrine-disrupting chemicals on wildlife, with special reference to the European situation. Crit Rev Toxicol 30(1):71-133.

Wahli, W., Martinez, E. (1991). Superfamily of steroid nuclear receptors: positive and negative regulators of gene expression. Faseb J 5(9):2243-2249. 
Washburn, S.A., Adams, M.R., Clarkson, T.B., Adelman, S.J. (1993). A conjugated equine estrogen with differential effects on uterine weight and plasma cholesterol in the rat. Am J Obstet Gynecol 169(2 Pt 1):251-254; discussion 254256.

Watanabe, T., Inoue, S., Ogawa, S., Ishii, Y., Hiroi, H., Ikeda, K., et al. (1997). Agonistic effect of tamoxifen is dependent on cell type, ERE-promoter context, and estrogen receptor subtype: functional difference between estrogen receptors alpha and beta. Biochem Biophys Res Commun 236(1):140-145.

Watters, J.J., Chun, T.Y., Kim, Y.N., Bertics, P.J., Gorski, J. (2000). Estrogen modulation of prolactin gene expression requires an intact mitogen-activated protein kinase signal transduction pathway in cultured rat pituitary cells. $\mathrm{Mol}$ Endocrinol 14(11):1872-1881.

Weihua, Z., Andersson, S., Cheng, G., Simpson, E.R., Warner, M., Gustafsson, J.A. (2003). Update on estrogen signaling. FEBS Lett 546(1):17-24.

Whitehead, M.I., Townsend, P.T., Gill, D.K., Collins, W.P., Campbell, S. (1980). Absorption and metabolism of oral progesterone. Br Med J 280(6217):825-827.

Whyte, J.J., Schmitt, C.J., Tillitt, D.E. (2004). The H4IIE cell bioassay as an indicator of dioxin-like chemicals in wildlife and the environment. Crit Rev Toxicol 34(1):1-83.

Wierman, M.E., Kepa, J.K., Sun, W., Gordon, D.F., Wood, W.M. (1992). Estrogen negatively regulates rat gonadotropin releasing hormone ( $\mathrm{rGnRH})$ promoter activity in transfected placental cells. Mol Cell Endocrinol 86(1-2):1-10.

Wolff, M.S., Toniolo, P.G., Lee, E.W., Rivera, M., Dubin, N. (1993). Blood levels of organochlorine residues and risk of breast cancer. J Natl Cancer Inst 85(8):648652.

Wong, B.C., Oehninger, S., Gibbons, W.E., Dong, K.W. (2004). Estrogen downregulates $\mathrm{GnRH}$ gene expression in human placental cytotrophoblast cells. Mol Cell Endocrinol 213(2):199-210.

Wormke, M., Stoner, M., Saville, B., Walker, K., Abdelrahim, M., Burghardt, R., et al. (2003). The aryl hydrocarbon receptor mediates degradation of estrogen receptor alpha through activation of proteasomes. Mol Cell Biol 23(6):1843-1855. 
Woutersen, R.A., Jonker, D., Stevenson, H., te Biesebeek, J.D., Slob, W. (2001). The benchmark approach applied to a 28-day toxicity study with Rhodorsil Silane in rats. the impact of increasing the number of dose groups. Food Chem Toxicol 39(7):697-707.

Wu, X.J., Lu, W.Q., Roos, P.H., Mersch-Sundermann, V. (2005). Vinclozolin, a widely used fungizide, enhanced BaP-induced micronucleus formation in human derived hepatoma cells by increasing CYP1A1 expression. Toxicol Lett 159(1):83-88.

Young, J.K. (1986). Thyroxine treatment reduces the anorectic effect of estradiol in rats. Behav Neurosci 100(2):284-287.

Yuan, Y.D. (1991). Female reproductive system. In: Handbook of toxicologic pathology (Haschek, W.M., Rousseaux, C.G., eds). London:Academic Press, 891-933.

Zhang, S., Li, X., Burghardt, R., Smith, R., 3rd, Safe, S.H. (2005). Role of estrogen receptor (ER) alpha in insulin-like growth factor (IGF)-I-induced responses in MCF-7 breast cancer cells. J Mol Endocrinol 35(3):433-447.

Zhou, J.G., Henry, E.C., Palermo, C.M., Dertinger, S.D., Gasiewicz, T.A. (2003). Species-specific transcriptional activity of synthetic flavonoids in guinea pig and mouse cells as a result of differential activation of the aryl hydrocarbon receptor to interact with dioxin-responsive elements. Mol Pharmacol 63(4):915-924. 


\section{Danksagung}

Ich möchte mich an dieser Stelle bei allen bedanken, die durch ihr Engagement zum Gelingen dieser Arbeit beigetragen haben.

Herrn Prof. Hardeland möchte ich für die Übernahme des Referats dieser externen Dissertation danken, ebenso Herrn Prof. Doenecke für die Übernahme des Korreferats.

Meinem Chef und Anleiter, Herrn Prof. Wuttke danke ich für die Überlassung des Themas aus dem Rahmen des EURISKED-Projektes und für die Möglichkeit der freien, selbstständigen Arbeit. Er hat mir zudem ermöglicht, mich wissenschaftlich auf Kongressen im In- und Ausland fortzubilden. Auch möchte ich ihm für die Diskussionen danken die mir immer wieder gezeigt haben, dass man noch einen Schritt weiter denken kann.

Prof. Hubertus Jarry danke ich für die Betreuung und die Unterstützung meiner Arbeit im Labor insbesondere bei dem Tierversuch. Ich möchte Ihm auch für seine stetige Diskussionsbereitschaft und für die kritische Durchsicht des Manuskriptes danken.

Bei der Arbeitsgruppe von Prof. Köhrle des Instituts für Experimentelle Endokrinologie der Charité Berlin bedanke ich mich für die Möglichkeit den 5'DI- und TPO-Assay in meine Arbeit aufnehmen zu können. Im Besonderen möchte ich hier Frau Dr. C. Schmutzler und Frau Inka Hamann danken.

Herrn Dr. Frauendorf aus dem Institut für Organische und Biomolekulare Chemie danke ich für die Möglichkeit der massenspektroskopischen Analyse der Tierseren, für seine persönliche Betreuung und Hilfestellung bei der Interpretation der Ergebnisse.

Prof. Dr. Wout Slob vom RIVM, Bilthoven, The Netherlands, möchte ich für die kostenlose Bereitstellung der PROAST-Software und Bas Bokkers für die Diskussionsbereitschaft zum Thema Risk Assessment danken.

Allen Mitgliedern der Abteilung Klin. und Exp. Endokrinologie möchte ich für die gute Zusammenarbeit und das angenehme Arbeitsklima danken, Guillermo Rimoldi, ein hervorragender Tierarzt, der mir in Bezug auf die Tiere immer helfen konnte, Martina und Julie für die Hilfe im Labor und ihre Kameradschaft, Annette und Claudia für die Einführung in die Technik der RT-PCR, Christel, der guten Seele des Zellkulturlabors, Maria für die Hilfe bei den RIAs und der HPLC sowie Sabine und Heidi für die Hilfe bei den Serum-Analysen der Blutfettwerte. 


\section{Lebenslauf}

Holger Klammer

$\begin{array}{ll}\text { Nationalität: } & \text { deutsch } \\ \text { Geburtsdatum: } & 28.03 .1976 \\ \text { Geburtsort: } & \text { Cuxhaven, Niedersachsen } \\ \text { Eltern: } & \text { Helmut Klammer und Christa Klammer, geb. Orthmann }\end{array}$

Schulbildung:

$1982-1988$

Grundschule Döse in Cuxhaven

$1988-1996$

Lichtenberg Gymnasium Cuxhaven

\section{Hochschulbildung:}

10.1997 - 5.2003 Studium der Biologie an der Georgia Augusta Universität, Göttingen. Abschluss Diplom-Biologe.

$5.2003-5.2006 \quad$ Dissertation: Pharmakologische Untersuchungen zu endokrinen Effekten des UV-Filters Ethylhexyl-methoxycinnamat. Bei Prof. Dr. W. Wuttke. Klin. und Exp. Endokrinologie, Klinikum Göttingen.

Beruflicher Werdegang:

17.4.2001 - 15.1.2002

25.7. -29.7 .2004$

31.7. -4.8 .2005$

15.5.2003-31.12.2005
Wissenschaftliche Hilfskraft am Göttinger Genom Labor. Mitglied des Organisationsteams des "Youngster day" der Bregenzer "Summer School on Endocrinology" 2004. Mitglied des Organisationsteams des "Youngster day" der Bregenzer "Summer School on Endocrinology" 2005. Wissenschaftlicher Mitarbeiter der Abteilung Klin. und Exp. Endokrinologie, Klinikum Göttingen.

\section{Wiss. Veröffentlichungen:}

Effects of Estradiol, Benzophenone-2 and Benzophenone-3 on the expression pattern of the Estrogen receptors (ER) alpha and beta, the Estrogen receptor related receptor 1 (ERR1) and the Aryl hydrocarbon receptor (AhR) in adult ovariectomized rats. Christiane Schlecht, Holger Klammer, Hubertus Jarry, Wolfgang Wuttke Toxicology. 2004 Dec 1;205(1-2):123-30.

Multi-organic risk assessment of estrogenic properties of octyl-methoxycinnamate in vivo. - A 5 day sub-acute pharmacodynamic study with ovariectomized rats. Holger Klammer, Christiane Schlecht, Wolfgang Wuttke, Hubertus Jarry Toxicology. 2005 Nov 5;215(1-2):90-6. Epub 2005 Aug 19.

A dose-response study on the estrogenic activity of benzophenone-2 on various endpoints in the serum, pituitary 2 and uterus of female rats. Christiane Schlecht, Holger Klammer, Wolfgang Wuttke, Hubertus Jarry Accepted by Archives of Toxicology. 